Digitized by the Internet Archive in 2007 with funding from Microsoft Corporation 



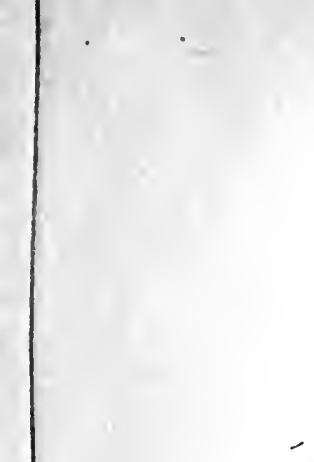





\title{
$80 !$
}

\section{INTRODUCTORY SKETCH OF THE}

\section{BANTU LANGUAGES}

\author{
BY
}

\section{ALICE WERNER}

Reader in Swahili, etc., School of Oriental Studies,

London Institution.

Author of Language-Families of Africa, Native Races of British Central Africa, etc.

LONDON :

KEGAN PAUL, TRENCH, TRUBNER \& CO., Ltd. NEW YORK: E. P. DUTTON \& CO. 


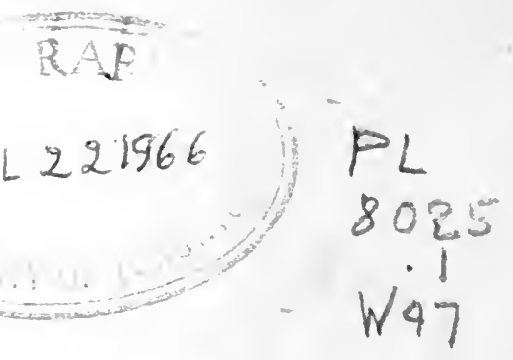

1098021

MAGISTRO ET AMICO

C.M.

Inter arma silent artes et amicitice: ne sileant in ceternum!

IX. Kal. Sept. MCMXVIII 1918 
ERRATA.

22, 1. 4 : for ili:zwe read i(li)-zwe,

55, 11. 18-19: delete "(which does not occur in Zulu.)"

59, 1. 2 : for " nasal" read "labial."

99, 1. 17 : for naba read nampa.

114, 1. 7: for nanku read nangu.

for nabo read nampa.

185, 1. I 2 : for Hereo read Herero.

222, 1. 2 I : "In" . . . . to end of page, delete and substitute ", while I have heard satu, which may be borrowed. Krapf gives both satu and chatu, the latter as a quotation from Steere." 


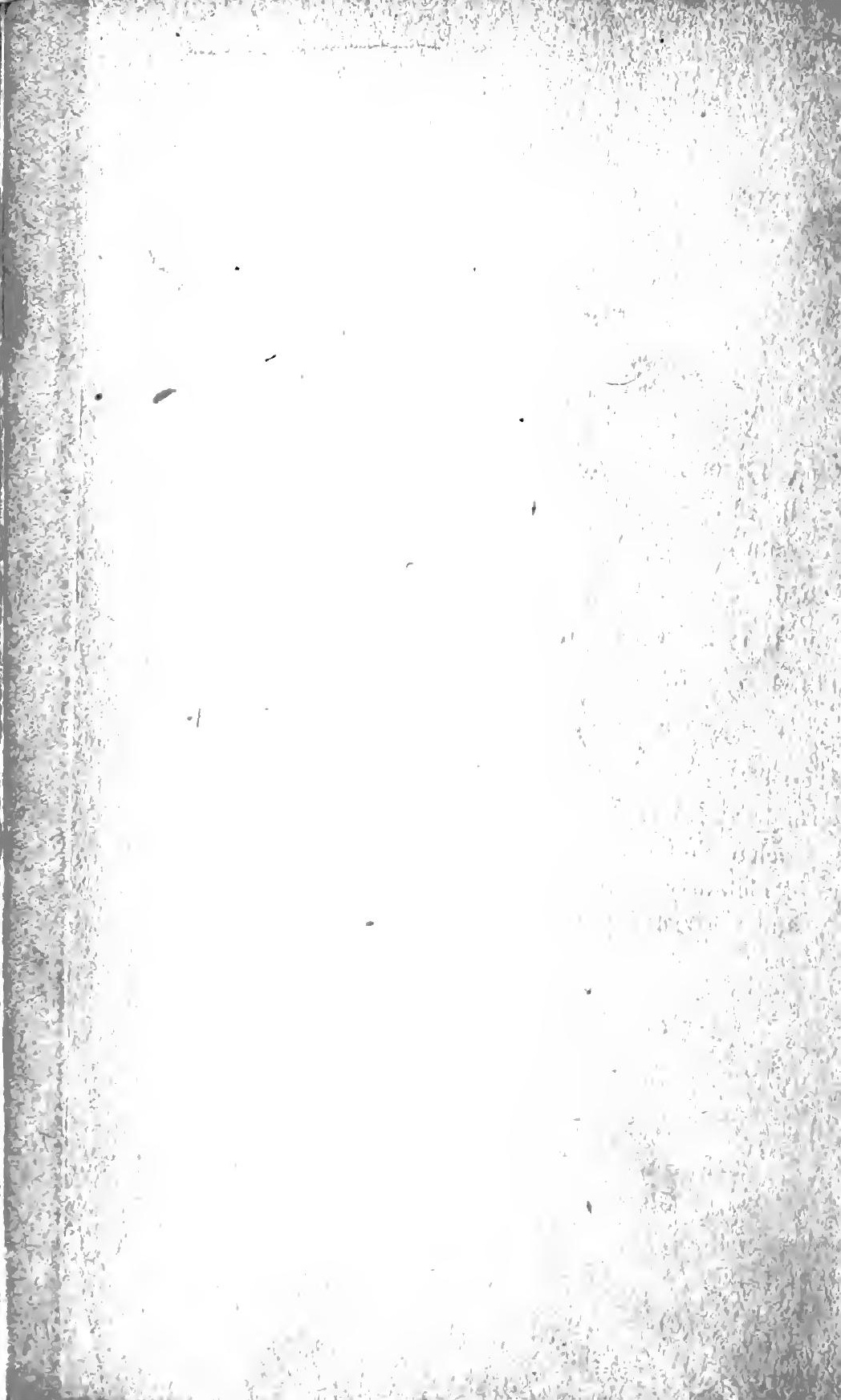




\section{CONTENTS.}

Preface

CHAPTER

I. INTRODUCTORY

II. The Alliterative Concord

III. The Noun-Classes ...

IV. The Noun-Classes (contimied)

V. Cases: The Locative

PAGE

iv

VI. The Pronoun

VII. The Copula and the Verb 'To Be'

VIII. The Adjective

IX. The Numerals

X. ThE VERB

XI. The Verb (continued)-Moods and Tenses

XII. Adverbs and Particles

XIII. Word BuIlding

XIV. Some Phonetic Laws

ApPENDIX I. Texts-1. Zulu

$"$
$"$
$"$
,
PENDIX

2. Herero

3. ILA

4. Nyanja

$\cdots$

$\cdots$

I

20

3 I

54

70

86

109

I 8 


\section{PREFACE.}

IT is well to'state at the outset that this little book makes no pretensions to originality. It has not, in all cases, been possible to give detailed references for statements which may be recognised as derived from one or other of the standard authorities (they are not numerous) on the subject. Sometimes, in the course of studies covering, intermittently, a period of some thirty years, one assimilates an idea so thoroughly as to forget where one first picked it up; sometimes, too, doing first-hand work at a language, one may, unknowingly, arrive at facts or deductions already recorded. In all such cases, the original owners are requested to believe that no misappropriation was intended.

It may be as well to state that the languages at which I have worked in situ, that is to say, in the countries where they are spoken, are Nyanja, Swahili, Zulu, and, in a lesser degree, Giryama and Pokomo. Some others I have, to a certain extent, studied from the inside, with the help of books.

It will, I hope, be sufficiently clear from the title that the present work is only an "Introduction" and does not in any respect seek to enter into competition with those of Bleek, Professor Meinhof, Father Torrend and Sir Harry Johnston. I am under great obligations, more or less, to all four, though compelled to differ, occasionally, with all respect, from each; but I venture to think I have occupied some ground not completely covered by any of them, yet important from the beginner's point of view.

If I might venture to appeal to my own experience, I should say that my feeling on first introduction to Bleek's Comparative Grammar was one of mere bewilderment, 
caused, I think, partly by the highly technical character of the first part, which presupposes a considerable acquaintance with phonetics, and partly by the use of Lepsius's alphabet, which, though not very difficult, involves a little preliminary training if one is to use the book profitably. Moreover, this alphabet has been considerably modified (and, in my view, improved) by Meinhof, so that there is a slight additional difficulty involved for those who have already made the acquaintance of the latter.

It is superfluous to say anything in commendation of the Lautlehre and the Grundzïge einer vergleichenden Grammatik der Bantusprachen; they are as yet practically the only works of their kind, ${ }^{1}$ with the exception of Mlle. L. Homburger's highly specialised study, which is of comparatively limited scope. But experience has taught me that they are of very little use to at least three-quarters of the students, whom it has been my lot to induct into one or other of the Bantu languages. For one thing, there is as yet no English edition of either, and-in spite of recent improvements in this respect-the number of English people who can study a subject by means of a French, German or Italian book (which is a different thing from gathering the drift of a novel or a newspaper article) is still deplorably small. For another, like Bleek, they presuppose a kind and degree of philological knowledge which few of the people who take up some Bantu language at short notice have had time or opportunity to acquire.

Here, parenthetically, at the risk of seeming to attempt the impossible feat ascribed to "Old Man Hyena," who split in two with the effort-I want to say a word about two opposite errors.

I have repeatedly insisted, in the following pages, on

1 Father Torrend's book, valuable enough in some ways, has to be used with caution, not only because of the errata unavoidable in a pioneer work, but because the learned author bas not been proof against that temptation to unbalanced theorising which is apt to beset the African philologist. De Gregorio's Cenni di Glottologia Bantu, so far as I have examined it, does not seem to go beyond the material furnished by Bleek and Torrend. 
the danger of being misled by preconceived notions of grammar into erroneous treatment of Bantu speech. Therefore it would seem as if a knowledge of Latin and Greek were no help tuwards the acquisition of African languages, and indeed, as we shall see, such knowledge has in some cases given rise to positive stumbling-blocks. But the fact remains that those who have enjoyed a sound classical training are best fitted to cope with the unfamiliar prefixes, affixes and infixes of the "Lingua Bantu."

The truth is that-at any rate till quite recently-the classics have been the only subject taught in our schools and universities which provided a thorough grounding in the principles of comparative philology. Neither Latin nor Greek will by itself throw any light on the structure of, say, Zulu or Ganda-nor, for that matter (except for its greater approximation, in some points, to primitive characteristics) will Hebrew. No very great amount of classical scholarship is needed to discriminate between roots and formative elements, to distinguish and compare the functions of the latter and to ascertain and apply the laws of sound-shifting. But it is the method and the principle which make all the difference, and those who follow them will never go astray over fruitless comparisons with Akkadian, Tibetan or what not. So that, if some parts of my book should seem to be needlessly elementary, I may be allowed to point out that I have found them by no means superfluous in practice.

I have not dealt with theories of origins or conjectures as to the successive Bantu migrations. Neither have I attempted a classification of the Bantu languages into "branches" (Bleek) or " clusters" (Torrend). I cannot help thinking that it would be premature at present and will be for some time to come. Father Torrend perceived that new facts had (to some extent) disturbed Bleek's arrangement; and there are still so many languages of which little or nothing is known, that we can scarcely regard his own as other than provisional. The queerest isolated links of affinity are continually cropping up in unexpected places and upsetting one's 
most cherished prepossessions; and, for my part, I am perfectly content, to take the languages as we find them, leaving the questions of how they came to be where they are, and whether they have a right to be there, to more competent heads and a future stage of inquiry.

Neither have I attempted to treat of Bantu phonetics from the strictly scientific point of view. This branch of the science, which is still more or less in the pioneer stage, is safe in the hands of Mr. Daniel Jones and Professors Meinhof and Westermann-I would only take this opportunity of emphasising its importance. The time has passed when the practical linguist or the research student could afford to rely on his ear and a certain amount of theoretic knowledge gained from the older works on the subject. It is one which can never be satisfactorily studied from books alone, and everyone intending to proceed to Africa ought to avail him or herself of the excellent practical courses now open.

I have tried to explain in the text the various shifts and compromises I have been forced to adopt in order to arrive at a working orthography for my own immediate purpose. Both Meinhof's diacritic marks and the alphabet of the I.A.P. have raised endless typographical difficulties, and I have found it best in the end to fall back on Steere's rule-of-thumb, explaining, where they occur, such symbols as he failed to provide for. It may be necessary to repeat that $k h, t h, p h$, stand for the aspirated consonant and not (except where specially pointed out, as in the case of Herero $t h$ ) for the sounds which we associate with those symbols.

The aim of the book is not to furnish all details with regard to any particular language, but to depict the broad principles underlying the structure of all belonging to the Bantu family, in such a form as to facilitate the subsequent study of the one specially chosen. Their grammar is of so homogeneous a character that it is unusually easy to construct such a general outline. Nor need the student be afraid with any amazement when he finds that his own chosen idiom fails to conform in one or more particulars to the outline here sketched. 
By the time he has advanced so far as to discover this, he will know enough to fit the differences as well as the resemblances into the framework.

It has, of course, been impossible to provide for every contingency, for instance, I have just become aware that Chaga possesses an infixed adverbial (intensive) particle for which I know no parallel elsewhere. I shall be grateful to anyone who can give me any information throwing light on the distribution of this particle, if it is not an isolated phenomenon-but no doubt we shall be able to read all about it in Sir Harry Johnston's great book, when the present distress permits of its publication. Very likely it contains the answers to many other puzzles nere suggested; but, all the same, I venture to repeat that there are some who will read it to better purpose, when it comes, after making use of the humble stepping-stone here offered them.

It only remains to thank those who, by word or letter, have contributed information, advice and encouragement, both in former years and recently. Chief among these I/ wouldmention Professor Meinhof; Sir H. H. Johnston; Dr. Cook, Miss Allen (of Gayaza), and the Rev. H. K. and Mrs. Banks (of Mbale), all of Uganda; the missionaries of the C.M.S. at Mombasa ; the Rev. Dr. Hetherwick, Blantyre; Mrs. Lloyd of St. Faith's, Rusape, and the Rev. H. Buck (Rhodesia), the Rev. H. B. Barnes (Penhalonga, Rhodesia); Miss Nixon-Smith, U.M.C.A., Likoma; the Ven. Archdeacon Woodward and Miss Woodward; the Rev. W. A. Crabtree (late of Uganda) and others. I hope anyone accidentally omitted will not think me ungrateful.

Any criticisms or comments-especially coming direct from Africa, will be heartily welcomed.

Wasalaam!

A. IVERnER.

School of Oriental Studies,

Finsbury Circus,

London, E.C. 2. 


\section{INTRODUCTORY SKETCH OF THE BANTU LANGUAGES}

\section{CHAPTER I \\ INTRODUCTORY}

THE Bantu family of languages is spoken throughout Southern and Central Africa, as far as the Gulf of Cameroons on the northwest, and the Tana river on the north-east. This area is interrupted by the following islands or 'enclaves' of speech belonging to other families :

The Galla : between the Sabaki and Tana.

The Masai: to the east and south-east of Lake Victoria.

The Jaluo ('Nilotic Kavirondo'): at the northeastern corner of Lake Victoria.

The Hottentots and Bushmen : in South Africa. Also several small and little known tribes (Mbugu, Sandawi, etc.), in the depression south-east of Kilimanjaro, whom we need not specify more particularly. 
In the Cameroons and along the southern edge of the Congo basin, the line of demarcation between Bantu and non-Bantu (in this case Sudan or 'Nigritian') languages is not very easy to draw. In the former territory we find several languages classed as 'SemiBantu,' or 'Bantoid,' which share certain characteristics with the family, though not apparently belonging to it. But these, and the exact delimitation of the frontier, need not concern us for the purposes of this book.

The number of known Bantu languages is well over 200; but as there are probably others yet to be recorded, and as some names may have to be omitted (being synonyms, or denoting mere dialects-if not altogether erroneous), this figure must be regarded as merely provisional.

The principal features of the Bantu languages are so clearly marked in all, that, as far as grammar goes; a knowledge of-one materially facilitates the acquisition of the rest. Most of them differ from each other no further than do French, Spanish and Italian; in some, the resemblance is even closer. Natives of one tribe cannot, in general, understand the language of another, without 
learning it (though they pick it up very easily), nor can the European expect to do so; but the second language should cost him far less labour than the first. And an acquaintance with the framework of Bantu grammar, comprising, at least, those features which all the languages have in common (and which, to those who know only the idioms of Europe, are so striking and novel as to impress themselves readily on the memory) is a useful preparation for taking up the study of any particular language in Africa.

The name Bantu was first introduced by Bleek (1827-1875), who may be called the father of African philology. It is simply one form of the word for 'people,' whicl is used throughout the languages of this family. Various objections have been raised to this name, but no better one has been proposed, and it has now so far gained currency that it would be extremely difficult to displace. As its meaning is perfectly clear, and as it is easily pronounced, there seems to be no sufficient reason for rejecting it. We shall therefore continue to speak of the Bantu family.

Though the name was not introduced till 
the middle of the nineteenth century, the existence of this language-family was at any rate conjectured as early as I808, when the German naturalist, Lichtenstein (who had spent four years travelling in South Africa), published a paper entitled Remarks on the Languages of the savage tribes of South Africa, with a short vocabulary of the most usual dialects of the Hottentots and Kafirs. The two Bantu languages of which he collected specimens were 'Kafir' (Xosa) and Chwana. Many of his words are recognisable, in spite of a curious orthography; but he does not seem to have grasped the system of prefixes, and sometimes confuses the singular and the plural of a word. However, he had no doubt as to the relationship of these languages to each other and the fundamental difference between them and that of the Hottentots He says: "All the idioms of the South African savages must be regarded as dialects of one or the other of these two principal forms'; and the information he was able to obtain respecting the more northerly tribes led him to the conclusion that "we are justified in considering all the inhabitants of the East Coast of Africa, from $10^{\circ}$ or $12^{\circ} \mathrm{S}$. to the frontiers of the Dutch Colony, as one 
nation . . . . to which further research may perhaps compel us to add the inhabitants of the South-west Coast.'.

A similar conclusion was reached independently, a few years later, by our own orientalist, William Marsden (I754-1836). In 1816 , he drew up a paper of instructions for collecting words and sentences, to be used by the members of Captain Tuckey's ill-fated expedition to the Congo, in which he remarks on the similarity between the vocabularies previously obtained in Angola and Loango and the specimens of the Mozambique language dictated by a native of that country who had been Marsden's servant in India. But the study of the Bantu languages singly, and without reference to their place in a system, goes back to the middle of the seventeenth century. In the library of the British Museum is a curious little book - with Southey's autograph, dated 'Keswick, I8 8 o,' on the title-page-printed in 1642 and containing a short exposition of elementary Christian doctrine, under the form of a dialogue, in the language of Angola, with a Portuguese version on the opposite page, and a few introductory hints (in Portuguese) on pronunciation and 
grammar. It was the work of a Jesuit missionary, P. Francisco Pacconio, but was revised and edited after his death by $P$. Antonio Do Couto, to whom it is generally attributed. The language is that now called Mbundu, and, though somewhat disguised by the Portuguese spelling, appears not to differ appreciably from that spoken to-day. Some years later, in 1659 , an Italian friar, Giacinto Brusciotto, published in Latin a grammar of the Congo language, to which we shall have occasion to refer more than once in subsequent pages. Cust remarks: 'The book is very small, and the author was not a linguist'; which seems to me unduly severe. He certainly grasped the characteristic features of the language in a way some later writers failed to do: Cust himself says, 'he remarks the use of prefixes, and he classes the nouns.' We have just seen that Lichtenstein did not understand the system of prefixes;-it is, of course, not surprising that a passing traveller, picking up, in the short time at his disposal, what linguistic information he can, should be unable to do more than record words and phrases without penetrating very far into their grammatical relations. But it does seem 
strange that Dr. Van der Kemp, whose help he acknowledges with regard to the Xosa language, should not have called his attention to peculiarities so striking and so unlike anything that could previously have come in his way.

But the great advance in the knowledge of African languages followed the remarkable development of missionary activity which characterized the end of the I8th and the beginning of the Igth century. Moffat's translation of the Bible into. Sechwana was begun in I83I; Archbell's grammar of the same language appeared in 1837 , Boyce's Xosa grammar in 1844; while at the same time Casalis, Arbousset and the other French missionaries were active among the Basuto and marking their progress by valuable linguistic work. About the same time, Krapf, on the eastern coast of Africa, was practically the first to make the Swahili language known to European scholars:-for, though two or three vocabularies had been collected (chiefly by the praiseworthy exertions of British naval officers) they do not seem to have attracted much attention. It was the material sent home by Krapf which first made possible 
anything like a scientific study of the subject, and the beginnings of this may be seen in three remarkable essays contributed by Ewald, Pott, and Von der Gabelentz to the first and second volume of the Zeitschrift der Deutschen Morgenländischen Gesellschaft-work produced in the golden age of German scholarship, before it had begun to lose itself in overspecialisation. These essays were the precursors of Bleek's Comparative Grammar, the first part of which appeared in I862.

Bleek's book, though of course it has been supplemented by later research, and, as might be expected, requires some correction in detail, remains the foundation of everything that has been done since. I shall not attempt to give any account of this more recent work, though I shall frequently have occasion to refer to the outstanding names of the last thirty or forty years-men who have not merely given us grammars and dictionaries of separate languages, but examined their structure from a scientific point of view and done something towards determining their relationship to each other and to the other speech-groups of the world. Such have been Müller, Lepsius, Meinhof, De Gregorio, and others. In this 
country, Sir Harry Johnston is, sad to say, almost the only writer who has occupied himself with the Bantu languages not merely in detail but also from the comparative point of view.

Bleek confirmed Lichtenstein's vièw (which, considering the data he had to go upon, almost deserves the name of a brilliant intuition) that all the languagres of South Africa fall into two groups, ${ }^{1}$ and he was able, as Lichtenstein was not, to account for the differences on philological grounds. The one crucialdistinction between them, he considered, lay in the fact that the one group-the Hottentot-has grammatical gender; the other-the Bantu-has nôt.

This difference, Bleek thought, was based on a fundamental difference of organization, and from it he deduced an ingenious argument, proving that people whose speech has no grammatical gender were not merely at present

${ }^{1}$ Bleek was uncertain whether to reckon two groups or three. He felt that not enough was linown about the Bushman language to pronounce definitely as to its classification, but was inclined to think it of a distinct type from the Hottentot. Recent research goes to show that he was probably right and that it is allied to the Sudan family. 
incapable of personifying nature, but that they could never in the future advance beyond a certain limited range of ideas. However, as fuller knowledge has shown many of his premises to be untenable (he thought, for instance, that the kind of animal-stories so well known to us through Uncle Remus was confined to the Hottentots and unknown to the Bantu), we need not occupy ourselves with his conclusion.

It is certainly remarkable that the three great inflected families of language-the Aryan, Semitic and Hamitic-corresponding to the three divisions of the ancient world and the civilizations (broadly speaking) of Europe, Assyria and Egypt, should possess grammatical' gender and the rest be without it. But we need not think that the possession of this characteristic draws a hard and fast line on one side of which no progress is possible, for (setting aside the case of Japan and China), recent research has thrown a good deal of light on the way in which gender arose, and we find that some languages, classed with the Hamitic 'sex-denoting' family, only have it in a rudimentary form; some Bantu languages show signs of a tendency to acquire it; and 
languages at a very advanced stage, as English, tend to lose it.

'Absence of grammatical gender,' it may hardly be necessary to say, means, not that no account is taken of sex-distinctions, but that they are not in any way shown by the form of words. All languages have words for 'man' and 'woman,' 'male' and 'female'; but those of which we are speaking have nothing corresponding to 'he,' 'she,' ' his,' 'her'; nor can they indicate a feminine noun by any change in the word: if it is absolutely necessary to distinguish the sex a word is added, as in our ${ }^{\circ}$ 'he-goat,' 'she-goat,' 'buck-rabbit,' ' doerabbit,' etc. Still less do they attribute sex, by a grammatical convention, to inanimate objects, as is done in Latin, French, German, etc.

The Sudan languages (which include Twi, Gã, Ewe and others, spoken in Western and Central Africa) have no grammatical gender; but neither have they, properly speaking, any grammatical inflections at all. The Bantu languages, however, do indicate number, person, and, in a limited sense, case; and, for verbs, in addition, voice, mood and tense.

They are usually reckoned as belonging to 
the class of Agglutinative languages. These are distinguished from the Isolating languages on the one hand and the Inflected on the other by the fact that, while they indicate grammatical relations by particles prefixed or suffixed to the root, these particles are recognizable as independent words and can be used as such. This, as we shall see, does not quite apply to the Bantu languages, where some of the 'formative elements' (prefixes and suffixes) can no longer be used separately, and sometimes we even find internal changes in a word, comparable to those by which in English we form the plural of a noun like foot or the past of a verb like run.

So that it would be nearer the truth to call them 'partially inflected languages,' or 'Janguages in course of acquiring inflection.' For we must remember that the three classes just mentinned are not hard and fast divisions, Jike water-tight compartments; but a live language is continually growing and changing and will suoner or later pass from one class to another.

The first point which strikes one on beginning to examine these languages is the employment of profixes where we should expect to find suffixes-e.g., to indicate the 
plural of nouns, the agreement of adjectives, etc. We shall find that suffixes are also used in certain cases; but the system of prefixes is so characteristic and peculiar that Bleek rightly regarded it as a distinguishing feature of this family, which-before finally adopting the designation 'Bantu'-he called the 'prefixpronominal languages.'

It was also noticed by Brusciotto who, at the very outset of his Grammar, says: 'In the first place it must be observed, in general, that in this language we have to attend, not to Declensions (i.e., terminations), but rather to Principiations (i.e., Prefixes).'

For want of acquaintance with this principle we sometimes give a double plural to an African word, as when we speak of 'the Basutos,' '. the Mashonas,' or use a plural for a singular, as 'a Basuto,' 'a Bechwana'-the singular in these cases being Mo-suto, Mochwana. Besides these prefixes indicating singular and plural, there are others indicating the language (as Ki-swahili, Lu-ganda, Se-chwana, Chi-nyanja) and the country (as U-kami, Buganda, etc.)-varying, of course, with different tribes. It may be well to note in this place that we shall uniformly, throughout this book 
use the names of languages without prefix; as Chwana, Ganda, Sivahili, etc.

Though Bantu nouns have no gender and so cannot be classified as masculine, feminine and neuter, they are divided into several classes-usually eight or nine, distinguished by their prefixes. These prefixes are repeated, in one form or another, before every word in agreement with the noun; and this method of indicating agreement (which will be fully explained and illustrated in the next chapter) is called the Alliterative Concord.

These three,points: the absence of grammatical gender, the system of prefixes, and the Alliterative Concord, may be called the principal characteristic features of the Bantu family.

We may mention a few others, put on record long ago by Lepsius, as distinguishing the Bantu family from the Sudan languages on the one hand and the Hamitic (Berber, Galla, Somali, etc.) on the other.

(1) Personal Pronouns are always prefixed to verbs, never suffixed-as they are in Hebrew, Arabic and the Semitic languages.

(2) The Genitive always follows its governing 
word. That is, they always say 'the house of the man,' never (as in the Sudan languages) 'the man's house.'

(3) The usual (but not invariable) order of words in the sentence is: Subject + Verb + (Noun) Object.

(4) The object-pronoun is inserted ('infixed') between the subject pronoun and the verb-root. $\checkmark$ Thus, in Zulu, ngi-ya-m-bona, 'I see him,' is made up of $n g i=$ ' $\mathrm{I}$,' $y a$ (tense particle), $m=$ 'he,' bona $=$ 'see.'

(5) Syllables always end in a vowel.

Here it is well to say a word about stress (accent) and intonation.

In many Bantu languages it is an invariable rule that the accent-at any rate the accent most readily noticed-falls on the penultimate syllable, and, if a syllable is added, the accent moves forward. Thus, in Zulu, we have bóna, 'see,' which becomes, in the causative, bonisa, 'make to see.' In Swahili, nyumba is 'house,' but, the locative, 'in the house,' is nyumbani. This is called the 'rhythmic stress,' but there is also an 'etymological stress,'-viz., one on the root syllable. In words like bona, nyumba, these coincide; but 
otherwise, in Zulu and Swahili, the rhythmic stress seems to be much more strongly marked. In Ganda, it is the stress on the root-syllable which is noticed. There are a few languages which have the rhythmic stress on the antepenultimate.

Intonation, or pitch, is a very important feature in some languages, as in Chwana, where it serves to distinguish many words otherwise similar. It exists in Zulu, Xosa, Nyanja, etc.,-probably to a much larger extent than has hitherto been observed. All learners are advised to attend to this point very carefully. ${ }^{1}$

This book being devoted to the grammatical structure of the Bantu languages, it does not enter into my plan to discuss their sounds from a scientific point of view. Indeed many of them have not been examined at all in this respect, and others very imperfectly. Almost the only comprehensive work on Bantu phonetics at present in existence, Professor Meinhof's Lautlehre der Bantu-Sprachen, is not yet published in an English edition,

${ }^{1}$ It is possible that in some cases, pitch and stress have been confused. This, also, requires particular attention. 
though a translation is being prepared. Some of the Bantu languages are being phonetically analysed by Mr. Daniel Jones, Reader in Phonetics in the University of London, who has published some provisional results of his studies in Le Maitre Phonétique, in his pamphlet The Pronunciation and Orthography of the Chindau Language (Rhodesia), and more recently in the Sechuana Reader (see Bibliography in Appendix).

The sounds of the Bantu languages are, superficially, not very difficult, except in a few cases which at once strike the newcomer by their strangeness, such as the clicks in Zulu (which, however, do not properly belong to Bantu), the 'laterals' in this and some other South African languages; the Thonga and Venda 'labio-dental,' the very common 'bilabial' $f$ and $v$, etc. But there are subtler gradations, both of vowels and consonants, which are at once perceived by a trained phonetician, and which an untrained linguist with a good ear will consciously or unconsciously adopt without being able to define them, but which frequently escape the notice of the average person. Thus, perhaps, in Nyanja, the learner will be in doubt whether 
the word for 'five (people)' is asamu or asano; and an old resident who knows the language fairly well will tell him that 'these endings are very uncertain, and the people themselves sometimes say one and sometimes the other.' The truth is that the sound is intermediate between $u$ and $o$, the mouth-opening being wider than for the first and narrower than for the second. As this is not a treatise on phonetics, I shall make no attempt to spell the words quoted as examples according to the system of the International Phonetic Association, more especially since the sounds of so few Bantulanguages have been sufficiently analysed to make this possible. For my purpose, the spelling introduced by Bishop Steere for Swahili and generally used in Swahili books is, in general, sufficient. Its principle may be stated thus: the vowels are pronounced with the sound they have in Italian, the consonants (including the compound symbols ch, sh, th) as in English-each symbol standing for one sound and no more, and no sound having more than one symbol. On this system, c, q, and $\mathrm{x}$ are superfluous, so are sometimes used to denote sounds not provided for in the Roman alphabet, as the 
clicks in Zulu.1 (C is often used for the sound of $c h$ in "church" but may also stand for the somewhat different "palatal plosive."

As, however, some languages have sounds not found in Zanzibar Swahili, on which Steere's Handbook is based, a few extra symbols will be needed in our examples, and these will be explained where they occur. But it must be repeated that this can give only a very general idea of the sounds, and that anyone who has to acquire a Bantu language for practical use cannot do better than take a course of general phonetics, which will enable him to accomplish very useful work in recording correctly the sounds of unwritten, or, as is sometimes the case, hitherto atrociously mis-spelt, languages. ${ }^{2}$

1 Dinuzulu (late Chief of the Zulus) used to say that the English alphabet needed 'several more letters' in order to write $Z$ ulu satisfactorily. The Europeans who first recorded the language have in some cases expressed two entirely distinct sounds by the same symbol.

${ }^{2}$ See D. Jones, The Pronunciation of English and Noël-Armfield, General Phonetics. A table of the International Phonetic Association's Alphabet, and also of a script largely used on the Continent (Meinhof's moderni. zation of Lepsias's Standard Alphabet) will be found 'n Language-Families of Africa. 


\section{CHAPTER II}

\section{The Alliterative Concord}

Is Latin we say, 'Equus albus currit'_-' the white horse runs'; in the plural, 'Equi albi currunt.' The termination of the noun indicates the declension, case, and number; of the adjective, the gender, case, and number in agreement with the noun; of the verb, the tense, number, and person. The terminations of the noun and adjective are the same; that of the verb is different and has no relation to them.

This arrangement is somewhat different from that of the Alliterative Concord in the Bantu languages, but will help us to understand it, if we try to imagine the endings all alike ${ }^{1}$ and transferred to the beginning of the word. Let us take a specimen sentence in Zulu.

1 They are not really as much alike as the word 'alliterative' might imply, but they are all recognizable as derived from the prefix. 
Unfana ommbi uyatshaya inkomo yomfundisi - wami, ngiyakumlungisa. "The bad boy is beating the ox of my teacher: I will punish him.'

This sentence contains nouns of two different classes and words agreeing with them. Umfana is a noun of the first or 'person'-class: the root is fana, the prefix $u m$-, shortened from umu- (as seen in umu-ntu, 'person '). Omu-bi, 'bad,' is an adjective agreeing with unfana the prefix assumes the form omm because it was formerly preceded by a demonstrative particle $a$, and $a+u$ coalesce into o (i.e., the broad $o$, pronounced like ou in 'ought'). This means that, when the adjective is used attributively (that is, as in 'the bad boy'-not predicatively, as in 'the boy is bad'), it is really a relative construction that is employed : - 'the boy who is bad.' We shall be able to make this clearer in the chapter on relative pronouns. In the same way 'good' is omu-hle $(a+$ umu-hle).

The equivalent for an adjective can never be given in its complete form, unless the noun

${ }^{1}$ When it is necessary, in this book, to distinguish this ofrom the narrow $O$ (as in 'stone'), it is printed with a line under it, as in Meinhof's notation. 
with which it agrees is known. 'A good' (or ' handsome ') 'person,' is umu-ntu omu-hle; 'a fine ox,' inkabi en-hle; 'a beautiful country' ili-zwe eli-hle; 'a fine cattle-kraal,' isi-baya esihle; 'a 'beautiful face,' ubu-so obu-hle; 'beautiful language,' uku-kuluma oku-hle. For this reason, adjectives must be given in the dictionary under their root only: -hle, -bi, -kulu (large), etc. But these roots are never found standing by themselves in any Bantu language. They are always used with the prefix of the class to which they belong-viz., that of the noun with which they are in agreement.

U-ya-tshaya. Tshaya is a verb meaning 'beat.' The bare root in this form is never found alone, except in the second person singular of the imperative. Everywhere else it has some addition. Even the second person plural of the imperative takes a suffix, $-\boldsymbol{n i}$ : tshaya-ni = 'beat ye.' The other moods and tenses all take prefixes.

$U$ - is the personal pronoun of the first (or 'person') class. It will be recognised at once as part of the prefix umu. (The prefix, except in some languages which have departed considerably from the original type, is not in 
all cases identical with the pronoun.) This is the subject-pronoun: the second part of the prefix, $-m u$ (usually contracted to $-m$ ) is used as the object-pronoun, as we shall see presently. It should be noted that this subject-pronoun, $u$, can never be used apart from a verb or its equivalent. There is a separable, or independent, pronoun, of quite a different form, which will be considered in the chapter on Pronouns.

$-y a-$ is a tense-particle: originally the auxiliary verb $y a$, 'to go.' It imparts a kind of habitual continuative force: "yytshaya is rather ' he is beating,' or 'he is in the habit of beating,' than simply 'he beats.' In Zulu, the $-y a$-tense is the present most commonly used, though it cannot always be translated as above.

In-komo, 'a cow' is of the class which has the prefix $i$, or in- originally ini-. Nouns have no indication of case (except that they suffix $-n i$ for the locative), so that they have no distinct form for the objective, though some pronouns do.

Yomfundisi is for ya umfundist? $Y a$ is the particle corresponding to 'of,' which expresses the genitive case and varies its initial according 
to the noun with which it agrees-which is always the thing possessed, not the possessor. $I$, the initial vowel of inkabi, becomes $y$ before a vowel: $i+a=y a$. In $Z \mathrm{u} ! \mathrm{u}, a$ before $u$ amalgamates with it to form $o$, which is an intermediate position of the mouth between the two. In many other languages this amalgamation does not take place, because the initial vowel has been lost; thus, in Nyanja, we say ya muntu, not yomuntu$y a+u m u n t u$.

Um-fundisi, a noun of the person-class meaning 'teacher,' derived from the verb fundisa, 'teach.'

$W$-ami-'my.' The roots of the possessive pronouns are: -ami, 'my'; -ako, 'thy'; -ake, ' his, her'; -etu, 'our'; -enu, 'your'; -abo, 'their.' They take as prefixes the pronoun of the class with which they are in agreement: in this case the thing possessed is of the person class (umfundisi), and the pronoun will be $u$. But $u$ before a vowel becomes $w, u+a m i=w a m i$. Similarly, 'thy teacher' is umfundisi wako $(u+a k o)$, and so on.

Ngi-ya-ku-m-lungisa. Lungisa (causative of lunga) is properly ' make right,' 'straighten,' and so 'correct,' 'punish.' Ngi- is the 
inseparable subject-pronoun of the first person singular. $Y a-$ is the tense-particle already mentioned, but, in combination with the following particle- $k u$-it indicates the future. $-m$ - is the object-pronoun of the third person singular $=$ ' him.'

All these prefixes change for the plural. Supposing we take as our English sentence:

"The bad boys are beating the cows of our teachers; we will punish them."

The Zulu will be:

Aba-fana aba-bi ba-ya-tshaya izin-komo zabafundisi betu, si-ya-ku-ba-lungisa.

This needs no further analysis; but we may call attention to two points : the plural pronoun (inseparable) of the first person, si-, and the double plurality, if one may say so, of the possessive betu. It must be 'our,' plural of 'my,' in order to agree with the possessors, ('we,' understood), but the initial must be $b$-, not $w$-in order to agree with the . things (or persons) possessed (abafundisi). This double concord of the possessive is an important point, to which we must recur later on.

The same sentence would read in Ganda as follows : 
Omu-lenzi omu-bi a-kuba en-te yomu-igiriza wa-nge; n-na-mu-kangavula.

Aba-lenzi aba-bi ba-kuba en-te zaba-igiriza ba-nge tu-na-ba-kangavula.

Here, though the roots are mostly different, the identity of the formative elements will be . evident on examination. The chief differences are: $a$ instead of $u$ for the pronoun of the third person singular (which will be noticed in the chapter on the pronouns), and $e$ instead of $i$ as the initial vowel for the in-class. The possessive of the first person is -nge instead of $-m i$, but this is evidently connected with the $Z$ ulu subject-pronoun of the first person, $n g i-$, which, in Ganda, has been reduced to $n$-.

This sentence affords a very good illustration of the fact that, in comparing languages, one should take into account the grammatical structure rather than the vocabulary. All the noun-roots are entirely different from the $Z$ ulu ones; so are the two verbs, kuba and kangavula. If we looked to these alone, disregarding the prefixes, we might come to the conclusion that there was no sort of relationship between the two languages. But we should not be justified in doing so, for a comparison of single words may very easily lead us astray. 
Take the case of four European languages, which we know to be closely related: English, German, Dutch, and Danish. Here are four words which cannot possibly be derived from the same root:

Boy ; Knabe ; jonge; Dreng.

Yet the Dutch word exists in English as the adjective 'young,' and is used in German (junge) side by side with Knabe, which is our 'knave' -an instance of the way in which the same root may assume different meanings. Dreng is found in Anglo-Saxon in the sense of 'warrior,' and the old Icelandic use of it. to mean ' a valiant youth,' supplies the connection between the two.

'Queen' is the same word as the Danish Kvinde, 'a woman,' and therefore has nothing to do with the German Königin, which is the regularly-formed feminine from König, or the Danish Drottning, which, though used as the feminine of Konge ('king') is really that of an obsolete word Drott, meaning 'lord.'

Or take the French word cheval: it has nothing in common with the Latin equns, but is derived from a different word, caballus, not used by the classical writers, but existing in the language of the people. Again, the 
Spanish comer, 'eat,' cannot possibly come from the same root as the French manger; and the classical Latin is edere, which, at first sight, does not seem to be connected with either. But comer is derived from comedere, properly ' to eat up'-a more colloquial and popular word than edere-and manger comes from manducare, properly 'to chew'; whence also the Italian mangiare.

Why one language should choose the first of these two words, and another the second, is a 'question which; in the present state of our knowledge, cannot be answered-or only in the same way as Molière's doctor explained why opium sends people to sleep by saying that ' it has a dormitive virtue.'

So the roots, lenzi, kuba, iga ('learn,' from which are derived igiriza, 'teach, and omuigiviza, 'teacher') and kanga (frown,' of which kangavula, 'rebuke ' or 'punish ' is a derivative) are probably to be found in other Bantu languages, though I have as yet been unable to trace them. Ente, I believe, is not Bantu, though I cannot say whence it has been a'dopted. -bi, 'bad,' will be recognised as identical: it is found in most Bantu languages. Let us now take, from Swahili, an example 
of the concord in another class, which has the prefix $k i$-, in the plural vi-.

Ki-ti cha-ngu cha m-ti ki-me-vundika, ni-meki-ona ki-ki-anguka.

' My wooden chair is broken; I saw it when it fell.'

$K i$-ti, 'chair,' is originally ' a wooden thing' - $t i$ being a root which, with the prefix $m$-, means 'tree.' (The most primitive form of seat, after the mere stump or fallen log, is the stool cut out of a solid block, the cross-section of a tree.) 'Of' in this class is cha, because $k i$ becomes $c h$ before a vowel. The possessive pronoun consists of cha prefixed to the pronoun-root, which is for the first person -ngu (cf. Ganda, -nge: the subject-pronoun for the first person is mi). Cha mti, 'wooden,'literally ' of wood,' or ' of tree.' Ki-me-vundika, 'it is broken' : $k i$-, subject-pronoun of the $k i$ class, agreeing with kiti; -mlle-, a particle denoting the perfect tense of the verb; vundika is the neuter-passive of the verb vunda, 'break.' Nimekiona: ni- subject-pronoun of the first person singular; -ine-, tense-particle; $-k i$, object-pronoun agreeing with kiti; ona, verb, meaning 'see' (in Zulu, bona); anguka is a verb, meaning 'fall'; the first 
$k i$ is the subject-pronoun agreeing with $k i t i$; the second a tense-particle equivalent to ' if ' or 'when,' often giving the verb a kind of participial force.

The plural of the above is :

Vi-tivy-etu vya mtivi-me-vundika, tu-me-vi-ona vi-ki-anguka.

This needs no further explanation.

We thus see that the prefix of the noun is repeated, in a form more or less recognizable before every word in grammatical agreement with it. The way in which it enters into the composition of pronouns other than the simple subject and object prefixes, will be explained later. 


\section{The Noun-Classes}

We have already referred to Giacinto Brusciotto as the author of the first attempt at a Bantu Grammar. He was an Italian Capuchin, Prefect of the Apostolic Mission to the Kingdom of Congo, about the middle of the seventeenth century. Judging from his book (published at Rome in 1659), his linguistic aptitudes were of no mean order, and no doubt he had profited by many years' residence in the country. It is remarkable, at least, that he succeeded in grasping the principle of the noun-classes, which eluded more than one of his successors. We have seen that Lichtenstein missed it; and-even more unaccountably-Burton, writing about I860, with the work of Krapf and Rebmann before him, could speak of 'the artful and. intricated system of irregular plurals' in 
Swahili.1 In Cavazzi's History of the Kingdom of Congo, ${ }^{2}$ first published in I67I, it is stated that a missionary, after six years spent in trying to learn the rules of the language, only found out that there were none! It is strange that this book takes no notice whatever of Brusciotto or his grammar.

The first section of Brusciotto's manual ${ }^{3}$ has the following heading: "Of the Declen' sion of Nouns, or, as it is better expressed, 'their Principiation, and their Rules; wherein ' it is shown what articles are to be attributed 'to each noun, both in direct and oblique 'cases, for their correct construction in them'selves, or when they are joined to other 'words; and generally this is first to be noted 'that in the present tongue we must not look ' for declensions but rather principiations, for 'which we have the following Rules.' . . .

1 Zanzibar, I, 443.

${ }^{2}$ Istorica Descrizione de' tre Regni, Congo, Matamba et Angola, situati nell 'Etiopia Inferiore Occidentale $e$ delle Missioni Apostoliche esercitatevi da Religiosi Capuccini, accuratamente compilata del P. Gio. Antonio Cavazzi da Montecuccolo. (Milan, 1671.)

${ }^{3}$ Regulae quaedam pro difficillimi Congensium idiomatis faciliori captu, ad Grammaticae normam redactac. (Rome, 1659.) 
Later on, having reached the end of the 'Principiations,' he says, once more :

'As has been said above, the language of 'the Congos and others of Negro lands is not ' founded, nor forms its rules upon the 'declension of words, but on their principiation; 'therefore the rules which are distinguished ' and marked in this idiom are chiefly taken 'from the various principiations of the sub'stantives and varied accordingly.' From this it appears that he duly appreciated the importance of the noun-classes as a feature of the language.

The first thing we have to do in studying Latin is to master the declensions-the classes into which nouns are divided according to their terminations and genders." Such classes exist, though to a less extent, in German ; they have almost disappeared in Dutch, and entirely so in English. When we think of declensions, we also think of cases, each having its own case-endings.

It was quite natural that anyone educated, like Brusciotto, mainly on the classics, and more especially on the Latin grammar, should, in trying to discover the laws of an entirely strange language, look first for the declensions. 
He soon recognized that the plural of nouns was formed in different ways, according to distinct rules, but that the inflection came at the beginning of the word instead of at the end, so that he invented, as we have seen, the name of 'principiations' for the different classes so distinguished. Of these he enumerates eight, which can be identified without difficulty in present-day Kongo, ${ }^{1}$ allowing for differences of dialect and for some mistakes and confusions. It is curious that he does not notice the person-class, but makes 'gentile nouns' exceptions to his first and second principiations. At the end of his chapter, he quaintly adds :

'Note, with regard to the preceding, that ' there is no rule so strictly observed as to be 'without many exceptions, all which by 'practice and the Spirit of God inspiring, will ' be easily understood and by continuous and ' unwearied Jabour overcome.'

Exceptions are the refuge of the imperfect grammarian, and a knowledge of the Bantu

1 This spelling is preferred in modern books when referring to the particular language treated by Brusciotto, while 'Congo' is retained as the name of the river or its adjacent territories. 
languages, unattainable by our pioneer (though not, in his case, for want of 'continuous and unwearied labour') would have shown that they usually exemplify rules not immediately obvious.

Brusciotto may have been led astray partly by his belief in the existence of an article-a part of speech which, as we understand it in English, is not found in Bantu. He is not alone in giving this name to the initial vowel of the prefix - a point as to which we shall have more to say presently;-but it is less easy to see why he should have extended it to the possessive particle ( $w a, b a, y a$, etc.). We shall return to this point in the fifth chapter.

The number of noun-classes, as the 'principiations' are now generally called, varies in different languages, but is mostly eight or ten. There is some uncertainty about the original number, and Meinhof's theoretical table is, as he points out, not complete, since some languages have anomalous forms only to be interpreted as survivals of lost classes, and more of these may yet be discovered.

Meinhof, following Bleek, counts singular and plural classes separately, thus arriving at 
a total of twenty-one. Some singular prefixes have no corresponding plural, while some plural prefixes are attached to tivo or more classes having different prefixes in the singular.

As the order in which these classes are arranged is hardly the same in the grammars of any two Bantu languages, it seems most convenient in this book to follow Meinhof's arrangement and refer to the prefixes by his numbers. Some advantages are secured by placing singular and plural in the same class, and in drawing up a practical grammar it might be better to follow that arrangement; but the want of uniformity makes reference very difficult in a comprehensive survey. When we find, e.g., most Zulu grammars giving as the second class what Steere, in Swahili, calls the fifth, the French Fathers in Ganda the sixth, and Madan in Lala-Lamba the ninth, one is ready to ask why we cannot adopt some uniform system. But, when we remember how many classes have been dropped by one language and another (Duala, e.g., having only seven in all) we see that it is impossible to number them always in the same way, though we may keep in every case the same relative order. Some writers, conscious of the difficulty, 
have frankly given up the numbers and simply designate the classes by their prefixes (" the $m u-b a$ class,' 'the mu-mi class,' and so on). But as the prefixes assume different forms, and are sometimes lost, this arrangement is useless for comparative purposes unless some standard form is agreed upon. The following table contains the forms which Meinhof has arrived at as probably the original ones. Even if this view should be erroneous in some cases, it is at least possible to see how all the forms actually in use could have been derived from them; and, in any case, this does not affect their use as a means of reference.

The prefixes are given in Prof. Meinhof's orthography, as to which the following points should be noted: $v$ is the sound called ' bilabial v' which is very common in presentday Bantu, though in some languages it has become $b$ or $w{ }^{1} \quad \hat{\imath}$ may here be disregarded, merely remembering that in Meinhof's opinion the vowel of the $v \hat{i}$ prefix originally differed from that of the $k i$ prefix, also the $l i$ of the tenth class from that of the fifth. The etymological importance of

${ }^{1}$ See Noël-Armfield, General Phonetics, p. 71. 
this 'heavy i' is shown in his book on Bantu phonetics. $\gamma$ stands for the 'voiced sound' (which does not occur in English) of Scots ch in 'loch.'

It may be as well to state here that the orthography used in this book for specimens of Bantu languages is that adopted in the printed texts available for cach particular language. Where it has been found necessary to depart from this orthography, or where any symbol needs special explanation, the fact is mentioned in a note. No attempt has been made to unify the various systems: the only satisfactory uniformity would be that obtained by transcription into I.A.P. characters, and for this the study of Bantu is not sufficiently advanced. The reader not already familiar with this script, is referred to $\mathrm{Mr}$. Noël-Armfield's General Phonetics (I915).

$\mathrm{He}$ will also find a table of it facing page 30 of the author's Langugge-Families of Africa.

1. mu-

2. va- Plural of 1 .

3. mu-

4. mi- Plural of 3.

5. li-

For which, in this book, we use the Greek character $\chi$. 
6. ma- Plural of 5 and 14.

7. ki-

8. vî- Plural of 7.

9. $\mathrm{ni}$

10. lî-ni Plural of 9 and 11.

11. lu-

12. tu- Plural of 11,13 and 19.

13. ka

14. vu

15. ku No plural.

16. pa

17. $\mathrm{ku}$ Locatives. No plurals.

18. $\mathrm{mu}$

19. pî̀

20. $\gamma \mathrm{u}$

20a. $\gamma$ a Plural of 20.

21. $\gamma^{\hat{1}}$

Other classes and prefixes of which occasional traces survive, will be discussed later on.

It will make matters clearer if we subjoin to the above skeleton table of prefixes, which are mere abstractions and, as such, difficult to grasp and remember, specimen nouns from eight fairly typical languages, showing the forms in actual use for each class, with their concords as exhibited in the adjective and the possessive particle. As far as possible, words have been chosen which are found in all the eight languages, so as to facilitate a comparison of roots. 
No. 1 NOUN-

Zulu

Chwana

Herero

\begin{tabular}{|c|c|c|c|c|}
\hline $\begin{array}{c}\text { Class } \\
1\end{array}$ & Human Being & umu-ntu & mo-tho & omu-ndu \\
\hline 2 & Do. pl. & aba-ntu & va-tho & ova-ndu \\
\hline 3 & Tree & umu-ti & mo-re & omu-ti \\
\hline 4 & Do. pl. & imi-ti & me-re & omi-ti \\
\hline 5 & Tooth & $\mathrm{i}(\mathrm{l} \mathrm{i})$ zinyo & le-ino & e-yo \\
\hline 6 & Do. pl. & ama-zinyo & ma-ino & oma-yo \\
\hline 7 & Chost (thorax) & isi-fuba & se-huba & $\begin{array}{c}\text { [otyi-na }= \\
\text { thing }\end{array}$ \\
\hline 8 & Do. pl. & izi-fuba & li-huba & [ovi-na] \\
\hline 9 & Elephant & in-dhlovu & tlou & on-dyou \\
\hline 10 & Do. pl. & izin dhlovu & li-tlou & ozon-dyou \\
\hline 11 & Wand & $u(l u)-t i$ & lo-re & oru-ti \\
\hline - 12 & Do. pl. & - & - & otu-ti \\
\hline 13 & Little stick & - & - & oka-ti \\
\hline 14 & Human nature & ubu-ntu & vo-tho & o-undu \\
\hline 15 & Death & nku $f a$ & 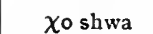 & oku-ta \\
\hline 16 & Place, at & - & - & opona \\
\hline 17 & - to & - & - & okona \\
\hline 18 & - in & - & - & omona \\
\hline 19 & [Diminutive] & [Found in Duala & , e.g., i-seru " & warf antelope' \\
\hline 20 & Clumsy person & - & - & - \\
\hline $20 \wedge$ & Do. pl. & - & - & - \\
\hline 21 & Giant & - & - & - \\
\hline $21 \mathrm{~A}$ & Do. pl. & - & - & - \\
\hline
\end{tabular}

NotE.-Words in square brackets are inserted when 
CLASSES.

\begin{tabular}{|c|c|c|c|c|}
\hline Nyanja & Swahili & Ganda & Gisu & Kongo \\
\hline mu-ntu & m-tu & omu-ntu & uinu-ndu & mu-ntu \\
\hline a-ntu & wa-tu & aba-ntu & baba-ndu & a-ntu \\
\hline m-tengo & $\mathrm{m}-\mathrm{ti}$ & omu-ti & $\begin{array}{l}\text { [kumu-ba }= \\
\text { sugar-cane] }\end{array}$ & $\begin{array}{l}\text { [mu-nse }= \\
\text { sugar-cane }]\end{array}$ \\
\hline mi-tengo & mi-ti & emi-ti & [kimyuba] & [ni-nse] \\
\hline dz-ino & j-ino & eri-nyo & li-sino & d-inu \\
\hline ma-no & in-eno & ama-nyo & kama-sino & m-enu \\
\hline chi-fua & ki-fua & eki-fuba & {$[$ kiki-ndu $=$} & [ki-nzu $=$ pipe] \\
\hline zi-fua & vi-fua & ebi-fuba & [bibi-ndu] & {$[\mathbf{l}-n z u]$} \\
\hline njobvu & ndove & en-jovu & $i-t$ sofu & nzau \\
\hline njobvu & ndovis & en-jovu & tsi-tsofu & nzau \\
\hline$[\mathrm{u}-\mathrm{k}$ onde $=$ net $]$ & $u-t i$ & [olu-ga $=$ cane] & $\underset{\text { bow }]}{[\text { lu-hingo }}$ & {$[\operatorname{lumbu}=\underset{\text { fence] }}{ }$} \\
\hline - & - & $\begin{array}{l}\text { [otu } \mathrm{dzi}= \\
\text { drop of water] }\end{array}$ & - & [tumbu] \\
\hline $\begin{array}{l}\text { [ka-ntu }= \\
\text { little thing] }\end{array}$ & - & aka-ti & $\begin{array}{l}\text { [ka-busi, } \\
\text { little goat] }\end{array}$ & - \\
\hline u-untu & $\mathbf{u}-\mathbf{t u}$ & obu-ntu & bubu-ndu & uwu-ntu \\
\hline ku-fa & ku-fa & oku-fa & ku-fwa & (ku) fwa \\
\hline pa malo & [nyumbani (pa)] & wa-ntu & ha-ndu & v-uma \\
\hline ku malo & $\begin{array}{l}\text { [nyumbani } \\
\text { (kwa)] }\end{array}$ & [ku-mpi, near] & ku-ndu & k-uma \\
\hline m'malo & $\begin{array}{l}\text { [nyumbani } \\
(\mathrm{mwa})]\end{array}$ & {$\left[\begin{array}{c}\text { munda }= \\
\text { the inside }]\end{array}\right.$} & mu-ndu & $m-11 \mathrm{ma}$ \\
\hline -pl. lo-seru 12, & and Ny+wen:2 fi- & ullu " bird," pl. & tufulu 12] & $\begin{array}{l}{[\mathrm{fi}-\mathrm{mbele}=} \\
\quad \text { little knife] }\end{array}$ \\
\hline- & - & ogu-ntu & - & - \\
\hline - & - & aga-ntu & - & - \\
\hline- & $k i-j i-t u$ & - & gugu-ndu & - \\
\hline - & & - & gimi-ndu & - \\
\hline
\end{tabular}

that with the same meaning has a different root. 
Zulu and Ganda-both too well-known for further comment-indicate, approximately, the two extremities of the Bantu area. Hererocalled by South African colonists Damara-is spoken in the south-western territory which till recently was German. It is a language, in many respects, of the highest interest; but its speakers are now sadly reduced in numbers. Nyanja extends, more or less, from the north end of Lake Nyasa to the Zambezi and is closely cognate-if not virtually identicalwith the main speech of Southern Rhodesiausually, though not very correctly, called 'Mashona' or 'Chiswina.' The range of Swahili is roughly from Warsheikh on the Somali coast to Cape Delgado (though the people themselves limit the name 'Sivahilini' to the coast north-east of the Tana mouth), but it has been carried as a trade language far into the interior, and even to the Congo. Gisu, sometimes called 'Masaba,' is a very remarkable tongue, whose principal speakers live round Mount Elgon in the north of the Uganda Protectorate: it has, perhaps, preserved more ancient forms than any other. Kongo (sometimes called Fiote) is spoken by large numbers of people on both sides of the 
Lower Congo, as far up as Stanley Pool, and in the old 'Kingdom of Congo' south-east of the river, where the Portuguese missionaries laboured.

Originally, we may suppose that some definite meaning attached to each class, just as, in languages possessing grammatical gender, the masculine and feminine terminations corresponded to a real distinction of sex. It would be difficult now to give any reason why hortus should be masculine, or mensa feminine; but no doubt, when it had once become an accepted fact that nouns in -us were mostly masculine and nouns in $a$ mostly feminine, words which happened to end in these ways were ranged under one category or the other, without regard to their meaning.

Sometimes it is still possible to say that a class consists of nouns denoting a certain kind of objects, such as the first (or 'personal') class, the fifteenth, which contains verbal nouns (infinitives), and the diminutive class found in some languages. Again, certain sets of nouns may be found in one class-e.g., trees in the third, though it contains others as well. Much ingenuity has been expendedand, I cannot but think, wasted-in drawing 
up definitions of the classes: the attempt seems to be hopeless at the present day, because prefixes originally distinct may have become identical in form, through elision or contraction, and so two or more classes have been merged into one. We know this to have happened in Swahili, where II $(l u)$ and I4 (vu) have alike been contracted into $u$ and are now treated as one and the same class.

Class 3-4 (mu-mi) contains, besides trees, a number of the parts and organs of the body, which may, at one time, have formed a distinct class. ${ }^{1}$

It should also be noted that the same word is found in two or more languages with different prefixes, e.g., 'year'; Zulu, umnyaka, 2 ; Nyanja, chaka, 7, etc.

The Fulfulde language of West Africa has a most remarkable system of noun-classes, much fuller and more clearly defined than anything now to be found in Bantu. Professor

${ }^{1}$ It is quite possible that they were originally locatives with the prefix $m u$ (mu-kono, really 'in the hand'), which became confounded with this class owing to the similarity of the prefix. To understand how this might have happened, we may refer to Nyanja, where the noun kamwa, 'mouth,' is never used by itself-only pa-kamwa and $m-k a m w a$, , at' and 'in the mouth.' 
Meinhof's theory as to this language and its possible connection with the Bantu family is set forth in his Introduction to the Study of African Languages. ${ }^{1}$

In some cases, the distinction of meaning implied by the prefix is quite clear. There is no doubt about the diminutives, nor the infinitive used as a noun (I5) ; I indicates persons; 7, (sometimes) collectivity; I4, either abstractions, or some substance taken in the mass, such as grass, wool, flour, etc. And we find, over and over again, that the same root may take different prefixes and have its meaning modified accordingly. In Zulu umu-ntu, I, is 'a person'; isi-ntu 7, 'the collectivity of beings '- - the world'; ubu-ntu, 'human nature.' Umu-ti 3 , is 'a tree'; $u(l u)-t i$ I I, 'switch' or 'wand' (this has suggested to some writers that Class II consists mainly of long, thin objects-which is scarcely borne out by the facts) $;^{2} u b u-t i$ I 4 ,

${ }^{1}$ Pp. 99, 100. See also Language-Families of Africa, Chapter VI.

${ }^{2}$ It is true that some words in Herero suggest this idea ; thus omu-ndu, 1, is 'a person,' ort -ndu, 11, 'a tall, thin person'; otji-tenda, 7, 'iron,' oru-tenda, 'a long, thin piece of iron.' 
'poison'; and in Swahili, we have ki-ti 7, 'chair'-i.e., 'the thing made of a tree,' or perhaps "the little tree (thing)' - (see ante p. 29).

Though, as we have seen, Bantu knows no linguistic distinction of sex, a very definite line is drawn between the living and the lifeless-or rather, perhaps, between the human and the non-human. The first ( $m u$ ) and second $(b a)$ classes, in every Bantu language, consist pre-eminently, if not exclusively, of names denoting human beings.

As a rule, even ghosts and other preternatural beings are not placed in the same class. In Zulu i-zimu (usually translated 'cannibal,' but in reality a kind of ogre or goblin), ama-toigo and ama-dhlozi (ancestral spirits) are of 5 and 6 ; in Nyanja, mzimm, the most usual word for spirit, is 2 , and so is Mulungu, which sometimes designates an ancestral ghost, though at others it seems to be used in a sense almost implying a 'High God.' Some languages include animals in the first class, but this is -evidently an afterthought.

The African mind, in general, inclines to treat

${ }^{1} K i$ - may here be the diminutive prefix-see next Chapter. 
animals as persons;-we see in their folk-tales that the distinction is kept up with difficulty. (Uncle Remus is sophisticated enough to be conscious of the confusion, and reminds his hearer that, once upon a time, 'creatures had sense same like folks.') While most of them are usually of the gth (ni) class (cf. in Zulu, imbuzi, 'goat,' inkomo, ' cow,' ingwe, ' leopard,' indhlovu 'elephant,' etc.), it seems to have been felt that this was quite illogical, so some languages (as Swahili) removed them into the first class without changing their form-i.e., treated them, in respect of all their agreements, as first-class nouns; others gave them a special plural, by placing the second prefix before their own plural one. The few names of animals which in Zulu and Chwana are included in the first class are treated in a special way, suggesting that they did not always belong to it. Their plural prefix is o-, not aba-, which is also taken by certain nouns denoting degrees of relationship (as $u$-yise 'father,' pl. o-yise, u-nina 'mother,' pl. o-nina) and all proper names." Perhaps there was once a separate

1 Proper Nouns are often used in the plural, to mean ' a person and those with him.' See Colenso, First Steps in Zulu-Kafir, §29. 
class for names of relationship (which in most Bantu languages are treated exceptionally in some way or other) and it is worth noting that most (not all) Zulu names of animals coming under this heading are compounded with mno- $(=$ mina $)$. The corresponding nouns in Chwana take the prefix bo- (vo-).

This first class has the prefix mu- - sometimes heard as mo-, sometimes worn down to $m$, and sometimes changing to $u n$-, especially before $\mathrm{t}$ or $\mathrm{d}$. In Zulu it is umu- or um-, sometimes contracted to $u-$. One might be tempted to think that the longer form is the more primitive one, and that languages like Chwana and Nyanja have lost the initial vowel. There seems reason, however, to think that this initial vowel is not really part of the prefix, but the remnant of a demonstrative which has become amalgamated with it. Gisu - a language in a very archaic stagesupplies the clue: not in this class indeed, but in the second, third, and fourth, where we have baba-ndu 'people,' kumu-kono (elsewhere umkono, mukono, mkono), 'hand,' plural kimi-kono.

Meinhof thinks that this demonstrative originally had the form $\gamma a$ and assimilated its 
vowel to that of the syllable which followed it, while the $\gamma$ passed, sometimes into $n g$, sometimes into $k$. Thus $\gamma$ a umuntu would become ngumuntu, Gisu kumundu, and, the consonant being dropped, the prefix would remain as umu-. This pronoun survives as the 'copula' (to be treated in a later chapter), and in Zulu we have ng'umuntu, ' it is the man,' ng'umuti, ' it is a tree.' 'This is pointed out by Bleek in his Comparative Grammar. ${ }^{1}$ On this theory of its origin, it is quite intelligible that he should call the initial vowel an article, especially as it is chiefly absent in cases where the employment of an article would be inadmissible-always in the vocative, and in certain negative sentences. However, as it is impossible by its means to make any distinction corresponding to that indicated by the use of ' $a$ ' and 'the,' the initial vowel can hardly be called an article in our sense.

This original $\gamma a$ probably accounts for the fact that in some languages (e.g., Swahili, Nyanja, etc.) the pronoun of the third person

1 Pp. 150,151. Of course he knew nothing of the Gisu language, which has so fully justified his deductions. 
(see Ch. VI.) is $a$ - instead of $\mathfrak{u}^{1}$. Forms like omuntu, omuti, perhaps show that sometimes, instead of the $u$ assimilating the vorvel which followed it, contraction took place :

\section{$(\gamma)+$ aumuntu $=$ omuntu.}

Names of tribes may be either of the second or the sixth class: Aba sutu, Bechwana, Barolong, Amazulu, Makaranga, Waswahnli, Agiryama, Abaganda. Those of the second have corresponding singulars of the first: Umsutu, Mochwana, Morolong. But sixth class nouns do not always have a singular of the fifth : $I$-zulu does not seem to be used for an individual of the Zulu nation-perhaps because it is the same as the word for the 'sky'-but we have i-Bunu, 'a Boer,' $i$-Lawu, ' aHottentot,' $i$-Xosa, ' a Cape Kafir.'

The concords of Class 3 are almost identical with those of Class $r$. There are, however, two differences in the pronouns, which we shall notice in a later chapter. Class 4 has the same pronouns as Class Io, though its prefix (and consequently its agreement with the adjective) is different. Besides the names of

1 Also for $g u, g i$ and $g a$ being occasionally found as pronouns in the third, fourth and sixth classes, instead of the more usual $u, i$ and $a$. 
trees and parts of the body (usually: 'arm,' 'finger,' 'leg,' 'foot,' 'heart,'-sometimes 'head,' etc.) this class contains some words not easily placed under any spccial heading, such as 'village' (i.e., a 'kraal' or collection of huts of any size, up to what can be fairly described as a town)- $m m u-z i$, mo-tse, mu-dzi, $m-j i, \quad m u-n z h i, \quad m u-n d i .^{1}$ (Herero, curiously enough, places it in 11 : ori-ithe.) Words denoting streams or rivers (though differing in form) very often belong to this class. So do, many proper names of rivers: Zulu Ungeni, Umzimkulu, etc. ; others are found in Class I I.

The fifth prefix is $l i$, in Zulu ili-, usually contracted into $i$-, as $i$-tshe (for $i l i$-tshe), 'stone,' $i$-zwi, 'word,' etc. In some languages this prefix has assumed the form $d i$-; in some it is lost altogether, except before roots beginning with a vowel, where it is sometimes represented by $d z$ or $j$ : Nyanja $d z$-ina, 'name,' which is in Swahili j-ina, (Yao l-ina). In Swahili, the pronoun $l i$ and the possessive particle $l a$, used with nouns like neno, 'word,' zirea, 'pool,' would be something of a puzzle if it were not

${ }^{1}$ Bleek thinks these may have originated as locatives in $m u$. See his Comparative Grammar, p. 130. 
known from other languages that these words must originally have begun with $l i$.

Names of fruits are found in this class, differing only by prefix from the name of the tree which produces them: Swahili m-buyu, 'baobab,' buyu, 'calabash' (which grows on it), m-kuyu, 'fig-tree,' kuyu, 'a fig,' m-chungu'a, 'orange-tree,' chungwa, 'orange' ; Zulu um-kiwane, 'wild fig-tree,' $i$-kiwane, etc.

Many words denoting liquids, or substances handled in bulk, which are not individualised and therefore have no singular, belong to the sixth class; e.g., 'water': Zulu ama-nzi, Swahili ma-ji or ma-i, Nyanja (and other languages), ma-dzi, Kongo ma-za, Duala ma-diba, etc. ; 'millk': Swahili ma-zirea, Ganda ama-ta, Chwana ma-shi; 'sour milk': Zulu ama-si, Herero oma-ere; 'millet': Zulu ama-bele, Nyanja ma-ere, ma-pira, etc., etc.

Here we may mention a feature which at first sight seems puzzling in Chwana and some other languages. Nouns of Class 9, besides their own plural sometimes take a second in

${ }^{1} \mathrm{Nazi}$, 'coco-nut,' tende, 'date,' ndizi, 'banana,' are exceptions, being of the ninth class. But none of these three seem to be original Bantu roots. The names of the trees are quite regular: $m$-nazi, $m$-tende; but the banana-tree is $m$-gomba, not $m-d i z i$. 
$m a-$, indicating that there are very many of the thing in question; e.g., nku, 'a sheep,'-plural $l i-n k u$, but 'many sheep' $=$ ma-nku. These may be regarded as collectives with no singular, and they are possibly connected with the lost $\checkmark$ augmentative class, to which we shall recur at the end of the next chapter.

It will be seen by reference to the Table that the form assumed by the sixth prefix in Gisu is kama-, in accordance with the principle already explained. I have not met with any other example of this form; but the original $\gamma a$ prefixed to the ma explains why the pronoun in some languages (Giryama, Ganda, etc.) should be $g a$. It is usually $a$ or $y a$.

It is less easy to see why the prefix should appear in Herero as oma-. But that language, as the Table shows, has a tendency to make all the initial vowels $o$ : the only exception is the fifth prefix, which has assumed the form $\iota$-. 
Thf Noun-Classes (contimued)

THE forms of the seventh and eighth prefixes vary considerably. Besides those shown in the Table, we have:-

Duala . . . e-, be-: e-koto, 'cap,' pl. be-koto. Ila (Middle Zambezi) . . . chi- shi-: chi-bia, 'pot,' pl. shi-bia.

Kikuyu (British East Africa) . . ki-, i-: ki-hato, 'broom,' pl. i-hato.

Konde (north end of Lake Nyasa) . . . ikiifi-: iki-tala, 'bedstead,' pl, ifi-tala.

In Ronga (Delagoa Bay), and in some dialects of the language spoken in Rhodesia the eighth prefix has a very peculiar sound, written in the International Phonetic Alphabet $\sigma$ and by Meinhof $s$. It is produced by getting ready to say ih (as in 'thin') and then rounding the lips, as if for $w$, and somewhat resembles the whistle which results from blowing into a key. Venda (North Transvaal) gives this prefix the 
voiced sound, which is written $\rho$ and by Meinhof $z$.

This class, like some others, consists of two or three originally distinct ones, which may account for the prefix conveying several different senses. Sometimes it has a kind of instrumental force and is then used to make a noun out of a verb, implying the thing by means of which the action is accomplished, as isi-hlalo (Zulu) 'a seat,' from hlala, ' to sit' ; Nyanja chi-psero, 'a broom,' from psera, 'to sweep'; chi-peta, 'a winnowing-basket,' from peta. Sometimes it seems to convey a collective sense, as in Zulu, isi-ntu (already remarked on), isi-Zulu, " the whole of the Zulus, the Zulu nation,' isi-zwe, 'tribe, nation,' from $i$-zwe, 'country.' This is distinct from the use of the prefix to express language wichdoes not occur in-Zutut: Chi-Nyanja, KiSwahili, Se-Sutu; or, more accurately, 'likeness, fashion, manner,' as its application is not confined to language. Again, it forms a kind of abstract noun, expressing, not a quality, but the action of a verb, as Sivahili ki-lio, 'weeping,' from lia; Nyanja chi-funo, 'wish,' from funa.

In Swahili, a great many nouns in $k i$-are 
diminutives, $k i$ - having taken the place of the thirteenth prefix $k a-$, as it has also done in Kongo. ${ }^{1}$ In Nyanja, curiously enough, the old augmentative class (20) has become merged in the seventh, exclianging its prefix $\gamma u$ for chi-.

On the other hand, nouns which have dropped their prefixes, and whose stems begin with chi, ki, shi, etc., are liable to be mistaken for nouns of the seventh class. These are fairly numerous in Nyanja, as chinga, 'fence,' pl. ma-chinga, chindu, 'roof,' pl. ma-chindu.

This class also contains some nouns meaning persons. In $\mathrm{Zulu}$ these are derived from verbs as isi.hambi, 'a traveller,' from hamba, ' go,' isi-gijimi, ' runner, 'from gijimia, ' run.' In Swahili we find in this class personal nouns implying some defect, as ki-pofu, 'a blind person,' ki-ziwi, 'a dumb person,' etc. Probably these originally belonged to a 'depreciative class,' which will be mentioned later on.

The ninth prefix is usually found as $i n$ - or $n$ - : in Ronga yin-, Ganda, en-, Herero on-, Makua usually $i$ - without the $n$, as $i$ - $k u$, 'cloth,' which

${ }^{1}$ In Kongo, however, diminutives are distinguished from the nouns in $k i$-by reduplication of the root, as ki-mwananwana, 'a little child.' 
is equivalent to the Swahili or Yao $n g u o .^{1} n$ becomes $m$ before stems beginning with a labial, as im-buzi (Zulu), 'goat,' for $i n+b u z i$.

The tenth class properly has the plural prefix in addition to the singular ( $Z$ ulu $i z i$ - $n$ $d h l u, i z i-m-b u z i)$, but the former often disappears through contraction, so that singular and plural are alike, as Kongo nzo, Sivaliili and Nyanja, nyumba, 'house.' Some dialects of Nyanja, however, have zi-nyumba Io, and Herero, ondyuo 9, odho-ıdyuo ${ }^{2}$ Io, Ronga yin-dlu 9, tiyin-dlu Io. Ronga sometimes contracts both prefixes, as ndlebe, 'ear' (Zulu in-dhlebe), plural tin-dlebe, and may drop even the $n$, as in huku, 'fowl,' plural tihuku. Chwana Sutu and Venda have the tenth prefix $l i$ : puli, 'goat,' pl. li-puli; kxomo 'cow,' li-kxomo. 'This suggests that the primitive form may have been $l i-n i$-.

${ }^{1}$ Both in Chwana and Makua there is a tendency to substitute the voiceless stop for the voiced stop and nasal (i.e., $p$ for $m b, t$ for $n d, k$ for $n g$ ). Cf. puli, 'goat,' Nyanja, mbuzi; itotrua (Makua) 'star,' Yao, ndondwa.

${ }^{2} D y$ is probably the nearest equivalent to this sound in ordinary English spelling, but it may be that represented in the International Phonetic Alphabet by inverted f. Instead of $z$, Herero has the sound of $t h$ in 'there '-here represented by $d h$. 
So far as any rule can be laid down for them, most names of animals belong to the ninth class. Many of these are the same throughout the greater number of the Bantu languages. We give a few of the most striking examples :

Cow or ox: Zulu, inkomo, Chwana, kxomo, Ronga, homu, Herero, ongombe, Nyanja (and many other languages), ng'ombe, ${ }^{1}$ Bobangi (Middle Congo), ngombo. Even where the root is different, as 'Ganda ente, the word still belongs to the same class.

Goat: Zulu, imbuzi, Ronga, mbuti, Chwana, puli, Nyanja (and many others), mbuzi, Bobangi, mboli, Duala, mbodi, Herero, ongombo (a different root), Kongo, nkombo, and in some dialects, ntaba.

Sheep : Zulu, imvu, Chwana, nku, Nyanja, nkosa, Swahili, kondoo, Giryama, ng'ondzi, Ganda, endiga.

The dog is usually mbwa or imbwa-quite recognisable as representing his bark,-but in

' $N g$ ' thus written has the same sound as in 'ring,' 'sing,' etc. Meinhof writes it $\dot{n}$. Where no apostrophe follows, the sound is that heard in 'finger.' The former does not seem to occur in Herero or Pokomo. In the latter language 'cow' is ngombe, which would - be ridiculed as a mispronunciation by Swahilis or Anyanja. 
Zulu this has become inja, because $w$ cannot in that language follow another labat.

The eleventh prefix is found in most presentday Bantu languages, though its presence is frequently disguised by the fact that it has been contracted into $u$-; as Zulu $u$-ti for $u l u$ ti. Here it is still easily distinguishable by its concord-when we hear uti olude lwa leyo 'nkosi, ' the long staff of that chief,'-we know that $u t i$ cannot be one of the first-class nouns which have $u$-for their prefix $(u-b a b a$, etc.). Moreover, when used as proper names, (as any noun may be in Zulu, keeping its own prefix, and changing only the initial vowel), they appear in the uncontracted form; thus we have $u L u z i p o$, a man's name, from $u-z i p o$, 'a claw,' uLutuli, from u-tuli, 'dust.'

In Swahili, the distinctive concord is no longer seen, the pronouns, etc. being identical with those of 3 : utim-refu u-me-anguka, 'the long stick has fallen.' Moreover, I4 has undergone a like contraction, so that these two classes are merged in one. The $h t$-class still exist separately in Yao and Ila: in Nyanja there are a good many nouns beginning with this prefix, but they are treated as belonging to the fifth. In Ronga, though still distinct, it 
has modified its prefix to $l i$-, while the fifth prefix is ri-. As will have been noticed in Herero, some languages sound this prefix with $r$ rather than $l$. Sometimes it is used (instead of 7) to express language: Lu-ganda, Lu-nyoro, Lu-gisu: this seems to be confined to the northern region of the great lakes.

There is considerable divergence in the plural prefix appropriated to this class. The most usual appears to be the tenth, but sometimes we have the sixth. In Herero, Ndonga, Kongo, it has retained its original one, the twelfth (tu-), which also belongs to the diminutive class. Sometimes we find that, as in Io, the plural prefix is added without rejecting the singular; thus in Swahili, uti makes $n y u t i=n i+u t i$; in Mbundu (Angola), we have lubango, 'stick,'-pl. ma-lu-bango'.

The twelfth and thirteenth classes have dropped out in a good many languages. $K a$ - is properly the sign of the diminutive, and is still so used in Herero, Nyanja, Yao, Ila, Ganda; Pokomo, Giryama, Zigula, etc.

As we have seen, Swahili and some others have substituted the seventh prefix for it.

${ }^{1}$ Meinhof thinks this was at first the rule with all the classes and that the second prefix gradually dropped out. 
Zulu, Ronga, Chwana, and their cognate dialects have got rid of it altogether, and express their diminutive by a suffix-perhaps under the influence of the Hottentot language. E. g., Zulu, indhlwana (indhlu-ana), 'a little house'; Chwana pitsa, 'pot,' pits-ana, 'little pot.'

'Though tu- seems to be the original plural prefix attached to the thirteenth class, a variety of others have talien its place, and the learner should be prepared to meet with $p i$ - (a form of 8), $u_{-}, b u_{-},\left({ }_{4}\right.$, as in Herero), ma-, vi-, and tin(I0).

In Ganda, where the plural of aka-ntu, ' a little thing,' is obu-ntu, the twelfth prefix has a distinct and very curious use-otu-dzi, 'a single drop of water,' from ama-dzi, tu-nyu ' a little salt,' from mu-nyu. ${ }^{1}$ That is, it is used to individualise a single particle of something which has to be looked at or handled in the mass, like liquids, flour, grain, etc. These, as we have scen, when belonging to Class 6, have no singular; when of Class I4, they have no plural-or, it would be more correct to say, they have neither singular nor plural. This formation is also found in 'Conversely, lu-nyuu 'a lot of salt.' 
Pogoro, a language spoken east of the northern end of Lake Nyasa.

In Nyanja, the diminutive plural prefix is $t i$ - (which, Meinhof thinks, may have been a distinct class) : ka-mbalame, 'little bird,' plural, ti-mbalame.

Duala has a. different diminutive class, traces of which occur elsewhere, but only in the western part of the continent: it is the one numbered I9. Its prefix $i$ - is supposed to have been originally $p i$-, and its plural prefix is the twelfth, which has here assumed the form lo-: $i$-seru, a small kind of antelope-pl. lo-seru. In Kongo the prefix has assumed the form $f$ - and constitutes an additional diminutive class, which, however, has no plural of its own. This class is also found in Nywema and some other languages of the central regions between the Great Lakes and the Upper Congo.

The fourteenth class, as already stated, includes abstract nouns (e.g., Zulu ubu-ntu, Swahili $u$-tu, etc., ' human nature'), and names of materials which are not properly speaking either singular or plural : $u b u$-si (Zulu), $u$-chi (Nyanja), 'honey,' utshwala for ubwala= ubu-ala (Z.), 'beer,' utshane for ubu-ane (Z.), 
'grass,' ub-oya (Z.), ubwea (Ny.), 'hair of an animal.' If nouns of this class are ever put into the plural, they usually take the sixth prefix (ma): thus 'night,' ubu-suku, has no plural in Zulu, but the Chwanabo-sixo has the plural ma-sixo.

But there seems reason to suspect that most fourteenth class nouns which take a plural do not originally belong to the class at all, as they denote concrete objects which there seems no reason for including here. Probably the same thing has happened as with the $k i$ - and $u$ - classes in Swahili. Uta, 'bow'-originally bu-ta or vu-ta-is found in . nearly every Bantu languagè. In Nyanja it has the concord bu, which stands almost alone : uta bu-funa kutyoka, 'the bow is likely to break' (lit. 'wants to break'). The same is the case with boa, 'mushrooms,' said in Scott's Dictionary to be of Class I (no explanation is offered of the anomalous concord, but the existence of the bu-class in other languages makes it quite clear): boa bwanga bu-li apa ( $l i$ is here the verb 'to be ')-' my mushrooms are here.'

Then we have bicato, 'canoe,' stated to be of the fifth class, with plural ma-bwato; but 
forms like Pokomo waho (u-aho), pl. m-aho, seem to show that $b w$ - is the prefix (bu-ato). Nyamwezi has vato 14 and Konde ubrato (ubu-ato). This last has its plural of Class 4 : imyato (imi-ato), which may point to a still further confusion. The little group of northwestern Bantu languages, of which Duala is the chief (Benga, Dikele, Isubu), make the plural of the fourteenth class in $m i-$ : the same word is in Benga bwalu, mi-alu, in Duala b-olo, mi-olo. Duala has bw-ele, 'tree,' pl. mi-ele: a curious exception, as regards the singular.

These last can scarcely be explained as collectives, or nouns of material, though 'mushrooms' might: being considered in the first instance as food they would be thought of by the basketful. Even as to uta I am not quite clear: uta in Swahili seems to mean a bow with quiver and arrows all complete (the ' artillery' that Jonathan carried), while upindi is a bow pure and simple. The plurals nyuta and mata are given in the dictionaries, but they may be later formations. In Nyanja the plural mauta apparently has the same collective sense-at least, as applied to the three stars in Orion's belt, I understand it to mean 'The 
Bow and Arrows,' not 'The Bows.' Ubrt-so (Zulu), 'face,' is found almost everywhere and has the same root as $i$-so, ' eye' - as though it were a sort of abstraction: the 'eyeness,' if one might coin the word. In fact one does sometimes hear ' eyes ' used to mean 'face,' in Nyanja and probably elsewhere.

The fifteenth prefix, $k u$-, denoting infinitives of nouns, offers little difficulty and has the same form (except for the occasional presence of an initial vowel) almost everywhere. In Chwana it is modified to $\chi \circ$, and several western languages are. without it, though it has left traces in Kongo.

There are a few nouns in $k u$ with plurals in $m a-$, which are certainly not infinitives and are perhaps remnants of a lost class. They sometimes retain the $k u$-in the plural, after the ma- prefix: Nyanja kutu, 'ear,' pl. ma-ku-tu; but Herero oku-twi, oma-twi, Kongo $k u-t u, m a-t u$. Several of the western Bantu languages have the words for ' arm' and 'leg' similarly formed, and Herero has a iew more besides. Meinhof thinks these are locatives, a theory which will be more fully explained in the next chapter.

Classes $16,17,18$ are not found in Zulu or 
Chwana, though slight traces of them exist. They can better be discussed in the next chapter, in connection with the locative; here it may be sufficient to say that they differ from most other classes by having a movable prefix : a preposition is added before the usual prefix and entirely changes the concord. The preposition and its noun are treated as a single word. It is somewhat as though, instead of saying 'The house is near a field,' we said ' Near-the-house $n$-is a field,' or ' By-the-house $b$-is,' etc.

The locative prefixes have entirely disappeared in Swahili, but the concord remains, as we shall see.

The nineteenth class, already referred to, was not recognized by Bleek.

The remaining two classes-more properly four-were also unknown to Bleek and only survive in a rudimentary condition. Ganda has a prefix ogu-, which seems to convey a -notion (I) of size, (2) of depreciation : ogu-ntu, ' a clumsy thing,' pl. aga-ntu, ogu-nyo, ' a large quantity of salt' (omu-nyo), as opposed to 'a small quantity' of the same, otu-nyo. In Gisu there is a class denoting large things, with the prefix $g u$-in the singular, gi-mi-in the plural: 
gu-koko, 'a giant fowl,' pl. gimi-koko, with a prefix now virtually equivalent to the fourth. It might be preferable therefore to enumerate them thus: 20 yu 2I ya 22 yul 23 $\gamma \hat{\imath}$ ( $\gamma \hat{\imath} m i)$.

But as a matter of fact, no language to-day seems to have kept both 20 and 22 independently. Both classes survive in Swahili, though one is completely merged in the fifth and sixth, and the other would be but for its anomalous plural. To express unusual size, a noun loses its original prefix in the singular and takes $m a$ in the plural, as dege, ' a large bird;' (from n-dege), pl. ma-dege. If the stem begins with a vowel it prefixes $j$, as joka, 'large serpent,' from nyoka. But if it is implied that a thing is not only large but monstrous, or ill-conditioned, the form is the same for the singular, but the plural has the prefix mi-: as jombo (from ch-ombo), 'a big ugly vessel,' pl. mi-jombo, vua, 'heavy rain' (implying something abnormal), pl.mi-vua. (Some of these forms in $m i$ - have no singular corresponding to them). But these distinctions are becoming blurred, and a further source of confusion is the insertion of $-j i$ - between the prefix and stem of monosyllabic diminutives. We may 
add that $k i$ - sometimes has a depreciatory sense. ${ }^{1}$

It has already been pointed out that some seventh class nouns in Nyanja (beginning with chii-) are really relics of an old augmentative class. In Kinga (spoken among the mountains $E$. of the north end of Lake Nyasa) there is a class with the prefix ugu- which does not seem to have a plural and conveys either an augmentative or a depreciative sense : it is no doubt an amalgamation of 20 and 22. Traces of the same are also found in Venda. Ganda uses both the $k i$ - and $l u$ prefixes with augmentative force. There is no need to follow out the matter any further, but the student should keep it in mind as a possible explanation of seemingly exceptional forms.

Hints of several other classes are found :

(I) We have already said that Meinhof considers the Nyanja diminutive plural $t i$ - as a distinct prefix, parallel with $t u-$, as $l i$ - is with lut

(2) There are in Nyanja one or two words,

${ }^{1}$ Steere's Handbook of Swchili, p. 19, 'ki-buzi, a poor little goat.' We have already referred to the depreciatory sense of $k i$ - when applied to persons, as kipofu, kiziwi: etc. 
tulo, 'sleep,' tubsi, 'dung,' which seem to stand in a class by themselves. The concords (tulo t-ambiri, 'much sleep,' tulo t-ache, 'his sleep,') indicate that $t u$ - is the prefix. We find otu-lo, 'sleep,' in Ganda, but it does not seem possible to place it, as the French Fathers ${ }^{1}$ do, in the $t u$ - class which denotes 'small quantities.' However, they may have been originally thought of as plurals and, as such, would belong to $\mathrm{Cl}$. I2, like tuvia 'fire' (Kongo) which, though generally used in the plural, seems to have a singular luvia.

(3) Some languages have personal nouns in $k a$ - which are not diminutive-this is especially marked in Herero-and we might compare Ganda ka-baka, 'king,' ka-tikiro, 'prime minister.' And we might suggest the large number of animal names in Nyanja, which begin with na and nanka (nadzikambe, ' chameleon,'nakodzwe; 'water-buck,' nankabai, 'hawk'). But enough has been said to show that the number of classes was once probably far greater than it is now, and to show that in languages not yet fully studied we are quite likely to come upon traces of extra classes.

${ }^{1}$ Manucl de Langue Luganda. Einsiedeln, 1894, p. 31 . 


\section{Cases: The Locative}

IF I begin by saying that Bantu nouns have nothing which can, properly speaking, be described as case, it will appear as if this chapter, being of the same kind as the famous one on 'Snakes in Iceland,' had better be left unwritten.

However, as we have already seen, there is a Possessive-if of a somewhat peculiar character. There is no difference in form between the noun-subject and the nounobject, but some pronouns have distinct forms for the accusative, as we shall see in the next chapter. There is something like a vocative. Perhaps the dropping of the initial vowel in Zulu, as 'Zatshake,' when addressing a man (instead of ' $u$ Zatshuke') is too slight to be mentioned in this connection; but Chwana 
(at least in some dialects) has a different terminal vowel for a noun, according as the person referred to is spoken to or spoken of. And Duala prefixes $a$ to nouns in the Vocative. Finally, the Locative in - $n$ i, though confined to a comparatively small number of languages, is a feature which must be taken into account, and it can hardly, for the purposes of this sketch, be classed under any other heading than that of Case.

If we limit the term 'case' to those relations which are expressed by inflexions of the noun-stem (declensional endings), we shall have to admit that English nouns are entirely without it, except when the possessive is indicated by 's. Case-endings are becoming obsolete in Dutch, though they still exist in German; they are better exemplified in Latin and Greek, and still more so in Sanscrit, which has seven cases.

The Latin declension, for instance (mensae, 'of the table,' rei, ' to the thing,' horto, 'from the garden'), indicates by means of the termination what we express by a preposition, or by the order of words in the sentence, which is our only way of distinguishing subject from object. The same relations are 
expressed in the Bantu languages by means of prepositions. $^{1}$

Indo-European prepositions are invariable. 'From,' ' to,' 'by,' ' with,' never change their shapes, whatever nouns they may precede or follow; and neither do the Latin $a b,{ }^{2} d e$, ex, pro, super, etc.

This is not the case with Bantu prepositions, though the difference is perhaps more apparent than real. We have already seen, in the second chapter, that the equivalent for 'of' assumes different forms according to the noun it follows. It is as though we said in English : 'the house hof the man,' 'the child chof the house,' 'the door dof the room.' This is because the initial of the noun-prefix is combined with the root $-a$, which, whatever its original force may be-we can for practical purposes assume to mean 'of.'

We can now see why Brusciotto called this $w a, y$, etc., an article. He saw that one part

1 This word is used for convenience. Meinhof points out that there are, strictly speaking, no prepositions in Bantu, the words serving as such being really pronouns or possessive particles-except na 'with,' which might equally well be rendered 'and,' and called a conjunction.

${ }^{2}$ The alternative forms $a, a b, e, e x$ are not variations in the sense here intended. 
of it meant 'of,' and-reminded of the way in which $d i$ ('of') combines with the article in Italian (del, dello, della, dei, degli, delle $)^{1}$ concluded that the other part of the word might be an article. The combination seemed to carry out that reversal of European rules which had struck him so forcibly in connection with the prefixes, and the conclusion he came to was a very natural one under the circumstances and does credit to his linguistic insight. He might have represented the whole thing in a diagram, thus:

$$
\begin{gathered}
D-E L \\
\mathbf{X} \\
W-A
\end{gathered}
$$

-the Italian article il having originally been the Latin demonstrative pronoun ille, while $u$ (which becomes $w$ before $a$ ) is the prefixpronoun of its class. With nouns of other classes, we should have ya, la, za, etc., just as in Italian with a feminine singular noun we

1 This combination (the 'partitive article') is better seen in Italian than in either French or Spanish, where it is not carried through consistently ( $d u$, de la, des; $d e l$, de la, de los). In Italian too, not only $d i$ and $a$, but the other prepositions con, in, per, are combined with the article and constitute something like a declension. 
have della, with a masculine plural dei or degli, and so on. But wa fulfils no function of the article as we understand it, the pronoun in it being purely representative and not demonstrative.

This possessive particle is closely connected with the possessive pronoun, to be considered in a later chapter. But I mention it here, because the next point can only be illustrated by the help of possessive pronouns in European languages. In English, as we know, possessive pronouns are among the few parts of speech which have grammatical gender-which show by their form the sex of the nouns they represent-or the absence of it. Possessive pronouns agree in this respect with the noun which stands for the possessor: ' his mother,' ' her father,'-while the reverse is the case in French : son père, sa mère, leave the sex of the possessor quite uncertain, though beginners insist on translating 'her father' by sa père.

Bantu nouns follow, with a difference, the French principle; 'the man's child' is in Zulu : um-ntwana wendoda (for wa-indoda) and not, as it would be if the concord followed the class of the possessor: um-ntwana yendoda $(y a-i n d o d a)$. 
I say 'nouns' advisedly, for we shall see, when we come to treat of them in the proper place, that possessive pronouns agree both ways: that is, the first part follows the class of the thing possessed, the last that of the possessor.

It is scarcely necessary to say, after giving the above examples, that the thing possessed always precedes the possessor, as in French (l'enfant de l'homme). In English, we have it both ways, according as we use the inflected possessive or not-' the man's child,' and 'the child of the man.' 'The Sudan languages' put the possessor first and say ' man child'having nothing corresponding to article or inflection, though sometimes a particle indicating ownership is suffixed to the first word.

There is no way of showing whether a noun is subject or object except by its position in the sentence, the subject coming before the verb and the object after, ${ }^{2}$ just as in English.

${ }^{1}$ See Language Families of Africa, p. 40.

${ }^{2}$ Arabic, which uses case-inflections, usually puts the verb first, the subject next, and then the object; but as the two latter are sufficiently distinguished by their endings, it really does not matter in what order they are put. 
Sometimes, where there can be no possibility of mistake, inversion is used for the salke of emphasis-as by us in rhetoric or poetry; but the outsider had better not meddle with figures of speech such as this, and it is scarcely necessary to mention them in a general outline.

We now come to the Locative; and this has to be treated under two different headings : the locative formed by prefixed prepositions and the suffixed locative in -ni, which seems to be a later development. There are not many Bantu prepositions, as we shall see in the chapter on Particles: the principal ones, which (or, at any rate, traces of them), are found in every Bantu language, are $p a, k u$, mu.

$P a$, roughly speaking, conveys the notion of 'at' or 'upon '; mu, of 'in,' and ku, of 'motion to and from,' though it sometimes has the meaning of 'outside.' It also serves as the sign of the infinitive; but here its function, if not its origin, is different, so that we are quite right in treating 15 and 16 as separate classes. ${ }^{1}$

Meinhof thinks that the use of $k \|$ as infinitive prefix was a later development from its locative function. 
$P a, k u, m u$ are the prefixes of Classes I6, I7, I8 respectively; but they differ in one important respect from the other prefixes. 'These, as a rule (with the exception, in some cases, of augmentatives and diminutives), are attached to the bare root, which cannot be used without them, while $p a, k u$, mu are prefixed to the whole noun, root and all, as in Nyanja pa-chilindo, 'at the look-out,' kuchilindo, mu chilindo; not pa-lindo, ku-lindo, mu-lindo. But in all other respects they are true prefixes and take their own concord, entirely superseding the one properly belonging to their noun when used by itself. For instance, chilindo, being a noun of the seventh class, would take the possessive particle, cha and pronoun chi:

Chi-lindo ch-a Pembereka chi-ri cha-bwino: (The) watch-hut of Pembereka it is good. But Pa-chilindo pa Pembereka pa-li pa-brino would mean, 'At Pembereka's watch-hut it is (a) good (place).'

So we may have also :

i Chilindo, also called nsanja ('staging' or 'platform') is a small temporary structure raised on poles, open or-roofed, erected in the fields so that watchers can overlook the ripening crops and scare away birds, monkeys or other depredators. 
Ku-chilindo kwa Pembereka ku-li kwa-bwino, with much the same meaning as the last sentence, except that the place is thought of from the standpoint of one who is at a distance from it and going, or thinking of going, towards it; while m'chilindo (for mu-chilindo) mwa Pembereka mu-li mwa-bwino, means: 'the inside of Pembereka's watch-hut is good.'

Some nouns, as kamwa, ' mouth,' are never found without the locative prefix-we have pa-kamwa, ku-kamwa and m-kamwa, but never kamwa alone. The word is evidently connected with mwa 'drink,'-perhaps $k a$ is the prefix of a lost class distinct from the diminutive.

Here are some further illustrations, also from Nyanja:

A-li-ku-nka ku munda kwa Champiti: he is going to (the) garden of Champiti.

Ku-mudzi kwanu ku-li kwa-bwino: at our village it is good.

Ku-Mlanje ku-li mpunga, koma ku-Kabula kuno ku-libe : at Mlanje there is rice but at Kabula here there is none.

Kuno, 'here,' is really a demonstrative, agreeing not with 'Kabula,' but with ' $k u$ Kabula,' as though, instead of 'here at Kabula,' one had said ' at this at-Kabula.' 
A mistake to be found in some of the older grammars is illustrated in Steere's Handbook of Swahili (p. 22) by the statement that a class (the seventh, in his arrangement) contains 'the 'one word mahali, place or places, which re' quires special forms in all adjectives and pro'nouns.' Mahali is really a borrowed Arabic word, which is sometimes Bantuized (oftener, I think, at Zanzibar than at Mombasa) by substituting $p a$ for the first syllable, as if the latter were a removable prefix, and so making it into a noun of the sixteenth class. Steere mentions the locative concord a little later on, but does not call it a class (though including it in his 'Table of Concords'). The change undergone by the Swahili locative (which we shall discuss presently) has so obscured the relation between it and mahali or pahali that without a fuller comparative study than was possible when Steere wrote, it was not likely to be perceived.

Several languages have a word for 'place' which is either pa-ntu or some cognate form and may have the same root as $m u$-ntu. In Ganda, where primitive Bantu $p$ becomes $w$, we have the nearly obsolete wantu, which was at first thought to constitute a class by 
itself. ${ }^{1}$ But $w a$, as well as $m u$ and $k u$, is prefixed to other nouns, which are also used as adverbs: $w a-n s i$, 'the ground' or 'below'; mu-nda, 'the inside,' 'or within.' There is also a prefix $e$, not generally found among the locatives, but which may possibly have some connection with the peculiar Zulu form.

In Poliomo we have fantu (bilabial $f$, for $p$ ), in Giryama hatu, elsewhere hantu, handu, etc. (A great many East African languages substitute $h$ for $p$, except in certain particular cases: e.g., Giryama has hendza, 'love,' for Swahili penda.)

Some languages have this word also with the prefix ku: kuntu, kundu; but mu-ntu, $m u-n d u$, if used at all is less common, perhaps because it would have the same form as the word for " person.'?

1 "The tenth class contains the single word wantu, "place"; this word is obsolete except in the single expression buliwantu, "everywhere." But its influence in the language is great, because adjectives, pronouns, verbs and adverbs are all formed with the prefix wa-, referring to this disused word, e.g., wano wa-lungu, "this is a pretty spot." - Pilkington. Wano walungu exactly corresponds with Nyanja pano ( $p a l i$ ) pabwino. ${ }^{2}$ In Zigula" the prefix appropriate to the word hantu "place" is $h a$, and as it belongs exclusively to this word, its mere presence is sufficient to indicate that place is the 
Kongo has vuma (v for p), kuma, muma, as three different forms of the word for 'place.' These take the locative concords as we find them elsewhere, but other nouns preceded by the corresponding prepositions keep their concords instead of taking a locative concord. Muma seems sometimes to be treated as the plurai of vuma : this may arise from a confusion of the $m$ - with the sixth prefix (as though it were contracted from ma-uma) and possibly indicates that the whole system is dying out in some of the western Bantu languages. Bentley remarks concerning vuma: 'In most Bantu 'languages a corresponding word for place ' will be found standing in a separate class of 'its own, and wearing a prefix $v a, p a$, or 'something similar.' This is the same mistake adverted to just now, and no doubt one reason for it is that the prefixes of these words are not, as a rule, removable; but they ręally come under the same heading as the locatives

substantive referred to, so that the word hantu is often omitted. The same rule refers to the more indefinite $k u-n t u$ and its appropriate syllable $k u-$, and also to $m u-n t u, m u-\cdot$ - Kisbey.

Archdeacon Woodward, though mentioning the muconcord, does not refer to the word mu-ntul, in a place,' which, however, certainly occurs in the Likoma dialect of Nyanja. 
which are made up as wanted and simply put the preposition before the ordinary nounprefix. We draw a distinction between the two-but the Bantu speaker feels none.

We now come to the suffixed locative in $-n i$, which seems to be confined to Bleek's South-Eastern Branch of the Bantu family and to a few languages in East Africa, of which Swahili, Bondei, Hehe, and Makua are the chief, if not the only ones-and in Makua it is combined with the prefixed locativemashi=water; $v a$-mash $i-n i=$ at the water; $m-m a s h i-n i=$ in the water.

But the prefix has quite disappeared. in Swahili, and the locative is simply formed by suffixing -ni, which may mean 'in,' 'at,' 'on,' 'from,' ' to,' etc.

$n y u m b a-n i=$ in the house. The accent is always $m j i-n i=$ to the town. shifted forward by the kiti-ni = on the chair. lucative suffix, see p. 15. etc.

But the concord differs according to what is implied in the suffix. 'In my house,' is nyumbani mirangu, 'to my house,' nyumbani kwangu; 'he is sitting on my chair,' anakaa kitini pangu, and so on. 
A-li-anguka mlangoni pangu.

He fell down at my door.

Atakwenda shambani kwake.

He will go to his plantation.

Amelala nyumbani mwako.

$\mathrm{He}$ is lying down in your house.

This concord is not found in Zulu, where, however, the rules for applying the suffix are not quite so simple as in Swahili. We may suppose that it originally had the form -ini: this is rendered probable by the effect it has on the final vowel of the noun. A becomese, $e$ and $i$ remain unchanged; $o$ becomes we, and $u, w i$ (or sometimes $i$, eliding the final vowel instead of changing it into $w$ ). The initial vowel is changed into $e$ (in a few cases, in I I and $\mathrm{I}_{4}$, into 0 ), for which $\mathrm{I}$ can suggest no reason, though it may possibly have some connection with the locative prefix which appears in Ganda as e-.

intaba $=$ mountain makes entabeni.
izwe $=$ country $\quad "$ ezweni.
isi-hlalo $=$ seat
in-dhlu $=$ house $"$ esihlalweni.

In Chwana this locative is found in the form $n g$, as in the well-known place-names Mafeking and Shoshong. The same termination is used to form a kind of participle, to 
which we shall refer later on, in connection with the relative pronoun and the verb. In Ronga and other languages of the Delagoa Bay district, the locative suffix is - ni, though the final $i$ is frequently dropped: tikwen, "in the country,' from tiko.

The preposition $k u$ still exists in all these languages (in Chwana under the form $\chi 0$ ), but $p a$ and $m u$ are no longer found independently. That they did exist in Zulu is shown by the adverbs pansi', pezulu $(=p a+i z u l u=$ 'on the sky' = 'above '), pa-kati, 'in the midst,' pa-ndhle, 'outside,' etc. When used as prepositions these are followed by kwa, as pakati kwendhlu (kwa-indhlu), 'inside the house,'which, properly, should only go with $k u$ - but has quite usurped the place of $p a$ - and $1 m$-. The latter, however, survives in Chwana, in combination with the suffix, as mo motseng, 'in the village' (motse).

Some nouns whose presence in the $k u$-class

${ }^{1}-n s i$ is no longer used in Zulu as a noun, but it is found in Swahili as nti, nchi, meaning 'land,' 'earth.' Instead of the adverb pa-nsi, 'down,' below,' ti-ni or chi-ni is used. In Chwana the root and prefix (ha-tse) have become so closely welded together that they are looked on as inseparable and have been given a fresh prefix, le-hatse 5 . 
is difficult to understand and is rendered still more perplexing by the fact that they have a plural in ma-, are to be accounted for as Locatives. The Nyanja kutu, 'ear,' pl. ma-kutu, might be taken if it stood alone as a fifth-class noun which has dropped its prefix li-; but it cannot be dissociated from the Herero oku-twi, pl. ona-twi, and Ndonga oko-tshwi, pl. oma-kotshwi. Properly, the word means 'to the ear,' 'the place of the ear,' and then, the word being generally used with the locative prefix, the separate nature of the latter was forgotten, as was the case with the Chwana hatse. "The same applies to the Herero oku-oko, 'arm,' pl. oma-oko; Kongo $k$-oko, pl. m-oko. Other examples in Herero are oku-rama, 'leg'; oku-ti, 'veld, open country,' oku-ruo, ' hearth,' oku-apa, 'armpit.' It is evident that all these may have a locative sense, and that, wherever similar words are found, they should be placed in Class I7. The uncertainty about the prefixes shows that their original meaning is almost, if not quite forgotten, and that they tend more and more to be regarded as part of the stem. 
CHAPTER VI

The Pronoun

The Pronoun is one of the most important features of the Bantu Languages. I do not even add 'next to the Prefixes,' because the two are so intimately associated that it is difficult to say which should have the priority.

It used to be thought that the Pronouns and Prefixes were, in the last resort, identical, whatever their origin-whether they were nouns which had lost their distinctive character and become mere formative elements (like the suffixes of 'king-dom,' ' man-hood,' 'lord-ship,' which have long ceased to have any independent value)-or whether they already, even as separate words, had the force of pronouns. (Bleel's discussion of this subject-Comparative Grammar, pp. I23-I31should be carefully read, though time has shown that it requires some modification.)

Meinhof (Grundzüge, p. 35) points out that 86 
the prefix and pronoun are not identical, but that the latter is really the demonstrative particle, discussed in Chapter III., which became incorporated with the prefix and was then, in many cases, lost, but survives, e.g. in Zulu, as the 'initial vowel.' It was, as we have seen, originally $\gamma a$, but assimilated its vowel to that of the prefix which followed it.

Thus we have:

$3 \gamma a+m u=\gamma u m u=u m u$, and the pronoun $\gamma u=g u, u$

$4 \gamma a+m i=\gamma i m i,=i m i \quad ", \quad, \quad \gamma i=g i, i$

$6 \gamma a+m a=\gamma a m a=a m a \quad$ ", ", $\gamma a=g a, y a, a$

$9 \gamma a+n i=\gamma i n i=i n-$

$" \gamma y i=y i, i$

Where the prefix does not begin with a nasal, e.g., in $2,5,7,8$, the demonstrative (or ' article') disappears without leaving a trace, and the noun-prefix only remains, to serve as pronoun-so we get the pronouns $b a, k i, l i$, etc. ${ }^{1}$

1 Class 1 has been omitted here because, as Meinhof says, "it contains all sorts of irregularities, as is not surprising in a class so much used.' One would expect its pronoun to be $\gamma u$, like that of Class 3 , and in fact $u$ and $o$, which are found in Zulu and Chwana, evidently come from that form. But the Sivahili $y u$ cannot have come from it, so Meinhof thinks there must have been a second pronoun $\gamma y u$, of which he explains the formation on p. 36 of the work cited in the text, whence the substance of this note, and of the paragraphs imme- 
- This simplest form of the pronoun is never -or, if at all, very seldom-used by itself, but is always attached to a verb, or to an adjective with the verb'to be' understood. We shall refer to it, henceforward, as the 'Inseparable Pronoun.' Its use as the 'copula'-where, in some cases, it assumes a different form-will be discussed in the next chapter.

The following Table shows, the 'Inseparable Pronoun' in our eight typical languages, as compared with the noun-prefixes. Some languages-especially Duala and Kongo-tend to use the unaltered prefixes of all classes before verbs by a merely mechanical repetition, having lost their feeling for the pronoun as such. This explains the occurrence of such forms as mi- and ma-, where we should expect $i$ - and $a$-.

The pronouns. of the first and second

diately preceding it in the text, is taken. As for the alternative pronoun $a$, which has almost displaced $y u$ in Swahili, it is no doubt a remuant of the unaitered $y a$; but it is not clear why it did not assimilate its vowel to the first prefix, or why, in Herero and Chwana, for instance, $a$ is sometimes used in dependent sentences, while in principal sentences we have $u$ or its equivalent. This last fact may possibly be connected with the function of $a$ as relative particle. 
persons have, of course, no noun-prefixes corresponding to them and stand outside the framework of the classes. They are therefore placed by-themselves at the head of each column in the Table.

The use of these pronouns is illustrated in Chapter II. They are used both as subject and object; the first class and the second person, singular and plural, are in almost all cases the only ones with separate objective forms. And, even of these, the second person. plural is not common. (Swahili has -wa-, Zigula, -mi-, Ganda, -ba-). Whatever other. -particles are prefixed to the verb-root, the object-pronoun must always come next it.

E.g., u-ya-ngi-bona (Zulu), 'he sees me'; wa-ku-tshaya (Zulu), 'he beat thee'; a-li-mm fundisha (Swahili), 'he taught him.'

Duala and Kongo have no object-pronoun before the verb-though it exists in some cognate dialects such as Isubu. The object is expressed by a separable pronoun following the verb.

The reflexive pronoun, which is alike for all persons and numbers, is placed in the same position as the object-pronoun. In Zulu it is $z i$, as in $u k u-z i$-tanda, 'to love one's self'; in 


\begin{tabular}{|c|c|c|}
\hline \multirow{2}{*}{ 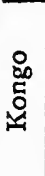 } & \multirow{2}{*}{ 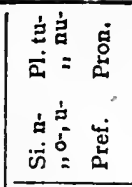 } & 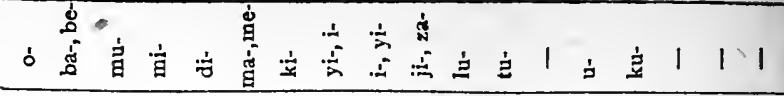 \\
\hline & & 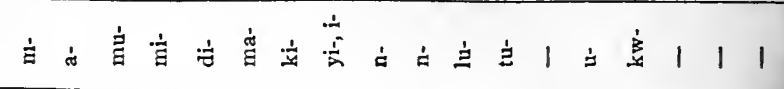 \\
\hline \multirow{2}{*}{$\frac{n}{0}$} & \multirow{2}{*}{ 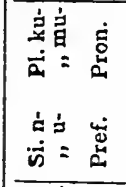 } & 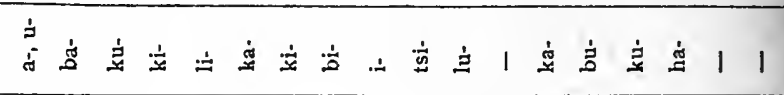 \\
\hline & & 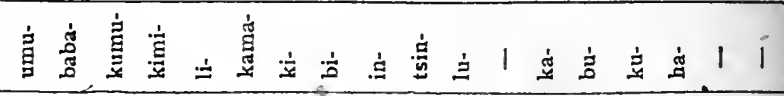 \\
\hline & \multirow{2}{*}{ 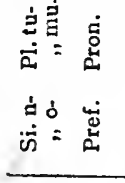 } & 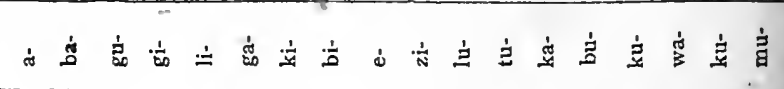 \\
\hline & & 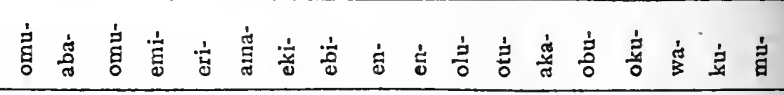 \\
\hline \multirow{2}{*}{ 藏 } & \multirow{2}{*}{ 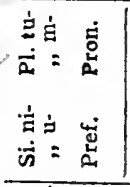 } & 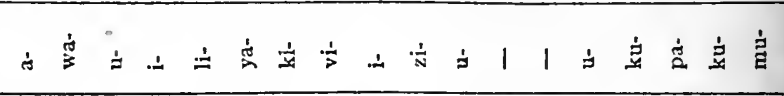 \\
\hline & & 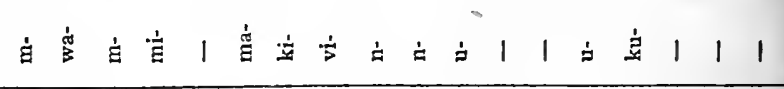 \\
\hline \multirow{2}{*}{$\begin{array}{l}\text { 䍃 } \\
\text { 党 }\end{array}$} & \multirow{2}{*}{ 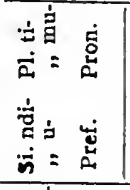 } & 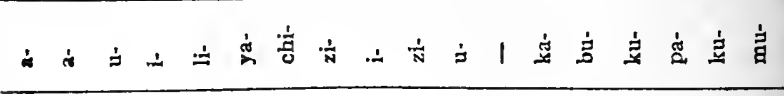 \\
\hline & & 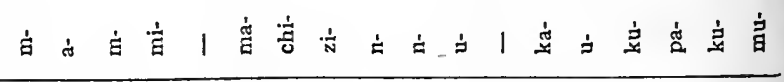 \\
\hline \multirow{2}{*}{ 离 } & \multirow{2}{*}{ 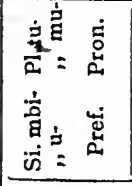 } & 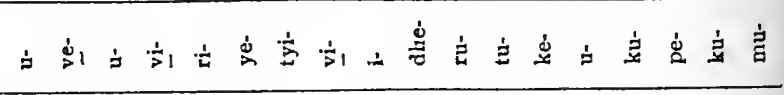 \\
\hline & & 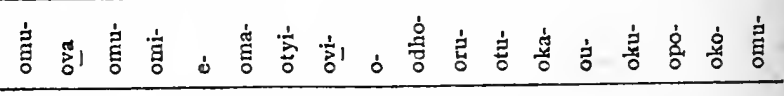 \\
\hline \multirow{2}{*}{ 碞 } & \multirow{2}{*}{ 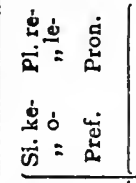 } & 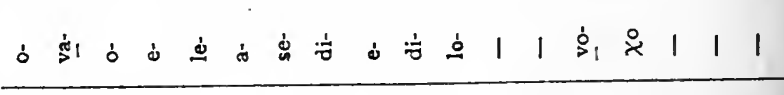 \\
\hline & & 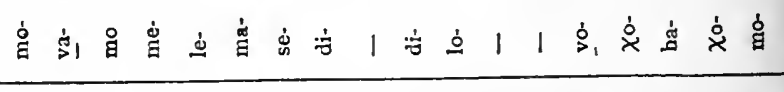 \\
\hline \multirow{3}{*}{$\stackrel{\Xi}{3}$} & \multirow{2}{*}{ 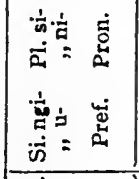 } & 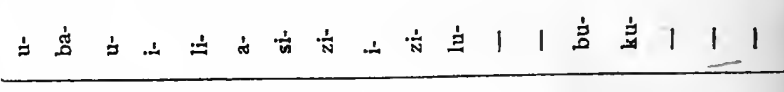 \\
\hline & & 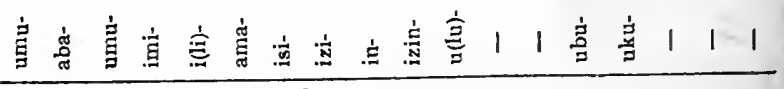 \\
\hline & :் & $\therefore \infty$ \\
\hline
\end{tabular}


Nyanja, $d z i$; in Swahili $j i$; in Herero $r i$; elsewhere $i, y i$, etc. Meinhof thinks the original form was $\gamma \hat{\imath}$.

There are longer forms of the pronouns, which can stand by themselves and need not be used with the verb except for emphasis. The different languages form these in various ways, and in some of them it is difficult to trace any resemblance to the Inseparable Pronoun. In fact they are built up rather on what is called the 'prepositional form' of the pronouns (though some of them depart considerably even from this), which, accordingly, it will be better to take first.

This is a form which is suffixed to prepositions: expressions like ' with me'; 'to him,' etc., being treated as one word. There is a form for every class-just as there is of the Inseparable Pronoun-as well as for the First and Second Persons. Thus we have (in several languages) nami $(=n a+m i)$, 'with me,' ' and I,' kumi, ' to me,' etc. These forms are also used in connection with Relative Pronouns, as we shall see presently.

Like the Inseparable Pronoun they are never found alone-if not attached to prepositions, they are suffixed to the possessive 
particle, in a way which will be explained presently.

The separable, or independent, pronouns are usually-if not always-built up out of these forms. They exist in most languages for the three persons singular and plural, and, in some, for all the classes. But some, like Swahili and Nyanja, have none for any classes after the first and second, using the demonstrative pronouns instead.

The Possessive Pronoun consists of two parts and has to be considered under two aspects.

It is made up of :

(1) The possessive particle of the class to which the thing possessed belongs (wa, ba, ya, etc.), and

(2) Either (a) a special pronoun-root for the first and second persons, or $(b)$ the 'prepositional form' of pronoun indicating the class of the possessor. The first class is usually exceptional in this respect, having a different suffix for the Possessive.

We will now take the six possessive pronouns of the three persons singular and plural in the same êight languages as before. Chwana seems to be exceptional in having some of the 


\begin{tabular}{|c|c|c|c|c|c|c|c|}
\hline & Zulu & Chwana & Herero & Nyanja & Swahili & Ganda & Gisu \\
\hline $\begin{array}{l}\text { IstPers. } \\
\text { 2nd ", }\end{array}$ & $\begin{array}{l}\text { Si. Pl. } \\
\text {-mi, -ti } \\
\text {-we, -ni }\end{array}$ & $\begin{array}{l}\text { Si. Pl. } \\
\text {-no,-ro } \\
\text {-o, -lo }\end{array}$ & $\begin{array}{l}\text { Si. PI. } \\
\text {-ami,-ete } \\
\text {-ove,-ene }\end{array}$ & $\begin{array}{lc}\text { Si. } & \text { Pl. } \\
\text {-ne, } & -f e \\
\text {-we, } & -n u\end{array}$ & $\left|\begin{array}{cc}\text { Si, } & \text { Pl. } \\
\text {-mi, } & -s w i \\
\text {-we, } & -n y i\end{array}\right|$ & $\begin{array}{c}\text { Si. Pl. } \\
\text {-nge, -fe } \\
\text {-we,-mwe }\end{array}$ & $\begin{array}{l}\text { Si. Pl. } \\
\text {-se, -fe } \\
\text {-wo,-nywe }\end{array}$ \\
\hline$\underset{1}{\text { Class }}$ & -ye" & $-e$ & $-\mathrm{e}$ & $-y e$ & -ye & -ye & -ye \\
\hline 2 & -bo & -vo & -awo & -0 & -0 & -bo & -we \\
\hline 3 & -wo & -0 & -awo & -wo & -wo, -o & -gwo & $-k w o$ \\
\hline 4 & - yo & -yo & -avyo & -yo & $-y \circ$ & $-g y o$ & -kyo - \\
\hline 5 & -lo & -lo. & -aro & -10 & -lo & -lyo & -lyo \\
\hline 6 & -wo & -0 & - ao & -wo & -wo & $-g \circ$ & -ko \\
\hline 7 & -so & -so, -sho & -atyo & -cho & -cho & -kyo & $-k y o$ \\
\hline$\therefore$ & -20 & -cho & -avyo & $-z 0$ & -vyo & -byo & -byo \\
\hline 9 & - yo & $-y o$ & -ayo & -yo & -yo & - yo & -90 \\
\hline 10 & $-z o$ & -cho & -adho & $-z o$ & $-z o$ & $\cdot z o$ & $-t$ so \\
\hline 11 & -10 & -lo & -arwo & -wo & -wo & -lwo & lwo \\
\hline 12 & - & - & -atwo & -to & - & $-t w o$ & - \\
\hline 13 & - & - & -ako & -ko & - & $-k o$ & $-k 0$ \\
\hline 14 & -bo & -vyo, -yo & $-a w o$ & -bo & -wo & -bwo & -bwo \\
\hline 15 & $-k o$ & $-\chi_{0}$ & -akwo & -ko & $-k o$ & -kwo & $-k w o$ \\
\hline 16 & - & - & -apo & -po & -po & -wo & -bo \\
\hline 17 & - & - & -akivo & -ko & -ko & -kwo & - \\
\hline 18 & - & - & -amo & $-\mathrm{mo}$ & $-m o$ & $-m u$ & - \\
\hline
\end{tabular}

This form of pronoun does not appear to be used in Kongo. 
SUBSTANTIVE PRONOUNS.

\begin{tabular}{|c|c|c|c|c|c|}
\hline$\Rightarrow$ & Zulu & Chwana & Herero & Ganda & Kongo \\
\hline $\begin{array}{l}\text { 1stPers. } \\
\text { 2nd " }\end{array}$ & $\begin{array}{lr}\text { Si. Pl. } \\
\text { mina, tina } \\
\text { wéra nìna }\end{array}$ & $\begin{array}{lc}\text { Si. } & \text { Pl. } \\
\text { nila } & \text { rona } \\
\text { wona lona }\end{array}$ & $\begin{array}{c}\text { Si. Pl. } \\
\text { owami, } \\
\text { owete } \\
\text { ove, } \\
\text { owena }\end{array}$ & $\begin{array}{l}\text { Si. Pl. } \\
\text { nze fwe } \\
\text { gwe mwe }\end{array}$ & $\begin{array}{l}\text { Si. Pl. } \\
\text { mono yeto } \\
\text { nge yeno }\end{array}$ \\
\hline$\underset{1}{C \text { Class }}$ & yena & ene & eye & ye & yandi \\
\hline 2 & bona & rone & owo & bo & $y \in u$ \\
\hline 3 & wona & one & owo & gwe & wau \\
\hline 4 & yona & eone & ovio & gye & miau \\
\hline 5 & lona & yone & oro & lyo & diau \\
\hline 6 & wona & one & owo & ge & mau \\
\hline 7 & sona & shone & otyo & kye & kiau \\
\hline 8 & zona & chone & ovio & bye & yau \\
\hline 9 & sona & eone & oyo & ye & yau \\
\hline 10 & zona & chone & odho & ze & zau \\
\hline 11 & l(w)ona & lone & oruo & lwe & luas \\
\hline 12 & - & - & otuo & tive & twau \\
\hline 13 & - & - & oko & ke & - \\
\hline 14 & bona & yone & owo & bwe & wa \\
\hline 15 & kona & $\chi$ one & okuo & kwe & kwau \\
\hline 16 & - & - & opo & wo & vau \\
\hline 17 & - & - & oko & kwe & kwan \\
\hline 18 & - & - & omo & mwe & mwau \\
\hline 19 & - & - & - & - & fiau \\
\hline
\end{tabular}

Nyanja, Swahili and Gisu use the Demonstratives for all classer but the first.

Nyarja. 1st Pers. Si. Ine 2nd iwe 3rd iye Swahili. " mimi " wewe " yeye Gisu. " " ise ", iwe " niye

Nyanja. 1st Pers. Pl. ife 2nd inu 3rd awo Swahili. " sisi " ninyi " wao Gisu. " " ifwe " inywe." abo 
forms reduplicated ( $-a \chi a \times 0$ instead of $-a \chi 0=a k o$ ). There are also forms in some dialects which are simply these separable pronouns with the possessive particle prefixed to them--a rona, 'our' (lit. 'of us') ; -a lona, 'your'; -a vona, 'their.'

\begin{tabular}{|c|c|c|c|c|c|c|c|c|}
\hline & Zulu & Chwana & Herero & Nyanja & Swahi & i Ganda & Gisu & Kongo \\
\hline MY & $-a m i$ & $\left\{\begin{array}{l}\text {-ame } \\
\text {-aka }\end{array}\right.$ & -andye & -anga & -angu & -ange & -ase & -ame \\
\hline THY & -ako & $-a \chi a \chi 0$ & -oye & -ako & -ako & -0 & -owo & $-a k u$ \\
\hline HIS & $-2 k e$ & 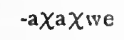 & $-\mathrm{e}$ & -ache & -ake & $-e$ & -ewe & -andi \\
\hline OUR & -etu & -eshu & -etu & -atu & -etu & -afwe & $-e f e$ & -eto \\
\hline YOUR & -enu & -eno & -enu & -anu & -enu & -amwe & -enywe & eno \\
\hline THEIR & -abo & -2vo & -awo & $-a^{\circ}$ & -20 & -awe & -awe & $-2 u$ \\
\hline
\end{tabular}

These, if the thing possessed is of the first class, have the possessive particle wa prefixed to them: wami, wame (some Chwana books print $o$ ame), wandye, wanga, wangu, etc. In Zulu, ' my child' is umntwana wami; in Nyanja, mwana wanga, and so on. 'My children,' would be abantwana bami, ana anga ; 'my village,' unuzi wami, mudzi wanga, 'my country,' izwe lami, dziko langa. 'There is no need to multiply examples.

In all these pronouns, the second part of the 
word does not vary, but if the possessor is of the third person and of any class except the first, the suffix has often to change as well as the prefix.

In Zulu, ihashi lake is ' his horse,' supposing that ' his' represents a noun of the first classsay $\iota m u-n t u$, $\iota m-$ fana, etc. But it might stand for a fifth-class noun: $i$-Bum, 'a Boer,'-or a seventh: isi-hambi, 'a traveller,'-or a ninth: in-doda, 'a man' ; in-kosi, 'a chief.' In these cases we must say:

$$
\begin{aligned}
& \text { His (the Boer's) horse }=\text { ihashi lalo. } \\
& " \text { (the traveller's) }, \quad=\text { ihashi laso. } \\
& " \text { (the chief's) }, \quad=\text { ihashi layo. }
\end{aligned}
$$

That is, the first part of the word is the possessive particle agreeing with the thing possessed, and the second the pronoun agreeing with the possessor.

In this way, the number of classes multiplied by itself will give the number of possible possessives-or would, if some of the forms did not coincide, so as to make them less numerous. There is a neat diagram of Gisu forms on p. 34 of the Rev. J. B. Purvis's Lumasaba Grammar. We need not give a table, as, the principle being known, it is quite 
easy to combine any form wanted from the previous tables.

The double agreement seems to be confined to the more archaic Bantu languages. It is found, as we have just seen, in Zulu and Gisu; also in Chwana, Herero, Ganda, Kinga and others; but not in Swahili, Nyanja or Kongo.

Demonstrative Pronouns. - These are usually three in number; one, equivalent to 'this,' denoting what is near the speaker; a second, what is somewhat farther off (in some cases, what has been referred to before); and the third, what is at a distance. They are built up, in different ways, from the Inseparable Pronoun; a very common modification is that the first demonstrative ends in $u$, which is changed in the second to $o$, while the third is formed by suffixing another syllable to the first, or to its latter half. This process is most clearly seen in Swahili and Nyanja. Sometimes the first half appears to be taken, as in Kongo (o-yu, and $o-n a, a-y a$, and $a-n a)$. Li (Ganda) and la (Gisu) may be the same element as le, which, Meinhof thinks, may be connected with the root-le, -de, 'long,' and so suggest distance. This and other points relating to the origin of the demonstrative, 
which it is no part of my plan to discuss, may be found in the second chapter of the Grundzïge einer vergleichenden Grammatik der Bantusprachen.

\begin{tabular}{|l|l|l|l|l|l|l|l|l|l|l}
\hline & Zulu Chwana Herero & \multicolumn{2}{c}{ Nyanja. Swahili Ganda Gisu Kong } \\
\hline THIS & lo & e n & ingui & uyu & bu-yu & ono & uno & oyu \\
THAT & lowo & eouo & ngo & uyo & bu-yo & oyo & uyo & oyo \\
THAT & lowaya & eole & nguini & udya & yu-le & oli & ula & ona \\
YHONDER & laba & vano & imba & awa & ba-wa & bano & bano & aya \\
THOSE & labo & vauo & mbo & awo & ba-wo & abo & abo & owo \\
THOSE & labaya & vale & mbeni & adya & wa-le & bali & bala & ana \\
\hline
\end{tabular}

There are other demonstrative forms built up from these-e.g., the two 'emphatic demonstratives' in Kongo, which we need not notice here.

In Nyanja we have two other demonstrative roots which may be mentioned here, because they are used in a way which illustrates the transition from the demonstrative to the relative. They are -mwe, 'the same,' and -mene, 'this same,' 'that same,' 'that very one,' etc., with their compounds, formed by suffixes corresponding to the three degrees of the demonstrative already given. -Mene, 
when used without these suffixes, simply means 'who,' or 'which,'-as

$$
\begin{aligned}
& \text { mu-ntua-mene a-na-gwira nchito. } \\
& \text { The man who did work. } \\
& z i-n t u \text { zi-mene zi-na-ni-sautsa. } \\
& \text { The things. which grieved me. }
\end{aligned}
$$

But

muntu ameneyu = this same man.

muntu ameneyo and amene $u d y a=$ that same man. chi-ntu chi-mene-chi $=$ this same thing. kasu li-mene-lo $=$ that same hoe, etc., etc.

We shall return to these two pronouns in the course of the next section.

A special form of demonstrative-sometimes called 'adverbial demonstratives,' and meaning 'Here he is,' ' here they are,'-is especially noticeable in Zulu-nangu, nanku, náa, etc. They need not be further noticed here.

The Relative Pronoun.-This constitutes somewhat of a difficulty in many Bantu languages, though some cannot be said to have any relative at all. The relative, as we understand it, hardly belongs to the earlier stages of speech. It implies a co-ordination of ideas - a fitting of separate notions together, whereas children, and primitive people, think of one thing at a time and express it in a 
sentence by itself. The child will say, 'I saw a man. The man had a dog,'-putting the two ideas, as it were, side by side. The next step is-'I saw a man; he had a dog'; and then we come to-'I saw a man who had a dog." In the second case, we have two co-ordinate sentences, of equal importance; in the third, a principal and a subordinate sentence, which together make up a complex one. Many Bantu languages cannot form complex sentences at all, and those which can, only do so to a limited extent.

In Nyanja there is no true relative. The typical form of sentence runs thus :

muntu a-na-dwala dzulo wafa.

The man (who) was ill yesterday is dead:

-literally, 'The man, he was ill yesterday: he died.' But, to make the reference of the second clause more definite, a demonstrative is inserted. One could say, uyo wafa, or udya wafa; but more commonly either mwe or -mene is employed.

muntu yemec anadwala dzulowafa. Or muntu amene anadwala dzulo wafa. mbalame zimene zinadia mbeu za-gwidwa.

'The birds which ate the seeds have been caught.' 
Pamene (Class I 8), ' the place which,' is used for 'where '-and, by an extension of meaning, for 'when.'

In other languages the relative is rendered by a particle prefixed to the verb and the 'prepositional form' of a pronoun placed after it. The simplest form of this is found in Swahili: a-sema-ye (or, in Mombasa dialect, a-sema-e), 'he who speaks'; li-anguka-lo, 'that (fifth class) which falls'; ki-waka-cho, 'that (seventh class) which burns.' This, when analysed, is seen to be really equivalent to 'he speaks (that is) he '; 'it falls (that is) it.' This seems to be nearer the mark than to speak of a relative pronoun expressed by a syllable formed of the letter $-o$, preceded by the initial consonants proper to its antecedent ' (Steere's Exercises, p. 22) ; but the construction is exceedingly difficult to make clear, except in the light of comparative grammar.

When the relative is the object, it may be expressed by using the same form, but inserting the proper object-pronoun before the verb and making the suffixed pronoun agree with the object, not the subject.

Thus '(the knife) which I want,' is (kisu) ni-ki-taka-cho-literally, 'I it want '(that is) it.' 
-Po, $-k o$, and $-m o$, as relatives, indicate the notion of 'where' or 'when'-ni-lala-po, 'where (or when) I sleep'. ; a-taka-po, 'when he wishes.' As we see, this relative is intimately combined with the verb-so it is in many other cases; and this once more illustrates the difficulty of applying our received grammatical classification and arrangement. In Steere's Handbook of Swahili, the treatment of the verb has in some degree to be anticipated in the chapter on pronouns, while that on the verb has to include the application of the relative pronoun to certain tenses.

While the use of the accepted nomenclature is, up to a certain point, convenient and even necessary; we must never allow ourselves to think of its definitions as rigid boundaries, as though words could be isolated in closed compartments, like specimens in a museum. This applies even in English: if children are taught, for instance, in parsing a sentence like 'Tell him that he must not do that,' to call the first 'that' a conjunction and the second a pronoun, they will be apt to lose sight of the connection between the two. But if we treat grammar as a kind of unchanging framework 
into which every language must be fitted, we get such absurdities as conjugating a verb 'to have' which does not exist, or 'declining' a Bantu noun, which, as we have already seen, cannot be done.

A more elaborate form of the Swahili relative combines the two pronouns with a tense-particle as well as the verb and thus forms three tenses; in the simpler form no tense-distinction is possible.

Present: a-na-ye-piga, u-na-o-piga, li-na-lo-piga. 'he (it) who (which) strikes.'

Past: a-li-ye-piga, u-li-o-piga, li-li-lo-piga.

'he (it) who (which) struck.'

Future: a-taka-yo-piga, u-taka-o-piga, li-taka-lopiga.

'he (it) who (which) will strike.'

$N a, l i$, and taka must be reserved for discussion in the chapter on verbs.

If the relative is the object, the pronouns are changed as before indicated, the only difference being displacement of the suffix (since the object-pronoun must always come next to the verb-root).

'The thing which I like.'

Kitu ni-na-cho-ki-penda (penda = like). 
'The house which we bought.'

Nyumba tu-li-yo-i-nunua (nunua = buy).

In neither of these forms do we find anything like a special relative particle, different from the pronouns which, as has been said, may be met with in other connections. In Zulu, we $\checkmark$ have two such particles: $a$-, which is prefixed and usually combined with the Separable Pronoun as subject, and -yo, which is suffixed -in all cases, whatever the class of the antecedent. Perhaps we can trace a similar tendency at work elsewhere, for in Zanzibar Swahili 'there is a disposition to make -0 'the general relative' (Steere), as alio- for aliye-, lilio-, for lililo-, etc.

Examples of the $Z$ ulu relative are :

unuıntu o-bona-yo (for a-u-bonayo) = 'a man who sees.'

$a b a-n t u a-b a-k a l a-y o=$ 'people who cry out.'

indhlela e-lungile-yo (for a-i-lungile-yo) $=$ 'the right path.'

(Lungile is the perfect of the verb lunga, 'to be straight' or ' right ').

The object is inserted in the same way as already shown : 
umuntu a-m-bonayo' = "a man whom he sees."

We shall again have to notice this relative particle $a$ when we come to the Adjectives.

In Ganda, the principle of the Relative formation is that of prefixing $a$-to whatever other pronoun comes before the verb. Thus abantu a-ba-laba, 'people who see.' (The singular, omu-ntu a-laba, is indistinguishable from that which means ' a man sees,' because $a+a$ coalesces with $a$.) This prefix appears as $o$ or $e$ according to the class of the subject: omu-ti o-gu-gwa, 'the tree which falls'; emi-ti e-gi-gwa, 'the trees which fall.'

Chwana indicates the relative by suffixing the locative termination to the verb, without any change in the pronoun.

'He who has come'-co o tsileng, (tsile, perf of $t s a$ ) this one he has-come.'

Perhaps the most literal rendering of tsileng would be 'is-at-having-come': the perfect indicating a state of completed action. In fact, this form of the verb is often called a

1 When the object is in the relative, with a subject of Class $1, a$-is used without the pronoun (u-)-i.e., the relative prefix is $a$ - and not 0 -. 
participle, and is used as such : mo xo yeng' in eating'; and, looked at closely, it is easy to see that the idea of the participle and that of the locative may run into one another.

In Ronga the relative construction consists of:

(1) the demonstrative, followed by the Inseparable Pronoun.

(2) $-k a$ suffixed to the verb, if present, $-i k i$, if past. mhunu lweyi $a-f a m b a-k a=$ 'the man who walks.' (man that he-walks.)

Tihomu leti ti-famba-ka = 'the cattle which walk.'

Tihomu leti hi-ti-shab-iki= "the cattle which we bought.'

$$
\text { (shaba = 'buy'; } h i=\text { 'we.') }
$$

M. Junod thinks this $k a$ is originally an auxiliary verb.

Herero seems to come nearest to our conception of the relative. There is a special form of pronoun, different from the demonstrative and used exactly as we use 'who' or 'which '-though, of course, it varies with the class of the antecedent.

(1) omundu ngu muna = 'the man who sees.'

(2) ovandu mbe muna = 'the people who see.'

(3) omuti mbu $u a=$ 'the tree which falls.'

(4) omiti $m b i u a=$ do. (plural). 
(5) eho ndi muna $=$ 'the eye which sees.'

(6) omeho nge muna $=$ do. (plural).

The above is the 'participial present' tense, which is of simpler formation than the 'present.'

There are variations for other tenses, which need not be given here.

Finally, Kongo has no relative, properly speaking; 'the relative pronouns are identical in form and usage with the demonstrative.'

We might enumerate other varieties; but the above are sufficient to show that various stages of evolution from the simple to the complex sentence are illustrated in different parts of the Bantu language-field.

This is, perhaps, the best place to mention the Interrogatives, some of which, by function, are pronouns, some adjectives, and some adverbs. Some are invariable; others take the class-prefixes; and of the latter, some, which are used as adjectives (and also the words for 'all' and 'only '), are inflected like pronouns. (This point will be more easily made clear when speaking of adjectives.)

The following Table shows how the treatment of these words varies, even when the roots are cognate. 


\begin{tabular}{|c|c|c|c|c|c|c|c|c|}
\hline & Zulu & Chwana & a Herer & o Nyanja & Swahil & li Ganda & Gisu & Kongo \\
\hline WHO? & ubani? & -marg? & -ani? & ndani ? & nani? & -ani? & nanu? & nani? \\
\hline WHICH? & $-p i ?$ & the? & -ne? & $-\mathrm{ti} ?$ & -pi ? & $-k i ?$ & - & nkia? \\
\hline WHAT? & -ni? & -ng ? & tyike? & chiani? & nini? & $\mathrm{ki}$ ? & kina? & nki? \\
\hline WHERE? & -pi? & kac? & pi ? & ku:i? & wapi? & -wa? & hena? & kweyi? \\
\hline WHEN ? & nini? & leng? & rune? & liti? & lini? & $\mathrm{di}$ ? & lina? & (mweyl? \\
\hline $\begin{array}{l}\text { HOIV } \\
\text { MANY? }\end{array}$ & -ngaki? & -kac? & -ngapi? & -ngati ? & -ngapi ? & -meka? & -enga? & $-k w a ?$ \\
\hline $\begin{array}{r}\text { OFWHAT } \\
\text { KIND? }\end{array}$ & -njani? & -ang? & $-k e ?-$ & $-\tan i ?$ & gani? & $-t y a$ ? & -rye & - \\
\hline
\end{tabular}

The forms without hyplens are invariabla.

There is a set of pronouns sometimes called the 'Indicative Form,' meaning 'It is I,' 'It is he,' etc. But, as they are a combination of the Pronoun and the Copula, it will be better to reserve them for the next chapter. 


\section{CHAPTER VII}

The Copula and the Verb 'To Be'

In most European grammars, the first thing learned is the conjugation of the verbs 'to have' and 'to be.' In Bantu there is no verb 'to have,' and 'to be' is relegated, comparatively speaking, to the background. 'Have' is expressed by 'be with,' or simply by ' with,' with the 'be ' understood. 'I have a house' is in Swahili nina nymmba: literally 'I with house'; in Zulu 'we have maize' is sinombila (si-na-umbila). This one fact shows how necessary it is for thóse who draw up grammars to take the language as they find it, instead of trying to fit it into the framework of any pre-conceived scheme. The late Dr. Henry began his Chinyanja Grammar -in many respects an excellent piece of work-by conjugating the non-existent verb 'to have.' 
110 THE COPULA AND THE VERB 'TO BE'

Most-if not all-Bantu languages have a verb ' to be,' but it is not often used in more , than one or two tenses, and, in many cases, does not appear at all just where we should expect to find it. Thus its place may be supplied by the inseparable pronoun, as, in Zulu : l'itanga 'it is a pumpkin,' l'ulwandhle ' it is the sea,' si'sitsha ' it is a dish,' etc.

Or it may be omitted altogether.

SWAHILI: Hamisi mpagazi: 'Hamisi (is) a porter.' ZULU: ngi-lapa: 'I (am) here' (lapa = here); Ku-njalo-ke 'it (is) so.'

Herero: Owami omuhona: 'I (am) a king.'

Sometimes 'is,' 'are,' are rendered by an invariable particle: Swahili ni, Nyanja ndi, Chwana ke.

Nyanja: Nyalugwe ndi chirombo choopsya:

'The leopard is a terrible beast.'

Chwana: Boshwa jwa tau ke letlalo:

'The lion's inheritance is the skin.'

(Proverb.)

SWAHILI: Dalili ya moua ni mawingu:

'The sign of rain is clouds.' (Proverb.)

As stated above, the inseparable pronoun of the class to which the noun belongs can be substituted for this invariable copula, as $H i i$ i 
nyumba (instead of hii ni nyumba) 'this is a house'; hizi zi nymmba, 'these are houses'; mti $u$ mzuri, 'the tree is fine' (Swahili); l'itanga, 'it is a pumpkin' (for li(li)tanga): l'ulwandhle (lu(lu)lwandhle) 'it is the sea'; b'utywala 'it is beer'; zinkomo (contracted from z'izinkomo), 'they are cattle' (Xosa); lo' muntu l'idaka, 'that man is a sot'; waba l'ukuni, 'he was (like) a $\log$ ' (Zulu). But we sometimes find forms which cannot be thus accounted for, as in Zulu : nguwena, 'it is you'; nguyena, 'it is he'; y'imina (or umina) 'it is I'; ng'umuntu, ' it is a person'; ng'amehlo, 'they are eyes,' etc.

The truth seems to be that this copula is the old demonstrative root supposed by Meinhof to have been originally $\gamma a$, which being placed before nouns gradually assimilated its vowel to their prefixes, became $n g u$, $n g a, n g i$, etc., and finally dropped its consonant or became a mere duplicate of /the prefix (as in Gisu $b a-b a-n d u$ ). In Swahili $n g u$ survives in the form $y u$ as a copula, in such phrases as yu mzuri, 'he is handsome'; though before the verb it has generally been replaced by $a$. Ila has retained the copula to a greater extent than. many other languages, 
and it may be of interest to give the forms for the different classes here:

(1) Ngu muntu: 'it is a person.'

(2) Mbo bantu: ' they are people.'

(3) Ngu munzhi: 'it is a village.'

(4) Nji minzhi: ' they are villages.'

(5) Nd'isamo: ' ' it is a tree.'

(6) Ngu masamo: 'they are trees.'

(7) nchi chintu: 'it is a thing.'

(8) nshi shintu: 'they are things.'

(9) nimpongo : 'it is a goat.'

(10) nshimpongo: 'they are goats.'

(11) ndu lusmo or ndumo: 'it is a razor.'

(12) ntu tushimbi: ' they are girls.'

(13) nku kashimbi: ' it is a girl.'

(14) Mbuxane, or mbu buzane: 'it is meat.'

(15) nku kufuna: 'it is love.'

(16) (not found).

(17) nku kutwi: ' it is an ear.'

(18) (not found).

Most languages combine the copula with the personal pronouns (in the 'prepositional' or 'enclitic' form) for such expressions as ' it is I,' 'it is he,' etc. In Swahili ndi is used instead of $n i$ for this purpose.

1 This is a very exceptional word for 'tree,' as puzzling as the Chwana setlare. In the plural it is hard to see why assimilation has not taken place: one would have expected nga masamo. 


\begin{tabular}{|c|c|c|c|c|c|}
\hline - & Swahili & Nyanja & Ila & Giryama & Gisu \\
\hline 'It is I' & ndiıni & ndine & ndime & nuìml & isono \\
\hline 'It is this ' & ndiwe & ndiwe & ndiwe & naliwe & niwe \\
\hline 'It is he' & ndiye & ndiye & inguwe & videye & niye \\
\hline 'It is ne' & ndiswi & ndife & ndiswe & diswi & nifwe \\
\hline 'It is you' & ndinyi & ndinu & ndimwe & ndinxi & ninywe \\
\hline 'It is they' & ndio & ndiwo & imbabo & ndo & nibo \\
\hline$\underset{3}{\text { Class }}$ & ndio & ndio & inguo & ndo & nikwo \\
\hline 4 & ndiyo & ndiyo & injiyo & sctoyo & nikyo \\
\hline 5 & ndilo & ndilo & indidio & ndoro & $n i l, 0$ \\
\hline 6 & ndiyo & ndiwo & ingao & ndicgo & niko \\
\hline 7 & ndicho & ndicho & inchicho & ndocho & nikyo \\
\hline 8 & ndivyo & ndizo & inshisbo & ndozho & nibyo \\
\hline 9 & ndiyo & ndiyo & injio & ndoyo & niyo \\
\hline 10 & ndizo & ndizo & inshisho & ndozho & nitso \\
\hline 11 & ndio & - & indula & ndolo & niltro \\
\hline 12 & - & ndito & intuto & - & niko \\
\hline 13 & - & ndiko & inkako & ndoko & niko \\
\hline 14 & - & ndiwo & imbubo & ndo & nibwo \\
\hline 15 & ndiko & ndiko & inkuko & ndoko & nikwo \\
\hline 16 & ndipo & ndipo & - & ndoho & nibo \\
\hline 17 & ndiko & ndiko & - & ndoko & nlkwo \\
\hline 18 & ndimo & ndimo & - & nilomo & nimu \\
\hline
\end{tabular}


114 THE COPUla AND THE VERB 'TO BE'

This form does not seem to be used in Ganda, where 'it is I "' is nze, 'it is we,' $f e-$ the same as the pronoun standing alone.

The above must be distinguished from what is sometimes called the 'adverbial demonstrative, meaning ' here he is,' etc., as in Zulu I nanlu, 2 now, 3 nangu, 4 nansi, etc., with three forms, corresponding to degrees of distance, like other demonstratives.

The copula is sometimes prefixed to adjectives used predicatively (that is, in sentences like 'the man is good' as distinguished from 'the good man') as in Ila bantu mbabotu 2 'the people are good.' Most of the other prefixes, however, have dropped or absorbed it, as masamo malamf $u 6$ ' the trees are tall,' or ' the tall trees.' This point is worth noting in connection with the difference (to which we shall refer in the next chapter) between the treatment of adjectives when used as predicates and as epithets. Another, and somewhat unexpected use of the copula is to introduce the agent after passive verbs. We find, in Zulu, c.g., kutshiwo ng'u Ngoza loko, 'that is said by Ngoza'; and the obvious explanation is that $n g^{\prime}$ is the preposition $n g a$, which usually indicates instrumentality. Or 
THE COPULA AND THE VERB 'TO BE' 115

it would be the obvious explanation, were it not for the disturbing fact that $\operatorname{gra} u \mathrm{Ngoza}$ should normally become ngo Ngoza, instead of eliding its final vowel and leaving the $u$ intact, as is done here. Furthermore, if this were so, why should we find ngilibele y'imiscbenzi, 'I have been delayed by works,' and not ngemisebenzi? In Swahili, the construction which the foreigner would expect, and which is sometimes heard, is mimepigwa na huyu, 'I have been struck by this (man)' (na, literally 'with' or 'and'). But the more usual and idiomatic form is nimepigwa ni huyu'-i.e., literally: 'I have been struck-it is this man.' So the Zulu sentences given above are really equivalent to: 'It is said-it is Ngoza (who said it).' 'I have been delayed-it is works (which have done it).'

As already said, there is an actual verb equivalent to 'to be' in most, at any rate, of the Bantu languages, though its sphere is much more restricted than a knowledge of European speech alone would suggest. There are several roots common to a number of languages, which do not, however, all use them in the same way. They are all monosyllables, and therefore classed by most 
grammars among 'irregular verbs'-though that is hardly a satisfactory way of describing them.

Thus, in Sirahili, we have $k u-w a$, used in the past ( $a-l i-k u-w a$ ' he was') and the future (a-ta-ku-ica 'he will be') but never in the present. This is the same root as the $\mathrm{Zulu}$ uku-ba, which also is not much used in the present, except as an auxiliary. Nyanja prefers $l i$ (or $r i){ }^{1}$, which in Swahili is only found as a particie indicating the past tense. Ganda has both $b a$ and $l i$, and Herero has $r i$. These seem to be the two commonest forms. Kongo uses what Bentley calls 'the defective verb' $n a,{ }^{2}$ as in kina var'a 'it $(\mathrm{Cl} .7)$ is here,' and also kala, which 'is much more definite, and . . . means to be habitually or generally.'

But kala is also found in Nyanja and (as $k a a$ ) in Swahili. Its primary meaning is 'sit,' and thence 'stay' or 'live' in a place: in Nyanja its use is so extended that sometimes it is really equivalent to a verb ' to be.' The

1 The pronunciation varies with the preceding vowel: ndiri, uli, ali, tiri, etc.

$N n a$ is 'to'be' in Chwana. 
Zulu hlala ${ }^{1}$ seems to be the same word, but its meaning is not quite so widely extended. This verb is an excellent illustration of the way in which the abstract notion of 'being' may be developed out of such a simple concrete one as 'sitting ' or 'staying.' Kara is similarly used in Herero.

1 As a rule, Zulu $h l$ corresponds to $s$ in Nyanja; -hlanu, -sanu, "five'; in-hlatu, n-satu 'python': hlamba, samba 'bathe.' There is, however, a Nyanja word sala 'remain' (of which the use is somewhat more restricted than kala) but it is more properly tsala, and sala is also found in Zulu (as in the parting salutation sala kahle.) Ila has kala 'sit,' and shala 'remain,' side by side. 


\section{The Adjective}

There are very few real adjectives in Bantu. Their place is often supplied by nouns and verbs. Thus Nyanja has no adjective to express 'bad' or 'black'; but there are verbs ' to be bad ' $(k u-i p a)$ and 'to be black' $(k u-d a)$, and the place of the adjective is taken by a kind of participle formed of the infinitive with the possessive particle prefixed to it. 'Black' is wa ki-da 'of being black,' or, more literally, ' of to-be-black,' and 'bad 'wa ku-ipa, usually contracted into woipa.' This construction, which has a genitive or partitive force, as the Chwana participle in $n g$ has a locative force, sometimes replaces a relative pronoun. We can say, for instance, mnyamata wosaka (for wa-ku-saka) nyama, 'the youth who hunts

${ }^{2}$ Monosyllabic verbs do not contract, so it is $w a-k u-d a$, never woda. 
game,' mzungu wosakala 'the white man who never sits down.' ( $\mathrm{Sa}$ is a negative particle, to be explained in a later chapter.)

Or the idea may be expressed by a tense of the finite verb. 'He is fat' is a-li-ku-nenepa, from $k u$-nenepa 'to be fat'; 'there are too many fowls' nkuku zi-churuka (ku-churuka 'to be too many'). So, too, in Zulu: uku-lamba ' to be hungry,' uku-tshisa ' to be hot,' uku-godola ' to be cold,' uku-lunga ' to be straight' (and thence ' upright,' 'good '), etc.

Nouns are usually made to do the work of adjectives by having the possessive particle prefixed to them. So, in Nyanja, wa mpamvu is 'strong' (literally ' of strength') ; 'good' wa bwino, 'many' wa mbiri, 'new' wa tsopano. Bwino and mbiri are not at present used by themselves; tsopano is an adverb of time meaning 'now' (so that 'a new thing' is, literally, 'a thing of now'); but all three may once have been nouns.

Zulu seems to prefer a relative construction in similar cases; 'a strong man' is ummuntu onamandhla (a-u-na-amandhla); literally ' a man who he (is) with strength.' And a very common and curious idiom in Swahili is the use of mwenye 'owner,' in the sense of 
'having': mwenye nguvu 'strong,' literally 'owner (of) strength.'

The genuine adjective roots (to be distinguished from the derivative adjectives, which will be mentioned presently) are few in number and should probably be reckoned among the most primitive elements of Bantu speech. Some of them can be traced through many if not most of the Bantu languages hitherto studied; others might seem to be confined to one or two; but it would be very rash to dogmatize when so much still remains to be known. Sometimes, when present-day forms seem quite unrelated, the parallel is found to have existed in an older stage of the language; and sometimes the cognate word is found to have different senses in two languages, like -kulu, which is used almost everywhere for ' large,' but in Kongo and Herero has come to mean 'old.' The following list is not complete but comprises the most important of these root-adjectives.

Adjectives derived from verbs have various endings, of which, perhaps the commonest are $-u(-f u,-v u)$ and -2 . So, in Swahili, we have nyama-vu 'silent' from ku-nyamaa, and -tuli-vu' gentle' from ku-tulia. With regard to 
ere-vu 'cunning' and vi-vu 'idle,' it does not seem certain that they can be traced to verbs, and -refu'long, compared with le and -de in other languages, suggests that it is the same root, with the termination - $f u$ suffixed to it.

In Herero, we have -potu 'blind," dhorodhu 'black' (from the verb dhorera), faradhu'damp' (from tarara).

Of adjectives in -e, Herero has -kohoke 'clean,' from the verb kohoka, and'-pore 'just,' 'gentle,' 'kind,' from pora, of which 'the primary meaning is 'to be cool."2

In Ila, a language of the Middle Zambezi, there are a large number of adjectives ending in - shi, usually derived from verbs in $-k a$ :

-dimbushi ' foolish,' from ku-dimbusha ' to be foolish.' -komoshi 'broken,' „, ku-komoka 'to be broken.' -zapaushi 'ragged,' , ku zapauka 'to be ragged.'

Some of these adjectives can scarcely be

Phonetically the same as the root of the Swahili noun $k i$-pofu; but -pofu is not used in Swahili as an adjective, in the sense of 'blind.'

'A widely distributed root, which usually has the secondary meaning 'recover' (from illness) - probably with reference to the reduction in temperature. But in Herero, the notion of 'cooling' seems to suggest that of being, or becoming 'moderate '-and so 'reasonable,' 'just,' gentle,' etc. 


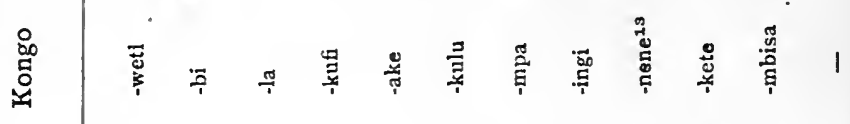

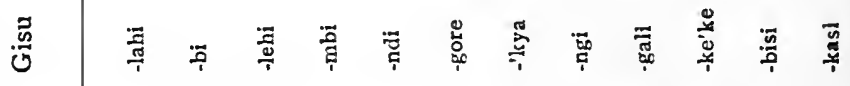

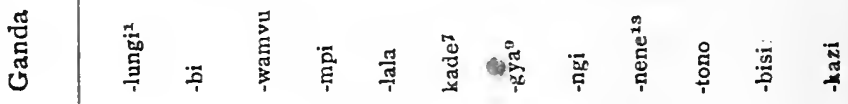

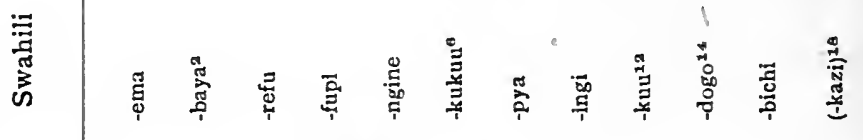

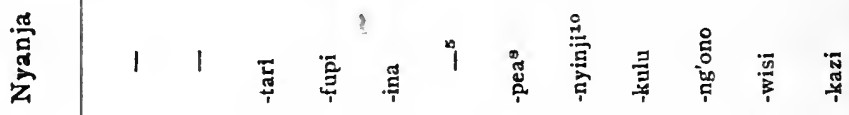

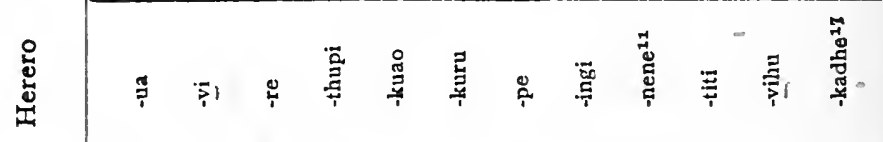

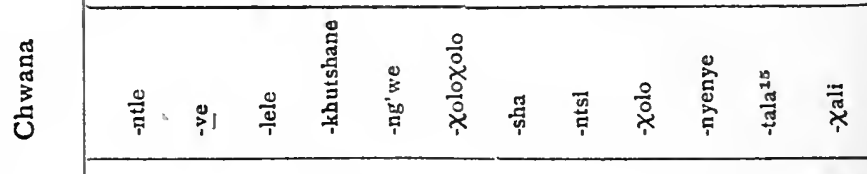

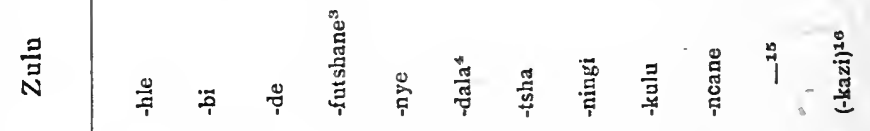

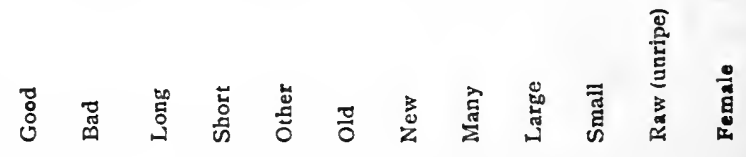


1 Probably connected with the verb lunga, which (c.g. in $\mathrm{Znlu}$ ) means ' to be straight,' and so 'to be right,' ' good,' etc.

- Old Sivahili has -wi (-bi, vi).

- Diminutive of -fupi, which appears in the adverb kufupi.

- This word is also found in Nyamwezi, Shambala, Bondei and some other East African languages.

- Instead of an adjective, Nyanja has the verb kalamba 'to be old,' and -a kale, which means ' of long ago.'

- -kukuu, in the sense of 'worn out' applied to things. Of persons, -zee is used, or in some dialects -zima, properly 'whole,' and so 'grown up.' Kale is also sometimes used, as in Mji wa hale, 'the old town,' at Mombasa.

' eda 5, a noun, meaning 'age' has perhaps the same root as -dala, but there does not seem to be an adjective of this form.

8 Used in some dialects.

- This modification returns to its original form after a nasal, as mpya in $\mathrm{Cl} .9$.

10 Preferred to - a mbiri in some dialects.

11 This is found, e.g., in Swabili, with the meaning 'thick,' 'stout.' I doubt whether the Zulu -nene 'generous' is from the same root.

12 More commonly used in a figurative than in a literal sense; the usual word for the lattor is -kubwa.

$18-k w l u$ is used in the sense of ' mature ' or 'important,' etc.

16 When used with the simple prefix -nere means ' too large '; to make it mean merely ' large ' it requires another prefix. This very curious point in Kongo grammar will be touched on later.

18 In the Lamu dialect -titi and - toto are used.

16 Perhaps the root which we find in the other columns exists in the Zulu $u$-bisi and Chwane le-vest. 'fresh milk." With tala compare Herero taradhu 'damp' :- 'wet' is one of the meanings of -wisi in Nyanja.

17 Only found as a suffix, in inkosi-kazi, etc.

18 Herero has no $s$ or $s$ : the former is represented by the sound of th in 'thin,' the latter by that of th in 'there' (here written $d h)$.

19 Only found 25 a suffix in one or two words; the root the has taken its place. 
distinguished from passive participles, as the Ila komoshi, 'broken,' given above, and, in Sangol:

f-nhu fi-tele $\chi e^{2}$ 'cooked food,' from tele $\chi$ a ' cook.' umu-pixi mu-hongole 'a hewn tree,' from hongola hew.'

The Concord of the Adjective is often something of a puzzle. A priori, nothing could be simpler: you have your adjective root, and you place before it the prefix of the noun with which it is to agree. This happens, in fact, with most of the classes in Swahili.

1. m-tu m-zuri 'a handsome man.'

2. wa-tu wa-zuri 'handsome men.'

3. M-ti m-zuri 'a fine tree.'

4. mi-ti mi-zuri 'fine trees.'

5. tunda zuri 'a fine fruit.'

6. ma-tunda ma-zuri 'fine fruits.'

7. ki-ti ki-zuri 'a fine chair.'

8. vi-ti-vi-zuri 'fue chairs.'

9. nyumba n-zuri 'a fine house.'

10. nyumba n-zuri ' fine houses.'

11. u-pindi M-zuri 'a fine bow.'

15. ku-shona ku-zuri ' fine sewing.'

16. pahali pa-zuri 'a fine place.'

1 The Sango (or Lori) people live to the north-east of the Konde, some distance north of Lake Nyasa.

${ }^{2}$ The Greek $\chi$ is used to indicate the Scottish sound of $c h$ in 'loch.' 
Adjectives do not seem to be used, in Swahili, with the localives of the seventeenth and eighteenth slasses, though they are e.g. in Nyanja.

The above is perfectly plain sailing, with the exceptions of Class in which has taken the concord proper to Class 3, the contracted form $u$ being doubtless associated with that class through its pronoun, though the $u$ has disappeared from the third prefix. (Of course the old form for I I would have been lu-pindi lu-zuri.) Phonetic laws have produced some modifications in Classes 9 and ro (such as the change of $n$ into $m$ before a labial and its loss before $k, t$, and some other sounds) but these need not concern us here.

In Nyanja, the case is different. Here the principle seems to be that the inseparable pronoun is prefixed to the adjective root and the Possessive Particle to it as chachikulu 7 zazikulu 8, etc. It is not quite consistently carried out in the First Class, for there the noun-prefix takes the place of the pronoun: $w a-m-k u l u$, not $w a-\imath-k u l u$; perhaps in order to preserve the distinction between it and Class 3 , which is wokulu (contracted from $u$ 'a- $u-k u l u$ ).

This applies to all real adjectives in Nyanja: 
any which do not take the concord as above are treated either as nouns or as verbs. But in Zulu a distinction is observed, to which we shall now come.

The real adjectives, in $Z u l u$, prefix (I) the relative particle $a,(2)$ the noun-prefix. coalesces with the initial vowel, i.e., when followed by $u$, it makes $o$, when followed by $i, e$. The contracted prefixes return to their original form.

Thus we get omu-hle (a-umm-hle), eli-hle (a-ili-hle), olu-hle (a-ulu-hle), etc.

But there are some other adjectives, which take shortened prefixes in Classes I, 3, 4 and 6 (i.e., o- e-a-, instead of omm, emi, ama) as umu-ntu o-nsundu 'a brown man,' imilomo e-banzi 'wide mouths,' ama-hashi a-mhlope 'white horses'-not omu-nsundu, emi-banzi, ama-mhlope. The reason for the distinction is not very clear, but some at least of the adjectives so treated are originally nouns, as -lukuni 'heavy' (u(lu)-kuni 'a log of wood'), -luhlaza 'green' (u(lu)-luhlaza 'green grass').

Then, in Chwana, both the Pronoun and Noun-Prefix are added to the Adjective, but in the reverse order from that in which we find them in Nyanja. 
It will be sufficient to illustrate this by examples from these three languages and Ganda. In dealing with a Bantu language which has not been much studied, the learner should pay special attention to this point, as the system followed may be different from any of those which have been enumerated. We must not too hastily assume-having studied the theory of the Alliterative Concord, not wisely but too well-that we can ajply the noun-prefixes, as they stand, to the adjectives; which, so far as it has taken place, is probably a late development.

The adjective selected for the illustrations is -kulu, which is found in most Bantu languages, though in Ganda it does not seem to be used quite in the sense here implied.

Many languages make no distinction between the form of an adjective when used as an epithet or as a predicate; but some, as Zulu, Xosa and Ganda, drop the initial vowel in the latter case.

ZULU: Umu-ntu omu-hle 'a good man'-but unu -ntu mu-hle 'the man is good.'

GANDA: ebi-gambo ebizibu 'difficult words,'-but ebi-gambo bizibu 'the words are difficult.' 


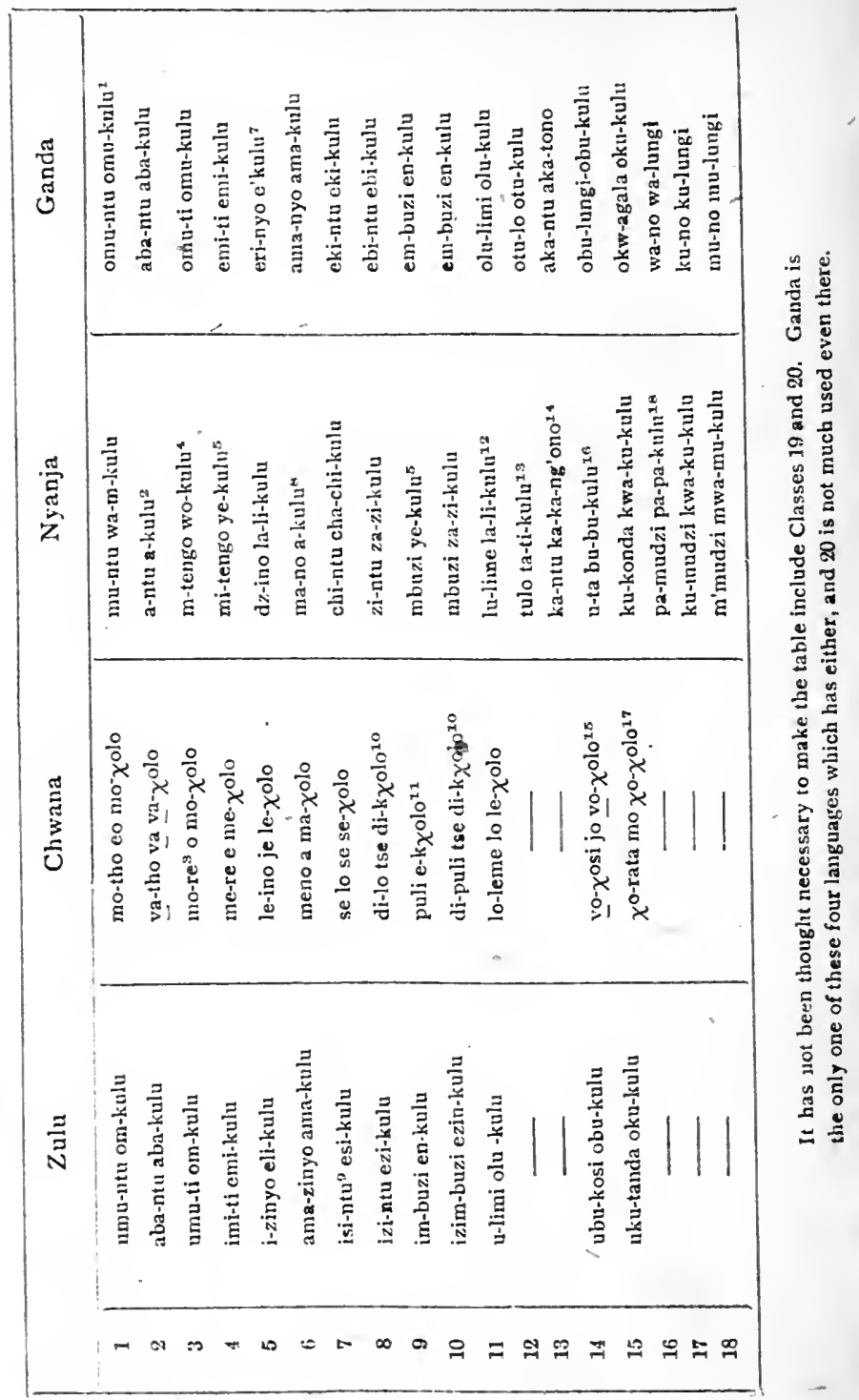


1 -kulu in Ganda is generally used in the sense of 'grown-up.'

2 Contracted from $a-a-k u l u$.

'The usual word for 'tree' is se-tlhar, but more is sometimes used with the meaning of 'herb' or 'medicine,' or in a figurative sense.

- Contracted from $u \cdot a-u \cdot k u l u$.

- Contracted from $y a-i-k u l u$.

- The particle je seems anomalous here, like tse in 8 and 10 and jo in I 4. Meinhof thinks these forms may be relatives (Grundzing einer vergleichenden Grammatil der Bantusprachtn, p. 32), but does not fully explain then.

7 The full prefix is only found in Ganda with some monosyllabic adjectives, such as eri-ngi ' many,' eri-mpi 'short,' etc.

8 Shortened from $a-a-k u l u$. In the Likoma dialect this class has the pronoun $y a$, and the adjective has the form of $y a-i-k u l u$. The $v$ is an almost extinct remainder of the initial consonant to which the Giryama $g a$ is a nearer approach.

- Isi-ntu does not mean 'a thing,' as the other words in this row do, but has been inserted because it is the same word, though changed in meaning.

10 Xolo hardens into kXolo after the di-(li-) prefix, which is the same as $z i$ in many other languages.

11 The same hardening (see last note) takes place after, , which also is contracted from $\ell-\ell$.

12 The occurrence of the forms lulime, lulimi, along with lilime, in Nyanja, shows that the IIth class is not quite merged into the 5 th, though in process of disappearing. Pronunciation seems to fluctuate, as in lipenga 'trumpet,' which is sometimes heard as lupenga and in Yao definitely belongs to the lw-class. In Nyanja words beginning with $l u$ have their agreements according to $\mathrm{Cl} .5$, as is the case here.

13 Tulo still survives in these two languages, and its adjectires would agree as above, if they were used.

14 Of course -kulu cannot be used with this class.

13 Some dialects have vo vo- $\chi 0$ lo or v'o-1'o- $\chi 0 l o$.

26 Some concords of uta in bu- are given in Scott's Dictionary. and though the abnve may not be in use, this would be the correct form.

17 I do not know how to explain this mo-.

so See the remarks on the Locative Class in Chapter V. 
The distinction may seem a slight one, but it must not be overlooked.

(The copula is not used in $\mathrm{Zulu}$ before adjectives, as it is before nouns and pronouns.)

We mentioned on a previous page a number of adjectives which are devived from verbs. But there are also verbs derived from adjectivesat least it is difficult to see how the Yao kulungwa ' to be great' can be anything else; though, curiously enough, the adjective -kulu is not found in this language. And, again, there are some cases where it is difficult to tell whether the verb or the adjective should have the priority. Mr.E.W.Smith, in his Handbook of the Ila Language, says (p. 6I): 'Many of the adjectives proper have corresponding verbs which may be used in place of them as predicates,' and gives a list which we need not reproduce in full. Some of them seem to be formed with the suffix -u, as -lemu 'heavy' (verb ku lema), -botu 'good' (verb $k u$ bota), but ku fwimpa ' to be short' seems just as likely to be formed from the adjective -fwafwi (or its root $f w i$ ) as vice versa. We are reminded of the Nyanja verbs fini-mpa'to be short' and tani-mpa 'to be long'; but there are no adjectives -fini and -tani. There is the root 
ta in -tari, however, and $f i$ may be akin to the $f u$ in $f u p i$. At any rate the possibility suggests itself that either the verb or the adjective, or both at the same time, may be derived from one of those 'interjectional roots,' which will be discussed in a later chapter.

There is no need to waste any time on the Degrees of Comparison. They do not exist, as grammatical forms. There are various ways of expressing comparison-the commonest, perhaps, is the use of some verb meaning 'pass,' ' excel' or the like.

Nyanja: Ndi ichi ndi icho cha-pambana ndi icho: 'that is better than this.' (Literally: 'it is this it is that-that (which) excels is that.')

ZULU: indoda idhlula umfana emandhleni: 'a man is stronger than a boy' ("passes a boy in strength').

Or, kmma is used (the pronoun of the eighth class followed by $n a$, equivalent to 'there is ') ; indoda inamandhla kunomfana (kuna umfana). The idiom is not quite easy to explain, but the idea underlying it may be somewhat similar to the Swahili kuliko 'where there is,' as in nyumba hii ni nzuri kuliko ile 'this house is finer than that '-literally, ' is fine where that is '-i.e., so 
fine that it would attract attention when the other was in view, and therefore superior to it.

In Kongo, the simplest form of the adjective implies that the quality is possessed to excess; an additional particle has to be inserted for the ordinary or what we should call the positive form.

Sometimes it almost seems as if the notion of comparison were absent till imported into a language by European speakers. Thus, the author of Elements of Luganda Grammar, after mentioning the use of the word singa ('surpass'), says (p. 58) 'Singa in this sense is rarely heard among the peasants until they have come in contact with European thought - . thus . . . they would say'-for ' Bring a longer stick,' 'This stick is short, bring a long one,' and so on.

What we mean by the Superlative is expressed either by some equivalent to 'very,' ' exceedingly,'-or by some such phrase as 'surpassing everyone else,' ' excelling all.' 


\section{The Numerals}

Numerals, of course, are a kind of adjective ; but, in Bantu, their agreements are not always the same as those of other adjectives, and in any case they are important enough to deserve a section to themselves.

They are so convenient for the purpose of comparing different languages, that perhaps more attention has been given to them than to any other part of speech; and being among the easiest words to ask for, they are found in the vocabularies of all the early travellers.

The numerals from one to five, and the word for ten are, with few exceptions, common to the whole of the Bantu area. The numbers six, seven, eight and nine present considerable differences. Some have no separate words for these numbers at all, but call six 'five and one,' seven 'five and two,' and so on. This does not facilitate arithmetical operations and children in mission schools are usually taught 
the English names of the numbers before entering on the mysteries of addition and subtraction. 'Eighty-seven' is certainly easier to deal with, at least for the instructor, than ' five tens and three tens and five and two.'

Where the numerals from six to nine exist, they are sometimes nouns, with an unmistakable reference to the practice of counting on the fingers. Thus, the Zulu for six is isi-tupa, 'the thumb'-showing that the counting begins with the little finger of the left handseven is isi-kombisa, 'the forefinger.' Eight and nine are expressed, rather cumbrously, by 'leave two fingers' (or 'bend down two fingers') and 'leave one finger' respectively, It is curious that Xosa, which is so closely related to Zulu, has -tandatu for six, which is also found in some of the Eastern languagesPokomo, Giryama, Nyamwezi, etc.

This is probably a modified reduplication of -tatu 'three' (contracted from tatu na tatu), just as -nane, sometimes used for 'eight,' seems to be a doubling of -ne, 'four.'

The numbers up to five sometimes (as in Zulu) agree like ordinary adjectives, sometimes (as in Nyanja) they take the inseparable pronoun. 'Ten' seems to be a noun-it is 
usually invariable, but sometimes, when it has kept its prefix, it is treated as a noun, and preceded by a connective particle, as in Zulu: abantu abay' ishumi-literally 'people who are ten.'

The following table shows these six numerals in ten languages. Konde is spoken at the head of Lake Nyasa, on the eastern side.

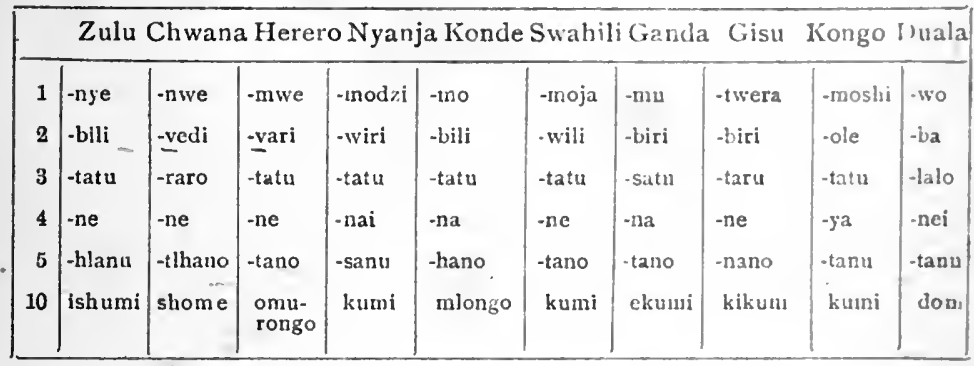

Zulu (but not Xosa) omits the initial vowel in the prefixes of nye: mu-nye, li-ny'e, si-nye, not ommye, elinye, etc. (which would mean 'some,' 'other').

The roots as given here are sometimes modified when preceded by noun-prefixes, e.g., in Swahili, -wili becomes mbili when agreeing with a noun of the tenth class. We may also notice that there is often a distinct set of numerals without any class-agreement, used in counting where no particular things counted 
are specified. Thus, in Swahili, we count: mosi, pili, tatu, nne, tano, whereas the same numbers applied to people would be: (mtu) mmoja, (watu) wawili, watatu, wane, watano; to trees: (mti) mmoja, (miti) miwili, mitatu, uine, mitanó; to nouns of the seventh and eighth classes : kimoja, viwili, vitatu-and so on.

Yao (an important language occupying a considerable area in Nyasaland and the Portuguese territory) has mcheche (nvariabie) for four, the root of which is found in Makua as -cheshe. Yao has another peculiarity, in treating five (msanu) as invariable.

Some dialects of Chwana use mphecho 'completion' instead of -thano, that is" the whole hand '-the five fingers.

The root -rongo or -longo sometimes serves to form multiples of ten: e.g., in Pokomo 'ten' is kumi, but 'twenty' mi-ongo mi-wii. In Swahili mwongo survives, meaning 'a decade'; in the older reckoning (now mostly superseded by the Muhammadan Calendar) a month was divided into three miongo of ten days each. Twenty, etc., are usually expressed by makumi followed by the number required; but sometimes, though rarely, there is a special word for twenty. Such is $d u$ in 
Isubu, ${ }^{1}$ which seems, however, to be borrowed from the Sudan languages. Konde occasionally, along with amalongo mabili, ${ }^{2}$ has umundu' a man'-i.e., both hands and both teet. Swahili uses the Arabic word for ' twenty'-ishirini.

Sometimes there are distinct words for ' hundred ' and 'thousand,' but in other cases these are only treated as multiples of ten. The Lower Kongo people and the Baganda have the completest systems of numeration, because they have been used, for many generations, to deal with a cowrie currency, and the latter in particular have an ingenious plan of varying the prefixes for tens, hundreds, thousands, tens of thousands: thus, Io is kumi, Ioо ekikumi, I, о०о olukumi, Iо,0о० akakumi, beyond which this form of numeration does not seem to go. At least I find in the Rev. G. R. Blackledge's Luganda Vocabu'lary a word for 'a million,' which is quite distinct-akakala. Kongo does not use this

1 Isubu is spoken in the Cameroons delta, by people living between the Duala on the south and the Bakwiri on the north.

${ }^{2}$ Or imilongo mibili, as would be expected from the usual singular. There is also the curious form tu-longo tu-bili. 
system of prefixes, but has words for Ioo, I,000, I0,000, I00,000 and I,000,000.

The numbers in the following table, if not preceded by a hyphen, are invariable, except in so far as they are treated as nouns, and behave like ishumi in Zulu. These are marked*. Those with a hyphen prefixed agree like those in the first table.

\begin{tabular}{|c|c|c|c|c|c|c|}
\hline & Xosa & Chwank & Herero & Kiong"s & Enala & $11 a$ \\
\hline 6 & $-\operatorname{tandatu}$ & -rataro & hambonwe & sambann $^{5}$ & mutoba & ${ }^{*}$ chisambomwi ${ }^{6}$ \\
\hline 7 & - -sixenxe & - shupa $^{2}$ & hambonbari & nsainbwadi & saınba & *chiloba \\
\hline 8 & -sibozo & -3 & hamboiddatu & nana & lombi & *lisele \\
\hline 9 & -litoba & - & muviu & vwa & dibua & *ifuka \\
\hline
\end{tabular}

Continuation of above.

\begin{tabular}{|c|c|c|c|c|c|c|}
\hline \multicolumn{4}{|c|}{ Hehe $^{7}$ Nyamwezi Giryana } & Kikuyu & Gisu & Ganda \\
\hline 6 & mutanda & -tandatu & -hondahtid & -tandatu & -sesaba & omukaga \\
\hline 7 & $\begin{array}{l}\text { natur- } \\
\text { gate }^{8}\end{array}$ & $\begin{array}{c}\text { mpun- } \\
\text { gati }\end{array}$ & fungahe & mugwanja & musafu & onusamvu \\
\hline 8 & munane & m:na:e & -nane & -nana & kinane & omunana \\
\hline 9 & igonza $^{\circ}$ & $\begin{array}{l}\text { ken- } \\
\mathrm{da}^{10}\end{array}$ & chenda & kenda & kyenda & omwenda \\
\hline
\end{tabular}


1 Though the forms for 7,8 and 9 look identical with the

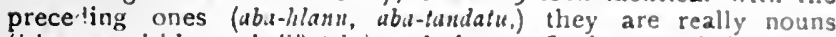
(isi-xenxe, isi-bozo, $i($ i $)-\{0 b, t)$ and the prefix is preceded by the relative particle. Otherwise it would be aba-renre, not aba-si$x e n x e$ and so for the others. -xuxe (the $x$ stands for the - lateral click') and bozo seem to be horrowed Hottentot roots. $i(l i)$-toba is evidently a noun formed from the verb $b_{0 b} d^{\prime}$ bend down' (cf. tob'umun wenunye for 9 in $Z u l u$.)

2 From the verb shupa' show,' 'point.'

3 These numbers are not given, as they are similar to the Zulu: 'bend down two fingers,' ' bend down one finger.' There is, liswever, in some dialects an almost obsolete word for 8, sestisti, of which the derivation is curious: suaya means 'to mark' (with paint), and as this is nsually done with the middle finger of the right hand, it comes to be synonymous with 'eight.'

- hamb.r (the same word as the $Z$ ulu for 'go ') means ' jump over' (t.e., from the thumb of the left hand to the thumb of the right) -hambo-mue ' jump over (and take) one.'

5 Kongo numerals have a double system of agreement (for the details of which see Bentley, pp. 567-570); in the 'primary form ' $7,8,9$, and to are invariable, in the ' secondary' they take prefixes.

6 This looks like a variant of the Herero word; but the only meanings given for samba in Mr. Smith's vocabslary are 'wash, bathe, swim.'

7 The Wabehe are to be found some distance N. E. of Lake Nyassa and to the south of the Wagogo.

- Fungate is still used in Swahili, meaning 'a period of seven days'-but only in connection with a wedding (see Krapf, s.v. and Steere's IIandbook, p. 91). It was, no doubt, the old word for 7 , but has long been replaced by the Arabic saba'a.

I I have fonnd no other example of this form.

10 Also found in Swahili, though not sa olten as the Arabic tissa or tisia.

11 'Cerebral $t$ ' becomes $h$ in Giryama. The difference be:ween the two $t$ 's is very important in Swahili: -tat?, with cerebral "' becomes in Giryama $-h a h u$, but $-t h n$, with dental $t$, tsano. - Cerebral' $t$ is pronounced by piessing the tongne against the hard palate, 'dental ' by pressing it against the teeth : our ordinary English $t$ is between the two, being 'alveolar'-i.t., the tonguo touches the gums or 'tooth-ridge.' The two t's in Swahili may be distinguished, if necessary as t (-tatu) and -! (-tano) or the cerebral, as the commoner, may be left unmarked. The Rev. W. E. Taylor, in his Africun Aphorisms, prints the dental t in italic; but in lis version of the Psalms it is underlined. The difference is more important at Mombasa than at Zanzibar, where most of the words which at Mombasa have dental $t$ are pronounced with $c h,-m a t o=$ macho 'eyes '; tcki $=$ chcku 'laugh.' 
Some of the words for 'hundred' and 'thousand' are as follows :

\begin{tabular}{|c|c|c|c|c|c|c|c|c|c|}
\hline \multicolumn{2}{|r|}{ Zulu } & \multicolumn{3}{|c|}{ Herero Kongo Duala } & Ila. & Nyanja & Hehe & Kikuyu & a Gisu \\
\hline 100 & ikulu & ethere & nkama & ebwea & mwanda & dzana $^{2}$ & igana 4 & igana & litondo \\
\hline 1000 & inkulung & eyovi & ezunda & ikoli & chulu & chik wi ${ }^{3}$ & imbirima & $\begin{array}{l}\text { a ngiri } \\
\text { ng }\end{array}$ & $-^{5}$ \\
\hline
\end{tabular}

The Ordinal Numórs are usually expressed by turning the cardinal number into a noun preceded by the possessive particle of the noun with which the number is to agree.

Thus in Nyanja muntu wa chi-modzi, wa chiwiri, wa chi-tatu 'the first, second, third person.' Chintu cha chi-modzi 'the first thing' ; nyumba ya chimodzi ' the first house,' etc., etc.

But the first ordinal is not always an actual

1 This looks like a diminutive of $i k n l n$, but I do not know how to explain it.

${ }^{2}$ Also in Ronga. In some dialects zana.

${ }^{3}$ Kikwi was formerly used in Swahili, but is now seldom if ever heard. The usual word is the Arabic clfu (mia for 10c).

"This (or gana) is also used in Nyamwezi, Shambala, Zigula, Giryama, Poliomo, etc.

${ }^{5}$ Gisu has no special word for 1,000, kamatonda kikumi ' ten hundreds' being used.

Konde expresses 'a hundred 'by 'five people.'

Xosa has the same word for 'hundred ' as Zulu; but 'thousand' is iwaka. Nyanwezi nas killumbi for 'thousand.' 
numeral. In Swahili ntu wa kwanza is literally 'the man of beginning,' from kwanza $(k u-a n z a)$ 'begin'; and similarly in Zulu umuntu wokuqqala (wa uku-qala). ${ }^{1}$

Invariable numerals, as a rule, simply have the possessive particle prefixed to them, and in Ila this particle is prefixed directly to the stem even of the variable ones. In Herero a somewhat curious system is adopted: the inseparable pronoun followed by the verb tya 'say,' is prefixed to the stem of the numeral: 'the second man' is ommudu utya vari-literally 'the man he says two,'- ' the third tree' omuti utya tatu, ' the fifth name' ena rity'a tano.

The way in which the variable numeral is changed into a noun is not everywhere the same, and no general rule can be given. Zulu, like Nyanja, uses the seventh prefix for this purpose; Chwana and Ronga the fourteenth, Ganda the fifteenth; and sometimes, as in Swahili, the isolated forms of the numerals (those which serve for counting when no objects are specified) are used. In this language ' the first man,' as already stated, would be mtu wa kwanza.

${ }^{1} Q$ represents the 'cerebral ' click. 
The second tree mti wa pili.

The third name jina la tatu.

The fourth thing kitucha mne.

The fifth house nyumba ya tano.

' Twice,' ' thrice,' etc. are formed in many languages by prefixing $k a$-, which will be noticed later on, as it forms adverbs from other adjectives as well as numerals.

Special features to which attention should be directed are the dual pronouns and the distributive numerals in Ganda, and the forms in Zulu expressing 'both,' 'all three,' etc.: bobabili, bobatatu. But these belong to the study of particular languages, and cannot be dealt with here.

Some Bantu grammarians include the numerals among the adjectives; others (because of the difference in their agreement, already referred to, observable in some languages) place them among the pronouns. This difference usually extends to the words for ' all,' ' only,' and one or two others, sometimes called 'indefinite adjectives' or 'indefinite pronouns.'

The most logical plan appears to be to give the numerals a separate chapter as we have done. 


\section{CHAPTER X}

\section{The Verb}

THE Bantu verb normally consists of two syllables and ends in $a$, e.g. :

ZULU: lima 'cultivate'; hamba 'go'; tanda 'love'; lala ' lie down.'

Chwana: lema 'cultivate'; cta 'go'; rata' love' roma 'send.'

NYANJA: manga 'tie'; enda 'go'; konda 'love'; tenss ' carry.'

There are a few monosyllabic verbs, most of which are used as auxiliaries : some are now only found in composition, as tense-particles. They are seldom fully conjugated, and have some other peculiarities which have led to their being described as 'irregular verbs.' Sometimes, as we shall see more fully later on, it seems probable that they have been worn down from a dissyllabic stem. In other cases they may be original roots, perhaps 
traceable in the monosyllabic Sudan languages.

Verbs of more than two syllables are practically certain to be either 'derived forms' or foreign importations (as Swahili fikiri 'consider,' kubali 'agree,' which come from the Arabic). In the former case, the fact is sometimes disguised by the loss of the simple form. In $\mathrm{Zulu}$ there is a verb kumula ' untie,' ' undo '; this has the 'reversive' termination -ula, showing that it is the opposite of a verb kmma 'fasten'-but there is no such verb now to be found in Zulu. A very common verb in Swahili is simama 'stand'; now in other languages we have ima, yima, yema, jima, zhima ema (or ma) with this meaning; and ima is even found in old Sivahili. -Ama is a termination implying 'to be in" a position,' as ang-ama 'be suspended,' in-ama 'stoop' (be in a stooping position, $)^{1}$ etc.

${ }^{1}$ But sometimes we may get a verb which looks like a derived form, though it is not really one. Meinhof gives an instance of a Konde word hov-ela, 'hope,' which would naturally be taken for the applied form of hova. But there is no such verb as the latter, and the word is ultimately derived from the Arabic through the Swahili subiri 'be patient.' Other verbs of more than two syllables, formed direct from adjectives, nouns or 
Verb stems beginning with a vowel are not very common, and usually produce some modification of the prefix, owing to the contact of two vowels, which necessitates a special paragraph or section being devoted to them in most grammars. Comparative study makes it appear likely that these "vowel verbs" once began with a consonant, and Meinhof thinks this consonant was the voiced velar fricative, $\gamma$. This is not an easy sound to pronounce at the beginning of a word, and would very soon tend to disappear, or at least to become modified. In the above examples, where it has not been dropped altogether, it is represented by $y, j$, or $z h$ (pronounced like $z$ in 'azure').

In $Z$ ulu we find several verbs which may or may not have an initial e : ema (or ma) 'stand,' eza (or za) 'come'; emba (or mba) 'dig,' epa (or $p a$ ) 'pull up' (as weeds, etc.). These, we can see, are reduced to monosyllables by dropping the vowel, after the loss of the original initial consonant. The vowel

the invariable roots called 'sound pictures' or 'vocal images' will be noticed later. Some diacritic marks have been omitted from hovela-most Konde words bear more than could be printed here without confusion. 
being retained where it happens to be more easily pronounced, keeps the real state of the case before us; otherwise it might be thought that these were true monosyllabic verbs. ${ }^{1}$

Verbs which do not end in a are very rare (unless borrowed from other languages) and chiefly monosyllables. $T i$ 'say' is found in nearly every Bantu languages, and so is $l i$ ' to be,' in composition if not independently. The Zulu hlezi from hlala 'sit' being a perfect, does not count in this connection, yet even as a perfect it is irregular, since it should end in -e not -i. I have never seen it satisfactorily accounted for.

The 'Derived Forms' of the verb, to which we have already referred, might perhaps be most accurately described as 'Voices.' We, in Europe, have the Active and Passive, to which, in Greek, is added the Middle: we also have traces of a Causative, as in 'fall''fell' (= make to fall) 'sit ' - set (=cause to sit), etc. The Bantu languages have all these, and several others as well.

${ }^{1}$ It is possible that in some of these cases the $e$ may have been adopted by analogy-e.g. in $e z a$. 
The Passive is formed by means of the suffix - wa : pig-wa (Swahili) from piga 'strike,' bon-wa (Zulu) from bona 'see.' Sometimes the suffix is -iwa, (as in IRonga), -edwa or -idwal (Nyanja), -ebwa or -ibrea (Ganda), -igwa (Konde). Duala has the very peculiar form -be. The suffix may cause considerable modification in the stem of the verb, as in Zulu, where $w$ cannot follow $p, b$, or $m$.

The Neuter-Passive, usually ending in $-e k a$ or $-i k a$ (sometimes in -uka, -aka or -akala) is distinguished from the Passive by expressing a state, or the possibility of being subjected to an action, rather than the actual undergoing of the action on some definite occasion. Thus, in Swahili, kamba y'afung uk $a^{2}$ is: 'the rope is (in a state of being) unfastened,' but kamba yalifunguliza is: 'the rope was unfastened' (by some person or persons). In Zulu,

${ }^{1}$ Whether it is edwa or $i d w a$ depends on the rowel contained in the verb stem. This 'Law of VowelHarmony' will be noticed in a later chapter.

'Fung-uka is really a compound form, being the intransitive (or neuter passive) of fungua, the reversive (see p. 150 below) of funga 'fasten.' Funguliwa, the passive of fungua, is formed from the original fung-ula, $-l$ between two vowels being usually dropped in Swahili, and verb-stems ending in $l$ making their passive in -iwa. 
inkanyezi ya-bonakala is:" 'the star was visible,' but 'the star was seen' "(by A. or B.), inkanyezi ya-bonwa.

The Applied (sometimes called the 'Relative' or 'Prepositional') form of the verb gives rise to numerous idioms, some of which have no exact European equivalents; but the most general rule which can be laid down for its use implies that the action is done with reference to some person or thing other than the direct object of the verb. If the verb is intransitive, and therefore has no direct object, this form makes it transitive, and enables it to take one. The ending is usually -ela (-ila) or -era (-ira); in Swahili -ea (-ia). Ex. :

ZULU: hamba'go'; hambela 'go to'- anyone, and so 'visit.'

hlala 'wait'; hlal-ela 'wait for.'

lima 'cultivate'; lim-ela 'cultivate for' some one else.

Nyanja : dula 'cut'; dul-ira 'cut for' anyone. nena 'speak'; nen-era 'speak to 'or,'for,' etc.

The Causative, as a rule, has the ending -isa or -isha, or some easily recognisable modifi- 
cation of the same. Its meaning needs no further explanation.

ZULU: vala'shut,'val-isa 'make to shut,' hamb. isa 'make to go,' talld-isa 'cause to love,' etc.

Nyanja : dul-itsa 'make to cut,' lim-itsa 'make to cultivate,' nen-etsa 'cause to speak.'

Swahili: funda 'learn,' fund-isha 'teach' (i.e. 'cause to learn'), soma 'read', som. esha ' make, or help, to read.'

Herero: rara 'sleep,' rar-itha 'make to sleep,' thura 'swell,' thur-itha 'cause to swell.'

An Intensive form is sometimes found, identical in form (though not in origin) with the Causative. Thus, in Nyanja, mang-itsa (from manga, 'tie') may mean, either 'cause to tie 'or 'tie tightly,' end-etsa either 'make to walk' or 'walk far.' This is also the case in Zulu, but here, the intensive sometimes reduplicates the causative termination and ends in -isisa: buza 'ask,' buz-isisa 'inquire thoroughly.' There is another intensive, in Zulu, ending in -ezela, which belongs to the

'It has not been thought necessary to take any notice here of the causatives in $-z a$ and other variations arising from the presence of certain consonants in the stem. The causative in $-y / c$ is a distinct form, sometimes found side by side with the others. 
applied form. In Rundi ${ }^{1}$ and probably elsewhere, the Intensive is a combination of the Applied and Causative endings : rira 'weep,' riririsha 'weep continually'; saba 'ask,' sabirisha 'ask persistently.'

In Luganda, the Applied termination is reduplicated: tonya 'drip,' 'rain,' tonyerera 'drizzle incessantly.' Sometimes the root of the verb is wholly or partly reduplicated, to convey an intensive, or sometimes, rather, a repetitive force, but this is not the same thing as the verbal forms we are considering.

The Reversive form has the ending -ula (-ıra, in Swahili-ıua)-sometimes -ulula, e.g. :

Nyanja: tseka 'shut,' tseg-ula 'open,' pinda 'fold,' pind-ula 'unfold.'

GANDA: simba 'plant,' simb-ula 'dig up,' jema 'rebel,' jemt-ulula 'submit.'

KONGO: kanga, 'tie,' kang-ula 'untie.'

ILA: $\quad a m b$ a 'speak,' $a m b-u l u l a$ ' retract' (unspeak), yala 'shut,' yal-ula 'open,' soma 'sheathe,' som-onona 'pull out.'

${ }^{1}$ Spoken in the country near the north end of Lake Tanganyika.

${ }^{3}$ Ila and Herero both have two additional reversive endings, -ona and -onona. These are found when the stem contains a nasal ( $m$ or $n)$. Kongo also has -ona and $-1 u n c$. 
Herero: pata 'shut,' pat-urura 'open,' yonya 'be crumpled,' yony-onona 'smooth out,' etc.

This form is made intransitive by changing $l$ to $k$ : tseg-ıka 'be open,' simbuka ' be dug up.' The Reversive form is not usually enumerated in Zulu grammars, but certainly exists in the language : jaba is 'be mortified, disappointed,' etc., jab-ula 'rejoice,' and there are words in -ula like kum-ula 'unfasten' which distinctly have a reversive meaning, though the primitive verb may have been lost.

The Reciprocal, in -ana, implies, as may be gathered from the name, an act done by two or more people to each other:

SWAHILI : pend-ana ' love one another.'

Nyanja : meny-ana 'fight' ('beat each other,' from menya 'beat').

ZULU: ling-ana 'vie with one another,' 'be equal,' from linga ' strive.'

There are some variations in the ending. Kongo has-ajiana, or-asajiana, as well as -ana; Ganda -agana or -ang'ana, as ky'av-agana 'hate one another,' wullir-agana ' hear one another,' etc.; and Herero -asana, as mun-asana 'see each.other,' from muna 'see.' 
The idiomatic uses of the Reciprocal form are curious: we may give some examples.

ZULU: sa-bon-ana nomgani wami, 'we saw each other (I) and my friend.'

NYANJA: akulu a-bvut-ana mlandu 'the headmen 'contend in a quarrel ' (bvutana, reciprocal of bvuta ' be difficult.')

In Swahili this form enters into several expressions where its force is very difficult to render in English: kupatik-ana ' to be obtainable,'kujulik-ana ' to be knowable.' These are not quite the same as kupatika and kujulika, and the difference, probably, is in the implication that something is obtainable or knowable by everybody, the acquisition or information being, as it were, mutual.

The Stative form in -ama has left traces in most languages, even if it is not expressly recognised in the grammars. Verbs in -ama usually express an attitude:

NyAnja : er-ama 'stoop,' kot-ama 'be in a crouching position.'

Swahlli: in-ama 'stoop' (in-lar, the reversive' of the same root, means ' lift up ') ang-ama, 'be suspended' from anga 'float' (in the air)-angua, the reversive, means 'take down,' and ang- $u k a$, its intransitive, 'fall.' 
Kot-ama is found in Zulu, with the same meaning as in Nyanja, and we also find lul-ama 'rise up a little from a recumbent position,' fuk-ama 'sit, as a hen hatching' and pak-ama, 'be elevated,' which may be verbs of the same kind. Compare,

Herero: themb-ama 'be straight,' pik-ama 'be aslant' (from pika 'pull to one side ').

Chwana : el-ama (or al-ama) 'sit on eggs.'

KONGO: lal-ama 'be afloat,' lamb-ama 'be clenched' (said of a nail), kok-ama 'be hooked on to,' etc., etc.

Some languages have a Repetitive form in -ulula-others express the same idea by wholly or partly reduplicating the stem. Ila has ula 'buy, trade' ( $c f$. Nyanja gula), ul-ulula 'trade a thing over and over again'; nenga 'cut,' neng-ulula 'cut up again and again'; Kongo : sumba 'buy,' sumb-ulula 'buy again.' Kongo also has the suffixes -mmma, -olola and -onona.

These two languages have, in addition, a 'Persistent Repetitive,' which in Kongo has the suffix -ujiola, with various modifications. Ex. :

Tunga 'build,' tung-ujiola 'licep on rebuilding.' Kuna 'plant,' kun-ujiona 'keep on replanting.' 
Ila has no suffix for this form, but inserts $a$ before the final syllable of the verb.

sotoka ' jump,' sotaoka ' hop, as an insect.'

sandula ' turn over,' sandaula ' turn over and over.'

There are'some other endings of which the functions do not seem as yet to be very clearly ascertained: -ala, -ata, -nga (found in Herero) and a few more.

The PERFECT IN -ILE is sometimes reckoned among the Derived Forms of the verb, because it is not a tense, strictly speakingthat is, it does not refer to time, but to 'the condition or progress of the action' (Bentley), and because, unlike the real tenses, it is formed by a suffix.

Verbs formed from adjective-stems (as mentioned in a previous chapter) by the addition of $-p a$ or $-m p a$, cannot be reckoned among the Derived Forms. Such are the Zulu de-pa 'be tall,' Nyanja (and Swahili) nene-pa 'be stout'; probably the Nyanja $i$-pa 'be bad' is so formed from the root $b i$, originally $v i$, which has dropped its initial consonant. In $\mathrm{Zulu}$ we have a second form -pala, as kulu-pala 'be fat' (or 'big ').

In conclusion, we may remark that all 
these forms of the verb can be compounded with each other to almost any extent. So in Zulu: hamb-ela 'visit,' hamb-el-isa 'came to visit,' hamb-el-is-ana 'cause to visit one another,' hamb-el-is-an-wa, passive. of the last named. Extreme instances of this kind of cumulative composition are given in Bentley's Dictionary and Grammar of the Kongo Language, pp. 640, 64I. There is no need to say more on the subject here. 


\section{CHAPTER XI}

\section{The Verb (continued)}

Moods And Tenses

IF we ask ourselves what we mean by the term ' mood,' and find that it may be explained as 'manner of being,' it might seem that the distinction between the Derived Forms discussed in the last chapter, and Moods is not very clear. However, on considering some examples of each, it becomes evident that moods are the varions conditions under which some particular act is manifested: the action, say, of writing is contemplated as actually taking place (whether in past, present or future time)-or as possibly taking place under certain conditions-or as being desirable, and so on. But it is always the same action of writing. In the Derived Forms, the action itself is in some way modified: it is looked on from the point of view of the sufferer instead of the doer, or as reversed, caused, intensified, 
applied to someone or something, etc., etc. And each separate form is carried unchanged through all the moods and tenses.

Moods are only marked to a limited extent in English. We have the Indicative, Infinitive, Imperative and Subjunctive, though the last is going out of use (that is, as shown by the form of the verb itself: 'if I be,' 'that he love,' etc.). In Latin, the distinctive inflections of the Subjunctive are more strongly marked, and in Greek we have an additional mood, the Optative.

The definition of 'Tense' is simple enough, if we keep to European languages, where the word can be used in its strict etymological meaning. It refers to the time at which an action is performed-past, present, or future, with the sub-divisions of 'complete' and 'incomplete,' or 'perfect' and 'imperfect,' etc. But even here the matter is not quite so simple as it seems-should we, for example, call the French conditional a mood or a tense? For practical purposes, no doubt, the distinction matters little-yet it is worth thinking over in connection with our present inquiry.

When we leave Europe, we find-e.g., in the Semitic languages - that the word 'tense' 
no longer applies, or rather, it has to be used with a somewhat conventionalised meaning, for the distinction of time is not kept in view so much as that of completed and of incomplete or continuous action. We saw in the last chapter that the Bantu so-called 'Perfect' tense does not necessarily imply a past state of things. It is very often equivalent to the Present, indicating an action completed in the past, whose effects still continue: thus, 'he is asleep' is rendered by an expression meaning: 'he has lain down' (and is still lying).

If we bear in mind that both terms are elastic as to meaning, we can draw a very clear distinction of form between moods and tenses in Bantu. The former are distinguished by suffixes, the latter by prefixes. ${ }^{1}$

On this showing, the Perfect in -ile should count as a mood, and it appears to me that there is no good reason against its doing so. We have seen that some reclion it as a Derived Form, or Voice.

1 This cannot be taken quite absolutely: for instance, it does not apply to the Infinitive. (The Imperative, consisting of the bare stem, might be looked on as the ground-form whence the others are derived). But this, in spite of the prefix ku- (which marks neither person nor time) differs essentially from the tenses proper. 
Some writers recognise (e.g., in Zulu and Chwana) Optative and Potential Moods; but these, by their structure, are really tenses, and, since we cannot adhere to the strict definition of that word, they may very well pass for such.

We might reckon in Bantu eight moods, four of which, the Imperative, Infinitive, Indicative and Subjunctive, correspond, on the whole, with the notions expressed by those terms in European languages. The others are the Negative, the Perfect in -ile, the Continuative and the Relative.

The Imperative, as we have seen, consists of the bare verb-stem ${ }^{1}$ in the singular, and suffixes $-n i$ (really the pronoun of the second person) in the plural.

The Infinitive (which, as we have seen, is identical with the fifteenth noun-class) is distinguished, as a rule, by the prefix, $k u-{ }^{2}$ This,

${ }^{1}$ Perhaps it is better to follow Meinhof in using this term instead of 'verb-root,' for we cannct tell that these verbs are not ultimately made up of monosyllabic roots, going back to a pre-Bantu stage of speech.

${ }^{2}$ This prefix has been quite lost in Kongo, except in the case of the two vowel-stem verbs, $k$ w-iza and $k w-e n d a$. Duala shows traces of haviug had a different infinitive prefix. (See Meinhof, Grundzüge, einervergleichenden Grammatik der Bantusprachen, p. 10.) 
the Indicative and the Imperative all, in the present state of Bantu speech, end in $-a$, except in Herero and some of its cognates, and in the languages of the extreme north west (Duala, etc.). ${ }^{1} \quad$ Bleek seems to have considered this $-a$ a later accretion, and supposed that the verb originally ended in some other vowel. But this matters little to our present purpose. The Subjunctive ends in $-\ell$. Its uses are much like those of the European subjunctive, though more extensive; they can be better illustrated from the specimen texts at the end of the volume, which "contain numerous examples, than by any explanations given here. ${ }^{2}$

The Negative, which on our definition we must reckon as a mood, ends in $-i$. It is a feature not found in any European language, where the addition of some invariable adverb

1 Herero has one present tense which assimilates its final vowel to that of the stem, as me piti 'I go out' (from pita) ma mumu 'he sees' (from muna). Some of the Congo languages, such as Ngala, Poto, etc. (not Kongo itself) seem to possess presents ending in $-e$ and $-o$, which are probably to be explained by the same principle of Vowel-Harmony.

"Ex.: Zulu: ngi-hambe 'let me go'; Swahili: nijenge 'let me build"; Herero: nge-mune "let me see'; Ganda : a-lime 'let him cultivate,' etc. 
meaning 'not' is quite sufficient to negative any tense of the verb. The only difficulty that could arise is from the position of the negative, which, in a compound tense, has to be inserted between the component parts of the verb; and the two particles in French (ne . . pas), by doubling this difficulty make it necessary to learn a negative as well as an affirmative conjugation. But 'not,' nicht, non, and ne .. pas do not affect the form of the verb itself.

It is otherwise in Bantu. There are several different ways of forming the negative, but the main principle appears to be that a negative particle is prefixed and the final vowel of the verb altered to $i$. This is usually (though not in all languages) the Negative Present. The Negative Past is formed in a different way; and moreover there is not, as one might expect, a Negative tense corresponding to every Affirmative one. On the other hand, there are some negative tenses with no affirmative corresponding to them. This looks as though the Bantu mind conceived of 'not doing' a thing-just as the still more primitive mind conceives of 'more than one thing '-as a distinct and separate 
entity. ${ }^{1}$ And perhaps this is borne out by the fact that languages of relatively advanced development, like Kongo, have lost the final inflection, and express the negative merely by invariable particles. Kongo has one of these particles before the verb and one after, like ne... pas.

Betonda = 'they love.' Ke betonda ko 'they do not love.'

-In Duala, the negative particle si is used for all tenses, but is placed after the subject pronoun.

na loma 'I send'; na si loma 'I do not send.'

ba mende jipe 'they will cook'; ba si mende jipe 'they will not cook.'

The normal Negative Present is as follows:

\begin{tabular}{|c|c|c|c|c|}
\hline Zulu & Chwana & Swahili & Ganda & Gisu \\
\hline a-ngi-hambi & $\chi_{\mathrm{a}}$ ke reke ${ }^{2}$ & si-pendi ${ }^{3}$ & si-laba & hi-n-teka \\
\hline 'I do not go' & 'I do not buy & "I do not love" & "I do not see" & 'I do not cook' \\
\hline a-si-hambi & $\chi$ a re reke & ha-tu-pendi & te-ba-laba & bi.ba-teka \\
\hline 'We do not & ' We do not & "We do not & $\begin{array}{l}\text { "They do not, } \\
\text { see, }\end{array}$ & $\begin{array}{l}\text { 'They do not, } \\
\text { cook ' }\end{array}$ \\
\hline
\end{tabular}

${ }^{1}$ See Language Families, pp. 38, 39.

${ }^{2}$ This $e$ in Chwana is the 'narrow e,' approximating in sound to $i$.

${ }^{s}$ The negative particle in Swahili is $h a$, which is 
In Nyanja, the negative used throughout is si (contracting in the second and third persons singular to $s u$ and $s a$ ), and $i$ is sometimes (not always) suffixed to the verb-stem: as si-ndi -dziwa-i 'I do not know,' but si-ndi-dziwe is also heard.

We need not enumerate all the different negative particles in use, e.g., Ila $t a$, Yao nga, Zigula $n k a$, etc., but we must say a word in passing as to the negative in the other tenses of the Indicative. Swahili has a negative past formed by means of the infinitive: si-ku-penda 'I did not love'; ha-tu-ku-penda 'we did not love.' This serves as negative both to the Past Tense (ni-li-penda) and the Perfect Tense (ni-me-penda). ${ }^{1}$ Now, as -me-indicates that the action is finished, complete, the sentence ni-me-penda cannot be negatived merely by the addition of a particle. ${ }^{2}$ So another form is used : si-ku-penda is a negation

prefixed to the three plural pronouns, but contracts with those of the singular: si (originally ha $+n i), l m($ ha $+u$ ) $h a(h a+a) . \quad T e$, the Ganda negative particle, is in some dialects, used for all three persons alike as it is in $\mathrm{Nyoro.}$

${ }^{1}$ Modern Swahili has disused the Perfect in -ile and the one which has replaced it is, by its structure, a tense, not a mood.

${ }^{2}$ See Meinhof, Grundzüge (p. 64). 
of the Infinitive; literally 'not-I to love.' (This is different from the form actually in use as the Negative Infinitive, which is ku-to-penda, a contraction of ku-toa ku-penda, literally 'to take away loving.')

But Zulu negatives the Perfect by simply prefixing the Negative Particle: a-ngi-tandile 'I have not loved'; ka-tandile' 'he has not loved.' This is what might be called a mechanical formation; which means that, the original force of the inflections having been more or less forgotten, the prefixes and suffixes used with some tenses, etc., are applied to others, without reference to their abstract congruity.

There is, in Zulu, a Negative Past, made by prefixing $a$ - as for the Present, and suffixing nga: a-ngi-hamba-nga 'I did not go.'

The Negative Future is, as Professor Meinhof points out, a recent formation, ${ }^{2}$ and, as such, entirely mechanical.

${ }^{1} \mathrm{Ka}$ sometimes, in $\mathrm{Zulu}$, replaces $a$, which is never used, e.g. with the 3 rd person singular (if the subject is of the first class), or with a noun of the 6th class: umfana ka-hambile 'the boy has not gone'; ama-hashi $k a$-gijimi ' the horses do not run.'

${ }^{2}$ Grundziige, p. 65. 


\section{Swahili :}

ni-ta-penda 'I shall love'; si-ta-pendat, 'I shall not love.'

-tu-ta-penda 'we shall love'; ha-tu-ta-penda, we shall not love.'

This, of course, as it does not change the final vowel, is indistinguishable from the tenses we shall have to consider later on. But the Zulu Negative Future is different. It is recognizably a compound tense, made up of the verb $y_{a}$ ' go' and the infinitive; and the first part of the compound is negatived in the same way as the Present.

ngi-ya-ku-tanda 'I shall love' (lit. 'I go to love '). $a-n g i-y i-k u-t a n d a$ 'I shall not love.'

In all these indicative tenses, the negative particle comes first, but in the Subjunctive, the Participle, and the Relative Tenses, it comes after the subject-pronoun.

Subjunctive :

Zulu: ngi-ngal-tanli. Swahtha : ni-si-pende'I may

Relative : not love.'

$$
\begin{aligned}
& \text { aba-nga-yi-ku-tanda } \\
& \text { 'they who will not } \\
& \text { love.' }
\end{aligned}
$$

a-si-po-sema

'if he cloes not speak."

1 These forms were explained in Chapter VI. As to the reason for the difference in the position of the negative particle, see the reference in the last note. 
It will be noticed that the Negative Particle here is different from that used with the Indicative. In Swahili, si is used all through the Subjunctive, and not with the first person onlý.

The Perfect in -ile is found in a great many Bantu languages. Swahili, as remarked above, has lost it-except in some of the northern dialects-and it seems to have disappeared altogether from Nyanja, though not from the neighbouring Yao. It is sometimes shortened to $i$ or $e$, and assumes various modified forms-e.g. it may change the vowel instead of adding the suffix, as Zulu lele from lala, ${ }^{1}$ pete from pata, and in the verbs of the Reciprocal form, as hlangana 'meet,' perfect hlangene. Derived forms, especially the Applied, very frequently shorten the termination to $e$ : sond-ela 'approach,' perfect sondele.

It is not surprising that missionaries and others engaged in the reduction of a new language should sometimes have failed to recognise this 'Perfect' when they came across it, as its, use did not correspond with

${ }^{1}$ Lalile is also used, but with a somewhat different meaning. 
their notion of a tense. Yet that use is not without parallels nearer home. The Greek o' $\delta a$ 'I know,' is really the perfect of the verb meaning ' to see,' and Latin perfects used in a present sense, like coepi, memini, odi (which have lost their presents), and novi, (the perfect of nosco) 'I have come to know'=" I know,' are really exemplifications of the same thing.

The Contimative Mood, with the suffix $-g a$, is less frequently met with. It implies that an action is done habitually, or that it continues for a long time. It is found in Yao, Kinga, Konde, Sango, Ganda, Kongo, Benga, Duala and elsewhere-sometimes in one of the forms $k a, n k a, n g a$, or with other modifications. It is used in more than one tense, and is even sometimes added to the Imperative, to make it more emphatic. This, and the fact that Kongo suffixes it also (in the form $n g e$ ) to the Perfect, might seem to negative its being counted as a mood; but, though we do not as a rule find moods superadded on one another, after the fashion of the Compound Derived Forms, there does not seem to be any reason why we should say it is impossible in these two cases. Or, again, it is conceivable that the imperative $-g a$, at least (which is not exactly 
continuative, though it might, on occasion, be so) may not be the same suffix. The following are a few examples of this form, which does not exist in Zulu (unless-which I doubt -we could count the Negative Past), Nyanja, Herero or Swahili.

YAO: na-tawa-ga 'I was binding,' or 'I kept on binding' (tawa 'bind')

$n i-n d a w a-g a$ ' if I am binding.'

ni-nga-tawa-ga 'I should be binding' (if something else had happened).

GANDA: a-fumba-nga omupungi bulijo 'she cooks rice every day.' $a$-na-soma-nga ' he will read continually.' omu-ntu eya-kola-nga ebi-bya 'the man who-used-to-make bowls.'

KONGO: o unu n-tunga-nga e-nzo ame 'to day I am building my house.'

o unu n-tungidi-nge enzo ame 'to-day I-have-been-building my house.'

e lumbu kina ya-tunga-nga enzo ame 'the other day I-was-building my house.'

KINGA: ndi-tova-ga 'I keep on striking' (tova, 'strike.')

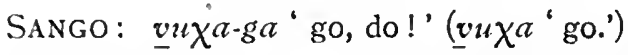

The Relative Mood may take, as in Zulu, an

${ }^{1} O$ underlined, in Meinhof's notation (used in the book whence this example is quoted), is the 'broad o,' like the sound of ou in 'ought.' 
invariable suffix for all persons and classes, or as in Swahili, a suffix varying with the class to which the subject belongs (a-penda-ye, u-anguka-o, li-vundika-lo, etc.). This applies to the first and simplest form of the Relative given in Chapter VI, which is (in Sivahili at least) ${ }^{1}$ without distinction of tense. But the other Swahili forms, if analysed, are found to follow the same principle: the first part of the word is an auxiliary ( $l i$ or $n a$ ) in the Relative Mood, followed by the Infinitive without ku: a-li-ye-penda, a-na-ye-penda, ki-li-cho-anguka, vi-li-vyo-vundika, etc., etc. As the Relative Pronouns were pretty fully discussed in Chapter VI., we need say no more about them here.

Before passing on to the Tenses, it may be well to say a few words about Participles.

We have, on previous occasions, referred to the quasi-participial forms existing in the Bantu languages: the very common one formed by prefixing the Possessive Particle to the Infinitive, and that with a locative termi-

${ }^{1} Z$ ulu also suffixes $-y$ o to the Perfect. The other verbal relative formations (those without $-y o$ ) are different in principle from the Swahili ones given in the text; but they need not be discussed here. 
nation, found only (so far as I am aware) in the various dialects of Chwana (including Sutu). But $\mathrm{Zulu}$ has something like a real Participle, which 'may be formed for all the Tenses' (Colenso, First Steps $\$ 232$ ), but, unlike our participles is preceded by a pronoun and found in all three persons, singular and plural. Except in the third person (where the pronouns are $e$ for the singular and be for the plural, instead of $u$ and $b a$ ), and when agreeing with a noun of the sixth class (when the pronoun $a$ is changed to $e$ ) the forms are identical with those of the finite tenses; and a participle is often only to be recognised by the difficulty of construing it as a finite verb in the context.

I shall not attempt anything like a complete enumeration of tenses. The simple ones are few and well marked, but there are endless compound tenses, built up with auxiliaries and other particles, which are not always easy to classify. The principle of their structure once recognized, however, they need present no great difficulty here.

The tense-particles not immediately recognizable as verbs may have existed as such in former times-indeed, it is practically certain that this was the case with most of them. 
The simplest form of the Indicative Present (in some languages, as in Swahili, it exists only in theory) is formed by prefixing the Inseparable Pronoun directly to the VerbStem.

\begin{tabular}{|c|c|c|c|c|}
\hline & ' See ' & Zult & Nyanjas & Ganda \\
\hline Si. & 1st pers. & ngi-bona & ndi-ona & $\begin{array}{c}\text { ndabal (for } \\
\text { n-laba) }\end{array}$ \\
\hline & 2:1], & u-bona & u-ona & o-laba \\
\hline & $31 \mathrm{~d}$ & u-bona & a-סิ & a-laba \\
\hline PI. & $1 s t \quad "$ & si-bousa & ti-ona & tu-laba \\
\hline & 2nd , & ni-bona & mu ona & mu-laba \\
\hline & $3 \mathrm{rd}$ & ba-bona & a-ona & ba-jaba \\
\hline
\end{tabular}

This tense seems, as Junod says of it in Ronga, not to convey any precise indication of time. The more usual Present, in Zulu, is one compounded with the verb $y a$ 'go': ngi-ya-bona 'I am seeing' or, more literally 'I go seeing.'

In some languages, a tense with similar meaning is formed by means of the prefix $-a-$, of which the exact force is uncertain. It usually contracts with the pronouns. The Swahili tense given below is that used at Mombasa; the corresponding one at Zanzibar is ni-na-ona, $u-n a$-ona', etc.

$N a$ is one form of the verb 'to be'; and in 


\begin{tabular}{|c|c|c|c|}
\hline Ronga & Chwana & Swahili & Zigula \\
\hline $\begin{array}{r}\text { nda-bona (ndi- } \\
\text { a-bona) }\end{array}$ & ke-a-vona & na-ona (ni-a) & $n-a \cdot o n a$ \\
\hline wa-bona (u-a) & wa-vona & wa-ona & w-a-ona \\
\hline a-bona $(a-a)$, & wa-vona & a-ona & a-ona \\
\hline ha-bona (hi-a) & re-a-vona & $\begin{array}{l}\text { twa-ona } \\
\text { (t } t ?-a)\end{array}$ & ch-a-ona \\
\hline ma-bona (mi-a) & Iwa-vona & mwa-ona & mw-a-ona \\
\hline ba-bona (ba-a) & va+a-vona & wa-ona & w-a-ona \\
\hline
\end{tabular}

some languages, instead of the above tense, we have one compounded with this auxiliary in one shape or another. Thus, in Nyamwezi, ndi-wona (for n-li-wona), u-li-wona, etc.; in Nyanja ndi-ri-ku-ona, literally 'I am to see (='I am seeing'), and so on.

Some languages ( $Z u l u$, Konde, Ganda and others) have a Past Tense identical in form with the Present in -a-. Others use na to form a Past Tense, e.g., Nyanja ndi-na-ona, etc.

The Future is very often formed with the auxiliaries meañing 'come' or 'go'-Nyanja ndi-dza-ona, Chwana ke-tla-vona, Zulu ngi-ya$k u$-bona (or ngi-za-ku-bona). S Swahili has ni-taona: ta at present means nothing by itself, but it may be shortened from taka ("wish" or 'want.') In Ganda, the Near Future is formed 
with the prefix $n a$, and the Far Future with the prefix $r i$. Both of them mean 'to be.'

The most peculiar Future is that in the Likoma dialect of Nyanja, which is identical with the Negative Past in other dialects-e.g., si-ni-fe 'I shall die.' The explanation seems to be that what one has not yet done is still in the futare, and, therefore, to say one has not yet died is the same as saying that one will die.

In Swahili, as already stated, there is a Perfect Tense differing from the form in -ile discussed under the Moods. It is formed with the particle -me- (which may be connected with mala 'finish ')-ni-me-ona 'I have seen.' A similar tense is formed in Pokomo with -ma-.

Giryama has two Perfects-the Perfect Mood, which is the older form, ending in -ere or -ire (ni-onere 'I have seen,' ni-fik-ire 'I have arrived '-from $f i k a$ ) and the tense, formed with $d z a$ : hu-dza-m'-ona 'we have seen him.'

Compound Tenses are very numerous in Zulu, chiefly built up on the verb 'to be' $(u k u-b a)$ and the particle nga, which mainly implies potentiality (e.g., nga-ngi-be-ngi-bona, 'I would have been seeing,' etc.), and Chwana has a still greater variety, introducing 
several other verbs. But these, and the particles which play so great a part in Nyanja (ma, ta, ka, ngo, etc.), must be left to the students of the respective languages. It only remains to say a few words more about auxiliaries 'and about monosyllabic verbs. (The latter are not always auxiliaries, and there are some auxiliaries of more than one syllable).

The auxiliaries which we have mentioned so far are employed as tense-prefixes, and inserted between the subject pronoun and the verb. But there are others which are grammatically separate from it, but necessary to its meaning. Some of these are defective, only used in one or two tenses and never apart from a principal verb; others are independent verbs, which have a peculiar use as auxiliaries. Thus in Zulu ponsa 'throw' means, as an auxiliary 'to be on the point of doing'-ngiponse $u k u w a$ ' I was on the point of falling.' In Ganda yagala 'like, love, want' is similarly used to express that something is about to take place: enyumba eyagala okugwa 'the house is likely to fall.' $V a$ 'go out' conveys that something has just been done, or that an act results from something mentioned 
'before; in the latter case it is equivalent to 'therefore.'

Tu-va ku-kola 'we have just been working.'

Sometimes the auxiliary is followed by an infinitive, as in the last examples, and as we should expect in European languages. But it is just as often followed by a finite verb, and this construction gives rise to some of the most curious and difficult idioms-e.g., in Zulu: u-buye u-hlangane nabo, ' do thou after that join with them.' Literally 'do thou return (buya) that thou mayest join with them.' In Ganda, mala 'finish' is used in various unexpected ways. It may denote, with a negative, 'non-completed, though intended action.' Ya-mala na-ta-kola 'as a matter of fact, he did not do the work.' Or we may find it in such sentences as mala ga-lya ' eat it just as it is'-whether you like it or not; (perhaps the idea is 'eat it and have done with it !')-mala ga-genda 'never mind, go!'

In Ronga, dyuleka neuter-passive of dyula 'seek' is employed as an auxiliary to express 'it is necessary,' and chuka 'start' (with surprise) to convey the notion of 'perhaps' 'by any chance,' or to emphasize a negative imperative. 
Ku-dyuleka ndi-famba 'I have to go.' U-ta-mu-khoma loko u-chuka $u$-mu-bonile 'You will seize him if by any chance you have seen him.' U-nga-chuke-u-hlaya 'Don't go to say. . . ,' = 'Don't think of saying. . . ?'

The use of the verb $t i$, properly meaning 'say' is very important. It will be mentioned again in the next chapter, as it occurs so frequently in conjunction with the 'descriptive adverbs' or 'sound-pictures' so common in the Bantu languages. But besides this use, it enters into a variety of characteristic idioms.

It is found in most languages (except perhaps those of the Congo), though now disused in Swahili. In Chwana, it has the form $r e^{1}$, in Herero $t y-a(t i+a)$ otherwise it scarcely varies. Its infinitive is often used as a conjunction, equivalent to 'that' ( $c f$. our 'that is to say,') as in Nyanja:

Antua-ganiza kuti ndi mfiti

'People think that (they) are wizards (who)

zi-sanduka makoswe

- 'change-themselves (into) rats.'

Sentences like this, where it is equivalent to 'saying,' show the connection quite clearly:

1 Where $e$ in Chwana corresponds to an $i$ in Zulu, it is the narrow $\boldsymbol{e}$-intermediate between French $\dot{e}$ and $i$. 
Tambala a-lira kuti "kukuluku!'
"The cock crows saying "kukuluku!",

Other tenses, simple and compound, are used more or less as conjunctions, e.g., Nyanja nga-ti 'if' Ila a-no-ku-ti 'whereas,' Zulu ku-nga-te, ku-nga-ti-ti. Ila has a-tela 'lest,' antela ' perhaps,' which may be applied forms of it. A very common idiom is to use it as an auxiliary at the beginning of a sentence, with some such meaning as 'when,' 'as soon as,' or ' it came to pass that. . . .'

Irregular Verbs. Bantu verbs can be irregular in two ways, neither of which need cause much difficulty. They may be of one syllable only, or they may end in some other sound than $a$. $T i$ and a few others are irregular in both ways at once.

Genuine Bantu verbs of more than one syllable which do not end in $-a$ are so rare that we need do no more than mention them.

The monosyllables are more important, but of these a certain number must be eliminated, which are not original monosyllables, but have only become so by attrition. The case of the Zulu ma or ema 'stand' (Swahili sim-ama) was referred to in the last chapter, and there 
is a whole number of verbs in Zulu, found either with or without an initial $e$. Such are (e)mba 'dig " (e)ba 'steal,'. (e)pa 'thin out'2 (as seedlings) (e)zwa 'hear.'

Some have more than one syllable, and these (like (e)muka 'go away' (e)tula ' talke off ') look like Derived Forms.

It seems clear that these (or most of them, for some might have been formed later, by 'false analogy') originally began with a consonant which was dropped, and then the initial vowel, when it' could not easily be contracted with the pronoun, was elided also. ${ }^{\mathbf{3}}$ It is interesting to see that Nyanja, while keeping the initial vowel in ima 'stand' has incorporated the infinitive particle with mba 'dig,' which is now ku-kumba. Perhaps this is to avoid confusion with imba 'sing,' as it has not been done in the case of $k u-b a$ 'steal." Nyanja has no objection to the contact

1 Probably the Swahili j-embe 'a hoe' comes from the same root.

${ }^{2}$ To be distinguished from $p a$ 'give,' which seems to be an original monosyllable.

' "Vowel verbs'" are usually reckoned among 'irregular verbs,' on account of this contraction, which is not always applied in the same way.

${ }^{4}$ Cf. Swahili $i b a$ (Mombasa) and jepa (Lamu). 
between two vowels, and, as a rule, sounds them both distinctly, not often contracting them into an intermediate sound, as is done in Zulu; and perhaps this is why it retains the original $i$ in ima, which in Zulu is altered to $e$.

When we come to primitive monosyllables -or what we may fairly presume to be suchwe find, apart from tense-particles and recognised auxiliaries, several verbs expressing simple and universal notions (such as 'eat,' 'drink,'، die,' etc.), in so many Bantu languages that they are likely enough to have formed part of the original common stock. The following table exhibits some, but by no means all, of these.

The great interest of these primitive verbs lies in the fact that it may be possible to trace them in the Sudan languages, as indeed, I think, has been done with one or two. But such questions lie outside the scope of this book. 


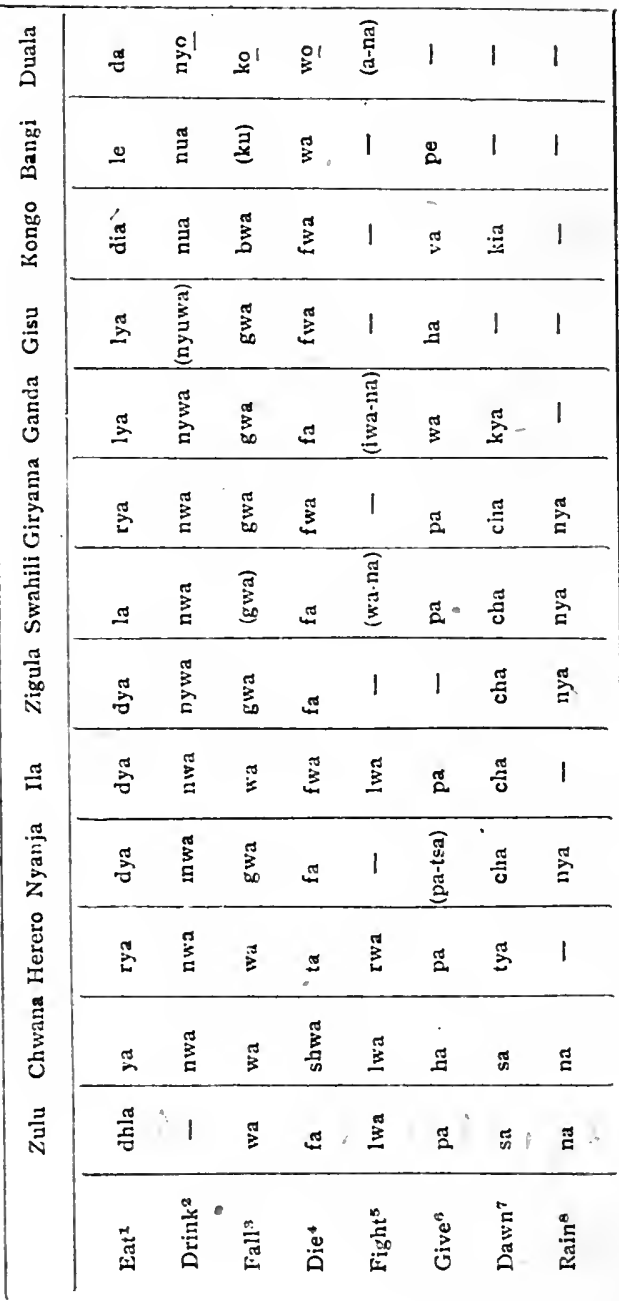


1 The Kongo form of this word is spelt as given here in Bentley's Dictionary, but I have no doubt that it is pronounced dya, as it is in Nyanja, where many of the printed books have dia. The same applies to the spelling nua (for nu'a) and kia for ky'a in kongo and Bangi. Bangi is spoken in the district near the junction of the Kasai with the Congo.

2 The old root has been lost in Zulu, probably for hloripa reasons ${ }^{*}$; the word now used is puza. Zanzihar Swahili has njua, like Ganda, etc. Note the tendency of Duala verbs to end in-o.

3 Gwa is found in old Swahili : the modern word is anguka. The usual word in Bangi is kita, but $k \bar{u}$ is given as an 'indeclirable adjective' suggestive of falling. It may be the root of Duala ko.

4 A dissyllabic form of this word is found in Yao (uuia) and Kikuyu (kun). The former must not be confused with Swahili ua 'kill,' which is the same word as $Z$ ulu and Kongo bula 'strike.'

- Nyanja Zigula and Swahili have lost this, and use words meaning 'strike each other' (mcnyuna, towana, pigand). Giryama and Ganda use the reciprocal lw-ana, and Kongo has nw-ana, evidently another form of the same ro.

- $\mathrm{Ha}$ in Chwana is used in the special sense of "giving fond." The word used in Kongo is vana, reciprocal of va, which could correspond etymologically with $p a$.

7 Kia and kya (which should probably be spelt alike) may be the same sound as that indicated by cha and tya. See Noël-Armfield, General Phonetics, p. 9r.

8 This is only found in some dialects of Nyanja : it is not used at Blantyre, probably to avoid confusion with a similar word, tabcoed as vulgar.

* This word in Zulu expresses what anthropologists call 'taboo.' People aro said to hlonipa a word, if they avoid it (I) as umproper or vulgar, (2) because it is the name-or part of the name-of a decuased chief, or (in the case of women) the head of the family. Thus, the wives and daughters of man naned u-Langa would bave to find soine other word when speaking of the sub (itanga). 


\section{CHAPTER XII}

\section{Adverbs and Particles}

I have preferred the term 'Particles' for the invariable parts of speech-except adverbs, which are somewhat more clearly definedbecause the words which act as prepositions and conjunctions may be-and often areused in other ways, and, in fact, they usually prove, on examination, to be different parts of speech altogether.

$P a, k u, m u$, which, as sometimes employed, are genuine prepositions, and treated as such in all the older grammars, are really pronouns, as we saw in an earlier chapter. In fact, Meinhof says there are no such things as prepositions in Bantu. The Zulu nga 'with' (in an instrumental sense, as watshaywa ngoncibitsholo 'he was hit with an arrow') at one time seemed to me a possible exception, but its use after the passive ${ }^{1}$ shows that it is really identical with the copula, as explained

${ }^{1}$ See above, pp. 114, 115. 
above. $N a$ 'with,' in the sense of 'along with,' is really the conjunction 'and,' perhaps the only undoubted conjunction.

We have already remarked that infinitives and even finite tenses of verbs may be used as conjunctions: e.g. (ui)kuti in Zulu and Nyanja ; $\chi^{0-h i t l h a-l i t e r a l l y ~ ' t o ~ a r r i v e ' ~(a t) ~}$ for 'until' in Chwana; Swahili kw-amba 'that' literally 'to say' (kutti not being used), Lala k-ımfwa 'and so' literally 'to hear.' Nyanja -ngakale 'although,'--used with a pronoun, a-nga-kale, chi-nga-kale, i-nga-kale, etc., from kala ' sit,' 'stay, be in a place,' and so, literally, ' it may be (that. . . .')

There is also an interesting use of nouns as conjunctions, as, Nyanja, chi-fukwa 'because,' which really means 'fault,' 'blame,' etc.; Duala onyola na, contracted from o nyolo a na, 'through the body of ' (" the fact that . . .' also meaning 'because.') In Swina pa musoro $p a$ 'on the head of ' and pa musana pa 'on the back of,' are used prepositionally for ' because of,' ' on account of.'

The ease with which these locutions change places is illustrated by the fact that some adverbs are.turned into prepositions by the addition of a particle. 
Thus pa-nsi (it is found in a great many languages, even where, as in Zulu, $p a$ by itself has gone out of use) means 'on the ground,' 'down,' but pansi ya is 'under' 'below. Tini (chini)'which takes the place of pansi in Swahili is treated in the same way.

It would serve no useful purpose to attempt enumerating all the possible words or combinations of words which might serve as prepositions and conjunctions: the above is a sufficient indication what sort of thing to look out for in any particular language.

With regard to Adverbs we have several possibilities to consider. First, there are the regular adverbs, formed from adjectives with the prefix $k a$-; to which we have already adverted in the chapter on the Numerals. These are found in Zulu, Nyanja (only with numerals), Ila, Nyamwezi (with numerals), Zigula.' They do not occur in Swahili, Ganda, Gisu or Kongo. Kale or kade 'long ago' found in almost every language, even those which have no other adverbs in $k a$, seems to be the adverbial of the root for 'long.'

${ }^{1}$ Besides the numeral adverbs this language has $k a-n g i$ 'of ten' (from -(e) $n g i$ ' many') and perhaps other words of the same kind. 
Then we have nouns preceded by a possessive particle, as in Swahili kufanya kwa uzuri ' to do beautifully.' Here the possessive particle agrees with kufanya, but it would also be used with a finite verb-I suppose still with reference to the infinitive; or perhaps because its real relations had been forgotten, so that it could be placed indifferently after any form of the verb.

Another way is to use an adjective with the prefix of the seventh or the eightl class-as Here R $_{1}^{\circ}$ tyi-nene 'very,' from -nene 'great'; Swahili vi-baya 'badly'; Duala bu-bi 'badly' which last might also be classed as a noun. Other nouns are used, by themselves, or with a particle prefixed, as Zulu na-munhla 'today,' Nyanja mawa 'to-morrow.'

Then we have the locative Adverbs-not merely those already mentioned, which are preceded or followed by a locative particle, as pezulu, panisi (some languages have also kunsi and munsi), tini, etc., but such as pano, muno, kuno, or hapa, pale, or mmmona, kukona, (Ila) and momwemo, pomwepo (Nyanja), with other variations, too many to be enumerated. These, however, are rather a kind of demonstrative pronoun. And it should nót be for- 
gotten that the Derived Forms of Verbs, in many cases, render adverbs unnecessary.

There are some invariable Adverbs, which do not seem to be derived from other parts of speech, as lero, leo, lelo 'to-day,' Nyanja tsopano (Yáo sambano) 'now,' kati 'in the middle' (sometimes with added prefixes), Yao soni 'again,' Nyanja -nso (suffixed to almost any other part of speech), 'also,' 'again'and others, which can be found by consulting the lists in various grammars. It may be that the etymologies of these are only as yet untraced, and they may be assigned to their proper position in time; but some of them possibly belong to the class described in the next paragraph, though they have settled down to a more assured position in the language than those we are about to mention.

These are what are sometimes called 'Sound-pictures'; other terms for them are 'onomatopoetic vocables' (Stapleton), 'descriptive adjectives' (Junod), 'onomatopoetic substantives' (Torrend), 'indeclinable adjectives ' (Whitehead), 'interjectional roots,' etc.

The importance of these has been more and more recognized of late years. They occupy a very prominent place in the Sudanic 
languages, and Westermann has devoted a good deal of attention to them in his Ewe Grammar. ${ }^{1}$ There is also a very interesting passage dealing with this feature of primitive language in Lévy-Bruhl's Les Fonctions Mentales dan's les Sociétés Inférienres. ${ }^{3}$ Dr. Hetherwick (Handbook of the Yao Language, p. 76) says :

' Certain words onomatopoetic in their character may be classed as adverbs. They represent the action or the idea referred to and may be used either with or without the descriptive verb; thus chum signifies the sound of falling into water, like our English "splash." Wa-gwile m'mesi, chum! "He fell into the water, splash!" $M y u$, with the fingers drawn across the lips, or accompanied by a peculiar motion of the hands, one over the other, signifies completion; Ngondo jaiche nekumala wandu myu! "The war came, and the population was completely destroyed." An idiomatic use of the verb kuti "to say," is used in conjunction-with such words. 'To the form -ati is prefixed the characteristic pronoun of the

${ }^{2}$ See The Language-Families of Africa, pp. 43, 66.

${ }^{2}$ Paris, 1910. 
object described, and joined with the onomatopoetic has the force and application of an adjective. Ngo jati pyu"red cloth" (literally the cloth which says pyu or red), Nale, ngope jakwe jati bi "Look, his face is black" (says bi-i.e., he is angry).'

Here we see one of the expressions noted accompanied by a gesture. In fact we may suppose them to have arisen out of the gestures which preceded speech-to be, as it were, gestures translated into, sound. To quote M. Lévy-Bruhl (p. I83) :

"It is not even necessary that these "auxiliaries" of description should be exclusively gestures or movements.' (The previous paragraph deals with the use of gesture, not in the absence of speech, but to help it out and make it more expressive.) 'The desire to describe may also try to find satisfaction by means of . . . a kind of pictures or reproductions of what one wants to express, obtained by means of the voice. Among the Ewe $\checkmark$ tribes, says M. Westermann, the language is extraordinarily rich in the means of directly reproducing an-impression by sound. This richness arises from an irresistible tendency to imitate all that is heard, seen, or generally 
perceived, and to imitate it by means of one or more sounds. . . . What is imitated, in the first instance, is apt to be movement; but we also have these imitations or vocal reproductions-these "vocal images," for sounds, odours, tastes, tactile impressions. There are some which accompany the expression of colours, abundance, degree, pain, enjoyment, etc. It is beyond doubt that many words in the real sense (nouns, verbs, adjectives) have originated in these vocal images. They are not, properly speaking, onomatopœias, but rather descriptive vocal gestures.'

Stapleton, therefore, defined them somewhat too narrowly in calling them imitations of sounds ${ }^{2}$ - in fact this is contradicted by the very examples he gives a few lines further back :

NGALA: mai mabandakani lilili 'the water has quieted down peacefully.'

butu boindi pi 'the night darkens darkly, or silently on all the heavens at once, etc.'

LoLo: "ntso kwi kwi kwi 'go quickly.'

This writer goes on to say: "These forms.

${ }^{1}$ Comparative Handbook of Congo Languages, p.130. 
are used very largely as interjections, and some are evidently amongst the most primitive elements of these languages. Some appear to be the roots from which nouns, etc., are formed,--sanja abameli bu o mai (Ngala) "the moon shines on the water brightly" (cf. bo-bu, "light"). Ndako foi foi (Kele) "the house is lit up brightly.",

It is a pity that the author did not illustrate this point a little more fully, as he does not tell us what noun is formed from foi foi: by analogy we should expect bo-foi. In the cognate Bangi language (which does not seem to possess the $f$ sound) poipoi $i^{1}$ expresses the brightness of a shining surface, such as polished wood or metal. It makes a verb poibana. A glance through the Dictionary shows numerous other examples: pioka' beat with a stick or whip,' from pio, the sound made by a switch; tsakana 'be dispersed' from tsa; zonga 'surround,' from zo. These are given in the Dictionary as derived from

${ }^{1}$ As printed in Whitehead's dictionary, this word has diacritic marks indicating that $o$ is the narrow $o$ with the 'raised' tone, and $i$ has the 'lowered' tone. This is important, as there are other words quite similar except for the tones. 
verbs, but it is not fair to mention this without quoting the passage from the Grammar (p. I 8) which relates to them:

' For the most part these are derived from verbs, or the verbs from them. For practical purposes it is here assumed' (but why ?) 'that they are derived from verbs. Those who maintain that the verbs are derived from them have the best of the argument, for these indeclinable adjectives are the most elementary parts of the language, and many may be traced to an onomatopoetic origin. These words are the most graphic in the language, they are the "colouring" words, the stories and common speech of the people are full of them, and often they have such force that sentence after sentence can be constructed by means of them, without the use of a single verb, the verb being indicated by these indeclinable adjectives. They take the place of adjectives to a very large extent, and in the dictionary their meaning will often be found indicated by an English adverb, yet in Bobangi they are adjectives.'

These languages of the Middle Congo and its northern affluents tend to shade off towards those of the Sudanic family. This would seem 
to account-I do not say for the abundance of these roots, for Ronga, Nyanja, Zulu, Yao, etc., are very rich in them, ${ }^{1}$ but for the frequency of nouns and verbs formed from them, and the ease with which they can be recognised.

In Zulu (which in many ways seems to be one of the younger Bantu languages), a number of verbs are plainly derived from these particles, though they are more usually introduced by ukuti. See $\S 298$ (p. 128) of Colenso's First Steps in Zulu-Kafir-a most instructive passage, though the author did not quite appreciate the character of these 'vocal images.' The remark (p. I29) that 'others are probably imitations of the sounds referred to' shows, however, that he was on the right track.

Some of the examples given to illustrate this derivation of verbs incidentally show that some verbs may seem to be Derived Forms which are not so in reality; thus hlepula

${ }^{1}$ And probably other languages, where no special attention has been called to them. In Velten's Nyamwezi grammar, e.g. (Velten's books are practically useful, but he is scarcely a safe guide in philology) we find $b u$ 'abundantly,' and po or pe 'also'-perhaps others. It is rather surprising to find no indication of such 'adverbs' in Gisu-but the work done on that language is admittedly very tentative as yet. 
'break off' looks like the reversive of a (non. existent) hlepa, whereas it comes straight, so far as one can see, from ukuti hlepu. So, too, boboza 'pierce,' which looks like a causative, is from ukuti bobo 'to have a hole in it'; and the same root gives us the nouns im-bobo and isi-bobo. Perhaps some of us have not left our childhood too far behind to feel in a dim way that bobo somehow suggests a hole (and it does so quite as much as the same word, in French nurseries, expresses 'something that hurts')-but even these will not be able to explain why it is so.

Some of the Zulu examples are so delightful for their own sake, that I make no apology for quoting them.

Ngaziti shwangalazi lezo' zinto zonke.

'I said shwangalazi to all those things-swept them away with a swish.'

"He says $x a f_{u x a f u}$ "- eats like a dog.

'It (the sky) said namanama (rained very gently) this morning."

'He said (or went) gigigi down the slope'-i.e., ran down-' and crossed over to the other side.' (Evidently getting impetus for the upward effort).

'The sun said tetete'-was low down in the sky.

${ }^{1} x$ indicates the lateral click. 
Mr. E. W. Smith (Grammar of the Ila Language, p. 66) mentions 'certain particles suffixed to adjectives which express superlative or absolute idea: They do not seem to be used with all verbs.

'NE. Menzhia la tontola-né, the water is very, very cold.'

'BU. Muntu u la tuba-bu, the person is very, or altogether white.

'Nswa. Menzhi a zunna-nswa', the water is altogether dried up.'

The acute accent (which is not explained in the text) may indicate a raising of the tone, or (more probably) that it is accented independently of the verb, and does not, as enclitics in Bantu usually do, draw the accent forward. In that case, it would surely have been better not to connect the two by a hyphen.

It would seem as if Ila had limited the scope of the Vocal Image to a mere expression of intensity. Or perhaps the author has to some extent mistaken its nature; for it seems clear-even without an inside knowledge of the language - that they do not mean 'very' or anything of the sort; but $n e$ is 'cold, 
bu 'white'; nswa 'dry,' piu 'red' (as in Yao), and so on. Mr. Smith goes on to say: - These particles are also used interjectionally, the verbs being omitted, e.g., Nda ka ya ku menzhi. Nswa! I went to the water. Quite dry!' This could not be explained on the supposition that nswa simply means 'very.' We should also like to refer back to the parallel columns of verbs and adjectives given by Mr. Smith on p. 6I-already adverted to in Chapter VIII. The adjectives there given look to me like developments (-biabe and -fwafwi are imperfect reduplications; all the others ending in $o$ or $u)^{1}$ from roots of this kind, and the verbs as if they had been formed directly from the roots. Of the 'superlative particles' I have only been able to trace one which has given rise to a verb: -pi, whence pia ' to be hot.' (This, as pya, psya, swa, etc., is found in most Bantu languages with the same, or some closely connected meaning. Meinhof thinks the ProtoBantu stem was PIA.) But I have no doubt that careful search would be able to discover a great many.

We shall recur to this point in the next chapter. 
In Swahili these particles are not conspicuous, yet I do not know how otherwise to account for tu 'only,' pia' also,' ' altogether,' 'entirely,' (watu wote pia), hima 'quickly.' A few are heard as expletives ("When the doctor pulled out my tooth, I felt-bu!' --lo-0-o! expressive of surprise, chub! of impatience, $\mathcal{f}$ etc.), but they are not used otherwise and do not seem to have given rise to any verbs or nouns. Perhaps the influence of Arabic, which has supplied some useful adverbs, prepositions and conjunctions, has favoured the disuse of the Vocal Image.

The late Revs. D. C. Scott and W. A. Scott, of Blantyre, collected, in a valuable little pamphlet-The Mang'onja Unit of Thought-some interesting specimens of what they have somewhat enigmatically called 'Buds or Thorns?' I take this title to imply a doubt whether such particles were really roots whencè speech was developed, or outgrowths of developed speech-atrophied 'fragments of verbs.' A few of the sentences may be here given in illustration.

'The lion did not spring-he just came, kuputu! kuputu! kuputu!-like a horse.'

'The eagle has swept past-kwāa.' 
'A man with a lame leg goes timpya, timpya, timpya.'

'The soldiers stood $n d a, n d a, n d a$ ' (in line).

'The stars are shining $n g^{\prime}\left(a n i, n g^{\prime}\left(r n i, n g^{\prime}\right.\right.$ ' $u n i$.

'He got into the mud and fell taproi! - he got out and fell into the water, pabva!'

'The guinea-fowl has run away 11 jo! njo! njo!' Here the verb used is iljonjola, clearly formed from the particle.

Further quotations are unnecessary, and would take up too much space, but I would direct the reader's attention to $M$. Junod's paragraphs $(\$ \$ 378,379)$ on Adverbes descriptifs (pp. I96, I97 of his Grammaire Ronga.) ${ }^{1}$ He strongly insists on the importance of these adverbs' and on the great number of verbs derived from them.

One point to notice, in conclusion, is that Vocal Images frequently contain sounds not otherwise found in the language, just as we use clicks not found in any articulate English words to express surprise, regret or (to a horse) encouragement. Chum (Yao and Nyanja) and chub (Swahili) have unwonted final consonants.

${ }^{1}$ His Elementary Grammar of the Thonga-Shangan Language (in English) is more generally accessible. The section on 'Descriptive Adverbs ' will be found on pp. 84-86. 
In Shambala, quite a number of these words begin with $p$-a sound which in that language is (except when preceded by $m i$ ) changed to $h$. This matter would evidently repay further study. 


\section{CHAPTER XIII}

\section{Word BuIlding}

$\mathrm{Wr}$ saw, at the outset, that inflexion by prefixes was a great and striking characteristic of the Bantu speech-family. We have seen, also, that suffixes play by no means a negligible part, as they distinguish both the Derived Forms and the Moods of Verbs. Further, some languages have the suffixed Locative; and we just remarked in passing that a good many adjectives are formed by suffixes. What more there is to say about these, and the other cases not already noticed, can best find a place here.

Nouns may end in any one of the five vowels. $^{1}$ Any one of these may be a suffix.

'I am-using this expression for convenience sake. They may, for aught I know, end in any of the fifty or so vowel-sounds recognised by phoneticians which exist in Bantu. But the old original five will serve the purpose of this exposition. 
but is not necessarily so; e.g., in mbwa 'dog,' nyati 'buffalo," the final vowel seems to belong to the stem.

Taking, first, nouns and adjectives formed from verbs, and going through the classes in order, we find that one of the commonest derivatives of this kind is the noun-agent, where the verb-stem takes the prefix of the first class, and changes its final $-a$ to- $i$ (in Herero to $-e$ ).

ZULU: "um-fiki 'one who arrives,' from fika 'arrive.'

$u m-f i$ 'deceased person,' from $f a$ ' die.'

HERERO: omu-tarere 'overseer,' from tarera, applied form of tara 'look.'

Chwana : mo-dihi 'worker,' from diha 'work'; mo-ruti 'teacher' from ruta 'teach.'

NyanJA : m-weti 'herdsman' from weta; $m$-pambi 'robber' from pamba.

GANDA : omu-zimbi 'builder' from zimba; omusomi ' reader,' from soma.

Other nouns prefix the first-class prefix to the unchanged verb-stem, as Swahili m-chunga (m-tunga) 'herdsman,' from chunga (tunga) to 'herd' ; m-gema' one who taps palm trees' (for

1 These words are Swahili, but they are found (sometimes in the same form) in many other languages. 
wine), from gema. But these are really a species of participle, and their verbal character is still so far felt in Swahili that they are usually (not always) followed by an object: mchunga mbuzi 'a goat-herd' ('one who herds goats') mfanya biashara 'one who makes trade,' i.e., 'a merchant.' But both in Swahili and in other languages we also find nouns of this kind without an object, which shows that there is a tendency to lose sight of their verbal character. E.g., Yao m-langa 'herdsman,' Nyanja m-londola 'one who traclis game,' from londola 'follow up' and the Swahili mgema already given.

There are some verbal nouns in $-e$ as Swahili $m$-tume ' messenger,' from tuma 'send.' We have already pointed out that adjectives in $-e$ are frequently derived from verbs, and from these we get names of the first class, like m-ime 'husband,' the adjective -ume 'male being derived from an almost obsolete (in this sense) luma 'cohabit.' Ganda has a set of nouns ending in $-e$ with a passive significanceomu-fumite ' wounded man,' from fumita 'stab,' omu-sibe 'prisoner' from siba, 'bind.'

' Not often used except in the sense of 'apostle.' 
Verbal nouns of the first class in $o$ do not seem to be so common, but are found in Yao, as m-jiganyo 'teacher,' from jiganya ' teach.' (Dr. Hetherwick, however, says that 'in actual use, the relative forms juakroiganya,' etc. -i.e., the infinitive preceded by the possessive particles-'are more frequently employed'). And, in general, it is so easy to make these forms for oneself that it is well to remember the warnings of experienced writers, and never venture on any not ascertained to be used by the natives themselves. Bishop Colenso says :

'The above words, however,' (i.e., um-fundi ' learner' and um-fundisi ' teacher') 'and most of the above kind which appear in the printed books, are formed by Missionaries, not by the Natives, who employ these derivatives much more sparingly, but may form them at pleasure, so that they cannot be entered in the Dictionaries as standard Zulu 'words.' Examples of the latter kind are $u m$-ondhli ' nourisher' used in an isibongo' of Mpande,

'Isi-bongo (from bonga 'praise ') is a song (generally a string of laudatory epithets) composed by the professional bards or 'praisers ' of the.Zulu chiefs, and handed down by tradition. 
so that it may be regarded as a kind of poetical license, and um-hambi 'traveller,' which occurs in a proverbial expression. Some such words, however, 'belong to the language'; and indeed we might add that even of the others, some (such as um-fundisi) have been found so useful that they are by this time fully naturalized.

And the late Dr. Scott, in the Preface to his Cyclopadic Dictionary of the Mang'anja Language, says :

- Yet no word can be formed at pleasure: it must bow to usage and wont. However clear the formation. . . . is . . . one must serve the language, not create it.'

But I cannot refrain from adding to this a remark I once heard from Professor Meinhof, to the effect that no one knows a language really well, until he can play tricks with it. The application of this, in connection with the previous quotations, must be left to the individual conscience of the linguist.

Adjectives, as we have seen, often end in $-u$ when derived from verbs ( $f u$ and $-v u$ are common terminations in this case) and sometimes when their derivation is not so clear. Meinhof derives -kulu from kula 'grow,' but it 
is open to question whether the derivation is not the other way about. Nouns in $-u$ derived from verbs, do not seem, to be so common,unless they are verbal adjectives used as nouns: e.g; m-tuliun 'a quiet, peaceable sort of person,' from tulia. ${ }^{1}$

There is in Swahili another suffix to personal nouns, which denotes habitual action : -ji, as m-sema-ji 'orator' from sema 'speak'; $m$-pa-ji 'a generous person' (but see note on this word in Madan's Swahili-English Dictionary), from $p a$ 'give.' I do not know if this particular ending is found anywhere else.

Nouns of the third class are sometimes formed from verbs with the ending $o$; Nyanja $m$-pepo and Herero om-bepo 'wind,' from pepa 'blow,' (this verb and its resulting noun are found in most Bantu languages, but the latter is sometimes of a different class); Herero omm-hapo 'shape,' from hapa 'grow'; Nyanja m-kotamirs 'lintel of a door' from kotamira 'stoop'; m-duliro 'mode of cutting' (the

${ }^{1}$ Chatelain says that, in Mbundu (Angola) $-u$ and -o have, in general, a passive 'or inactive' force and $-a$, $-e$ and $-i$ an active one. 
hair); Swahili m-teremo 'cheerfulness,' from terema ' rejoice'; m-pako 'plaster' from paka 'smear,' m-chezo (m-tezo) 'dance,' ' game,' from cheza (teza), mw-endo 'journey' from cnda' walk' (the same word is found in Nyanja, meaning ' $\operatorname{leg}$ '). Duala has in this class a peculiar suffix -ko: mu-anga-ko' roast meat' from anga 'roast,' mpoko ' gimlet,' from poa 'bore.'

Verbal Nouns of Class 5 ending in $o$ are common. They often mean the place where anything is done, as Ganda e-fumbiro 'a place to cook in' from fumba; Bangi ebombelo ' hiding place,' from bomba, 'hide.' In Kongo nouns of this kind, end in u: esumbilu 'place for buying' from sumba 'buy.' Sometimes these are only used in the plural, as Nyanja matero 'limits,' from tera, applied form of $t a$ 'finish'; malowero 'place where the sun sets,' from lowera, lowa. 'go in.'

Another kind of noun in $o$ belonging to this class indicates the result of an action, or sometimes the way in which it is done. Swahili chezo (tezo) 'game,' etc. (used as well as mchezo 3 , but more frequent in the plural, ma-chezo); pendo 'love,' 'liking' from penda. Also mapenzi, not used in the singular: in fact, many of these nouns only exist in the plural, 
e.g., Nyanja maganizo 'thought' from ganiza 'think'; matyolo 'breaking' from tyola, 'break'; majebo 'notches cut round a stick' from jeba; Swahili ma-choro 'carving,' ma-patano 'agreement' from ku-patana, reciprocal of pata 'obtain': 'get (from) each other ' = ' agree.'

Some have taken these nouns as plurals to the infinitive $(k u)$ class; but they should have been warned by the termination and the slight, but quite distinct, difference in meaning. Ku-chora, e.g., is the act of carving, ma-choro the carving itself (our English participle is ambiguous) ku-teza the act of dancing, matezo the dances (or games) themselves.

I may repeat here that the coining of words for oneself is apt to be a dangerous experiment. Because matezo comes from teza, and taka is 'wish' it is not safe to conclude that ma-tako means 'wants,' 'wishes' : if you do, the result will be embarrassing.

The seventh class has a good many nouns formed from verbs, sometimes without change in the final vowel, sometimes with the endings $e, i$ or $o:$ perhaps the last is the commonest. The chief meaning is ( $I$ ) the instrument with which, or the place or time where, anything is 
done, but we also find (2) a person who does a thing habitually, or excels in it. Some, however; can scarcely be distinguished in meaning from those mentioned in the last paragraph, as (Swahili) kitendo 'action,' kicheko 'a laugh '; Yao chi-nyengo 'deceit' from nyenga. Ganda: eki-gambo 'word,' from gamba 'speak.'

(1) ZULU! isi-bongo from bonga 'praise,' isi-fo 'disease' (that by which one dies).'

ChWANa : se-reko 'a thing to buy with,' from reka 'buy'; se-aparo 'clothing' from apara 'put on.'

YAO: chi-lindo 'watch-hut,' from linda 'guard '; chi-gono, 'sleeping-place . from gona.

SWAHILI : ki-fo 'placc of dying '; ki-funiko 'lid,' from funika 'cover.'

HERERo: otyi-dhera 'sacred place,' from dhera 'avoid for ceremonial reasons'; otyi-kunino 'garden,' from kuna 'plant.'

(2) ZULU': isi-lauli 'habitual jester,' isi-hambi

RONGA : shi-di 'great eater' (from $d a$ ), shi-yaki 'skilled builder,' from $y a k a$ ' build.' 
Nouns in $-e$ are

Nyanja: chi-poitde 'a mess of pounded food, froin ponda 'pound,' chi-kalidwe 'nature of a thing."

Chwana has a large number of verbal nouns belonging to the ninth class, which in form (as this class in Chwana has no prefix) and meaning are much like those of the fifth already mentioned: tiho 'work,' from diha 'do'; kepo 'digging' from epa 'dig'; picho ' assembly' from bitsa 'call.' These usually have a more and a less concrete meaninge.g., picho may mean the act of calling, or the assembly which is called; and there is another $k e p o$, with a difference in the quantity of the final vowel, meaning 'a digging-stick.' The differences in the initial consonant follow the special laws of sound to which Chwana is subject, and we may remark that, in kepo, $k$ is not prefixed to the root, but is a modified restoration of a lost consonant.

1 From kalidwa, passive of kala 'sit,' 'stay,' 'be 'verbs which with us cannot have a passive. Chikalidwe means, I suppose, 'the way in which a thing is,' as regarded by an outsider, and not from its own point of view-this might make its 'being,' in some sense, passive. 
In Herero we find some personal verbal nouns of this class: 0 -ndodhe 'an artful, crafty person' from rora 'test,' 'examine,' o-hodhe 'spy,' from hora 'spy out.' They are not so common elsewhere, but Meinhof derives the Zulu and Chwana word for chief in-kosi,

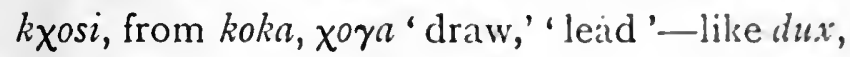
from duco.

We find some nouns of the eleventh and fourteenth classes derived from verbs, though the latter oftener come from nouns and adjectives. Yao, however, has a great many in $u$-, which seem to belong to this class.

GANDA: olu-tindo 'bridge' from tiuda 'bridge over'; olu-talo 'battle' from tala' set in array'; olu-imba' song ' from imba 'sing '; (in other languages this ends in 0 : Swahili $w$-imbo, Ila and others $l w$. imbo); olu-gendo ' journey' from genda 'go' (Nyanja Ml-endo), olu-gero 'a proverb' 'story,' from gera 'tell' (a story, etc.).

KONGo: lu-keselo 'how the cutting-down came about,' from kesela, applied form of kesa, 'cut'; lu-vangilu' the manner of

1 'One who will take nothing on trust' is the sense suggested by the derivation. 
being made'; 'manufacture,' from vanga 'make.' Of Cl. 14, umbangu 'skill,' from vanga; undoki 'witchcraft,' from loka 'bewitch.',

ILA : lufuno ' love,' from funa; lufuko 'dust,' from fuka 'rise' (said of smoke, etc.), lubeta 'judgment,' no doubt from beta, but the verb now in use is the derived form beteka.

SWAHILI : $u$-funguo 'key,' from fungua 'unlock'; $u$-fagio and $u$-peo 'broom,' from fagia, pea 'sweep'; u-pito, 'passage,' from pita 'pass'; $u$-putuzi ' nonsense, 'folly,' from puuza ' talk foolishly.' The last two are probably of $\mathrm{Cl}$. 14, which is not now to be distinguished from 11 in Swahili.

GANDA : Cl. 14, obu-sera 'flour,' from sera, applied form of $s a$ 'grind,' obu-ganza 'favouritism,' from ganza ' be fond of.'

NYANJA: u-limbo 'bird-lime' (obu-limbo in Ganda : probably from limba 'be firm, hard, tough,' also 'stick fast,' etc.), u-bvundo 'decay,' from bvunda 'rot'; u-sokedwe 'manner of sewing,' from soka; $u$ endedwe 'manner of walking,' from enda.

YAO: $\quad$-lindi 'watching,' from linda; uwii

1 Both these words have their initial stem-consonant modified by contact with the prefix, 
'theft,' from iwa'steal' ; and a number indicating the way of doing things, like the last two Nyanja examples: $u-t a w e "$ "plan of builing," "r-panganye " node of making,' from pornganya 'inake,' etc.

Xosa: ubu-xoki 'falsehood' from roka 'iell lies' (also Zulu) ; mbn-lumko 'prudence,'

- from lumka; ubu-sika 'winter' li.c., 'the cutting time'), from sika 'cut,' (also Zulu), etc., elc.

In Kele (Congo) we have, e.g., bo-lio ' door,' from lia 'shut.'

The Locative Class sometimes has a lind of relative form based on a verb-stem in the applied form; as in Nyanja: po-gonera, mogonera ${ }^{2}$ 'a place to sleep at' or 'in.' 'The latter implies that it is an enclosed place, and can therefore be used as an equivalent for 'bedroom'; so, too, mo-dyera 'dining-room' (from dya) and mo-sambira 'bath-room;' from samba 'wash.'

This does not exhaust the ways of forming

'Tawa 'tie' is used to mean 'build' (as mangh, with the same meaning in Nyanja) because in erecting the framework of a nativs hut, a great part of the work consists in tying the poles, or withes, together-and, again, in tying on the thatch.

'From gona 'sleep.' 
nouns; but these are the principal ones to be found in most languages. The passage on the Derivation of Nouns in Bentley's Kongo Gramnar (pp. 528-538) is both interesting and instructive, but it should be remembered that the system is not everywhere so elaborate. See also the section headed ' Formation of Nouns,' in the Rev. A. J. Wookey's Secreana Grammar, pp. Io-I4.

Before leaving the subject of noun-suffixes, it is necessary to notice the diminutive in -ana, which Zulu, Chwana and Ronga have substituted for the diminutive formed by the thirteenth prefix $(k a-)$. It is probably like the suffix $-k a z i$ ( $-k \chi a l i)$, which forms something like a rudimentary feminine gender, due to the influence of the suffix-inflecting 'Hottentot ' language-or languages.

We must say a few words about Denominative Verbs-i.e., verbs derived either from nouns or adjectives. They were mentioned in connection with the Derived Forms, but they are distinct from these, and probably of later formation. They are exceptional, in that they consist of more than two syllables, without going back to a simple verb; but they often look like derived forms; e.g., Swahili 
chafu-ka 'be dirty,' which is not the nejuterpassive-reversive of a verb chafa, but comes from chafu 'dirty.' So, too, toroka, 'run away' from m-toro 'deserter'; pevu-ka 'be grown-up' from -pevu 'full-grown.'

Verbs are also formed in this way by the suffix - $p a$, as nene-pa 'be ' or 'grow stout' (also found in Nyanja, where the adjective -nene is not used). In Herero we have handu-ka 'be impudent,' from the noun e-handu 5 ; raru-ka 'be greedy,' from e-raru 5 'gluttony,' dhandu$p a$ 'become young' from -dhandu; and others with the suffix para, as potu-para 'be blind,' re-para 'be long.'

In Zulu there are a few verbs in $-p a$ and -pala; de-pa 'grow tall,' kulu-pala 'be fat' (or ' big '). In Yao, verbs are often formed from Vocal Images by the suffix: -ma, as sisima ' be cold,' from si or sisisi.

Herero has a somewhat peculiar class of compounds, which we must not leave unnoticed. We saw, quite early in this book, that names of trees have practically everywhere the prefix of the third class. In Herero they are sometimes still further distinguished by suffixing the root -ti: omm-hama-ti, omutendere-ti, onm-ngroa-ti. (I am unable to say 
what these trees are, except that the last of the three is called by Brincker ' wild tamarisk.' Umu-nga, in Zulu, is a common species of mimosa.) Again, we have a number of words compounded with -ndu (the root of omu-ndu, umm-ntu).

$\begin{array}{rll}\text { omu-kadhe-ndu 'woman' } & (-k a d h e=\text { 'female') } \\ \text { omu-rume-ndu 'man' } & (- \text { rume = 'male ') } \\ \text { omu-hepu-ndu 'widow' } & \text { (Meinhof suggests a de- } \\ & \text { rivation from -hepu } \\ \text { 'discontented'!) }\end{array}$

Also :

ont-dume-wa 9 'male dog' (on-rume-ombwa)

omu-kuru-kadhe 1 'old woman' (-kuru= 'old ')

omu-dhoro-twa 1 'Hill Damara,' from -dhoro 'black'

and omu-twa

'Bushman.'

Another curious feature is the insertion of the interrogative particle $k c$ between prefix and stem, as imm-ke-ndu." 'What sort of person?' omm-ke-ti 'What sort of tree?'

Professor Meinhof says that compound nouns are unusual in Bantu ${ }^{2}$ and that perhaps

${ }^{1}$ The initial vowel $i$ is sometimes substituted for 0 in Herero-as in the Demonstrative Pronoun (Cl. 1) ingwi.

${ }^{2}$ Lautlchre, p. 135. 
those in Herero are due to the influence of Nama, in which they are very common. If he is referring to the compounds enumerated above, he is probably right; but he goes on to give a number of compounds consisting of a verb and a noun, which could easily be paralleled elsewhere.

Some of these are :

omu-rara-nganda 1 'neighbour'; that is 'one who sleeps (rara) in the same village' (onganda).

ome-pit' onganda 11 'vagrancy,' from pita 'go out' and onganda.

omu-dhemba-tima 3 'forgetfulness,' literally 'forgetting heart' (dhemba 'forget,' omn-tima 'heart'Nyanja mtima, etc.).

otyi-dhuma-we 7 'noise made by the fall of a meteor'-strange that this should be a common enough occurrence to have a word to itself-from "dhmmat 'roar' and $c$-we 5 'stone' (the verb diumma does not seem to be in use. Zulu has duma ' thunder,' but the word corresponding to the

1 An asterisk prefixed to a root or word means that it is not actually used in that form. 
Herero one should be zuma, which has a different meaning).

It would not be difficult to make a long list of similar compounds.

ZULU: in-dhlula-miti 9 'giraffe,' from dhlula 'pass' and imiti: it is 'higher than the trees.'

in-swela-boya 'a horrible portent' (sometimes 'a corpse')-literally' a thing without hair,' from swela 'lack' and ub-oya 'hair,' 'wool,' etc.

u-mahamba-nendhlwane 'caddis-worm,' etc., from hamba 'go' and indhlwana 'little house.'

kwa'Mamangalahlwa' the Back of Beyond' -literally: "At (the place of) "Mother! I'm lost!", '

Many Zulu proper names are such compounds, sometimes very curious and suggestive.

NYANJA: kokalupsya 'early rains' which 'sweep away' (koka) the 'burnt grass' (lupsya); mpinganjira 3 'obstacle in the way,' from pinga 'lie across,' and njira 'road ' fulagombe 'the bee-eater' (which builds its nest in a bank, like our sand-martin) from fula 'dig out' and gombe 'river bank.' 
IfA : chi-zhinga-lula 'intestinal fat' ("that which surrounds the bowel'). mu-dima-ku-bushu" small-pox' ("what digs (holes) on the face') and numerous others.

In fact the compounding of words (there are numerous examples of two nouns connected by the possessive particle forming an inseparable compound $d^{1}$ ' seems-if not so fully carried out as in Greek-to be by no means alien to the genius of the Bantu languages. It is oftenest found in proper names (as already remarked) and in the names of animals and trees.

1 ZULU: inja-yo-mSutu (' dog of the Mosutu')-a hairy caterpillar. iso-le-nkosikazi ('lady's eye ') - a flower (a kind of jasmine). 


\section{CHAP'TER XIV}

\section{Some Phonetic Laws}

I THINK I have sometimes been asked-by persons whose philological science was somewhat more imperfect than my own-whether Grimm's Law was applicable to the Bantu Languages. Of course, as the law in question is only a statement of what happens to certain consonants in the Indo-European languages, the answer must be no. But the principle on which it is based, that of the permutation of consonants, holds good, and scems to work out with unfailing regularity. That is, if we meet with any apparent irregularities, they are probably due, either to imperfect observation of the sounds, or to the operation of some law not yet ascertained: in either case, they will disappear in the light of further knowledge.

- In investigating the relations of any dialect with its kindred dialects, the first step 
is to determine to what sounds in the latter its own sounds regularly correspond."

This was done to a limited extent by Bleek -with remarkable thoroughness considering the number of languages at his disposal, and the small amount of material available for some of them. But the work can never be satisfactorily completed till the nature of all Bantu sounds has been determined with scientific exactitude. Meinhof, for instance, after working for years in order to discover the Bantu sounds regularly corresponding to the clicks in Zulu and $\mathrm{Xosa}^{2}$ was obliged to give up the task as hopeless for the present, chiefly because 'the method followed in these comparisons was a very rough one. The question whether the clicks were or were not aspirated, was never taken into account, and the tones were not investigated at all. Therefore, in cases where it seemed as if we had found two or three instances going to prove a particular sound-shifting, it is not certain that

1 Whitney, W. D., Language and the Study of Language (1884), p. 97.

${ }^{2}$ Most of these clicks occur in borrowed (Hottentot and Bushinan) words; but some are found in words which have parallel forms in other Bantu languages. 
even these were valid, and -. . . the results of infinite trouble are worthless from a philological point of view.'.

But, even now, some broad principles of correspondence can be set down as certain, though we must await the exacter definitions of phonetic science before filling in the details. As this book does not concern itself with phonetics, I should be straying beyond my province, if I attempted to do more than indicate these in the most general way; but a few hints on the subject may fitly close our survey.

The difficult sounds called 'laterals' (written $h l, d h l t l, t h$ ) are confined to Zulu, Chwana and Thonga. 'They are absent even from Herero and the Venda languages of the North Transvaal. The following table will illustrate the various sounds in which they correspond with other languages.

Here we find that $h l$ (which seems to be the

${ }^{1}$ Here ' $Z$ ulu' includes Xosa and the various subordinate dialects spoken by the AmaBaca, Swazis and others; Chwana comprises Sutu and Pedi (besides Rolong, Khatla, etc.) and Thonga (the $h$ is necessary to prevent confusion with at least three other Tongas), Ronga

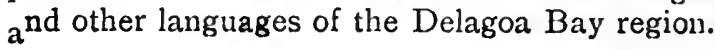




\begin{tabular}{|c|c|c|c|c|c|c|c|}
\hline & $Z u 1 n$ & Chwana & Herero & Venda & Nyanja & Swahili & Ganda \\
\hline Five - & -Hanu & thano & -:ano & $-\tan u$ & $\operatorname{san} u$ & fano & $\operatorname{tano}$ \\
\hline Python & in-blatu & thware & - & - & n-satu & chatu & - \\
\hline Elephant & in-d!.lovu & thon & on-ilyou & 11-น̉on & $n-j(u) v u$ & n-dovu & en-jovu \\
\hline
\end{tabular}

same sound as the Chwana lateral in the corresponding word, though written differently), is represented in the other languages either by $s$ or (dental) $t$, except in the case of the Swahili for ' python,' to which we must return presently. $d h l$ or $t l$, on the other hand are represented either by $j$ ( $d y$ is probably in some cases nearer the sound) dental $d$, or (in languages not included in the table) $z, d z$, or $s$ (Fokomo nzovu, Giryama ndzovu, Konde $i$-sof $(u)$.

(The names for 'python' used in Herero and Ganda seem to come from a different root, and I have not been able to get the Venda word. Ronga n-hlaru keeps the lateral and, like Chwana, substitutes $r$ for $t$.)

The apparent anomaly of the Swahili -tano and chatu requires a little further explanation. In the Mombasa dialect there are two kinds of $t$, in that of Zanzibar only one is recognised in practice. They may be distinguished here 
(though this book, on principle, tries as far as possible to avoid diacritic marks) as $t$ and $t$. In Mombasa printed books-the former, as the more usual sound, is left unmarked, the latter is underlined, or printed in italics, or distinguished in some other way. $t$ is pronounced with the tip of the tongue against the hard palate, $t$ with it touching-or even between-the front teeth. Get a Mombasa native to pronounce, first -tatu and then -tano, and, if you have even a moderately good ear, you cannot help hearing the difference.

Now many words (but not all) which at Mombasa have th, as fita ' hide,' teza 'dance,' jito 'eye,' are at Zanzibar pronounced with what (with apologies to the I.A.P.) I will write ch: ficha, cheza, jicho. Therefore chatu is the Zanzibar form, which, logically, at Mombasa, should be tatu. But I am not sure that it is so, never, to my remembrance, having heard the latter pronunciation. I In fact, the only time I can recall hearing a python mentioned in Swahili was by a Lamu man, and I think-but would not swear to itthat he said chatu. Krapf gives chatu, but as a quotation from Steere: it is possible that some other word is used at_Mombasa. 
But, looking again at our table, and taking it backivards- $-1 j^{1}$ in Nyanja does not always correspond to a Zulu lateral. We have njoka 'snake,' njati 'buffalo,' and njuchi 'bee,' which in 'Zulu are in-nyoka, in-nyati, in-nyosi. And sometimes we, find Zulu words containing ny not only-in Nyanja, but other languages as well, such as in-nyann 'animal,' or ' meat'which only in one or two cases that I have come across is nama (in Chwana and in Venda). Before coming to a conclusion in a case like this, one would want to be sure whether all the ny sounds were the same. Some may, perhaps, be quite properly written $n y$, while others require the symbol which for typographical reasons is banished from these pages-and as to the sound, see Mr. Noël-Armfield's General Phonetics, p. 63.

The comparative tables of words given in the preceding chapters will already have called attention to some correspondences, such as that between Zulu $t$ and Chwana $r$ (which $t$ and which $r$ are important points to be dealt

The presence or absence of a nasal before a consonant makes some difference as regards soundshif tings. 
with by the phonetician), the tendency of Chwana (which it shares with Makua) to prefer a voiceless stop to the same sound voiced and preceded by a nasal (e.g., rata $=$ tand $a$ and podi $=m b u z i)$; the curious absence of $p$ from a large group of East African languages, etc.

In most of these latter, the place of $p$ is taken by $h$, in Ganda by $w$ and in Pokomo, by 'bilabial $f$ '-written of by the German missionaries who have chiefly cultivated this language, and who spell the name of the people 'Wabfokomo.' Chwana, curiously enough, shares this tendency to a certain extent, though having no objection to the p-sound per se. The word usually found as pa-nsi is le-hatse or le-fatse, (the $p a$ - prefix being incorporated with the noun-root) and $p$ appears (as we saw just now) where one would not expect itinstead of $m b$ or $m v$. There is no $v$ in Chwana, but 'bilabial $v$ ' is a common sound, and-at any rate in some dialects-takes the place of

1 Here the o is an extra-narrow o (written in Meinhof's notation $\rho$ ) which approaches $u$ in sound: the word is sometimes written poli, in which case it must be remembered the 1 is 'cerebral 1.' If you try to sound 1 by turning the tip of the tongue up against the palate, you will find that it approaches very nearly to the sound of d similarly pronounced. 
$b$ also. $P$, unless nasalised (i.e., preceded by $m$ ) is not common in Kongo: perhaps the words in which it unquestionably occurs might on examination prove to be borrowed.

Herero has no $s$ or $z$, - the sounds substituted being those of the voiced and voiceless (i.c., as in 'there' and 'thin ') for which I have written $d / h$ and th respectively. Makua, too, and Kikuyu, have no $s$ sounds: the reason in all three cases is supposed to be the custom of extracting-or chipping away part of - two front teeth. On the other hand, Nyanja, Yao, and some others have no $h$, while Swahili seems to have an exceptional preference for the sound-as in the pronouns. (It should be noted that it frequently arises, in this language, from a contraction which one would scarcely expect to produce it : e.g. $h a$ - for $n i-k a-$ not to be confused with the negative $h a-$ - and $h i$-for $n i-k i{ }^{1}{ }^{1}$ Conversely, si-, in the negative of the first person singular, is a contraction of ha-ni.)

There are three main principles ${ }^{2}$ which we

${ }^{1}$ Steere, A Handbook of the Swahili Language, pp, $134,137$.

${ }^{2}$ See Meinhof, Lautlehre, pp. 12:16. 
must keep in mind when examining the structure of any language and its relation to others of the same family. These are:
(I) Assimilation.
(2) Dissimilation.
(3) Transposition.

We might add False Analogy, which often accounts for phenomena otherwise inexplicable, as when in Swahili we have julika 'be knowable,' from jua ' know,' which never can have contained $l$, as we see by the noun mjuvi, formed from it, and the parallel forms Nyanja dziwa, Pedi tzeva. But, as most Swahili verbs in -ua have dropped $l$, which reappears in some of the derived forms (e.g. pindua 'turn over,' applied form pindulia, passive -pinduliwa) jua has been made to 'follow the rule,' like many modern English verbs ('helped,' '-worked,' etc.).

(i) Assimilation may be (a) Incomplete, or (b) Complete, and is applied both to vowels and to consonants.

In Complete Assimilation, two different sounds occurring in succession are made exactly alike, for greater ease in pronun- 
ciation. Sometimes the second is assimilated to the first, sometimes the first to the one v.V following it. Thus, in Konde, the verb fisa 'hide' (Zulu fihla, Swahili ficha, fita) is sometimes heard as fifa. Shambala, having borrowed from Swahili the word for 'paper,' kartasi (itself borrowed from the Arabic) makes it into talatasi: the first consonant being influenced (in spite of the intervening $l=r$ ) by the $t$ in the next syllable but one.

If a sound becomes, not exactly the same, but only similar to that which precedes or follows it, we have Incomplete Assimilation. This is shown in Bantu when the prefix in- is followed by a labial $(p, b, f, v)$-when the dental nasal $n$ is changed to the labial nasal m. $N$, again (except in a few languages, e.g., Kongo and Makua), cannot be followed by $l$ or $r$ and changes these sounds to $d$; this is why the plural of $u$-limi 'tongue' in Swahili is (zi)n-dimi, instead of $(z i) n$-limi. ${ }^{1}$ In the same way, verbs whose stem contains $o$ or $e$ take the

1 Another case of Assimilation is when the two sounds unite to form a third, different from either. We have already met with the union of $a$ and $u$ to form $o$, and $a$ and $i$ to form $e$. In Chwana, if $n$ is followed by $v$, the two together become $p$. See Lautlehre, p. 13. 
termination $-e k a$ instead of $-i k a$, because the position of the tongue for $e$ is nearer to that for $o$ than is that for $i$. But these terminations are in most (not in all) languages governed by the Law of, Vowel-Harmony, which rests partly on Assimilation, and partly on Dissimilation and may be stated thus: If the verb-stem contains $a, i$, or $u$, the termination has $i$ : if $o$ or $e$, it has $e$. So, in Nyanja ang'-ana 'look' makes ang'an-ira, ang'an-itsa, lira 'weep,' lir-itsa ; funa 'seek,' fun-itsa; but yera 'be white' y'er-etsa and the passive yer-etsedwa, and omba 'strilie' omb-era, omb-etsa. In the case of $e, i$, and $o$ the sounds are-made quite identical, or at any rate brought nearer together; in that of $a$ and $u$ they are put further apart.

This last process belongs to Dissimilation. This arises when two similar sounds occur in close conjunction, and the speaker, to avoid confusing them, lays special emphasis on one and tends to slur the other, in order to make a difference between them. Some Yao verbs, whose stems contain $l$, have a perfect in iteinstead of -ile, as lolite, from lola 'look.'

Under this heading, special attention should be directed to the law discovered by Dahl, a 
missionary in Unyamwezi, and prevailing in many East African languages-among others that usually written as 'Kikuyu.' As a matter of fact, the people call themselves $A$-gikuyu; just as the infinitive prefix for certain verbs is $g u$, not $k u$, and the word for a stool is gi-ti, not ki-ti. All these words, and many more, are illustrations of Dahl's Law, which may be stated thus :

When a voiceless stop $(k, t, p)$ is followed by another voiceless stop, it becomes voiced. In other words, if $k$ is followed by either $k, t$, or $p$, it becomes $g$; $t$ becomes $d$, and $p$ becomes $b$.

This principle, if it had been clearly recognised by those who have dealt with Kikuyu, would have saved them a good deal of trouble. In Mr. Barlow's Tentative Studies (p. 5) it is mentioned as the 'Euphonic Change of $k$, and no doubt the fact that Kikuyu has weither $p$ nor (except nasalised) $d$ helped to obscure the real' bearings of the case. But the matter stands exactly' as it does in Shambala, Bondei and Nyamwezi-probably also in Yao, where we have nguku 'fowl' (Ayanja, nkuku) mbeko 'fire-stick,' which elsewhere would be mpeko.

NyamwezI: mbcho 'cold ' (mpcpo: the second $p$ has become $h$ ). 


$$
\begin{aligned}
& \text { deka 'cook' (elsewhere teka). } \\
& \text {-datu for -tatu' three.' }
\end{aligned}
$$

Shambala : m-gate 'bread'. (Swahili m-kate).

Transposition may occur in two forms: syllables may be transposed, as in Venda, where gidima 'run' is sometimes heard as digima, and Nyanja, where 'cough' is either sokonola or kosomola. Or a vowel in one syllable may intrude into another, as in the Konde perfect of -elupha1 'be white,' which is -elwiphe, for -eluphile; the $l$ being dropped and the $i$ taken into the previous syllable. Other interesting examples of this and similar changes may be found in the sections of Meinhof's Lautlehre already referred to.

A study of General Phonetics is indispensable to anyone taking up an African language. As already stated, this is a subject with which I have not attempted to deal, my object being merely to give an outline of such grammatical features as are common to the Bantu speechfamily. A list of the most useful grammars, dictionaries, and other helps towards the acquisition of particular languages will be found in the Bibliography.

'This $p h$ is an aspirated $p$. 
After embarking on the study ot some one language, it will be well (though I am aware that, till the English edition is published, this is more or less a counsel of perfection) to go systematically through Meinhof's Lautlehreder Bantusprachen or, at any rate, Chapters I. to III. and the one dealing with the language nearest to that on which the student may be engaged. But it is a book that cannot be used to much profit, unless one has some little notion of at least one Bantu language to begin with.

As the readers which a book of this kind can hope to meet with are necessarily limited in number, and (in one way or another) somewhat specialised in outlook, we may be excused if, feeling a sort of personal interest and parting from them not without regret, we remind them in the words of Brother Hyacinth that :

'If any be desirous of learning . . . beyond what is asserted in the preceding pages for the more easy understanding of beginners, and their careful recollection, he ought also sedulously to study and labour in learning what follows... . aind the preludes of other matters worthy to be known.' 


\section{APPENDIX I.}

TEXTS

I. ZULU

(a) Why the Rock-Rabbit has no Tail*

Ka-tiwa, ${ }^{1}$ im-bila ${ }^{2} \quad$ ya-swela ${ }^{3}$ um-sila

It is said, rock-rabbit was-without tail

ngo-ku-yalezela ${ }^{5}$ ezi-nye . $^{6} \quad$ Ngokuba $^{7}$ with-giving-a-message (to) others. Because na-mhla ${ }^{8} \quad \mathrm{kw}$-abiwa ${ }^{9}$ imi-sila la-lion the day (when) there were distributed tails it had buyis-ile $^{10}$ i-zulu; za-puma-ke ${ }^{11}$ ezi-nye clouded-over the sky; they went out so (the) others uku-ya-'u-tata ${ }^{13}$ imisila lapa ${ }^{13}$ i-tatwa kona $^{13}$; to take tails where they were taken;

y-ahlul-eka ${ }^{14}$ e-nye uku-ba i-hambe ${ }^{15}$ na-zo ${ }^{16}$, he was prevented another that he might go with them, ya-yaleza ezi-lwan-eni ${ }^{17}$ zonke ezi-ne-misila ${ }^{18}$ he sent-a-message to-animals all who with tails, ya-ti, ' 0 , nina ba-kwiti ${ }^{19}$, a-no-ngi-patela ${ }^{20}$ he said, ' $O$, ye our (people), do ye get-for me owami $^{21} \quad$ umsila; ngi-kohl-we ${ }^{22}$ uku-puma that which is mine tail; I cannot come-out em-godi-ni, ngokuba izulu li-ya-na.' from-hole, because sky is-raining.'

* From Callaway's Nursory Tales, Traditions and Historics of the Zulus (1868), p. 255. 
Za-buya-ke ezi-nye nemisila; leyo $0^{28}$ yona They returned, so, others with tails; that-one he a-i-ba-nga i-sa-ba ${ }^{24}$ na-msila ngo-ku-enqena ${ }^{23}$ he was not he still being with tail with being-disinclined uku-puma, izulu li-buyisile. Ya-lahla konke to come-out, sky it has clouded-over. He lost all oku-hle ngomsila; ngokuba umsila u-ya-siza good with a tail; because tail it helps eku-zi-pung-eni ${ }^{26}$; ngaloko-ke in-driving-away-from-oneself (flies); and so in this way, imbila a-i-sa-zi-pungi nga' rock-rabbit does not now drive away from himself luto. ${ }^{27^{\circ}}$

with (any) thing.

Se-ku izwi eli-kulu loko 'ku-libala kwe-mbila Now it is word great that loitering of rock-rabbit ku'bantu $^{20}$ aba-mnyama; ba-kuluma ngaloko to people black; they say with that 'ku-tsho kwembila, ku-tiwa kw-aba-nga-zisaying of rock-rabbit, it is said to those-not-tiring-them. katazi ngaloko oku-tandwa-yo aba-nye, n-aba-tsho. selves with that which is liked (by) others, and those who yo kwabanye, ku-tiwa, 'Bani, say to others (to act for them) it is said, 'So-ind-so,

a-w-azi ${ }^{31} \quad$ ukuba loko 'kutsho kwako kw-okuti', do you not know that that saying your of saying, "A-no-ngi-patela" " a-w-azi na ukuba umu-ntu "Bring for me" - lo you not know that a person

ka-pat-el-wa $a^{\text {st }}$ omu-nye, uma into leyo not is-carried-for (by) another, when thing that i-lingene $e^{35} \quad$ abakona? 0 ! it is-enough (only for) those (who are) there? O!

imbila ya-swela umsila ngokuyalezela. rock-rabbit went without tail by sending-message. 
Nawe, musa ukw-enza ${ }^{96}$ njenge-mbila ${ }^{37}$; And you do not do like (the) rock-rabbit; ku-yi-ku-zuza ${ }^{38}$ 'lu-to ngokuyalezela; zi-hamb-ele ${ }^{39}$ you will not get anything by sending-word; go for yourself ngokwako.' as to what is yours.' It (is) thus, then, story of mbila. A-i-kuluma-nga yona ngo-mlomo, ukuti,. rock-rabbit. He did not speak he with mouth to say, 'A-no-ngi-patela'; kwa-vela ${ }^{40}$ izwi $\quad k o d w a^{41}$ 'Bring for me'; there came forth word only ngokuba izi-lwane zi-ne-misila, ${ }^{42}$ kepa yona because animals they (are) with tails, but he

a-i-na 'msila' ; kwa-nga ${ }^{43}$ ya-swela umsila not-(is)-with tail; it (was) as if he went without tail ngokuyaleza, na ngokuba izulu imbila by sending-word, and because sky rock-rabbit i-ya-l-esaba ${ }^{44}$ uma li-buyisile; a-ihe is fearing it if it has clouded-over; he does not pumi emgodini uma li-ng-enzi ${ }^{45}$ izi-kau come out from hole if it not making gleams

zoku-sa.

of sunshine.

\section{n NOTES}

${ }^{1}$ Tizoa, passive of $t i$ ' say'; the prefix is that of Class 15 , which is used when there is no definite subject, like our 'it, or 'there.'

2 A noun of Class 9, the prefix in- becomes im- before a labial.

B Swela 'want,' 'lack.' Ya prefix of the past tense, agreeing with imbila.

" Umsila, a noun of the third class; pl. imi-sila, found in next line but one.

5 Yalezela, applied form of yaleza, ultimately from yala 'direct,' 'order'; yaleza means 'give a message,' and takes the 
thing, not the person, as its direct object, whereas yalezela takes a direct object of the person by whom, (not to whom) the message is sent. Ngoku-for "ga-uku.: nga "by means of,' prefixed to the infinitive.

6 ezi-nye agreeing with izi-la'ane 8 'animals,' understood.

7 For nga-ukuba, lit. ' with being '-i.e. ' because.'

- namhla, for na umu hla, often used for 'to.day.'

- abiva passive of aba 'distribute.' Monosyllalic verbs, and those beginning with a vowel, make their passive in -ita instead of $-v e$.

10. Agrees with izula, which, by a not infrequent exception, follows its verb. Pluperfect tense; the Perfect having both the Past (lil) and present (li) prefixes before it. Buyisa, lit. 'bring back,' is the causative of buya 'return'; the idea being that the sky 'brings back' the clonds from below the horizon.

" he an enclitic particle, usually rendered 'then,' ' just,' ' so,' etc. Unlike the interrogative $n a$, it draws forward the accent of the word to which it is attached, so that we pronounce zapumake, instead of accenting the syllable $p u$, as would otherwise be done. It is the subjunctive of the auxiliary $k a$ (Colenso, First Steps, p. 132).

12 This is a future infinitive, for ukujakutata: the $k$ of $k \|$ is often dropped.

t3 Lapat 'here,' followed by kona, has a relative force, the two together being equivalent to 'where' (not the interrogative 'where,' which is-pi). Kona is the pronoun of Class 15or, more properly, of Class 17 , which in $Z$ ulu has been merged in 15 -and usually means 'the place,' 'there' (not adverbially, like lapo, lapaya, but inore in the sense of the French $y$ ).

It Neuter-passive of ahlula 'overpower'; the subject is one 9 which seems to refer in a loose way to imbila, properly, it should be esi-nye 7 agreeing with isi-lw'ane 'animal,' which seems to be required by the sense.

is Subjunctive, agreeing with inye. There is no distinction of tense in this mood.

16 na-zo, agreeing with ezi-nye (izilitanc) above.

17 Ezi-lwan.eni, locative of izi lie'ane. It is not very usual to have nouns denoting living beings in the locative, though we sometimes find ebuntwini (more often $k u^{\prime}$ (bantu). Here it is used because yaleza cannot take a direct object of the person: it is therifore equivilent to a dative. Isi-luane for isi-lo-ane is the diminutive (suftix -ana or -ane) of isi.lo "wild animal,' but generally used for 'leopard.' Isiluane means a 
wild animal in general,-but more especially a carnivorous or noxious one, whereas in-nyamazane is 'game,' and more particularly 'buck.'

18 Relative construction (ezi=a+izi; nemisil. $=n a+i m i$ sila) literally ' which they with tails '-i.e. ' which have tails.'

is bakwiti or bakiti 'my' (or 'our') 'people'-ki=kn, followed by the 'prepositional' form of the personal pronoun (always iu the plural). See Colenso, First Steps, \$9r.

20 a-no-ngi-patela, Future Indicative, used authoritatively for Imperative (First Steps, \$222), with $a$, prefix of Imperative; $n o=n i y a ' u=n i y a k u$ : see lirst Steps, \$2+1.

${ }^{21}$ owami, relative form of the possessive $=$ "that which is mine.' It is generally nsed for special emphasis, 'my own,' etc. First Sieps, $\$ 137$.

22 Perf. passive of kohla, properly 'escape,' 'slip (the menory of) '-so that the usual ineaniug of kohlwa is 'forget' -i.e. 'be escaped' by the thing forgotten. The use here seems somewliat musual, but probably means 'coming-out has escaped me'-i.e. is beyond my power.

${ }^{23}$ leyo, demonstrative of $\mathrm{Cl}$. 9 'that one' (or rather 'the aforesaid one ')-agreeing with imbila, though the antecedent is not expressed in this sentence.

24 aibanga ncgative past of $b a$ 'be'; $a$ neg. prefix, $i$ pronoun agreeing with imbila understood. isaba is best taken as a participle, $s a$ here $=$ 'still'; the two verbs together may be taken as a compound tense and translated 'he no longer had.' Cf. First Steps, $\$ 27 \mathrm{I}$.

${ }^{25}$ For nga-uku-enqena: $n g a$, instrumental = ' with' or 'through.'

26 Locative of the infinitive; $z i$ is the reflexive pronoun.

$27 U(l i t)-t o$, usually nucontracted, because of the monosyllabic stem. Here nga'luto, not ngoluto, because following a negative, when the initial vowel is always elided, never contracted.

2s Verb 'to be' understood. The subject with which the pronoun agrees is ukulibala. Concerning se see the chapter on 'The Particles $\mathrm{S}_{A}$ and $\mathrm{SE}$ 'in Colenso's. First Steps, pp. I 2 2-I I6, especially $\$ 274$.

${ }^{29} k u^{\prime}$ bantu, more usual than ebantarini. A little later we find kwabanye ( $u$ becoming $w$ before a), not ku' banye; but $k u$ ' bantu seems to be preferred,-perhaps because kw' ' buntu is used with a different shade of meaning-' at (the house of) the people '-like chez. 
30 Ubani 'who' (interrogative, not relative) is sometimes used in this way, "when the name of a prison is not known or not immediately rememhered,' or in a familiar and slightly contemptuous style of address, 'You, sir!' 'you, fellow?' (u is always dropped in the vocative.)

"Awazt for $a-\| \cdot a z i, n$ becouning $w$ before the vowel-stcm. $A z i$ is one of the few verbs which end in $i$ and therefore caunot change their termination in the negative.

${ }^{82}$ Kwokuti for kwa ukuti 'of saying' - the possessive particle agreeing with the preceding loko "kutsho.

33 The sentence breaks off, and the question begins afresh.

${ }^{34} K a$, not $a$, is the negative for the third person singular, or nouns of the first class; $a$ being used in the subjunctive and in some forms of the relative, as the pronoun of the third person singular. Patela applicd form of fata 'carry" (in the hand or on the arm - not on the head, which is twala). This is an instance of the Bantu preference for the passive when European languages would liave the active construction.

8s Ling. 'try,' 'test,' 'strive' (in some languages, e.g., Nyanja, it means 'measure'); the reciprocal, lingana (perf. lingene) means 'try or strive with,' 'vie with, 'be as large as,' and so 'be sufficient for,' as "mbila "lingene labo' bantu 'the maize is sufficient for those people.' It may take a direct object, as in this sentence, and in the text (abaliclia), or be followed by na. Kulingine, without ant object, means ' $j$ is fair, fitting, reasonable.'

${ }^{86}$ The Negative Imperative is the Infuitive preceded by musa. I do not know that any satisfactory explanation of this has been given, but sa is a negative particle in some languages.

${ }^{37}$ For njenga ('like') imbila.

as Negative Future (2nd person sing.) of $z u z a$ 'ohtain,' $K u$ instead of $a-\|$ (which would rontract into o), probably to avoid confusion with the same person of the relative.

89 Hambela here means 'go for,' and not, as most commonly, ' go to ' $=$ ='visit'). $Z i$ the reflexice pronoun. The Subjunctive is generally used instead of the Imperative, when an object-pronoun precedes.

10 Past tense (ku-a-vela) with the indefinite subject ku; instead of saying izwi la-vela. This construction so exactly corresponds to our idiom of beginning with "there " and letting the real subject follow the verb, that we can translate quite literally.

"The adjective -odwa 'only' (which, like -onke 'all,' takes 
the concords of a pronoun, not of an adjective), with the concorcl of the $1_{5}$ th class-i.e., agreeing with an undefined subject. It is ofteu used as here, adverbially for 'only,' and thence easily glides into the very conmon sense of 'but,' in which it is synonymous witl kepa.

42 Note the difference between these two words: the first contracts because the verb (understood) is affirmative; the second elides' because it is negative.

${ }^{43} \mathrm{Ng} a$ as an auxiliary is 'used to express a wish or like. ness' and is followed by a finite verb. Compare wanga. angarela ' he wished that he might cross.'

"An unusual order of words, but not unknown.

4s ng' here stands for nga, the negative particle for the Imperative, Infinitive and Participles: see First Steps, $\$ \$ 259$, 263.

\section{Connected Translation}

It is said that the rock-rabbit (Hyrax) is without a tail, because he sent a message through someone else (instead of going himself). For, on the day when tails were distributed (t 8 all the animals), the sky clouded over; the others went out to get their tails where they were to be got, but he was prevented from going with them; he sent a message to all the animals who had tails (i.e., all who subsequently received them), saying, 'O ye my people, do ye obtain my tail for me; I cannot come out of my hole, because the sky is raining.' So the others returned with their tails, but he had none, through being disinclined to come out when it was cloudy. He lost all the advantage of a tail, for a tail is useful in driving away flies; and so the rock-rabbit has nothing now with which to drive them away.

And so that loitering of the rock-rabbit has become a great proverb among the black people; they make use of that saying of his with regard to those who will not take any trouble about what other people like, or who tell other people to do things for them. "So and so! As for that saying of yours "Just bring it for me," 
don't you know that you cannot have anything brought for you by another person, when there is only just enough for those who are on the spot? Oh!-the rockrabbit had to do without a tail because he sent a message. Do not be like him; you will not get anything by sending word through another; go and attend to your own affairs for yourself.'

This is the story of the rock-rabbit; he did not (exactly) say, with his mouth, 'Bring it for me'; the proverb only arose because (the other) animals have tails, but he has none. It was as though he went without a tail by sending word and because he feared the threatening look of the sky; for he does not come out of his hole except when the sun shines.

(b) Extracts from Native Letters*

Sa-fika e St. Helena, kwa-t' uba ${ }^{1}$ ngi-pume We arrived at St. H., it befell when I came out em-kunj-ini ${ }^{2}$ aba-kiti ${ }^{3}$ ba-jabula kakulu uku-ngifrom the ship our people rejoiced greatly to see bona, nga-puma ngi-nga-sa-tandi ${ }^{4}$ na kancane me, I caine out I no longer wishing even a little uku-hlala pakati ${ }^{b}$ kwomkumbi, so-ku-ngito stay inside of the ship, it having already gulisa.' Yebo-ke, 'Nkosazana ya-kiti made me ill. Ycs, indeed, lady of our (country) o-tandeka-yo, ${ }^{7} \quad$ ama-kosi lawa a-kwa' Zulu who is worthy to be loved, chiefs these of the Zulus ay' etanda ${ }^{9}$ kakulu uku-finyelela ${ }^{10}$ England they are wishing greatly to reach England a-bone aba-ntu nezwe la-kona
that they may see the people and country of there

* Written from St. Helena, in r 896-7. by a Natal Zulu, employed as secretary and teacher to the exiled chiefs. 
nomuzi ${ }^{11}$ lowo o-dumile-yo ${ }^{12}$ was' e London. ${ }^{18}$ and town that famous of at London.

Ngezindaba e-zi-vela e-kaya ${ }^{14}$ kiti, ngi-zwile

As to news which come from home our, I have heard ukuti aba-ntwana bami ba-ya-gula ${ }^{15}$ kakulu ngothat children my are ill greatly with mkuhlane.' Nokuti um-kuhlane w-andile ${ }^{16}$ fever. And that fever has increased

pakati kwezwe, kodwa-ke kuhle, nje, in the midst of the land, but yet it is well, indeed, noma $^{17}$ ku-njalo, ${ }^{18}$ ngoba i-kona innyanga even though it is thus, because there is a doctor ya-kiti
leyo
o-y-azi-yo ${ }^{19}$
nawe; yena of our (people) that-one whom you know, you also; she u-ya-b-elapa, kambe, $^{20}$ labo aba-gula-yo, is treating them, of course, those who are ill, njengokumiswa ${ }^{21} \quad$ kwake y'inkosi ${ }^{22}$ according to the being made-to-stand her by the chief

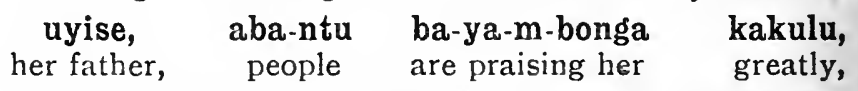

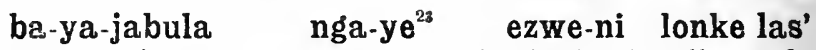
they are rejoicing on her account in the land all of Ekukanyeni ${ }^{24}$. . . Ekukanyeni.

Nkosazana-Omunye um-ntwana wenkosi yakwa' Madam-One child of the chief of

Zulu, u Ndabuko, u-zwile kimi ${ }^{25}$ The $Z$ ulus, Ndabuko, he has heard from me (when) ngi-m-xoxele ${ }^{28}$ indaba $^{27}$ ngawe ya leso' sizwe ${ }^{28}$ I related to him story from you of that tribe esi-mnyama 0 -wa-u-hlezi ${ }^{29}$ pakati kwa-so, ${ }^{29}$ na black which you stayed among them, and

ngezinncwadi lezo o-wa-u-zinge $e^{30}$ u-ngi-tsheleka from the books those which you used you lending me 
zona uku-ba ngi-funde ngesi-kati leso e-nga-ngi-gula them that Imightread at the time that when I was ill nga-so

kiti

Ekukanyeni.

Nga-loko at it at our (home) at Ekukanyeni.

Therefore

u-ya-tanda kakulu, u-ya-cela ukuba wena, he wishes greatly, he asks

that

you,

Nkosazana,

u-m-xoxele

izin-daba za labo

Madam, you would relate to him affairs of these 'bantu. Ngi-m-landisile ${ }^{\text {sq }}$ futi uku-ti aba-nye people. I have warrated to him also that baku lezo' zizwe ${ }^{33}$ ba-kuluma ngo-limi ${ }^{31}$ lwakwa' of those tribes they speak with tongue

of the

Zulu impela, ngitsho ${ }^{95}$ labo a-ba-biza u Nkulunkulu Zulus indeed, I mean those who call

God

ngokuti 'Mulungu," ${ }^{36}$ nabanye aba'lulimi lwabo" by saying 'Mulungu,' and others who tongue their lu-sondele $^{89} \quad$ kwolwetu; a-nga-jabula $^{\text {89 }}$ u-qobo ${ }^{10}$ approaches to ours; he would rejoice in truth

u Ndabuko uma wena, Nkosazana, u-nga-m-tumela

Ndabuko if you, Madam, you could send him in-ncwadi etile ${ }^{41}$ (Book), kumbe ${ }^{42}$ u-m-tumele book some or send him

in-cwadi (Note) yo-ku-m-xoxela ${ }^{\text {sh }}$ indaba ya labo letter

to relate to him

story of those

'bantu noku-m-tshela ukuti lezo' zizwe 'z'ake" people and tell him that those tribes they have built kuyipi $^{45}$ in-dawo, izi-zwe ezi-ngaki, za-yela-pi ${ }^{2 n}$ in which place, tribes how many? (and) where ditthey

na?

come from?

Nkosazana, njengokutembisa kwami ukuti Madam, as to promising my that

ngi-ya-ku-tuma ${ }^{47}$ ezi-nye izi-bongo zama-kosi akwa' I will send some praises of chiefs of the 
Zulu kuwe nga lesi 'sitimela, ${ }^{48}$ a-ngi-na-wo ${ }^{49}$ Zulus to you with this steamer, I have not ama-ndhla ukuba ngi-ku-tumele $e^{50}$ namuhla, kodwa strength that I might send you to-day, but ngi-ya-ku-ku-tumela ${ }^{50}$ ngesitimela I will send you by the steamer which comes. Ngi-sa-hamba ${ }^{52}$ kahle em-zimb-eni wami, uku-gula I now go will in (as to) body my, illness

loko e-nga-ngi-na-ko ${ }^{63}$ Ekukanyeni a-ku-ka-ngithat which I (was) with it at Ekukanyeni has not again $\underset{\text { yuki }^{54}}{\operatorname{arisen} \text { (upon) me here. } . . .}$

Magema MagWaZA.

\section{NOTES}

${ }^{1} \mathrm{~K} w a t i$, past tense, like the preceding safika, but with the indefinite subject $k u$, I5. An idiomatic use of the verb $t i$ ' say' (cf. First Steps, \$29o), which may often be rendered, ' and so,' or 'once 'upon a time.' $U b a$, a contraction of $u k u b a$ ' to be,' is here equivalent to uma 'when.' (First Steps, p. 81.) It is followed by the subjunctive ngi-pume.

' emkunjini, locative of $u m k k n m b i{ }_{3}$ ' ship.' $m b$ becomes $n j$ in accordance with the $Z$ ulu law that a labial is never followed by $w$. There is no apparent $w$ here, such as we find in endhlw-ini (from indhlu, $u$ becoming $w$ before -ini, but the form endhl-ini is also in use); but it is probably introduced into the termination by analogy with the $u$ of the stem: $u$ unkumbw$i n i$, for $u m k u m b u-i n i$.

${ }^{3}$ Abakiti lit. 'those of at us,' cf. First Steps, \$9r, and ante p. 236 , note 19 .

${ }_{4}^{4}$ This is not the Potential Mood (First Steps, \$247), but the Negative Participle (ib., \$269). Sa, 'when used with a negative verb, may be generally expressed by any more, any longer, at all, etc.' (ib. \$271).

${ }_{5}^{5}$ This is an instance of a word compounded with $p a$ like pansi, pezulu, pambili, etc.), thongh that preposition (or rather pronoun) is no longer used in $Z$ ulu. Um-kati 3 'space inter. 
vening between any two things' preserves the root kati 'between,' which is still so used in Swahili, though not in $Z$ ulu. (There is an adverl) kati ' although,' ' in spite of,'- which may have the same origin, thongh possibly a derivative of $t$.)

- This is not the infinitive, but a participle, having for its subject the pronoun $k \|$, which may be the indefinite subject ('it,' or 'there') or may agree with "kwhlala 'the staying.' So=se, the vowel being modified under the infuence of "in the next syllable. Se lias the force of ' now,' by this tıme,' 'already,'etc. (First Steps, $\$ 27 .+, 275$.$) . Gulistr, causative of$ gula 'be ill'; -ngt- is the object-pronoun, first person.

7 Tandeka, nenter-passive of tanda 'love' (First Steps, §86); for the relative etumtekay'o, sce $i b ., \$ 132 . \quad e=a+i$ is the Relative Prefix, because agreeing with intosazani 9.

8 .4 possessive particle agreeing with antakosi 6 (exceptional plural of inkosi 9-see First Steps, $\$ 38)$. Ku'a 'Zulu: $k w^{\prime} a$ ' at' (=French chez)-see First Stips, \$gz; "Zulu (the vowel elided is probably $u=u l u$ ) used for 'the whole Zulu uation '; $a k u$ ' $Z u l u$ is used instead of the locative-as' ezuluini because the latter would mean ' in ' (or 'from ') 'the sky' (ib., \$79).

IA pronoun agreeing with amakosi. A-ya-(ba) etanda, lit. 'they are, they loving': the verb -ba being understood.

10 finyelela (properly a double applied form of finya, but the latter does not seem to be used in any sense recognisable as cognate) 'reach, as a traveller a place,' followed by the locative. ('England,' as it begit:s with e, seems to be treated as a locative, withont further no:lification.)

1 Nomuzi=na umuzi 3 , 'kraal; people of a kraal, family'; hence used for 'village 'and 'town.' (Nyanja mu-dzi, Swahili $n$-ji.)

13 Literally 'that (town) which has thundered': dum-ile perf. of duma : the usual expression for 'renowned." 'glorious,' etc. Cf. Psalm viii., I: igama lako lidume kangaka emhlabeni wonke, lit. "thy name has thundered how greatly in all the earth.'

is $s$ is inserted before the Locative when it follows a Possessive Particle. See First Steps, \$6g.

"Locative of ikaya 'home,' 'dwelling.' The word is fonnd ainong the 'Nyika' tribes of East Airica (e.g., the Giryama) to denote the principal (fortified) village of the l'ribe. For the absence of the locative termination, see First Steps, $\$ 68$.

15 'Emphatic Present' (Colenso) or 'Present Progressive' (Bryant) tense. 
16 For $u$-andile; $u$ agreeing with $u m k u h l a n e ~ 3$, which is (Bryant) 'a general name for any acute disease accompanied by fever, such as ague, influenza,' etc., etc.

17 noma=na mma. For uma 'if,' 'when,' etc., see First Steps, $\$ 8 \mathrm{x}$.

${ }^{18} K u$ is here (as in the preceding kuhle) the indefinite subject, with the verb ' to be' understood.

19 Objective Relative (First Steps, §134) y (=yi, for $i$ ) agreeing with innyanga 9. The reference is to Miss Agnes Colenso.

20 For kambe, see First Steps, p. 75.

${ }^{21}$ For njenga ukunisw'a. Misa, causative of ma 'stand,' means, in the first instance 'make to stand,' establish, 'ordain, as a law or custom,' etc., whence the present sense is easily inferred. The infinitive is here used as a noun of the ${ }^{5}$ th class (8th in Zulu grammars), with which the possessive kwake agrees.

22 The Passive (ukumiswa) is followed by the Copula denoting the Agent (First Steps, \$roo et seq., and ante, p. II4). The 'Chief' is Bishop Colenso.

${ }_{23} y e$, pronoun of the third person singular (Firsi Steps, $\S 104)$ following, and governed by, nga (ib., \$\$93-99), and see ante p. $9 \mathrm{I}$.

${ }^{24}$ For this locative see First Steps, \$69, and ante, p. 243, note 13.

${ }^{25}$ kimi for kumi, like kiti, etc.—First Steps, §go.

${ }_{26} X$, in $Z$ ulu books, stands for the 'lateral click,' made by pressing the tongue against the side teeth and then withdrawing it suddenly. Xoxele, perf. of applied form, instead of xoxel-ile-First Steps, \$236.

27 For the various senses of indaba, see Colenso's or Bryant's Dictionary, s.v. Daba (in).

${ }^{28}$ isi- zwe 'tribe '-the root of $i(l i)$-zwe 'country,'-with the $7_{\text {th }}$ prefix-see ante, pp. 45,55 .

${ }^{29}$ Relative, with object in an oblique case (First Steps, §1 34): viz.; pakati kwa-so (so pronoun agreeing with isi-zwe 7). -o. is the Relative (and person singular) subject, wa- the subjectpronoun of the 2nd person combined with (Past) tenseparticle.-Pakati, used prepositionally, is always followed by kwa.

${ }^{80}$ Relative construction similar to owauhlezi. Zinge is a 
(defective) auxiliary verb, used (First Steps, \$3;4) ' to express "repeatedly," "confinually," " habitually," etc.' Zona (agreeing with izinncuadi 10 ) is governed by tsheleka, which, like all verbs of giving, etc. (see First Steps, $\$ 3+0)$, takes a dotıble accusative; but only one objective pronoun can be prefixed to the verb., viz., here, that of the person, -ngi-.

st A similar relative, but with the subject in the first person (prefix e-). The tense is the Past, which when combined with a Relative (cf. owallhezi, above) takes the prefixes both of past and present (nga., ngi-). Ngaso agrees with isi-kati 7 .

32 Perfect of land-isa, cansative of landa 'follow': ' make to follow'-hence ' "narratc.'

${ }^{33}$ Literally 'of at those tribes,' one would have expected ba lezo'zizwe-but the construction is like lwa kwa' $Z$ ulu, a little further on, and cf. note 8 above. Abanye must be translated ' some,' or 'others,' according to the context.

${ }^{3}$ For $n g a+u(l n)$-limi. The usual word for 'language.'

${ }^{85}$ Literally 'I say'

${ }^{36}$ Mulungu is used by the Yaos, Anyanja and other eastern tribes. It is difficult to believe, with Bleek, that it is the same word as Unkulunkulu, since the latter is plainly derived from -kuln, a root existing in all the languages where Mulungu is found. Unless, indeed, some other form was anciently in use among the $Z_{u l u s,}$ which only became Unkulunkulu through an adaptation of popular etymology.

87 Relative in the Possessive-see First Steps, $\$ 133$.

$88 \mathrm{lu}$, pronoun agreeing with ulimi II; sondele, perfect of sondela (see above, note 26). Sond-ela is properly an applied form of sonda, which, however, does not seem to be used.

89 Potential Mood.

$10 U(l u)-q o b o$ ( $q$ expresses the palatial click), properly 'sub. stance of a thing,' ' self,' 'person,' ' reality,' is used adverbially to express 'really and truly' (Colenso).

4 Tile is an adjective meaning ' certain, when the name or number is not known' (Colenso). It takes the prefix 0 . with Cl. $\mathrm{r}$, like a-mnyama, etc.; hence inncwadi etile, not entile. The original meanings of inncreali (Colenso's Dictionary) are : ' mark, made to show whether any one has entered a hut in the owner's absence; niark or sign told to a person who enquires his way by which he will know whether he is going right or not ; tribal token, as marks cut in the skin,' etc., and hence 'token generally, proof,' and, since the introduction of writing, 'paper, letter, book.' The writer has been compelled 
to distinguish between the two last-named senses by the addition of English words. The sense in which he here uses etile secms to be equivalent to 'some . . . or other.'

$\$ 2$ kumbe, 'periaps, with the idea of hope or expectation' (Colenso), but also equivalent to the conjunction 'or.' The latter is often expressed (as in Nyanja) by a word meaning 'perhaps'-the possible altennatives being set before the mind as conjectures.

${ }^{43}$ An example of the quasi-pariciple mentioned on p. 118 , joku- =ya uku-: $y$ 'a referring to inncwadi.

"4 ake perf. of $a k a$ 'build,' which is often used in the sense of 'live.' Ak:lana (reciprocal applied form) means 'to live near together,--lit. ' to build for' (or 'with respect to ') each other: hence ouk aclene ' neighbour.'

ss yipi, interrogative, 'which'? (of two or more), agrees with indawo 9 following it. - $p i$ means either 'where?' or 'which ?' (see First Steps, \$\$169.I 7r). Yipi, as used here is the object following $k u$ : as subject it would have to be preceded by the copula (iy'ipi). - $p i$ 'where?' takes the inseparable subject-pronoun as prefix: upi? bapi? lipi? ipi? etc.

's -pi, 'where?' is sometimes suffixed to the verb in this way, and draws the accent forward (zavelápi).

'7 This is the Future, 'I will send,' not the Present, with' object-pronoun, 'I am sending you'; tuma in the simple form caunot take a person as object; to do this it must be put into the applied form (tminela), as will be seen a little lower down.

48 An adaptation of the English word 'steamer.' St being a difficult combination in $Z$ uln, $i$ is inserted between the two consonants, and the first syllable being taken for the 8 th prefix (isi-), the plural is izi-timela. (There is a genuine $Z$ ulu word isi-timela, meaning ' darkness '-see Colenso's Dictionary, s.v., p. $5^{87}$ ). The same tendency is observable in Swahili, where the Arabic kitab 'book' becomes ki-tabu, pl. vi-tabu. $V i-m n i$ has even been heard at $Z$ anzibar, as the plural of ' (lamp-) chimney.'

19 Literally, 'not I with it '- - $w^{\prime} 0$ 'prepositional form' of the prononn of Cl. 6. Amandhla has no singular.

50 Here tumela takes the direct object of the person, and, the verb being in the future, $k n$ is repeated, or rather two different $k u$-particles follow cach other. See note 47 above.

${ }^{31}$ esi-, Relative Particle agreeing with isi-timela 8.

52 sa may be rendered by ' now,' 'still,' 'already.' See First Steps, chapter XVI. 
ss Relative-the construction like engangigula (see note $3 \mathrm{I}$ ), except that the verb is understood and the whole drawn into one word. The pronoun -ko refers to $u k u$-gula.

s4 Vuka 'rise up from a recumbent posture; . . . rise in anger, be in a towering passion' (Colenso). The personal object-ngi-is unusual with this verb, but may be used because it is taken in the sense of 'attack,' which is perhaps not incompatible with the second meaning given above. In that case, however, one would have expected the Applied form, vukelu, which is, in fact, so used; and vuki may be a mere slip on the writer's part. For the auxiliary $k a$ see First Stcps, $\$ 315$.

\section{Connected Translation}

We arrived at St. Helena, and when I landed from the ship, our people were very glad to see me. I also was very glad to land, having no desire to remain on board any longer, as I had been very seasick. Yes indeed! dear lady coming from our country! these chiefs of the Zulus wish very much to come to England, to see that country and its people, and that famous city of London.

As to the news which has reached us from home-I have heard that my children are very ill with fever. In fact, fever has been very prevalent in the country; but there is one very good thing, even though this is the case-for there is that physician of our people whom you also know, who is treating the sick according to the instructions received by her from the Chief, her father. The people praise her greatly, and they are rejoicing through her in all the country-side of Ekukanyeni. . . .

Madam,-One of the chiefs of the Zulus, Ndabulko, has heard from me a story which I related to him, having heard it from you, of that tribe of black people among which you (formerly) lived, and (gathered it) from those books which you used to lend me to read, at the time when I was ill, at our home, Ekukanyeni.

Therefore he wishes very much to ask that you, Madam, would relate to him the affairs of those people. 
I have also told him that some of those tribes speak a language exactly the same as that of the Zulus-I mean those who call God by the name of Mulungu-and others whose language resembles ours (though not quite the same). He would be very glad if you could send him some book or other, or perhaps a letter, to give him an account of those people and tell him what place they live in, and how many tribes there are, and where they came from. Madam, as to my promise that I would send you by this mail, some of the traditional songs praising the Zulu Kings, - I am not able to do so to-day, but I will send you (some) by the next steamer. I am now very well in health, as that illness which I had at Ekukanyeni has not again attacked me here.

\section{Herero.*}

Story of the Old Woman with the Bag

$\begin{array}{ccc}\text { Pa-ri }^{1} & \text { omu-kadhe-ndu } & \text { omu-kuru-kadhe, } \\ \text { There was } & \text { woman } & \text { old, }\end{array}$
ngu-ya-twa ${ }^{4}$ ora-natye ${ }^{5}$ m'ondyatu. ${ }^{6}$ E-yuxa ${ }^{7}$ ri-mwe who put children into bag. Day one pa-rire ${ }^{8}$ oya-natye, oxa-kadhona ox-engi, ${ }^{9}$ ya-ire $^{10}$ there were children, girls . many, they went $k^{\prime}$ oku-nyanda ${ }^{11} \quad k^{\prime}$ e-rindi, ${ }^{12}$ n' a-rire ${ }^{13} \quad$ tyi $^{14}$ to play in pool, and it happened that va-hukura otu-vanda ${ }^{15} n^{\prime}$ omi-tombe ${ }^{16} n^{\prime}$ they took off - little-skirts and necklaces and oyi-mbakutu ${ }^{17}$ n' $^{\prime}$ ou-ndyendye ${ }^{18}$ n'odho-mbongora ${ }^{19}$ (see note) and beads and (see note) n' a-ve-pundu ${ }^{20} m^{\prime}$ omexa. Kombunda ${ }^{21}$ omu-atye and they descended into water. Afterwards child

* Published by C. G. Büttner in Zeitschrift für afrikanische Sprachen, Vol. I. (1887). 
u-mwe wa-tarere ${ }^{22}$ kokure, n' arire ty' a-tara one she looked far, and it happened that she saw omu-kadhendu omukurukadhe, ngu n' oka-ti m' eke woman old, who with little-stick in hand, oru-horo-ti, ${ }^{23} \mathrm{n}^{\prime}$ ondyatu p' etambo. $\mathrm{Nu}^{24}$ ingwi a-long-stick, and bag on back. And that omu-kadhona wa-tyere $k$ ' ova-kwaw $0^{25}$ : 'Indyee girl said to (the) others: 'Come

tu-tupuke $e^{27} \quad$ 'ka-kurukadhe $e^{28}$ ingwina, let us run-away-from little old-woman yonder, ngu-twa ova-natye $m$ ' ondyatu.' Indino ${ }^{29}$ ty 'a-tya ${ }^{30}$ who puts children into bag. Now when she said nai, avehe ${ }^{81}$ arire tyi va-piti ${ }^{92} \quad m^{\prime}$ e-rindi okuso all it happened that they came out from pool to tupuka, nu auhe ${ }^{33}$ wa-torera oru-hira ${ }^{34}$ r-omurun-away, and every she took apron of

kwawo nu omitombe yy-omu-kwaw $0^{85}$ tyinga va-ri other and necklaces of other as they were m' oru-haka r-oku-tupuka, ndino arire tyi in haste of running-away, now it happened that ya-tupuka $k^{\prime}$ onganda. ${ }^{36}$ they ran to kraal.

$N^{\prime}$ omuatye umwe wa-dhembire etanda ${ }^{37}$ e-purura ${ }^{37}$ And child one she forgot (see note) (see note) p' ehi. ${ }^{88} \quad$ Ndino 'kakurukadhe arire ty' on ground. Now little-old-woman it happened that

a-pingene p' epurura, n'a-tora, she followed (and came) on epurura, and picked-up, arire ty' a-twa-mo m' ondyatu. ${ }^{89} \quad \mathrm{Nu}$ ing' it happened that she put-in into bag. And that omuatye unwe wa-tya: me-yaruka ${ }^{10}$ me-ka-pura ${ }^{11}$ child one she said: I return I go to ask epurura randye k' omu-twa, ${ }^{22}$ oka-kurukadhe, epurura my from Bushwoman, little-old-woman, 
tyiri ! ${ }^{48}$ hi n' oku-ri-etha-ko. ${ }^{44}$ Imb' oxa-kwawo truly! not-I with leaving-it-there. Those others xa-tyere : muatye ! arikana, ${ }^{45}$ omundu eingwi, ${ }^{46}$ they said: Child! please (beware of) person that, ngu, maku-dhu, ${ }^{47}$ utwa ovanatyo $m$ ' odhondyatu, who, it-is-said, she puts children into bags nu i-ko! $!^{43}$ N'e wa-tyere: ${ }^{49}$ kako! me-ka-eta and goes away! And she said: No! I go to bring epurura ra mama oku-kotoka k'omutwa epurura of my-mother to return from Bushwoman oka-kuru-kadhe. $\mathrm{Nu}$ imb' oxakwawo axehe little-old-woman. And those others all

va-ire k'onganda, n' eye, a- kotoka, a- ende they went to kraal, and she, she returning, she going

$$
\text { n' a- } \text { rixi }^{50}
$$

and she weeping n' oma-kono with hands ty'a-ri when she was m'ondyira kokure, on road far-away, k' otyi-uru. on head.
$\mathrm{Nu}$ And

\section{a-ravaere, ${ }^{51}$} she cried-aloud, a-ithana, arire ty' kakurukadhe, eta nguno epurura ra mama, little-old-woman, bring here epurura of my mother, ndi wa-tora. $\mathrm{Hu}$ omukadhendu wa-tya: which you picked-up. And woman she said:

Indyo, kambura.

N'e-a-ende, a-me-utuka, arire Come here, take (it). And she went, she running, and

ty' a-tumbuka popedhu, n' a-tya: Kakurukadhe, so she approached near, and shesaid: Little old woman, eta nguno epurura ra mama. N'e wa-tya rukwao: $:^{63}$ bring here epurura of my mother. And she said again :

\section{Kambura, n' arire ty' a-tumbuka, n' arire}

Take (it), and so she approached, and it came to pass
ty' e-mu-tono
that she her struck
oru-pyu
k' otyi-tama, on cheek,
nu and 
okakurukadhe

little old woman a- hakahana

she hastened oku-wira-ko s $^{\text {ss }}$

to fall-upon-her

n'a-petere $\quad$ m' ondyatu, n'arire ty' a-kutu and she doubled (her) up into bag, and so she tied ondyatu n'omuyia, n' arire ty' a-kutu ondyatu bag with thong, and so she tied bag p'etambo, n' a- yereka, ${ }^{37}$ on back, and she carried (her), it happened that a-i a-tedha ku-kwa-i ${ }^{58}$ ova-natye she went she followed where-there-went children

k'onganda.

to kraal.

a-mwa-tu it-there-died
$\mathrm{Nu}$ m' onganda

And in kraal

omu-kandi. ${ }^{60}$ feast.

arire ty' $^{\prime}$

onguroxa n' a-kare kongotwe y-onganda m' okuti. evening and she sat behind the kraal in the field. $\mathrm{Nu}$ kombunda oya-natye ye-mu-munu, ${ }^{62}$ arire And afterwards children they-her-saw, it happened tyi ya-raerere $k u$ ihe $^{63}$ a-ye-tya: Tate, ${ }^{63}$ that they cried aloud to their-father they said: Father, omukadhendu ingwi eingwi ${ }^{64}$ okakurukadhe nguwoman this she (is) that little-old-woman who a-dhepa ova-natye nu ngu-a-twa-mo omu-atye wetu she kills childreil and who has put in child our $m$ 'ondyatu. No ya-purire $\mathrm{ku}$ ihe a-ve-tya: into bay. And they-asked from father, saying:

Nga-tu-mu-tyite xi ${ }^{65}$ We are to (to) her do what?

Wererekee ${ }^{66}$ onguroya Catch-with-guile (in) evening oku-rara. $\mathrm{Nu} \mathrm{imb}(\mathrm{a})$ to sleep. And these
$\mathrm{Nu}$ ingwi ihe wa-tyere: And this father he said : tyi mamu-aruka ${ }^{67}$ when you (pl.) begin oya-natye onguroya children (in the) evening

tyi ma-ye-aruk (a) okurara, ye-ere ${ }^{\text {es }}$ when they began to sleep, they came to 
okakurukadhe n' a-ve-tya: Hama kakurukadhe, little-old-iwoman and they said: Mother, little-old-woman, mo-vanga tyike, ${ }^{69} \mathrm{ku}$-tya tu-ku-pe? N'e you want what that we may give you? And she wa-tyere: namba ${ }^{70}$ ami me-vanga tyike? vanatye she said: now, for my part, I want what? children vandye, ke-ndyi-pahere ${ }^{71}$ uri $^{72}$ orukune (o) ru-nene ; my, go (for) me look-for just log-of-wood large; mba $\mathbf{t}^{73}$ ombepera. N'owo va-ire, arire I am dead (with) cold. And they, they went, it happened tyi va-ka-paha oru-kune (o)ru-nene, ndu that they went-to-seek log large, which ya-muna rukuru, ${ }^{74}$ n'arire tyi ya-tora they saw long-ago, and it happened that they-lifted omumbeumbeu, ${ }^{75}$ n'aripe tyi va-eta,

all-together and it happened that they brought (it), a-ve-tya; kakurukadhe, twe-ku-etere ${ }^{76}$

saying: Little-old-woman, we-to you-have-brought orukune oru-twedhu, ${ }^{77}$ ndu-rara n' $\log \quad$ thick, which sleeps omundu, with person, omukadhendu okakurukadhe woman old o-tya ove, ${ }^{78}$ as you, n' a-yanyuka oyiandonya." N'arire and she stretches (herself) out (on) back. And tyi ye-mu-etere orukune. M' ou-tuku so they (to) her brought log.

In night

ty' a-rara, ova-natye arire tyi when she slept," children and so ve-kutura ${ }^{\text {so }}$ they untie ondyatu, n' arire tyi va-itha-mo omu-atye bag, and so they take-out-of-it child

\section{n'oxi-na} and things otjipurukute $^{\mathrm{R}_{2}}$ arire ovi-tyuma
vessels nu m'ondyatu
and into bag m' into dry bag it happened that they collected into (it) 
ou-puka, ${ }^{83}$ ngamwa, ${ }^{84}$ 'kapuka ke-rumata akehe. ${ }^{83}$ animals, all sorts, animal it bites everyone. Nu ondyatu otyi-purukute, arire tyi ya-kutu rukwao, And bag dry bag, so they tied again, n' owo a-ve-i k'onganda n' a-ve-twara omu-atye and they went to kraal and they carried child n' ovi-na mbi ${ }^{\Leftrightarrow}$ ya-ithire m' ondyatu, nu and things which they had taken-out from the bag, and

ve-yi-twarere they-then-brought

wa-dhepere he lilled ( $a$ beast for) omu-atye. $\mathrm{Nu}$ the child. ku ihe. to the father.
Ihe

The father

\section{omukandi, a-koho nao ${ }^{\mathrm{gT}}$} the feast, he cleansed with it kombunda afterwards

'kakurukadhe the old woman

arire ty' a-nununga ondyatu, a-tyangovathi, ${ }^{48}$ it happened that she felt the bag, she thought,

$\begin{array}{cccc}\begin{array}{c}\text { omu-atye } \\ \text { the child }\end{array} \text { in it } & \text { e-ri } \text { she }^{\text {sos }} \text { arire } & \text { ty' a-kutura } \\ \text { she untied } \\ \text { ondyatu } & \text { n'e } & \text { wa-tire } & \text { omadhenge } \\ \text { the bag and she } & \text { was (nearly) dead } & \text { (with) rage }\end{array}$
tyinene, kuty $a^{50}$ oxanatye ya-ithire-mo m'ondyatu. truly, that the children had taken-out from the bag. Ndino oupuka arire tyi wa-sakumukire Now the animals it happened that they crawled-out mu-ye, n'arire tyi wa-hiti m'orutu rwe aruhe, on her, and so they entered into body her whole, $m^{\prime}$ otji-nyo na m' oma-yuru na $m$ ' omeho, n'arire into mouth and into nostrils and into eyes, and so ty'a-koka. Oputyo. ${ }^{01}$ she ended. 'This is all. 


\section{NOTES}

$1 \mathrm{~Pa}$ locative prefix ; $r i$ verb 'to be.' Pari is the perfect tense, the one with the suffix corresponding to -ile is a 'Pluperfect,' or distant past. In the Present, the prefix would be pe, not pa.

3 Herero has a somewhat peculiar way of forming com. pounds. Instead of saying omu-nulu omu-kadho 'female person,' or using omu-kadhe by itself as a noun, 'woman,' the root $-n d u$ is suffixed. See ante, p. 215 , and note 23 , on oruhoroti; also Meinhof, Lautlehre der Bantusprachen, p. 135. Another curious featuse, to some extent analogous to the above, is the insertion of the interrogative particle $k e$ between prefix and root, as omu-ke-ti, 'what sort of tree?' omu-ke-ndu, ' what sort of person?'

3 -kadhe is suffixed to omu-kuru, which by itself means 'old (person),' in order to indicate the feminine. -kazi is similarly used in Zulu (as in indoda-kizi 'daughter,' inkosi-kazi 'queen': there is no independent word $u m-k a z i)$, though less frequently. The Herero are silpposed to have a mixture of Hamitic blood, or at any rate to have been in contact with Hamitic tribes (e.g., the Ga!la or Somali) before their soutlı. ward migration, and they nig!ht have borrowed from them the notion of a feminine suffix-which is quite foreign to the genius of the Bantu languages.

1 ngu relative pronom of the thir? person. In the Present it immediately preceles the verb-stem; ngu-twa 'who puts'; in the Perfect it is followed by -a: ngu-a-tiva (or ngu-ya-twa; the $y$ no doubt introduced to prevent the two syllables from gliding into ngwa) 'who put.'

5 The singular of this noun is omu-atye, the $n$, which, as we know froin other languages, belongs to the root, seems to have dropped out.

- ondyatu 9 is a leather bag or wallet, carried over the shoulder by people who go out to collect roots, etc.

7 The $5^{\text {th }}$ prefix is in Herero abbreviated to $e$ (as in $Z$ ulu to i): its full form is eri, the pronoun ri. Ejuva is the same word as Sango lidyuva, Nyanja dzuwa, Swahili jua, etc.

8 Rira 'become,' 'be,' (rire is the Historic Aorist); for its idiomatic use as an auxiliary, see below. 
${ }^{9}$ ov-engi for ova-ingi, arljective agreeing with ovanatye. ovakudhona 'girls' is, though a nomn, practically equivalent to an adjective, being placed in apposilion with ovanatye.

10 ire, pluperfect of the defective verb y'a 'go.'

"The frequent nse of $k n$, even where it would seem superfluous, as here before the Infinitive, seens a peculiarity of Herero.

12 Same root as Swahili and Pokomodindi 'hole' or 'pit'more especially applied to a deep place in the bed of a river or the sea. It also appears in such place names as Lindi, Malindi, Kilindini (the harbour at the som h end of Mombasa Island), etc. The Herero use erindi to mean what is called in South Africa a 'pan'-i.e., a ciepression in which water collects during the rains, drying up partially or wholly after they are over.

1s a.rire, followed by $t y i$ is equivalent to 'it happened that,' 'it came to pass that,' etc.,-or merely ' and so.' 'The pronoun $a$ (instead of $u$ ) is prefixed to the 'Historic Aorist' and the Subjunctive.

14 tyi 'say,' like $Z$ ulu ti, here 'used as a conjunction (cf. Zulu $u k u t i)=$ that.

$15 \mathrm{Pl}$. of oru-vanda $\mathrm{I2}$; the singular is not used in this sense. The word means a kind of apron or kilt worn by little girls (under 15 or 16 ) and consisting of a number of hide thongs (in Cape Dutch rimpies), hanging from a belt. In front these reach the feet,--behind they are long enongh to sweep the ground. A more ornamental kind of okavanda is the otjim. bakutu (pl. ovimbakutu), mentioned a little lower dowil, which consists entirely of omitombe (sce next note).

16 omitombe 4 are strings of small disks cut from the shells of ostrich-eggs, and rounded hy rubbing their cdges on a stone. As the process of preparing these 'beads' is slow and tedious, they are highly valued. They are worn, either in single strings, as necklaces, or the strings are looped together to form-a sort of bodice, called onutombe 3 .

17 ovimbakntu, see note 15 .

${ }^{18}$ oundyendye $\mathrm{I}_{4}$, (imported) glass beads, usually worn in strings round the neck.

$19 \mathrm{Pl}$. of ombongora, 9, a string of disks similar to the omitombe (see note $\mathrm{I} 6$ ), but made from the shells of snails or other molluscs, 
20 3rd pers. pl. 'emphatic aorist' of punda 'descend'; in this tense the final vowel is assinnilated to that of the stem.

${ }^{21}$ An adverb composed of $k u$ and ombunda 9 'the back'therefore 'behind ' or 'after.' In Herero, the $u$ of $k u$ is often elided before another vowel, instead of turning into $w$.

${ }^{22}$ 3rd pers. sing., pluperfect of tura 'look.'

23 oru-horoti is a compound of omu-ti analogous to omu-kadhe$n d u$. It means 'a long stick,' and is used in apposition with oka-ti, so that it is practically an adjective='long.' But Brincker's Dictionary does not give orlhoro in any sense which wonld imply this.

$24 \mathrm{~N} u$ is used to join sentences (or, in other words before a verb) $\rightarrow$ na nouns.

$25-k u a o(=k w a w o)$ is given in the grammars and dictionaries as an aojective meaning 'other,' but really it is the possessive pronoun of the 3 rd pers. pl. agreeing with Class 15. All three persons are used with the prefixes of Class I and Class $2:-$ omu-kwetu 'my (our) companion, house-mate, person of the same village, etc.,' pl. ova-kwetu, omu-kwenu 'you, etc.,' omikwar'o ' his, her, their, etc.'-like Znlu abakiti (see p. 236 ante) of which, however, there is no singular form corresponding to omit-kwetu.

26 Imperative plural of $y a$ ' come.'

${ }^{27}$ tupukee, applied form of tupuka, taking the direct object (o) kakurukadle.

29 Diminutive of omu-kurukadhe (note 3). Compare the use of kizee in Swahili for an old woman, mostly used of a witch or other uncanny person.

${ }^{29}$ Indino, properly a demonstrative agreeing with eyura 5 'day' (lit. 'sun ') : 'this day,' and so 'now.'

so Tyi here used in the sense of 'when.' Tya is the form used as an independent verb, when the meaning is actually 'say.'

${ }^{81}$ avehe 'all,' agreeing with $\mathrm{Cl}$. 2. The root is he which always prefixes $a$-followed by the personal or class-pronoun: $a-t u$-he 'all of us,' $a$-mul-he 'all of you, etc.'

\$2 'Historic Aorist' (Viehe), onc of the tenses which assimilates its final vowel to that of the stem-cf. pundu (note 20).

ss Auhe: -he 'all' agreeing with $\mathrm{Cl}$. I-singular of avehe. 
84 oruhira I I, a goat-skin apron worn next the skin, the other articles mentioned being put on over it. The initial $r$ of the next word stands for $r a$, the I Ith possessive particle, agreeing with oruhira. This elides the $a$ (instead of combining it, as in Zulu, with the initial vowel of the noun) - no doubt because the initial $u$ has already been modified to 0 (as is also the case in Ganda).

${ }^{86}$ The possessive particle of Class 3 is $v y a$ (not as in most languages $y a$ ), preserving a hint of the original $\gamma$. $N u$ before omitombe seems to contravene the rule given in note 24 , but may be a printer's error.

s6 onganda 9 is the word generally used for 'kraal,' 'village'; the word used in S.W. Africa is werft (Cape Dutch, though in this sense it seems to be peculiar to that district)-see Pettman, Africanderisms, p. 550. The Zulu umuzi 3 represents the word used in most Bantu languages; it is found in in Herero as oru-dhe II, meaning 'principal village.' Brincker translates onganda by Viehdorf 'cattlevillage,' which among the pastoral Herero would be the normal type of settlement. A village without cattle is ondua (which, ex hypothesi, appears to be a Nama village) or otjihuro.

s7 etanda and epurura appear to be more or less synonymous and consist of strings of iron and copper 'beads,' or hollow balls, fastened to the lower edge of the omutombe.

88 ehi 5 is the word which appears in Swahili as $u t i 9$; in $Z$ ulu, Nyanja, etc., as pa-nsi (it is not used by itself); just as -he 'all,' corresponds to Nyanja -onse and Zulu -onke. But it is something of a puzzle that $Z$ ulu should have the ns in pansi, and so is the elimination of the vowel in Herero).

89 Herero, as we have seen, prefixes $p a, k u$ or $m u$ to a noun, and does not possess the suffixed locative of $Z$ ulu etc. It also snffixes the pronouns - po, -ko - mo to the verb accompanying the noun-a usage also found in Nyanja, where the noun, moreover, frequently takes both prefix and suffix as m'nyumba-mo 'in the house.'

`The inseparable pronoun in Herero varies to an extraordinary degree. ' $I$ ' is me- with the Present, e- with the Aorist, mba- with the Perfect, and with the 'Jussive,' ng'e- or $h i$-; while it also has a distinct object-form ndyi-.

¿The particle $k a$ has a 'directive force' as mekatona 'I go (to) strike '-i.e., 'I am going to strike.'

2 Omm-twa, pl. ova-twa (cf. Zulu umu-twa, aba-twa) originally meant 'Bushman,' but seems to be used in a depreciatory 
sense of any non-Herero, and hence with the meaning of 'slave,' 'bondsman,' etc. Omu-tyimba, applied further on to' the same old woman, is used by the Herero of people who have no cattle, but pick up a living as they can in the Bush (and so $=$ ' pauper'); but other tribes apply it to the Herero themselves.

${ }^{43}$ tyiri, invariable, is called by Brincker an 'interjection of assurance.'

${ }^{44} e d h a=$ 'leave'; 'ri refers to epurura, ko, locative pronoun (I7).

45 arikana an exclamation/ of entreaty, variously rendered according to the context. Similar expressions are found elsewhere-e.g., the Yao chonde! It looks like the imperative of a reciprocal verb, but none such appears to be now in use.

46 a-ingwi for eye ingwi. Eye is frequently contracted to $e$.

47 dhu from dha 'come from' means, with the indefinite subject $(k u)$ 'it is said,' $m a-k, u-d h u$ is the tense called by Brincker the 'Simple Present,' which prefixes ma to all its pronouns.

$48 i$ is the aorist of the defective verb $y a$ ' $g \circ$ '; $k o$ the locative pronoun, here best rendered by 'away,' but a better equivalent would be the French $e n$ in s'en aller.

${ }^{49} e(y e)$, or eye, separable personal pronoun: tyere, pluperfect of $t y a$.

50 a-riri: this, like the preceding verbs is a participle, which in the simple form always assimilates the final vowel. Rira 'weep' (Zulu lila, Nyanja lira, Swahili lia, Pokomo ia) must not be confused with rira ' become.'

51 Ravaera, applied form of rava 'thrust in' (used, e.g., of Moses putting his hand into his bosom, etc.). The sense of ' crying aloud' is derived, according to Brincker, from that of 'thrusting the tongue into the throat' (stark die Zunge in die Kehle stecken); in the applied form 'cry aloud to' some one, ithana (cf. Nyanja itana) is properly a reciprocal; Swahili has the simple form ita.

52 See note 42. $o$ is elided in this word and the next, because they are in the vocative.

58 rukwao, used as an invariable adverb, ' again,' but really an adjective agreeing with oru-vedhe 'time,'='another time.'

${ }^{54}$ Historic Aorist. The rule of vowel-2ssimilation is not usually applied to verbs of more than two syllables, but there are some exceptions. 
${ }^{35} \mathrm{Ko}$ locative preposition. According to the usage of most Bantu languages, one would have expected oku-mu-zvira.

ss Pluperfect of peta, 'bend,' Swahili peta 'bend,' 'curve,' from which cömes pete ' ring.'

${ }^{67}$ vereka means to carry on the back, as native women do babies: bereka is similarly nsed in Nyanja, and beleka (or beleta) in $Z$ ulu, where im-beleko is the prepared goat-skin used for tying the child on.

68 Relative of the $k u$ - class in the past. We must understand something like 'to the place,' or 'at the time' after a-tedha.

s9 $m w a-$ is the locative pronoun for the past tenses, the subject of the verb being m'onganda. vadherwe is the passive of the applied form of vadha 'reach.'

co Omu-kandi is a feast of meat, when a bullock is slaughtered on special occasions. The feast is said to 'die' because it was just ending. $A-m w a-t h u$ seems to be a mistake for $a-m u-t h$, which is the Historical Aorist of ta 'die.' (This verb has a dental $t$, which distinguishes it from $t a$ 'be equal with.')

61 ere plup. of $y a$ ' come,' which takes we instead of wa for the pronoun of the $3 \mathrm{rd}$ pers. sing. in the past tenses. This and the aorist $y a$ (instead of $i$ ) distinguish it from $y a$ 'go away.' Okw-ti is really the locative (I 7 ) which in Herero is merged into the infinitive class (15)-see ante, p. 85. It means the open country-in fact is best translated by the Dutch veld.

$62 m u$ is here the objective pronoun of the Ist class, not the locative prefix.

es ihe 'his, her, their father '-cf. Zulu zyise. 'Your father' is iho (Zulu "lyihlo); 'my father' tate (cf. Nyanja tate, atate). This form is found in a good many languages, while others, like $Z$ ulu and Swahili, prefer (u)baba.

$$
\text { 64 } e=\text { eye : eye ingwe 'she (is) this' (or 'that') one. }
$$

os Subjunctive. In principal sentences (as here) this has $n g a$ - prefixed to it. For tyita' do,' cf. Nyanja chita. $v i$ is an invariable interrogative.

66 Brincker translates werereka by ' do a thing treacherously; (verrïterisch etwas $t u n$ ).

67 Second person plural of the Present, which prefixes ma to all the pronouns, though in the three persons of the singular it is contracted with them into me, mo, ma.

68 See ante, note $6 \mathrm{I}$. 
o9 Tyike 'what?' stands by itself after a verb, as here. When the question is asked, 'what is (are) he (it, they)?' - -kwatyike is used with the proper class-prefix: omukwatyike, ovakwatyike, otyikwatyike, etc.

70 In the original $n^{\prime} a m b a$, which, Prof. Meinhof tells me, is a mistake. "It should be namba " now," which is derived from $p a$ ' ('at').

71 Pahere (e) imperative plural of applied form (pahera) of paha 'seek.' Ke is the 'directive particle' $k a$, which modifies its vowel when followed by an object-pronoun. 'Go and seek for me a log.'

${ }^{2}$ uvi an invariable (adverbial) particle, equivalent to 'just,' 'only,' 'so,' ctc.

73 For $t u$, perfect of $t a$ 'die '; ombepera, a noun of the gth class.

74 Originally an adjective ('old') agreeing with ortl-vedhe, cf. note 53, on rukwao. A fairly good supply of firewood is to be obtained from the mimosas and acacias of the Herero country (Büttner). People are always on the look-out for dead logs which will burn easily, and, if they see one, note the place so that they can return for it when wanted. These girls remembered that they had noticed one in the bush some time before.

75 Translated by Brincker and Viehe 'zusammen,' ' gemeinsam'; it is evidently a noun of Class 3 , but the original meaning is nowhere given.

${ }^{76}$ Applied form of eta (Zulu leta) 'bring,' which enables it to take the direct object (- $k u$-object-pronoun 2 nd pers, sing.). $T w e$, instead of $t w a$, because $a$ always becomes $e$ before the object-pronoun.

77 Properly 'a log like a bull.'

78 i.e., 'which an old woman like you can sleep with': meaning that it is large enough to burn through the night, so that a person can sleep comfortably, without getting up to put wood on the fire.

79 Properly a plural noun of Class 8 , but it only seems to be used adverbially. ondonya 9 is both noun ('back') and adverb (' behind').

80 Reversive of kuta 'tie.'

81 A general word for 'vessels,' 'implements,' ' household stuff.' Chuma, in Yao, meaus 'beads,' (applied in Nyanja to property of any sort); in Swahili, 'iron'-but it is not certain that the three are the same word. 
82 This seems to be a descriptive epithet applied to the bag and to mean anything made of hide which is hard and dry and rattles.

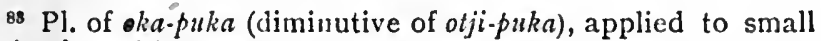
animals and insects.

84 ngamwa, indefinite numeral meaning 'all sorts,' of any kind whatever.'

85 'Every biting animal.' rumata 'bite': the simple form, ruma does not seem to be used in Hercro. $K e$ pronoun of $\mathrm{Cl}$. I 3 with the present tense.

${ }^{86}$ Relative Pronoun of Class 8 , agrecing with its antecedent ovina.

87 ' with it' seems to refer to omukandi. No doubt some sort of ceremonial purification is intended, to free the girl from any evil influences which may have emanated from the old woman. The sentence seems to inean that the father killed an extra beast (wa-dhepere imperfect of the Applied Form, not Pluperfect) as part of the ommkandi, which was not yet finished.

${ }_{68}$ This and some allied forms are derived from tya 'say' and ndovathi (ndovadhi) 'perhaps,' 'if haply,' and mean 'think,' 'be of opiıion that.' . . . .

${ }^{89}$ Om'eri contracted from omu eye u ri. (Information kindly urnished by Professor Meinhof, and see Brincker, Würterbuch, p. 83 ).

Do kutya used synonymously with tyi.

91 Opu, locative adverb, 'there,' ' in that place.' Combined with a pronoun, as here with -tyo ( $\mathrm{Cl} .7)$ it means 'that's all' (literally 'there (is) that ')-i.e., 'this is the end of the story.'

Connected Translation

There was once an old woman who used to put children into her bag (and carry them off). One day, a number of girls went to play in a pool; they took off their clothes and ornaments and went down into the water. After a time, one of them, looking out to a distance, happened to see an old woman who had a long 
stick in her hand and a bag on her back. So the girl said to her companions: 'Come, let us run away from the little old woman yonder, who carries off children in her bag.' When she spoke thus, all of them came out of the pool, in order to run away, and every one picked up the apron and the necklaces of her companion, as they were in such haste to run away. So they ran as fast as they could back to the village. But one child forgot her epurura and left it lying on the ground; and the old woman went up to it, picked it up, and put it into her bag. So the girl said, "I ain going back to ask that old Bushwoman for my epurura; I am not going to leave it there, truly!' But the others said, 'Please don't, dear!- they say that person puts children into bags and goes away with them!' She answered, 'No, I must get my mother's epurura back from that old Bushwoman.' So all her companions went home, but she turned back, and walked along, crying, with her hands on her head. And while she was on the path, she called out to the old woman, a long way off, saying, 'You horrid old pauper! bring me my mother's epurura, which you have picked up.' The old woman said, 'Come here and take it.' The girl ran up to her, and when she was quite near, said again: 'Old woman, bring my mother's epurura here!' The old woman said again, 'Take it!' and when the girl came close to her, she slapped her on the cheek." And then the old woman made haste and seized her and thrust her into the bag, and then tied up the bag with hide thongs and fastened it on her back and carried it so, and went on in the direction which the girls had taken to reach their village, where a great feast had been going on and was nearly ended. The old woman arrived there in the evening and sat down outside the fence in the open field. When, later on, the girls saw her, they called out

* It is not clear from the text, as it stands, whether it was the old woman who slapped the girl, or vice versa. But the women who related the story to Büttner insisted that the former was the case. 
to their father, saying, 'Father, the old woman out there is the one who kills children, and she has put our child into her bag.' And they asked their father, saying, 'What shall we do to her?' And their father said, 'Wait till the evening, when you are all thinking of going to sleep, and then you can entrap her.' So, in the evening, before those girls lay down to sleep, they came to the old woman (outside the kraal fence), and said, 'Mother, what would you like us to get for you ?' And she said," For my part, my children, what I should like is that you should just find me a good big log (to burn), for I am well-nigh dead with cold.' So they went to look for a large log which they had marked down some time before, and lifted it all togethet and carried it back and said, 'Little old woman, we have brought you a regular whopper of a $\log$, such that a woman can sleep all night beside it, lying comfortably on her back.' So they brought her the log (and put it on the fire).*

But in the night, when she was asleep, the girls went and untied the bag and took out the child and everything else that was in it, and they collected and put into it all kinds of biting insects and reptiles,-every creature that bites. And they tied up the bag again and went into the kraal, carrying with them the little girl and the things which they had taken out of the bag, and brought them to their father. And he killed another bullock for the feast, so as to purify his daughter with it. But, after a time, the old woman got up and felt the bag, thinking the girl was inside it (but she was not there), so she untied it and nearly died of rage, indeed, because the other girls had taken her out. So then all the animals crawled out on her and got into her mouth and nose and eyes (and stung her to death), and that was the end of her. That is all.

* It is to be supposed that the old woman had made a little fire for herself with such dry sticks as she could find, and only wanted fuel to keep it up through the night. 


\section{ILA*}

The Tortoise and the Hare

Ba-nyama ${ }^{1}$ bonse' ba-ka-fwe ${ }^{2}$ nyotwa, ${ }^{3}$

The animals all, when they were about todie (of) thirst, ba-amb,' ati :" 'A-tu-lukanke lubilo, they spoke, saying: 'Let us run (with) swiftness, tu-bone ati a-ka-shike ${ }^{5}$ ku menzhi.' (so that) we may see that he may arrive at water.' Pele, Fulwe ngu a-ka-zhala ${ }^{6}$ bana But Tortoise (it is he) who produced children banjibanji: u-la-ya-bu-zhika ${ }^{7}$ mwixu; ${ }^{8}$ umwi very many: he goes burying (them) in ground; one mxana ya-mu-zhika, ku-mbadi $\mathrm{ku}^{9}$ menzhi. child he him buried, by side of water. Inzho banyama baamb', ati: 'A-tu-tiane, So the animals they spoke, saying: 'Let us race, tu-ka-shike ku mu-longa, tu-ka-nwe menzhi.' when we arrive at the river, let us drink water.'

Ba-fuma, ba-lukanka, bonse baamb', ati : They started, they ran, all they spoke, saying: 'Tu-bone ${ }^{11}$ ati nguni ${ }^{12}$ u-ka-tanguna ${ }^{13}$ ku-shika.' 'Let us see that who is it he will be-first to arrive.' Pele ba-lukanka odimwi, ${ }^{14}$ ba-fulwe ba-la-yaBut they ran again, tortoises go along bu-amb'15 ati: 'Imbelembele, saying :

o-ba-shana. those who are with

* Ila is spoken in North-Western Rhodesia, by the people commonly called the Mashukulumbwe, whóse proper name is Ba-ila. They live on both banks of the Kafue, one of the northern tributaries of the Zambezi. They are closely allied (at any rate as far as speech goes) with the Balonga and Basubiya. The above story is extracted from the Rev. E. W. Smith's Handbook of the lla Language (see Bibliography). 
sulwe. ${ }^{16}$ Odimwi balukanka, odimwi baamb' ati : Mr. Hare.' Again they ran, again they said: 'Imbelembele, obashanasulwe!' Dimwi izuba $^{17}$ 'Forward, Hare \& Co.!' Another sun dia-ibila, ba-la-ya-bu-ompolola: it set, they go along shouting:

' Dimwi ${ }^{18}$

'Another (day)

kwa-shia. ${ }^{19}$ Imbelembele, obashanasulwe! it has grown dark. Forward, Hare \& Co.!'

Dimwi banyama bamana kufwa, ${ }^{20}$ mwana ${ }^{21}$ fulwe Next day the animals finished to die, child (of) tortoise o-wa-ku-di ${ }^{22}$ kumbadi ku menzhi, wo-ompolola ${ }^{29}$ he who was beside the water, he shouted

ati : 'Imbolembele, obashanasulwe!' Wezo saying: 'Forward, Hare \& Co.!' That

Sulwe wa-ya ku-fwa, ${ }^{24}$ wa-bula ${ }^{25}$ o-ku-shika ku Hare was going to die, he was-without arriving at menzhi. Mwana fulwe owakudi kumbadi water. Child (of) tortoise. who was beside

ku menzhi wa-ba-letelela ${ }^{28}$ menzhi mu-kanwa: water he brought-for them water in mouth:

ke-ziza ${ }^{27} \quad k u-l a p w i l a^{27}$ banyama. Ati : let him come to spit-out-for animals. He said "Ndimwe mwa-ku-zumanana, ati, "Fulwe "It is you you were quarrelling, saying, "Tortoise, tu-la-mu-shia $a^{20}$ we shall him leave (behind) lubilo." Inzho (in) swif tness." So

mwa-ba-nji ${ }^{30}$ ku-shika? you have become what to arrive?
Mu-di ba-nichi. ${ }^{31}$ You are children.

Ndimi mukando, nda-shika ku menzhi. It is I (who am) a big man, I bave arrived at water.

\section{Mudi banichi.' Ngonao ${ }^{82} \quad$ wa-ba-lapwila} You are children.' Immediately he spit-out-for them menzhi a-ku-di mu-kanwa. Ba-bula water it was in (his) nouth. They were without 


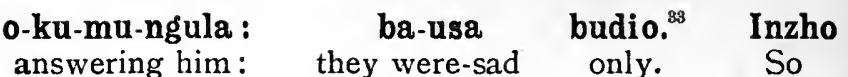
banyama baamb' ati : 'Tu-ka-fumbe ${ }^{34}$ mu-kalo, animals they said : 'Let us dig water-hole, tu-ka-ku-nwa ${ }^{85} \mathbf{u}^{36}$-mukalo menzhi.' Inzho that we may drink in water-hole water.' So ba-fumba. " Basulwe ba-kaka kufumba, inzho they dug. Hares they refused to dig, so baamb' ati: ' $\mathrm{Bu}^{37}$ mwa-kaka kufumba, inzho they said: 'Since you refused to dig, so ta-mu-ti-mu-nwe ${ }^{38}$ menzhi. you shall not drinli water.

ku-fwa

to die

bakaka they (who) refused nyotwa.' (of) thirst.' kufumba, ba-ya Mu-la-mana You shall finish

Kwa-shia, It grew dark, ku mukalo, to dig, they went to hole, ba-kwiba. ${ }^{39}$ Inzho banyama bamwi baamb' ati: they stole. So animals other they said :

'A-tu-ba-zube ${ }^{40}$ basulwe, tu-ba'Let us hide (from) them the hares, (that) we may see bone.' Inzho ba-ba-bona, ba-ba-kwata, them.' So they saw them, they caught them, ba-ba-anga. Pele baamb' ati: 'Bu mwathey bound them. But they said: "Since you tu-anga, inzho twa-beba. A-mu(have) tied us, so we (have) repented. Letyou tu-tole ${ }^{41}$ a-bwina, mu-ka-tu-yayile ${ }^{42}$ ngona. $^{43}$ carry us to burrow, (that) you may kill us just there.' 


\section{NOTES}

1 Nyama, in most Bantu languages, is a noun of the ninth class (though, in Swahili, when meaning 'an animal,' it usually takes the concords of the first). In Ila it has the prefix mи(pl. ba-nyama 2) and is thus included in the person-class. Other names of animals are treated in the same way, c.g., munyati 'buffalo' (Z. innyati 9 ; Ny. njati) mu.sef. 'eland,' mu. zovu' elephant.' Some names of animals (also included in Class I) are compounded with the prefixes sha $=$ "father of " and $n a=$ ' mother of ' (Stnith, p. 18). This seems to be dis. tinct from the use of sha- or shana-as an honorific prefix, e.g., shana-sulice, for sulwe I 'hare.' (Sulwe, ordinarily, has no prefix in the singular, but, being included in Cl. I on account of its meaning, its plural is ba-sulwe 2.) This is very common in African tales-e.g., in Ganda 'elephant' is enjovu 9, but when he figures in a story he is called Wanjovis, and in Yao stories the names of animals have the title Che prefixed to them. (Cf. 'Brer Rabbit,' 'Miss Cow,' etc.)

${ }^{2}$ Future Subjunctive (Smith, p. I6r). This seems, incongruously, to be used as a principal verb, but in reality it is equivalent to an adverbial clause, with 'when' understood. - The relation of time is often expressed not by an adverb, but by noods and tenses of the verb. . . . [e.g.] the preterite indicative and the subjunctive.' (Smith, p. 240).

${ }^{3}$ Nyota means 'thirst' in some dialects of Swahili, also in Nyamwezi, Karanga, etc. Ci. also Ganda enyonta, Yao njota, Herero onyota, Sutu lonyora.

- Ati, properly 3 rd pers. sing. of $t i$ 'say,' is used regardless of number or person, in a way which comes to be equivalent to the conjunctive 'that.' For other icliomatic uses of $t i$, see Smith, p. 185 .

8 Lit. 'that lie may arrive (first) at the water,'-i.e., 'who will arrive first.'

- Past (Preterite) of zhala 'bear,' 'beget': Zulu, zala, Swahili vyua (zaa).

- Properly the 'Immediate Future Habitual' tense (Smith, p. I56): the narrator goes back to the actual time of the incidents and treats them as if they were hippening before his eyes.

${ }^{8}$ Locative, $=m u$ ivu 'iu the ground.' Mr. Smith spells 
mwivhu, but the sound-see p. 7 of his Grammar-is clearly that of ' bilabial v.'

9 We should have expected kumbadi kwa menzhi, mbadi 9 being placed in $\mathrm{Cl}$. I 7 by prefixing the locative $k u$, but see Smith, p. 223. Mbadi is not given in the vocabulary as a noun, but cf. Nyanja mbali 9 'edge, side, rim ;' no doubt the same word used in Swahili as an adverb 'far,' etc.

10 tia 'be afraid ' (cf. Swahili tisha 'frighten'-probably a causative of the verb usually written cha'fear'), and so 'run away': tiana reciprocal, but apparently with the meaning ' run against' (or, 'in competition with') and not 'run away from ' each other.

11 Present Subjunctive, used in place of Imperative.

12 Nguni, interrogative (Smith, p. ror), lit.: 'it is who?'. A relative is understood after it, or rather, it is an example of a construction very common in the Bantu languages, even where relative promouns exist: the demonstrative, or even the ordinary personal pronoun are often preferred, as though it were less trouble to make a fresh assertion than to link up the clause with the preceding one.

13 Second Future (Smith, p. I57)-probably distinguished from the Preterite by tone.-tanguna, evidently a derived form of tanga 'begin,' but the force of the termination is not very clear: it can scarcely be reversive (Smith, p. I30).

14 Dimwi 'another' (agreeing with izuba 5 'day' or some similar noun, understood), and preceded by the instrumental preposition $o$ (Smith, p. 224), so meaning 'again.'

15 Same tense as in line 4-see above, note 7 .

${ }^{16}$ Obashanasulwe, a kind of collective pl., including the person named and those with him-see above, p. 48, and Smith, p. I8. This, or a similar idiom seems to be universal in Bantu-e.g. Sumbwa : nge Bandega, 'ce sont des hommes de Ndega' (P.Capus) ; Swahili : kima Hamisi, etc. Oba-is the plural relative prefix (Smith, p. Io\&).

17 Izuba 5 'sun'-here used for 'day.' The same form of the word is found in Tonga ( $Z$ ambezi), and cf. Nyoro izoba, Konde ilisuba, Ganda enjuba, etc. Other forms are lyuwa, dzwwa, riua, jua, iruwa, eyuva, loba, etc. The pronoun for Class 5 is in Ila $d i$. Dia is the form with past tenses.

18 Dimwi agrecing with izuba understood.

19 Kr'a I7 ( $k u$ - with the past tense) is the 'indefinite subject,' equivalent to 'it' or 'there' ('there was darkness'). 
20 Idiomatic use of mana 'finish' (see Smith, p. 187), meaning 'they all died together.' The sequel shows that 'died ' is not to be taken literally.

21 Wa omitted after mwana.

22 Past tense of verb 'to be' ( $d i$, Smith, p. 200), preceded by relative particle $o$.

${ }^{23}$ wo for wa: a beconing o before the verb ompolola (see Smith, pp. I2-13). The tense is the 'aorist' (Smith, p. I50).

24 Aorist of $y^{\prime} a$ ' go,' followed by infinitive kn-fwa. IVezo is the demonstrative pronoun of the first class meaning 'tliat' (already referred to).

${ }^{25}$ bula 'lack,' ' be without,' sometimes followed by 2 noun, as "Idabula shidyo 'I have no food,' sometimes, as here, by the infuitive preceded by a relative particle. 'He was without arriving '=' he failed to arrive.'

26 letelela, 'Double Relative' (Applied) form of leta: let-ela 'bring to,' let-el-ela 'bring to' a person 'for' his use.

${ }^{27} 3$ rd pers. sing. Imperative of the irregular verb kweza (=ku eza or $k u i z a$ ) 'come '-sce Sinith, pp. 182, I83.

${ }^{28}$ lapwila, Applied ('Relative'). form of lapula 'spit'-see Smith, p. I20. We should have expected $k u$-ba-lapwila.

23 Imnedirute Future Tense (Smith 155).

${ }^{80} b a$ is the verb 'to be,' also used in the sense of 'become' (Smith, p. I84). Translate "What has become of you that you did not arrive?'

s1 Pl. of. mwanichi (or mwaniche) 'youngster.' The ordiuary word for 'child' is merana.

${ }^{82}=$ ngon'are'o: 'substantive locative pronoun' =('the place) just there' combiued with the demonstrative awo i 6 (Smith, p. 2I6). Here userl as an adverb of time, 'just then,' or 'immediately.'

ss bud to 'merely.' Sinith suggests that it may be a noun of Class I4 meaning ' nothingness.' But the fourteenth prefix is 'the basis of a number of adverbs of manner' (Smith, p. 217) and possibly -dio might be explained as a pronominal stem agreeing with some $5^{\text {th }}$ class noun understood.

B6 Future Subjunctive used as Imperative.

s5 Another form of the Future Subjunctive-(see Smith, p. I62).

36 $u$ is the form assumed by the locatives $m u$ and $k u$ before 
nouns which already begin with those prefixes-e.g., $u-k u b o k o$, for $k u-k u b o k o$ or (as here) $u-m u k a l o$ for $m u-m u k a l o$.

${ }^{37} \mathrm{Bu}$, used as a conjunction and meaning 'since,' is probably a pronoun, perhaps agreeing with busena I4 'place,' understood.

${ }_{38}$ Negative Future (Smith, p. I7I).

${ }^{39}$ Kwiba=kuiba 'steal.' Cf. Zulu (e)ba, Nyanja $b a$, Swahili $i b a$ (in the northern dialect jepa, which may preserve a trace of the lost initial consonant).

${ }^{40}$ Ist pers. pl. Imperative (Second Form: Smith, p. I63). $Z u b a$ 'hide' (intr.) as it takes a direct object of the person, must mean ' hide from ;' but we should have expected the Applied Form.

41 Second Angmented Form of the Present Subjunctive, with the particle $a$ prefixed (Smith, p. I63).

42 Future Subjunctive of yayila, which is the applied form of yaya 'kill.' The force of the Applied Form is not obvious here, as tuyayile would ordinarily mean 'kill . . . . for us,' and no second object is expressed-or, indeed, required by the sense.

43 Locative demonstrative emphasised: "just on that place).' (Smith, p. 9i.)

\section{Connected Translation}

[This story is not very clear as it stands, but it seems to be a confusion of two different tales, both of which are widely distributed in Africa: that of the race between the 'Tortoise and the Hare, in which the former wins by planting out his family along the track (cf. Uncle Remus, 'Mr. Rabbit finds his match at last'), and one where all the animals join together to dig a well: the Hare refuses, and is not allowed to draw water, but does so by a trick, which is finally detected and frustrated by the Tortoise. This latter story is found in Jacottet's Contes Populaires des Bassoutos (Le Chacal et la Source), in Theal's Kaffir Folk-Lore, in the Swahili collection entitled Kibaraka (Sungurana 
Mgomba and Hadithi ya Vinyama), in Mrs. Dewar's Chinamwanga Stories ('The Rabbit and all the other Animals') and elsewhere. All details of the trick by which the water was stolen and that by which the thief was captured are here omitted.]

Once upon a time, when all the animals were dying with thirst, they said to each other: "Let us run swiftly and see who reaches the water first.' But the Tortoise, who had borne very many children, went on burying them in the ground (along the course), and one child she buried beside the water. So the animals said, "Let us race each other, and when we reach the river, we shall drink the water.' 'They started, they all ran, they said, 'Let us see who will be the first to arrive.' They ran again, and the Tortoises went on saying, 'Forward! forward! Mr. Hare and his friends!' Again they ran, again they said, "Forward! Mr. Hare and his friends!' The sun set once more, and they went on shouting, 'Once more it has become dark. Forward! Mr. Hare and his friends!' Next day the animals all died together, ${ }^{*}$ and the young tortoise who was beside the water shouted, saying, 'Forward!' as before. The Hare was just about to die, without reaching the water. The young Tortoise who was beside the water brought them some water in his mouth, in order to spit it out for the animals. He said: "It is you who were spiteful, saying, "As for the Tortoise, we have outrun him." Now what has become of you that you did not arrive? You are only children! I am a grown man-I have reached the water-but you are children!' Thereupon he spat out the water which was in his mouth. They could not answer him; they remained sad and silent. Afterwards the animals said: 'Let us dig a water-hole, and then we shall be able to drink.' So they dug. But the hares refused to dig, and so the others said: "Since you have refused to dig, you shall not drink any water.

- Probably this is to be understood in the sense of being ' kilt entirely.' 
You shall all of you die of thirst.' When it was dark, those who had refused to dig went to the water-hole and stole water. So the other animals said, 'Let us lie in wait for the hares, so that we may see them.' So they saw them and caught them and bound them. ${ }^{\circ}$ But they (the hares) said, 'Since you have tied us, now we repent. Carry us to our burrow, that you may kill us just there."*

\section{Nyanja}

The Story of the Cock and the Swallowt

Tambala ndi namzeze

a-na-palana

Cock and swallow they made-with-each-other chi-bwenzi, ${ }^{1}$ ndipo namzeze friendship, u-dze and swallow kwatu." you (must) come to our (house). $\begin{array}{cc}\text { a-na-ti, } & \text { 'Koma } \\ \text { he said, } & \text { 'But } \\ \text { Ndipo } & \text { tambala } \\ \text { And } & \text { Cock }\end{array}$ a-na-muka, a-na-ka-peza ${ }^{6}$ namzeze, a-li pa nsanja." he went, he found swallow, he is on nsanja. Ndipo mkazi wa namzeze, a-na-pula ${ }^{8}$ ma-ungu, And wife of swallow, she took-off pumpkins, ndipo namzeze a-na-lengalenga, ${ }^{9}$ and swallow he-flew-up-aloft,

a-na-tenga he took

\footnotetext{
* This seems inconclusive, but no doubt the sequel is omitted as too obvious: viz., that the too credulous animals did as they were asked. Brer Rabbit more subtly entreated Brer Fox not to 'fling me in dat briar-patch.'

t MS. collected at Blantyre, from a boy whose home was in the neighbourhood of the Murchison Falls, on the Shire River. Mr. R. S. Rattray has published a longer version of the same story - (from Central Angoniland) in Some Folk-Lore, Stories and Songs.
} 
maungu, na-patsa ${ }^{10}$ tambala, ndipo tambala a-na-ti, pumpkins, and-gave (to) cock, and cock said,

'Udze kwatu.'s

Ndipo tambala a-na-nka 'You (must) come to us.' And cock went kwao," na-uza mkazache ${ }^{11}$ kuti, $^{12}$ "u-ndi-ika ${ }^{18}$ ine home, and told his-wife saying, "you-me-put me mu mpika ${ }^{15}$ ya mponda, ${ }^{15}$ 'ndipo a-na-m-pika into pot of gourds,' and she-him-cooked

pa moto. Ndipo namzeze a-na-dza, na-peza on fire. And swallow se came, and found tambala a-li mu mpika, ${ }^{16}$ ndipo namzeze a-na-ti, cock he is in pot, and swallow he said, 'Pulani ${ }^{17}$ mponda, ndi-funa ku-nka kwatu.' Ndipo 'Take-off gourds, I want to go horne.' And mkazi wa tambala a-na-pula mponda, ndipo wife of cock she took-off gourds, and

a-na-peza tambala, a-ta-fa, ${ }^{18}$ namzeze she found cock, he-was-already-dead, swallow a-na-bwerera ${ }^{19}$ kwao wo-sa-dya $a^{20}$ mponda. he-returned home not-having-eaten gourds.

${ }^{1}$ Chi-bwonzi 7, from bwensi 5 'friend' (see p. 55). Ndipo, properly the copula joined with the pronoun of the roth 'locative) class, is very commonly used in Nyanja for 'and, 'and so,' ' and then.' In Swahili it is more often fourd in its original sense of 'that is where,' 'that is how,' etc.

'Nyanja has the verb $t i$ 'say' conjugated in all, or most, of its tenses, while keeping its original force, unlike Zulu, where it is apt to pass into adverbial, etc., senses. This is the past tense in -ma-. See Hetherwick, Manual, p. 5 o.

' Koma 'but,' olten begins a sentence in this way, where there seems to be no adversative meaning; but perhaps a kind of polite deprecation is implied. 
4 $u$ - $d z e$, subjunctive (used for imperative) of $d z a$ 'come.'

${ }^{5}$ Kwatu possessive pronoun of Class I5 $_{5}$, ist person plural. Chez hous is a closer parallel than any we have in English. But it should be noticed that it is always kwatu, never kwanga, even when the speaker is referring to himself only. It is the same in the second and third persons-cf. kicao (chez lui), lower down, where I have translated it simply by 'home.' Some nouns'of relationship are always used with a plural possessive in the Bantu languages-cf. udade wetu ' my sister,' umne wabo 'his elder brother,' in $Z$ ulu.

${ }^{6}$ For this tense see Hetherwick, Manual, pp. 150, I56. It here seems to indicate the interval between the act of starting from home (muka) and 'finding' the Swallow-as though we had to understand ' and, when he arrived, he found.' . . . Peza, as here used, involves a sort of bull; it is not meant that the Cock saw the Swallow sitting on the nsanja (see next note),- -but that he did not see him : he found him not there, he being on the usanja. It is very common for Africans to say, 'I saw him not there,' or the like-which, after all, is not very different from 'I found him aiready gone,' as we often say-illogically, perhaps, but not irrationally.

$7 N$ sanja is a kind of staging erected over the central fireplace in a hut, on which meat is placed to be smoke-dried, and seed-corn, beans, etc., to protect them from the attacks of mice and insects. It forms a little loft under the point of the conical roof.

8 Pula 'to take a cooking-pot off the fire,' is often used, by an extension of meaning for 'dishing-up food,' and in European households generally means 'bring in dinner.'Ma-ung $u$, plural of $d z-u n g u 5$.

9 He would, as a matter of fact, have come down from the nsanja, but having descended (probably at the back) under cover of the smoke, he would then fly up, as if emerging from the boiling pot.

10 'And' in Nyanja, is $n i$ or $n d i$, not, as in some other languages na. This na-is made up of $n i$ and the pronoun $a$, and is often found in continuous narrative, prefixed to the second of two consecutive verbs. Cf. below, na-uza, na-peza, etc.

11 mkazache. Nouns expressive of relationship are often combined with the possessive in this way: Nyanja: amako ' thy mother,' amache ' his mother' (but in some dialects mai wake); Swahili mkeo 'thy wife,' mkewe 'his wife,' etc. The 
rule does not apply uniformly, for Nyanja has atate wako 'thy father' while Swahili has babangu, babako, babake (often further abbreviated into bake) as well as mamangu, etc. (See Hetherwick, p. 87).

12 Literally 'to say'; equivalent to 'that,' but often used (as here) where 'that' would be superfiuous in English.

is We should have expected $u$-ndi-ike, and possibly the MS. is wrong. Ine ' me' follows for enıphasis: 'But, as for me, you must put me.' . . In Mr. Rattray's version, the corresponding sentence runs: 'Mawa (to-morrow) u-pike muungu, ndi-kaitana (and then I will call) bwenzi langa, ndipo ine u-ndi-ike m' mpika momo.' Here the position of ine is varied for still greater emplasis. Momo is a strengthened form of mo 'in it.'

"This is written without a hyphen, because the $m u$ really has prepositional force. Had it still been felt as the locative prefix (mu-mpika, or m'pika 'the-inside-of-the-pot') it would have been followed by mw' $a$, not $w a$, as the possessive particle.

is Mponda are a small kind of gourd, not uulike the species known to cultivation as ' custarl-marrows,'- - very delicate if properly cooked.

is Here, again, it is not meant that the Swallow saw his friend in the pot, otherwise what follows would lose all point. Of course the meaning is ' $\mathrm{He}$ did not find him, for he was in the pot.'

17 In Nyanja and some other languages, such as M akua and Venda, the plural of the second person is used instead of the singular where special politeness is intended. But this idiom does not seem to be very general in Bantu.

18 The verb $t a$ 'finish' is used as an auxiliary, particle to indicate 'complete action.' See Hetherwick, p. I6r.

t9 Bwer-era, applied form of bwera 'return,' appears to imply a return from, though only the place to which he returned is expressed in words.

20 Wo-sa-dya for wakn-sa-dya, literally 'of to-not-eat' is a kind of negative participle in very common use. In the Likoma dialect, where the ordinary negative serves to express the future (si-ni-chite 'I shall do') this participial form is almost the only one, and is used without reference to person or time : wo-sa-chita, pl.o-sa-chita 'not doing,' wo-sa-lima 'not cultivating,' etc., etc., see.pp. 118, 169 . 


\section{Connected Translation}

The cock and the swallow made friendship with each other, and the swallow said, 'But you must come to my house.' And the cock went, and did not see the swallow, for he was sitting on the staging over the fireplace. And when the swallow's wife took the pumpkins off the fire, the swallow flew up (through the smoke, as if he had come out of the pot) and took of the pumplins ${ }^{z}$ and gave them to the cock, who said 'you must come (in return) to my house.' And the cock went home and told his wife to put him into the pot of mponda gourds (which she was going to cook for the guest). So she cooked him over the fire, and when the swallow came, he did not see the cock, who was inside the pot. (After waiting for some time), the swallow said, 'Please dish up the gourds, for I want to go home.' She did so and found the cock already dead (in the pot). So the swallow went home, without having eaten any of the gourds.

\section{- 5. SWahiLI \\ (a) Lamu Dialect (Kiamu).}

Stories about the People of Shela*

I. Pa-li-kuwa na ${ }^{1}$ tu wa Shola, ${ }^{2}$ hu-amkuliwa There was a man of Shela, he was called

Bwana Mgumi,

Mr. Mgumi,

ku-m-tilia ${ }^{6}$ to pour for him a-ka-twaa ${ }^{4}$ and he took

\section{kibarua ${ }^{5}$}

a day-labourer mai $^{7}$ katika $^{8}$ kasiki $^{9}$, na kasiki water into a jar, and jar

* Dictated by Muhamadi bin Abubakari (Kijuma) 
hiyo ${ }^{10}$ hu-ngia mi-tungi ${ }^{11}$ esherini. Ule ${ }^{12}$ that-one there go in jars twenty. That kiba-rua a-ka-tia mai, hatta kasiki i-ka-yaa, ${ }^{13}$ labourer and he poured water, till the jar it was full,

a-ka-mwambia, 'Bwana, kasiki i-me-ziye and he said to him, "Master, the jar it has exceeded ku-yaa."14 Ka-mwa-mbia, "Shindilia" ${ }^{15}$ mai, to be full. And he said to him, "Press down the water, twaa $\mathrm{mti}^{18}$ huu, u-ka-shi-ndilie. ${ }^{17}$ take pestle this, that you may press down.'
A-ka-m-pa
mti,
ule akapiga,

And he gave him the pestle, and that (man) struck, kasiki i-ka-yundika ${ }^{18}$ tini $^{19}$

(kasiki ile the jar it was broken below

i-me-zikwa tiati ${ }^{20}$ nusu), (jar that mai it was buried (in) the ground half), ya-ka-shuka ;

akamwambia, it went down; and he said to him, ongeza $^{21}$ tena basi ${ }^{22^{2}}$ mai!' add again then water!' Until the water yakashuka kwa tini, ${ }^{21}$ ndipo a-lo-po-yua ${ }^{25}$ and it went down from below, that is where he knew kasiki imexundika. Ndiye akatoa habari the jar it is broken. It is he (who) put forth the news

kibarua. the labourer.

II. Mngwana ${ }^{27}$ wa Shela mmoya, a-li-weka Gentleman of Shela one, he put away

baruti, i-ka-ngiwa ${ }^{29}$ mai, akamwambia gunpowder, and it was entered (by) water, and he told him, mtumwake, 'Twaa kikaango, ${ }^{80}$ weke moto-ni, .his slave, 'Take frying-pan, put on fire,
na-taka
ku-kaanga
baruti
I want
to roast (dry)
powder
yangu, my, 
i-me-ngiwa mai, na-taka kukaanga mimi it has been entered by water, I want to dry (it) I mwenyewe, $^{31}$ wewe hu-to-yua ${ }^{32}$ kwa uzuri. ${ }^{33}$, myself, you will not know properly.'

Mtwmwake

His slave ,

\section{a-ka-twaa}

and he took

kaweka motoni kamwambia, 'Bwana, and put (it) on the fire and said to him, 'Master, tayari!' $K_{\text {Kenda }}{ }^{34}$ bwana, ready!' And he went,

\section{baruti} the powder i-ka-m-teketeza and it burnt him the face and beard habari ya-tendeka Shela. affair is done (at) Shela.

\section{Mwinda kungu $\mathbf{u}^{38}$}

\section{kikaango,} the frying-pan,

A hunter (of) bush-buck, he got. (caught) a bush-buck,

a-ka-m-funga and he tied (on) him

ka-m-wambia, and said to him, kisu

a knife akatia and he poured baruti the powder zake. ${ }^{86} \quad$ Hini $^{87}$ his. This

\section{a-ku-tinde, ${ }^{41}$} she is to kill you, kidneys and liver let her put by for mimi, kiya, nitwelee ${ }^{42}$ mkakambe. ${ }^{43}$ me, when I come, that I may add (them to my) porridge.'

A-ka-mw-eta ${ }^{44}$ And he sent him

a-ka-rudi, and he returned, kwake $^{46}$; mke wake ka-mu-pa mkakambe mtupu, ${ }^{47}$ to his; wife his and gave him porridge bare,

kamwambia, 'Nso na ini $\mathrm{li}^{48}$ wapi?' and he said to her, 'Kidneys and liver is where?' 
Akamwambia, And she said to him,

kamwambia, and he said to her,

ni-me-m-funga I have tied (on) him

kamwambia, and she said to him,

$$
\text { a-si-le } e^{50}
$$

and he did not eat

\author{
'Hu-ku-eta,' \\ 'You did not send ' (them),
}

'Ni-me-m-tuma Bwa' Kungu, 'I have sent him, Mr. Bush-buck, ukumbuu a girdle

na and

kisu'; a knife';

'He has not come';

mkakambe,

katoka the porridge, and he went out

kenda ku-m-zengea, ${ }^{\text {s1 }}$ a-si-mu-one. Basi, and went to seek him, and did not find him. So, hatta sasa watu wa Shela u-ki-w-amkua 'Bwa' until now the people of Shela if you call them 'Mr. Kungu, hu-teta. Bush-buck; they quarrel (with you).

\section{NOTES}

${ }^{1} \mathrm{~Pa}$ is the pronoun of Class $\mathrm{I} 6$ (locative), and it is quite easy to translate pa-li-kuwa 'there was,' but the $n a$ which follows seems superfluous. We must remember, however, that the pronoun represents some noun meaning 'place' (no doubt the obsolete pantu, which has been replaced by pahali or mahali) and that the construction is, literally, 'The place it was with'-i.e., 'it had '-cf. the French use of avoir in il $y$ avait.

2 Shela is a town within a half-hour's walk of Lamu, but the people consider themselves quite distinct, and the Lamu men affect to look down on them as stupid and iguorant, and tell numerous tales against them, of which the three given in the text are specimens. They resemble those of the exploits attributed to the men of Gotham, "or the mutual taunts of 'Hampshire hogs ' and 'Wiltshire moon-rakers.'

3 Amkua, elsewhere meaning 'salute' is used at Lamu for 'call.' A Mombasa man would have said huitwa or aliitwa. The 'habitual tense' in hl. (see Steere, Handbook of the 
Swahili Language, p. 126), which has no distinction of number or person and may refer either to present or past, is more freely used in the Lamu dialect than in the more southerly ones.

'Twaa 'take,' here means 'hire,' 'engage.' It is the same word as the Zuli twala, which, however, means 'carry' (on the head) - a good illustration of how identical roots may diverge in meáning.

5 Kibarua, literally ' little letter,' has come to mean, first, the 'ticket' given to people hired by the day and handed in when their wages are paid, and, then the person so hired.

6 Tilia, applied form of tia, 'put,' ' pour'-Zulu tela.

7 Mai (nayi), Kiamu for maji. See yua, yua, mmoya, etc., later on.

8 Originally kati ka 'the middle of' (perhaps a trace of the $k a$ - class which has disappeared from Swahili). Used like a preposition in the sense of 'in,' 'on,' etc.

${ }^{9} \mathrm{Kasiki}$, a large earthen jar, three feet or more in height, sometimes seen at the door of a small village mosque, instead of the usual tank (birika), which holds the water for ablutions.

10 Hiy'o, demonstrative, Cl. 9 ; here=' the aforesaid.'

1 Plural of $m$-tungi 3 'water-jar'; the usual size holds about a gallon. Esherini (ishrin, ishirini) is Arabic, like the other words generally used for the higher numerals.

12 Ule, Kiamu for y'ule, Distant Demonstrative of Class r.

$13 i$ - pronoun, agreeing with kasiki 9; $-k a-$, sign of the Narrative tense (Stcere, Handbook, p. 134). Yaa=jaa in Mombasa and Zanzibar Swahili : cf. Nyanja dzala and Zulu zala 'be full' (dist. from zala 'bring forth').

14 An idiom implying ' not only full but overflowing.' Ziye, for the more usual zidi (Arabic) 'be abundant,' ' exceed,' etc.Kamwambia; the initial pronoun of the $k a$-tense is sometimes omitted.

15 Shindilia (doubly applied forn of shinta 'conquer,' of which the original meaning was, probably, 'beat down,')used for pressing down grain into a basket or measure, to make it hold more.

16 Mit, with dental $t$ ( $Z$ anzibar $m c h i$ ) seems to be a distinct word from mt $i$ 'tree,' which has the cerebral $t$ and does not change in the Zanzibar dialect. The 'pestle' used for pounding grain is a pole of some heavy wood, about four or five feet long and of a thickness to be easily grasped in the 
hand. The pestle used in Nyasaland (munchi, munsi) is much thicker and is raised between the open hands which do not meet round it.

17 For the subjunctive with -ka-, see Steere, Handbook, p. $14 \mathrm{I}$.

18 Neuter-passive of vunda (Zanzibar, vunja). The implica. tion is that ' it was in a state of being broken,'- - it was found to be broken '; if the man's agency had been emphasised, $i-k a$ vundwa would have been used.

13 Zanzibar, chini: it is really the locative of $n t i$ (nchi) 'earth,' 'ground.' Cf. the $Z$ ulu adverb $p a-n s i$, which has survived the introduction of the locative in $-n i$ and the loss of the noun -nsi.

20 Tiati 'earth,' only found in Lamu and other northern dialects. I have been unable to arrive at its derivation.

" Causative of ongea, the intransitive verb meaning 'increase,' no doubt the applied form of onga, not in use.

23 Basi, sometimes spelt bassi (but it is better to avoid double consonants in writing Bantu words), is the Hindustani bass 'enough!'-constantly used in a variety of ways, c.g., 'that's all!'-'well!'-'and so"-'so then'-etc. The position here is unusual.

${ }^{23}$ Arabic for 'until,' but often used for 'even,' or (in narrative) as a mere connective.

${ }^{24}$ See note 19. Kwa might be taken here as having something like an instrumental force, indicating the way by which the water disappeared.

${ }^{25}$ a-lo-po-, Kiamu form of the relative (alipo). Yua for juasee note 7. Ndipo is the 16 th pronoun combined with the copula, to form the kind of demonstrative (see Steere, Handbook, pp. I16-117), which means 'This is he, it, etc.'; in this instance 'this is that (place) where '-i.e., ' the time when.'

${ }^{26}$ For the various meanings of toa, primarily 'put out,' 'take out,' see Madan's Swahili-Engiish Dictionury, s.v.

${ }^{27}$ Mnswana 'a free man' (not a slave) and therefore often used to denote an edncated or civilised person,-or a man of good position. Also mungwana, and, on the southern Mrima, or among inland tribes mulungwana, thongh it seems doubtful whether a derivation from Mulungu could be made out. The word is not in Krapf. Mmoya, see note 7 .

28 ngia, sometimes heard as ingia, but in the north at any rate, the former seems to have better authority. The con. 
struction illustrates the Bantu use of the passive in cases where it would be unexpected, or even impossible in a European language: cf. also amefiva ni mume for 'her lusband has died,' and amekwenda kwitw'a ' he has gone to be called '-i.e., ' some one has gone to call him.'

${ }^{29}$ For mtumwa wake. Such contractions are mostly con. fined to words denoting relationship, e.g., babake, mamake, mumeo, nduguze, etc.

${ }^{80}$ Kikaange (from kaanga, 'roast,' 'fry') is used for a European frying-pan, tut in native honseholds denotes a shallow earthen pipkin, which serves a similar purpose.

${ }^{31}$ When following a pronoun this word means 'myself,' 'yourself,' etc. : it is really a contraction of mwenye wak ' the owner of it ' (i.e., it is to be supposed, of the identity expressed by the pronoun).

${ }^{82} \mathrm{Hu}$-to-negative future prefix of the 2 nd pers.sing., instead of ha-u-ta-. See Steere, Handbook, p. I49, where this form is only recognised as used with the Infinitive and is derived from toa 'take out.' Comparison with other Bantu languages suggests that it may have had a different origin.

so Vizuri is often used in the sense of 'rightly, etc.; at Lamu, the abstract noun (uzuri) preceded by the instrumental $k w a$, is preferred.

${ }_{84}$ For $a-k a-e n d a$. The subject, by a not unusual exception, follows the predicate.

35 The idiom here is more easily parallelled in French than in English : (la poudre) lui brûla le visage. See Steere, Swahili Exercises, p. 20 : the possessive, in a similar sentence, is seldom, if ever, used in Swahili.

${ }^{36}$ zake agrees with the second noun only. $N$ devu ro is really the plural of $u d e v u$ II, which means 'one hair of the beard.'

si Kiamu form of the ninth pronoun (hii). Tendeka, perhaps because no agent is mentioned; otherwise one would have expected the passive. But perhaps the meaning is 'Such things are (only) possible to be done at Shela!'

38 Usually the noun-agent formed by prefixing $m$ - to the unaltered verb-root is followed (as here) by a noun as object -so that it might almost be called a participle. Occasionally, however, a noun of this kind is found standing alone, as mgema (not mgemi) 'palin-tapper).'

39 'A girdle made of a narrow cloth' (Steere). The con- 
struction 'he bound his knife on him' is similar to that mentioned in note 35 .

40 Mrasa, used for 'mistress,' 'lady,' and, with a woman's name, as the equivalent for 'Mrs.' or 'Miss'-e.g., Mwina Somoye, Mwana Esha, etc. This is sometimes called the feminine of Bwana and is practically employed so to a certain extent, though bibi is more usual at Mombasa and nana (originally 'grandinother' at Lamu). Krapf enters this mwana as a different word from mwana 'child' (which, in Swaliili, seems to be confined to the meaning 'son'). It is possible that they may he either (I) different words which by phonetic clıange have become identical in form, or (2) the same word which has become differentiated in meaning. But Burton's suggested derivation from the Arabic ummana 'our mother' (see Taylor, African Aphorisms, p. 31), seems very doubtful.

1 Tiuda, Zanzibar chinja 'slaughter'-especially in the correct Moslem fashion. Probably it was the time required for this ceremony that inade the bunter unwilling to stop.

62 Twelea (spelt by Krapf toelea) is to add the fish, chicken, or other kitowco to the rice or porridge.

43 Old word for 'porridge' (sima or ugali).

" eta, Kiamu for leta, which means 'bring' or 'send' (a thing) according to circumstances (tuma is used of sending a person), kenenda for a-ka-enenda: enda and enenda are synonymous. Ule, of course, is the kungu.

46 Mombasa kisha, for a-ki-isha; 'when he had finished,' but now practically an adverb. 'Good Swahili speakers at Lamu prefer it to the Arabic khalafu (halafu).

46 Locative concord: in Nyanja it would be $k \| n y u m b a$ $k w a c h e$; the $k u$, implying motion towards, has been replaced by the locative $-n i$ in Swahili.

it -tuptk 'bare,' 'naked' is often used thus ('porridge and nothing more,'-whereas it is always eaten with some 'relish' -kitoweo or mtuzi). Cf. the line from a popular song:

' Wanipa maji matupu kunisonga moyo.'

'You have given me mere water (the barest minimum of hospitality), to twist my heart.'

\&8 Pronoun agreeing with ini 5, the last subject. (Nso 10, cf. Zulu $i z i-n s o$.)

19 A common sluortening of Bwana in the Siu and neighbouring dialects. 
so Subjunctive, because the action follows and is in a sense dependent on what goes before: he did not eat because he had been told that the buck had not come. Similarly, in next line asimuone "without finding him' ("so that he did not find him '). Ha-ku-ya (Kiamu for $h a-k u-j a$ ): Negative Past which can be used either for 'did not ' or ' has not.'

s1 Ze'tgea, used at Lamu instead of tafuta 'seek.'

\section{Connected Translation}

I. There was a man of Shela who was named Bwana Mgumi, and he engaged a day-labourer to fill a large jar, holding about twenty gallons, with water. The man poured in water till the jar was full and then said, 'Master the jar is full and running over.' The master answered, 'Take this pestle and press it down'-giving him a pestle, with which he pounded the bottom of the jar (which was buried in the ground for half its height), till it cracked, and the water began to go down. So the master said, "Do you see?-now pour in some more water!' And he did so, and it was only when the water kept running away at the bottom that he knew the jar was broken. It was through the labourer that this story got about.

II. A certain gentleman of Shela had put away some gunpowder, and (after a time, found that) the damp had got into it, so he said to his slave, "Take a fryingpan and put it on the fire; I want to dry my powder, which has got damp; but I want to do it myself, as you will not know how to do it properly.' So the slave took the frying-pan and put it on the fire and said, 'Master, it is ready.' Then the master went and poured the powder into the pan and it (blazed up and) scorched his face and his beard. This is the sort of thing that happens at Shela.

III. A hunter cauglit a bush-buck and tied his knife round it with his girdle and said to it: 'Go to my wife and ask her to kill you and put by the liver and kidneys, 
so that I can eat them with my porridge in the evening.' So he let him go, and the buck disappeared. In the evening, when the hunter returned home, his wife gave him nothing but porridge for supper, so he said to her, 'Where are those kidneys and that liver.' She said to him, 'You did not bring any'; and he said, 'I sent Mr. Buck and tied a knife round him with my sash'* but his wife said, 'He has not come.' He would not eat his porridge, but went out to look for the bush-buck and could not find him. And so, to this day, the Shela people get angry with you if you address them as ' $B w a$ ' Kungu.'

\section{(b) Kinvita (Mombasa Dialect)}

Story of the Man who did not know when he was rell off.t

Alikuwako mtu mmoja maskini sana, akaketi There was man one poor very, and he sat siku hiyo, ${ }^{1}$ akasema, day that, and he said, - Ni-ta-kwenda kwa 'I will go to Mwenyiezi Muungu, ni-ka-ombe ni-pawe ${ }^{2}$ Almighty God, that I may pray I may be given riziki $^{3}$ yangu, kwani n-na dhiki sana.' living my, for I have trouble greatly.' A-ka-ondoka a-k-enda zakwe, akafika $\Lambda$ nd he rose up and he went his (ways), and he arrived mbali sana, akaona ziwa li-na ${ }^{6}$ maji mangi. far very, and he saw a lake it has water much. Akaoga, kisha akenda zakwe. Andhe bathed, afterwards he went his (way).

* As a rule, in telling this story, the narrator repeats the speech in full. In dictation, it was given more concisely.

$\dagger$ Dictated by Muhammad bin Macalim 'l Betawi, at Mombasa. 
Akenda, akamwona simba, ha-oni, And he went, and he saw him a lion, he does not see,

a-na-konda ${ }^{8}$

and he was thin

\author{
na ndaa,
}

with hunger, akamwambia, and he said to him,

'Mwana Adamu, wenda wapi ?' Akamwambia,

'Child (of) Adam, you go where ?' And he said-to him,

'Nenda kx́a Mwenyiezi Muungu, ${ }^{\text {' nenda omba }}{ }^{10}$ 'I go to Almighty God, I go pray nipawe nami

I may be given I too

riziki.'

a living.'

Akamwambia,

'Ukenda" ni-ombea

And he (the lion) said to him, "When you go pray for me

na mimi, ni-funuke

also me, I may be opened (as to)

ni-pate na chakula ni-le.'

I may get also food (that) I may eat.' And he said-to him,

\section{'Yyema.' Akenda zakwe. Akamwona}

'Good.' And he went his (way). And there saw him

nyoka,

a snake,

\section{a-ka-mw-uliza,}

and he asked him,
'Wenda wapi?'

'You go where?'

Akamwambia 'Nenda kwa Muungu, nenda And he said to-him 'I go to God, I go (to)

omba riziki yangu.' pray (for) living

my.'
Akamwambia, And he said-to him,

'Ukenda, niombea na mimi; jua

'Where you go, pray-for me also me; the sun li-na-zidi, ${ }^{12}$ sipati chakula; basi, nataka has exceeded, I do not get food; well, I wish

$\begin{array}{ccc}\begin{array}{c}\text { myua } \\ \text { rain may fall, (so that) }\end{array} & \begin{array}{c}\text { tu-pate } \\ \text { we may get }\end{array} & \begin{array}{c}\text { chakula.' } \\ \text { food.' }\end{array} \\ \text { Akenda zakwe. } & \begin{array}{c}\text { A-ka-tokea } \\ \text { (13 }\end{array} \text { mji } \\ \text { And he went his (way). } & \text { And he appeared (at) town } \\ \text { mkubwa, akamwona } & \begin{array}{c}\text { surutani mwanamke, } \\ \text { large, and he saw }\end{array} \text { the sultan, a woman, }\end{array}$


akamwambia, 'Wenda wapi?' Akamwambia and she said to him, 'You go where?' And he said to her 'Nenda kwa Muungu, nenda omba riziki yangu.' 'I go to God, I go (to) pray (for) living my.'

Akamwambia 'Ukenda niombea na mimi, And he said-to him 'When you go pray-for me also me, mimi surutani, mwanamke, raia zangu I (am) a sultan, a woman, subjects me ha-wa-ni-sikizi, na mji ha-w-ishis ${ }^{1 s}$ vita. Basi, do not obey me, and town does not finish war. Well, nataka ya-ondoke haya. ${ }^{15}$ Akenda I wish they may go-away, these (matters).' And he went zakwe.

his way.

Akafika,

And he arrived, akamwambia

and he said-to
Mwenyiezi

Almighty

Muungu, 'Mimi, n-na-ku-ja, na-ona dhiki sana

God, 'As for me, I have come, I see trouble much kwa umaskini, through poverty, nnakuja I have come (to) omba pray

u-ni-wasii ${ }^{16}$ kwa riziki.' Akamwambia, you (to) me assign for (my) living.' And he said to him, $\begin{array}{ccccc}\text { 'Riziki" } & \text { zako sasa nyingi } & \text { sana, } \\ \text { '(means of) living } & \begin{array}{l}\text { na } \\ \text { thy }\end{array} & \text { now } & \text { many } & \text { very, }\end{array}$

\section{zamwayika.' \\ Akamwambia,} they are being wasted.' He said to him, huku, na-li-mw-ona mwanamke, hither, I saw

a woman,
'Ni-li-po-ku-ja 'When I came a-me-ni-ambia, she said to me,

" na mimi, niombea kwa Mwenyiezimgu, mimi " and me (too), pray for me to Almighty God, I ni mfalme, raia zangu hawanisikizi, na am a queen, subjects my do not obey me, and mji wetu hawishi vita."' Akamwambia, town our does not end war." ' And he said to him, 
'Mwambie, "wewe ni mwanamke, pata mume

"Tell her, "you are a woman, get a husband

$$
\text { a-ku- } 00,{ }^{18}
$$

that he may marry you,

ya-ta-ondoka, they will go-away,

\section{yote hayo." ' \\ Akamwambia : \\ ' Kisha} all these (things)."' And he said to him: "Afterwards n-na-ona nyoka, ameniambia, jua ni lingi, I saw a snake, he has told me, the sun is much, hawapati chakula, ataka myua.'
they do not get food, he wants rain.'

Akamwambia, And he said-to him, 'Na-tue ${ }^{19}$ 'Let him put down johari iliyo kitwani, i-ta-shuka mxua nyingi which is in (his) head, it will come-down rain much sana.' Akamwambia, 'Kisha na-li-ona simba very.' And he said-to bim, 'Then I saw a lion ha-oni, akanambia, "niombea kwa he does not see, and he said-to me, "Pray for me to Mwenyiezimgu Almighty God

kisha

(and) then (that)

Akamwambia, He said to him, nipate that I may get eyes,

nipate
that I may get
nipate
I may get

'Mwambie

'Tell himi

apake yangu, my,

chakula." , food." yakwe mat:-2i, yatafunula mato, na his on his cyes, they will be opened, the eyes, and a-taka-cho-ona $\mathrm{a}^{20}$ mbele na-le, ndio that which he sees before (him) let him eat, that-is riziki yakwe.' Ākamwambia, 'Hewallah!' living his.' And he said-to him, 'Hewallah!',

akenda zakwe. Akamwambia yule surutani and he went his (way). And he said-to her that queen

kama like (that) which a-li-xyo-ambiwa. ${ }^{2 z}$ he had been told.
Mwanamke

The woman 
akamwambia, ' $\mathrm{N}$-oa ${ }^{28}$ wewe, utapata mali said-to him, 'Marry me you, you shall get property mangi ; kisha ${ }^{24}$ u-ta-ku-wa mfalme wewe.' much; (and) then you shall be king you.'

Yule akasema, 'Sitaki mali wala That-one and he said, 'I do not want property nor sitaki ufalme, mali mimi nayo mangi I do not want kingdom, property I with it much sana, na-pawa, very,

I am being given (it),

Akenda zakwe.

Akamwona

And he went his (way). And he saw him ni Muungu. ${ }^{25}$ it-is God.'

\section{akamwambia kana ${ }^{26}$} and he said to him like (that) which he had been told. Nyoka akamwambia, 'Twaa wewe hii The snake said to him, 'Take yourself this johari.' Yule maskini akasema, 'Si-i-taki, jewel.' That poor man he said, 'I do not want it, mimi, mimi mali yangu ni mangi for my part, I property my is much

\section{sana, ni-li-o-pawa,}

very, which I was given (it),

Akenda

zakwe.

And he went his (ways).

akamwambia,

and said to him,
'Mwenyiezimgu

'God Almighty sitaki tena.' nyoka, the snake,

"Paka mate yako, mato yako "Smear spittle your, eyes your

Akamwona simba, And he saw him the lion, Chakula chako u-taka-cho-ona akwambia, says to you, Food your (is) that which you will see in front (of you).",

Akapaka And he smeared Aka-mwona And he saw him mato yakwe, yakafunuka. eyes his, and they were opened.

anasimama, ${ }^{27}$ he stood, 
akapeleka mkono ${ }^{28}$ akamshika, akasema, and he stretched out paw and seized him, and said, 'Nitapata wapi chakula chengine, mimi?' Yule 'I shall get where food other, I?' That mwana Adamu aka-sema, 'Mimi na-ku-ombea, son (of) Adạm, he said, 'As for me, I pray for you, yanafunuka mato yako, sasa wataka they have been opened eyes your, now you want nila?' Akamwambia, ' Sijui, eat me?' And he said to him, I do not know (but), - mimi, nitakula, nitimize maneno as for me, I will eat you, that I may fulfil words yako,' Akamla. Hadithi your.' And he ate him. The story inafika it has arrived hapa. ${ }^{29}$ here.

\section{NOTES}

1 Hiyo is the demonstrative implying 'that previously referred to '- here meaning the day to which the story relates.

- Pawa, Kimvita passive of pa (Lamu powa, Zanzibar pewa) $O m b a$ is used for 'pray' in the sense of making a definite request (also used for ' $\mathrm{beg}^{\prime}$ ') - $k u$-sali means to repeat the ritual prayers.

3 From the Arabic razaqa 'provide,' (hence er-Razzaq, one of the names of God);--it is used for 'subsistence,' 'daily bread,' ' rations,' etc.

4 For nina: the contraction of this pronoun is specially common at Mombasa. Cf. Stigand, pp. 29-30.

3 -akwe for -ake, the Kimvita form of the possessive 3 rd pers. sing. Stigand unaccountably says (p. 29), 'this is not often heard.' The expression enda zako (zake, ctc.) has njia (ndia) (pl.) understood after it, and corresponds exactly to the Scottish provincial 'go your ways.'

- $l i$ is the pronoun agreeing with ziwa 5 (Nyanja dziwe 5 , 
Ila $i$-zhiba 5). Zulu and Ganda have the same word with the prefix of Class 7: isi-ziba, eki-diba. Mangi, Kimvita-more southern dialects mengi.

T The construction leaves it uncertain whether the lion saw the man or vice versa; the insertion of the objective pronoun wonld favour the former view, as this usually indicates that some definite person or thing is meant (performing to a certain extent the office of the definite articie), while, on the other hand, it is obvious that, if the lion was blind he could not see any one. However, ona is often used for 'meet' or 'find,' as well as 'see,' and this rendering seems to suit the context best.

- A-na-konda, not, as in the Zanzibar dialect, a present, but a perfect, cf. li-na-zidi later on.

- Kwa only used in this sense before nouns denoting persons, like the French chez. Really the possessive particle of the locative $k u$-class (I7) with a noun understood; (nyumbani=ku-nyumba) $k w a$. The instrumental kwa (as in kukata $k w a k i s u)$, though the same in origin, is, in usage quite distinct. Mwenyeezi, componnded of muenye 'owner' and ezi, (enzi, Arabic 'izz), ' power,' 'authority,' is never used unless followed by Munngu (Mungu, Mngu or $M g u$ as below). The name Allah is not often used by Swalili Moslems, except when speaking Arabic; it seems to be confined to expressions like Hewallah! - which is now nothing more than a form of assent, and Allah Allah! originally an adjuration-' for God's sake,' -but generally used to mean 'be sure you don't forget,' ' be quick, whatever you do,' etc.

so Nenda omba. The infinitive following a finite verb (especially after enda, $j a$ and isha) often drops the $k u$, thus constituting a seeming exception to the rule that the verbstem is never found without a prefix, except in the Imperative.

11 Both -ka- and -ki- are frequently contracted before enda. Here the sense requires $-k i$.

12 This looks like the present in -na., but that tense is not used at Mombasa, where the -na-tense has a perfect force -i.e., it implies an action which has taken place in the past, but whose effects are still continuing. Cf. anakonda (note 8), which means 'he became thin and is (or was at the time when the events occurred) thin.' Cf. also mnakuja, lower down. The perfect in -me-, however, is also used at Monbasa.

is tokea, applied form of toka, 'come ont,' properly means to 'come out to or for some one'-i.e., appear to him (it is therefore used of ghosts, etc.) and always implies a spectator or 
spectators. Here the meaning is 'he came in sight of (the inhabitants of) a town.'

14 Hawishi for ha- $u$-ishi: $u$ agreeing with the subject $m j i 3$. Isha, is here used actively.

15 Haya demonstrative 6 agreeing with mambo understood.

16 More usually wasia (from the Arabic wasi)-properly, 'make a will' 'give testamentary directions,' and thence ' appoint,' ' assign.' Some word like vitu or mali is understood after it.

17 riziki is here treated as a plural. Mwaya (also mwaga 'spill,' 'empty.' The neuter-passive, mwayika, is best rendered by 'are going to waste,' or ' are lying unused.'

18 a 'marry' (only used of the man, olewa is the word applied to the woman and $o z a$, 'give in marriage' is said of the parents or guardian), is the same word as the Znlu lobola, and illustrates the degree of attrition stems may undergo in Swahili through the loss of medial consonants.

19 tua 'set down,' as a load off the hend, also (Madan)' settle down,' 'rest,' etc.; hence the applied form tulia 'be calm,' 'be quiet.' Cf. Zulu tula 'be silent,' etula 'take off' (as a hat, or a pot off the fire), which are probably the same word, the $e$ having been introduced to differentiate the latter. (Of the fairly numerous $Z$ uln verbs in e some have lost an initial consonant and are in process of shedding the vowel, as emba, or $m b a$ ' dig,' in others the $e$ seems to be an accretion (as above).-Na tue, less usual than katue (Steere, Handbook, p. I40).-The jewel in the snake's head seems to be taken for granted as if possessed by all snakes, but it may be less summarily treated in the original story.

${ }^{20}$ For the construction of the Objective Relative, see Steere, Handbook, p. IIg. $A$ - is the pronoun of the 3 rd person agrecing with the subject ( $\operatorname{sim} b a)$, -taka- the sign of the future, -chothe relative pronoun, object, agreeing with kitu understood. We should, however, have expected the object-pronoun to be inserted as well as the relative: a-taka-cho-ki-ona. For nale, see last note.

21 See above, note 9 .

22 The full form would be vitu alivyoviambiwa 'the things which he had been told thein,' but the pronouns of the 8th class are often used without reference to a subject-cf. the adverbial use of vizuri.

${ }^{25}$ It is more usual to substitute the Subjunctive for the Imperative when there is an object-prononn (e.g., mpe 'give him '), but we also find nipa ' give me.' 
24 Kisha, in this case, ' moreover,' 'besides'-not 'after. wards.'

25 If a connective particle is expressed after the Passive (there is sometimes none) it is oftener $n i$ than $n a$ which would be the natural word to use, according to European ideas. The literal rendering of the $n i$ construction is-e.g., in this passage: 'I am being given - it is God (who gives).'

${ }^{30} \mathrm{Kana}$, equivalent to kama, but not so common.

27 anasimama, Perfect in -na-: so, too, yanafunuka and inafika, lower down.

28 mkono, properly used of human beings, but also of quadrupeds when the paw is-as here-used like a hand.

29 Meaning, "The story having arrived at this point, it onds here.'

\section{Connected Translation}

There was once a very poor man, who, on a certain day, said to himself, "I will go to (the house of) Almighty God and pray to him to give me enough to subsist on, for (as it is) I am in great distress. So he rose up and went his way, and when he had reached a place a long distance off, he saw a lake containing much water. $\mathrm{He}$ bathed and then went his way. As he went, there met him a lion who was blind and very thin with hunger and said to hiin "Son of Adam, where are you going ?' So he said, 'I am going to the abode of God, to pray that I may be given enough to live on.' And the lion said, "IVhen you go, pray for me also that I may have my eyes opened and get food to eat.' The man replied, 'Very well' and went his way. Then he saw a snake who asked him, "Where are you going?" and he said, 'I am going to God to pray for sustenance'; and the suake said, 'When you go, pray for me also; there has been such a drought that I cannot find anything to eat, so I want the rain to come that we may get food.' The man went on till he reached a large town, where the Sultan, who was a wornan, saw him 
and said to him 'Where are you going?' [He answered as before.] She said, "When you go, make a request for me also. Though $I$ am the Sultan, I am a woman, and my subjects do not obey $m e$, so that the quarrelling and fighting in my town never cease. My prayer is that this state of things may come to an end.' So he went on.

And he arrived and said to the Almighty, 'I have come, because I am in great trouble through poverty-I have come to beg you to assign me sufficient means of living.' And He said to him, 'You have abundance to live on now, but it is being wa:ted.' 'The man then said, 'On the way here I saw a woman who said to me, "Pray for me also to the Almighty: I am a queen, but my subjects do not obey me and war never ends in our town." He said "Tell her; "You are a woman, you had better get married, then all these troubles will cease." ' The man then said, "After that, I saw a snake who told me that, because of the drought, his people cannot get food-he would like it to rain.' The Lord answered, 'If he lays aside the jewel which is in his head, the rain will fall abundantly.' 'The man went on, 'After that I saw a lion who was blind and who asked me to pray that he might recover his sight and also be provided with food.' The Lord said, 'Tell him to smear his eyes with his spittle, and they will be opened, and then let him eat whatever be sees before him,-that is (assigned him for) his subsistence.' So the man said 'Hewallah!' and went his way. When he came to the queen, he gave her the message with which he had been charged, and she said, 'Marry me yourself, you will acquire much wealth, and you shall be king.' But the man answered, 'I do not want your wealth, nor do I want the kingdom, I for my part have very much wealth of my own, which is being given me by God.' So he went on. When he came to the snake, be likewise gave him his message, and the snake offered him the jewel out of his head, which the man refused, saying ' $I$ have just had a large property given me, I do not want any more.' Then he went on and came to the 
lion, and delivered the message as it was given him. The lion did as directed and recovered his sight, and, seeing the man standing before him, stretched out his paw and seized him, saying, "Where shall I get any other food than this?' The man said to him, "Why, I prayed for you, and your eyes have been opened, and now are you going to eat me?' And the lion said, 'I don't know about that, but I have to eat you in order to carry out your directions.' So he ate him. And the story ends here.

\section{GANDA*}

The Story of Ndyakubi and Ndalakubi

Awo'

o-lwa-tuka ${ }^{2}$

Well then, which arrived (there was a)

omu-saja man

eri-nya-lye ${ }^{3}$

name his

omu-kago
Ndya-kubi,"

Ndya-kubi, ne-ba-ta ${ }^{5}$ and they made

blood-brotherhood with Ndalakubi.

ni Ndalakubi. Awo Ndalakubi

n-a.gamba and be said (to) n-o-n-daba' ; and me see ';

n-a-tuka
Ndyakubi, Ndyakubi,

awo

so

ewa nti, ${ }^{6}$ saying,

Ndyakubi Ndyakubi
So Ndalakubi

"O-ja-nga" 'Come' Ndalakubi. Ndalakubi and he arrived at (the house of) Ndalakubi. Ndalakubi

n-a-gamba and he said (to)

o.fumbire ${ }^{11}$ you may cook for

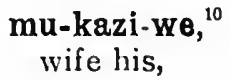
wife his,

nti, saying, n-a-genda and he went

omu-genyi emere. ${ }^{12}$ Āwo omu-kazi Genda 'Go (that) 


\section{n-a-genda a-fumba ${ }^{13}$ emere $n$-e-gya $a^{14}$}

and she went she cooked plantains and they were done

$$
\text { n-a-gi-reta, }{ }^{15}
$$

and she them brought (to) guest and he ate

omugenyi

n-a-lya

$$
\text { na-ta-kuta. }{ }^{16} \quad \text { Nagamba Ndalakubi }
$$

and he was not satisfied. And he said (to) Ndalakubi
nti,
'Muna-nge ${ }^{17}$
sikuse. ${ }^{18}$
Ndalakubi

saying, 'Friend my I am not satisfied.' Ndalakubi

nagamba omukazi nti "Genda ofumbe and he said (to) wife saying 'Go that you may cook

emere, omugenyi ta-kuse, ofumbe plantains, guest is not satisfied, (see) that you cook nyingi.' Awo omukazi nagenda many.' So wife and she went emi-wumbo ${ }^{19}$

bundles

gy-emere of plantains o-tano, five, afumba she cooks na-gyo $0^{20}$ and those

\section{n-a-gi-reta}

Ndyakubi,

and she brought them (to) Ndyakubi,

$$
\text { n-a-gi-mala-wo, }{ }^{21} \quad \text { era }^{22} \text { natakuta. }
$$

and when he had finished them still he was not satisfied.

Nagamba Ndalakubi, nti, And he spoke (to) Ndalakubi, saying,

sikuse.'

I an not satisfied.'
Ndalakubi

Ndalakubi
'Munange,

'My friend, n-a-lya and he ate omukazi nti, 'Genda
wife saying, "Go to (the house of) my friend gundi, ${ }^{23}$ 0-n-sabire-yo ${ }^{24}$ emere, $\mathrm{nze}^{25}$ so and so, that you may beg for me there plantains, I
e-mpwede-ko. ${ }^{26}$
Omukazi nagenda asaba they are finished for me. Wife and she went she begs

\section{emere,}

plantains,

emiwumbo kikumi, ${ }^{27}$ nagireta,

and she brought them

nagireta ; nafumba and she cooked

bundles 100 , and she brought them ;

Ndyakubi Ndyakubi 
nalya emere

and he ate plantains natakuta. nagimalawo

and when he had finished them Nagamba,

Ndalakubi Ndalakubi he was not satisfied. And he spoke, nti, ' línunange, sikuse.' Ndalakubi saying, "My friend, I am not satisfied." Ndalakubi
n-a.damu, ${ }^{28}$
nti
'Emero
empwedoko.' and he answered, saying 'Plantains are finished for me.' Ndyakubi Ndyakubi

ka-n-gende let me go (with) nagamba nti, and he spoke saying, enjala, munywanyi ${ }^{\circ 0}$ hunger, dearest friend n-fire that I may die ku on

\section{Na-da-yo} And he returned there to his (own house.) Ndalakubi ya-laba ${ }^{22}$ a-genze, ${ }^{83}$ naye nagenda Ndalakubi he saw he has gone, he too and he went oku-mu-kyalira, : to visit him, natuka ewa and he arrived at (the house of)

Ndyakubi. Ndyakubi Ndyakubi. Ndyakubi

nti, 'Genda
saying,
y-omugenyi.'
of guest.'

nagifumba, and she cooked then,

\section{nagireta;}

Ndalakubi and she brought them;

katono.

Awo

a little.

So

ne-bu-ziba.

and it is stopped up. nagainba

and he spoke (to)

ofumbe

that you may cook

Wife

nagenda and she went
Omukazi omukazi

wife

emere

plantains
$\mathrm{Na}$

And 
Ndyakubi (to Ndyakubi nti, saying,
'Nasula wa? ${ }^{86}$

'I shall pass the night where?'

Ndyakubi

nagamba

nti, 'Na-ku-segulira

Ndyakubi and he spoke saying, "I will remove for you ku-kitanda ${ }^{38}$ kxange

kw-o-no-sula.' from bedstead my where you will pass the night.' Ndalakubi nagamba nti, 'Si-gya-wo.' Ndalakubi and he spoke saying, 'I do not get-in there.' Ndyakubi Ndyakubi nawangulawo empagi, and he pulled out there a post, Ndalakubi

Ndalakubi

neyebaka.

and he slept.

\section{nagenda} and he went

\section{Yali}

He was

\section{yebaka. ${ }^{40}$}

he slept.
Nendyakubi

Ndyakubi too

\section{na-mu ita,} and he called him,

$$
\text { we-n-suze }{ }^{41}
$$

yebase,

he is asleep,

$$
\text { nti, }
$$

saying,

si-gya-wo

where I have put up I do not get in (as to)

Ndalakubi

Ndalakubi

- Munange,

'My friend, ebi-gere, my feet,

\section{bi ri, bweru.' Ndyakubi nagamba} they are outside.' Ndyakubi and he spoke (to) mukaziwe nti, 'Genda ewa gundi, his wife saying, 'Go to (the house of) so and so,
a-m-pole ${ }^{42}$
emuli." ${ }^{43}$
Omukazi nagenda

that he may lend me reeds.' Wife and she went

na-zi-reta.

Ndyakubi

and she brought them. Ndyakubi na-kokera ${ }^{4}$ and he pushed out

enyumba ekiro ekyo. Ndalakubi nagenda
house night that. Ndalakubi and he wen

yebaka, bwe-yebaka ${ }^{45}$ ebi-gere he sleeps, when he slept

bweru.

Naita outside.

- Munange,

'My friend, when you came feet

bya-gukira

they projected
Ndyakubi

Ndyakubi nti, saying, 
emere nyingi, laba nze kakano, ebigere biri, plantains many, see me now, feet are bweru, ebi-solo bi-ja ku-n-dya bigere.' outside, animals they are going to eat me the feet.' Ndyakubi nagamba nti, "Si-ri-ko" Ndyakubi and he said - saying, "I have not

\section{we-na-gya muli zimpwedeko,}

where I shall take out reeds they are finished for me,

$\begin{array}{cccc}\text { nemiti } & \text { si-ri-na.' } & \text { Ndalakubi nagamba } \\ \text { and poles } & \text { I have not.' } & \text { Ndalakubi and he spoke }\end{array}$

nti, 'Bwe-wa-ja ewange ba-ku-fumbira saying "When you came to my (house) they cooked for you emere nyingi, nolya nogana plantains many, and you ate and you refused
okukuta
emere,
ne-zi-gwa-ko

to be satisfied (with) plantains, and they were finished
n-o-ng'amba
nti,
'Munywanyi
wange,

and you spoke to me saying,

kang'ende let me go (with)

ebisolo

bindire $e^{47}$

animals they may eat me

wange.'

my.'

Ndyakubi

Ndyakubi enjala'

hunger'

'Dearest friend nange kale! leka and I-well! let (be)ebweru, munywanyi outside, dearest friend nagamba and he spolie

nti, saying,

\section{'Munange,}

wefunye, ${ }^{48}$

'My friend, draw up (your legs), cease to stretch out, nange bwe-na-ja-nga ${ }^{50}$ ewuwo na-lya-nga-ko and I whenever I come to your (house) I will eat

katono, m-onerede. ${ }^{\text {s1 }}$ Ndalakubi nagamba a little I have repented.' Ndalakubi and he spoke
nti,
saying,
- To-kola-nga ${ }^{52}$
bwotyo,
like that,
nze
bwe-na-kw-etondera ${ }^{\text {s3 }}$
when I admitted to you
nti,
saying,
"Emere
"Plantains 
empwedeko," are finished for me," you quarrelled buyombi, ${ }^{54}$

a quarrelling,

\section{nawe}

and you

emere

plantains whenever you come

o-gi-rya-ng?

you shall eat them

\section{bulungi,' 56}

decently.'

\section{NOTES}

1 A wo is here a mere connective, equivalent to ' and so,' or the like. It seems to be a distinct word from the locative awo.

2 The subject of olwatuka is olw-naku $x \mathrm{r}$ 'day' understood: (on) the day which arrived' being equivalent to 'once upon a time.'

${ }^{3}$-lye, possessive 5: in Ganda the possessives of the and and 3 rd persons singular are usually suffixed to the noun.

' Ndyakubi means 'I eat badly,' (the $l$ of lya becoming $d$ after 12) and Ndallakibi (froin lala) 'I sleep badly.' Lala does not seem to be used in this sense now, having been replaced by $e b a k a$.

'This is the 'narrative tense' (Pilkington, p. I8) of the verb 'ta, which properly means ' $k$ ill,' but is used idiomatically. Oku'ta omukago appears to be the technical ternn for 'making blood-brotherhood.' See Roscoe, The Baganda, p. I9. The 3rd person plural is here (as often) used impersonally, like the French on.

6 nti seems to be the only trace left in Luganda of the verb $t i$ 'say,' unless the adverb otyo is connected with it, as suggested in Elements of Luganda Grammar, p. 206.

7 The Imperative with $-n g a$ sufinxed is called in Elements (p. 68) the 'Far Future Imperative,' but it is doubtful whether it can be restricted to distant time. IVith a Negative Imperative, -no has the force of 'never:'

8 and person singular, narritive tense of laba 'see,' for $n a-u-n-l a b a$. Nat $\quad$ contracts into $n$, aild $l$ becones $d$ after $-n-$, which is the object-pronoun of the first persou. 
- Ewa is the locative particle, corresponding to $p a$ and $k w a$ in other Bant languages and equivalent to the French chez. $K w a$ does not seem to be thus used in Ganda, though we do find it as the possessive particle of the $\mathrm{r}_{5}$ th class: okufa kw'a $k a b a k a$ 'the death of the king.' $E w a$ is a double locative: $w a=p a$, while $e$ is a separate prefix meaning ' at ' or 'to' (see Elements, p. 97) and possibly connected with the Zulu locative prefix (ante, p. 83). It is often found with suffixed possessive-ewa-ngt, стu-wo, etc.

10 -we suffixed possessive, 3 rd person. Gamba is the vero found in Swahili as amba (generally used in the applied form ambia 'say to,' 'tell'). From it we get eki-gambo 7 ' word,' cf. Yao magambo 6 'discussion.'

11 and person singular subjunctive of the applied form of fumba 'cook.' Contrary to what we find in Zulu, Swahili, Nyanja, etc., it is accented fúmbire. This difference in accentuation and an apparent preference for short vowels make the sound of spoken Ganda very puzzling to one accustomed, e.g. to Swahili or Nyanja.

12 emere, 9, properly 'steamed and mashed plantains,' but used for 'food' in general, this being the staple dish of the Baganda. (See Roscoe, pp. 435-6).

13 rd person singular, present tense (used for past).

14 gya 'be cooked,' 'be done,' etc; Nyanja psya (pya), Herero pya, etc., originally, had the sense of 'burn,' like the $Z$ ulu tsha. It must be distinguished from two other verbs both of which occur furtber on in this extract: gya 'take out' and gya 'get into' (a space).

15 ret $a=Z$ ulu (and other languages) leta, Herero eta, etc. ( $r$ and $l$ are to a certain exterit interchangeable in Ganda, the former being heard before $a, o$ and $u$, and the latter before $e$ and $i$ ). $g i$ - is the object-pronoun of cl., 9 the subject-prononn being $e$-or $y$-. It is very rare to find, except in Class $\mathrm{I}$, the object-pronoun differing from the subject; its position seems to have preserved the initial consonant, which has been worn away at the begiuning of a word.

16 The $k$ in kuta 'be satisfied' is the 'exploded' or 'long' consonant (see Elements, pp. I4, 15) indicated in C.M.S. books by a prefixed apostrophe ('kuta), and in those of the French Fathers by donbling the consonant (natakkuta): the former method seems preferable. The sound is really a combination of a consonant with the glottal stop, which is very common in Hamitic langnages (c.g. Galla). These 'exploded' consonants are not marked in the text from which our extract is taken and it has not been thought necessary 
to distinguish them here. Natakuta is negative narrative tense.

17 muna means 'one of' and is therefore never used without a possessive pronoun or a noun. following: muna-fc 'one of us,' muna-Budu 'a man of Budu.' Properly it should not be used with a singular pronoun, but it has acquired the sense of ' friend,' ' companion,' etc.

18 si.kuse, Négative Perfect of kuta, and person tu-kuse, 3rd ta-kuse. $t a$ is the negative particle corresponding with the Swahili $h \bar{a}$.

19 omu-wumbo 3 (from $u$ 'umba 'wrap up for cooking in a leaf') is a bundle of plantains, which are always prepared in this way. In the Manuel de Langue Luganda, it is translated 'marmites,' but this is evidently a nistake-gyemere for gya emere-note gya 4, agreeing with emiwumbo.

${ }^{20}$ (e)-gyo, demonstrative, agreeing with emi-wumbo: the $-g i$ in the next word has the same agreement, alld is consequently 4 not 9 .

21 Narrative tense, followed by the locative relative -wo (here ='when,' like -po in Swahili). mala 'finish,' with its derived forms malira, maliza, is found in Swahili (though here almost ousted by isha), Nyanja, Yao, etc.

22 era seems to be used either as an adverb or as a conjunc. tion. It may also mean 'and,' 'besides.'

${ }^{23}$ gundi, used like goa in Poknmo and fulani (Arabic) in Swahili, to designate some one whom one cannot or will not name.

24 and person singular subjuactive of sabira, applied form of $s a b a$ 'ask':- o- (before a vowel $w$-) subject-pronoun, and person singular; - n-, object-pronoun, 1 st person singnlar; yolocative suffix, equivalent to 'in that place' (Elements, p. 70) : the whole word ineaning "where you may request food for me.'

${ }^{25}$ nze, separable prononn, ist person singular-bere used for emphasis =' as for me.'

${ }^{26}$ Perfect (w'ede) of gwa 'come to an end,' agreeing with emere $g$ and followed by the locative pronoun $-k o$. The $-m p$ represents the object-pronoun of the first person, this being the iorm assumed by $n$ before $w$. The construction suggests a common Irish idiom, e.g., 'He's lost it on me' (Jane Barlow, Irish Idylls.)

${ }_{27}$ Note the difference between ekumi and kikumi. Lukumi is $\mathrm{I}, 000$ and $k a k w m i$ ro,000. 
${ }^{28}$ da 'return' seems in da.mu 'answer' to be compounded with $m u$ in a way not quite easy to explain, but probably growing out of the usage by which va.mu (e.g.) means ' get out from inside.' (Elements, p. $7 \mathrm{r}$ ).

${ }^{29}$ kale, interjection of 'exhortation,' here equivalent to ' Oh! very well!' or the like. kang'ende subjunctive, preceded by $k a$, which is generally added to the ist person singular and plural (Elcments, p. 69). Note ng'ende, not ngende $-n$ and $g$ combining into $n g^{\prime}$.

so munywanyi a term of endearment, sometimes equivalent to 'light of my eyes,' ' darling,' etc.

st (e) kubo 5 is 'a path trodden down,' possibly connected with kuba 'bcat.'

$32 y a-l a b a$, 3rd person singular (note the difference in the pronoun) of the 'Far Past' Tense (Elements, p. 27).

$3 s$-genze, perfect of genda.

' 14 This is the 'Partitivc' use of -ko (like French en)-see Elements, p. 70.

${ }^{35}$ obude $\mathrm{I} 4$, constantly used in indications of time. Obude buziba is, literally 'the time of day becomes stopped' (as a bottle with a cork: the Manuel de Langue Luganda renders, 'le moment se bouche' ti-bwa-lwa), Negative 'Far Past, agreeing with obude. The whole phrase means 'it was not long before it got dark.'

${ }^{86} w a$, adverb, indicative of 'place generally,' used interro. gatively for 'where?' (Elements, pp. 46, $5 \mathrm{I}$ ). It is the locative pronoun $p a$, a prinitive $p$ becoming $w$ in Ganda.

37 Segulira should properly be the applied form of a reversive veri) derived from sega, which, however, does not occur in the vocabularies in any meaning that would be appropriate. Seguka, intr. is 'move one's position.' $\mathrm{Na} \cdot \mathrm{ku}$ segulira here means, not 'I will nuake roon for you' on my bed, but 'I will give up my begd to you.'

${ }^{80} \mathrm{Ku}$-kitanda $\mathrm{I} 7$, treated as one word and therefore followed by the possessive kwange. Kwonosula=ku-o-no-sula: 2 nd. pers. sing. of the Near Future, preceded by $k u=$ on (which). Note the distinction between sula 'pass the night ' and ebaka, used of actual sleep.

${ }^{39}$ This is $g y a$ 'get into a space'-see Note 14 above.

40 ebaka, properly a reflexive verb, e being the reflexive pronoun ( $Z$ uli $z i$, Swahili $j i$, Nyanwezi $i$, etc.). But many such verbs have acquired distinct meanings of their own. (Elements, p. II7.) As it begins with a vowel, the Past is y-ebaku, for ya-ebaka. 
11 suze, perfect of sula; we- adverb corresponding to the ocative wa I6 (Elements, p. 96), as in wano we-n-tambula, here where I walk.'

42 For $a-n-w o l e$, from wola 'lend.' The nasal n preserves the $p$ sonnd elsewhere lost in Ganda and is itself,modified by the influence of the $p$ into $m$.

${ }^{43}$ enuli ro plural of olu-muli II. Reeds are used in thatching a house, the thatch reaching down to the ground.

44 Ndyakubi, baving previously pulled out one of the supports in order to give his friend more room, now makes an extension 'to the thatch with the borrowed reeds. Huts being round, the foot of the bedstead (placed so that, in a square room it would be parallel with the wall), would necessarily come in contact with the thatch.

45 b'e', relative $=$ ' when' agrees with obude ${ }_{4} 4$ understood.

$46 n a$ understood after $r i$, as often in the negative. Gya ' take out,' as from a store.

47 For bi-n-live, applied form of lya.

48 ef $u n y a$, reflexive of $f u n y a$ ' clench' (the fist), 'fold' etc.used here of drawing up the knees. Wefunye=o-efunye, and person singular of the Subjunctive.

49 lanama, by its form and sense is evidently a stative, but no verb lana appears to be in use.

so The suffix-nga may denote either present, past or future action, so long as it is repeated or habitual. (Elements, p. 9r.) Here it is equivalent to 'whenever I come.'

${ }^{51}$ For $n$-bonercde, perfect of bonera, 'repent'; $b$, after changing $n$ to $m$, disappears.

52 Negative Imperative: -nga suffixed to this mood implies a general prohibition (Elements, p. 35); -otyo is an adverb meaning ' just so' and $b w(e)$ 'how, depends on some implied $14^{\text {th }}$ class noun meaning 'state' etc. (Elenents, pp. 94-106.)

58 etonda ' confess a fault and be sorry for it' (Blackledge); ctond-era 'confess to (any one)' here used of the regretful admission that his provisions are exhausted.

${ }^{54}$ That is 'merely quarrel,' ' do nothing but quarrel ';-for this peculiar use of the I 4 th prefix, see Elements, p. ro7.

s5 $n o$ is an 'intensive interjection '; leka, 'let, ' allow,' often used before the subjunctive, like our 'let 'though its primary meaning seems to be 'leave' ('let alone.') Some languages have it with the meaning 'stop' (intr.)

56 Abstract noun, (from -lungi 'good') used as an adverb (Pilkington, p. 6g.) 


\section{Connected Translation}

Once upon a time there was a man whose name was Ndyakubi, and he made brotherhood with Ndalakubi. And Ndalakubi said to him, 'Come and see me (some day.)' So Ndyakubi went, and arrived at Ndalakubi's house, and the latter said to his wife, 'Go and cook food for the guest.' So the wife went and cooked food, and, when it was done, she brought il, and the guest ate, but he was not satisfied, and he said to Ndalakubi, 'My friend, I have not had enough.' Ndalakubi said to his wife" 'Go (again) and cook a great deal of food, for our guest is still hungry.' She went and cooked five bundles of food and brought them atso to Ndyakubi, and he ate it, and when he had finished he still had not had enough and said to Ndalakubi, "My friend, I am not satisfied.' Ndalakubi said to his wife, 'Go to my friend so and so and ask him for some plaintains, for mine are all finished.' The wife went and asked for plantains and brought them and cooked a hundred bundles. Ndyakubi ate the food and when he had finished it, he was still unsatisfied and said [as before.] Ndalakubi answered, 'I have no food left,' so Ndyakubi said, 'Never mind, I will go away hungry, my dear friend, and die by the roadside (if I must).' So he returned home. Ndalakubi saw that he had gone, and (some time afterwards), he, too went to pay a visit to him, and when he arrived at Ndyakubi's house, the latter said to his wife 'Go and cook food for the guest.' His wife went and cooked it and brought it when it was done, and Ndalakubi ate a little of it. Soon after this it grew dark. Ndalakubi said to Ndyakubi, 'Where an I to sleep ?' Ndyakubi answered, "I will give you my bedstead so that you can sleep.' Ndalakubi said 'There will not be room for me,' so Ndyakubi pulled out one of the posts of the house, and Ndalakubi went and lay down to sleep. Ndyakubi also slept. When he was asleep, 
Ndalakubi called him and said, 'My friend, in the place you have given me to sleep in, there is no room for $m y$ feet, they are outside.' Ndyakubi said to his wife, 'Go to so and so and borrow some reeds,' and the woman went and brought them, and Ndyakubi made an extension to the house that night. Ndalakubi went and slept, but when he was asleep (he thrust) his feet (through the thatch and awoke and found that they) were projecting outside. So he called out to Ndyakubi, "My friend, when you came to my house you ate large quantities of plantains-now, see how my feet are outside, and the wild animals will come and eat them.' Ndyakubi said, 'There is no place where I can get any more reeds they are all done and I have no poles.' Ndalakubi said, "When you came to my house, they cooked for you an enormous amount of food, and you ate, and yet you kept on saying you had not had enough, and when the food was all finished, you said to me, "My beloved friend! let me go away hungry!"--and so I say, "Never mind, dearest friend-let the wild beasts eat me outside your house!"' So Ndyakubi said, 'Oh! my friend, just draw up your legs and don't stretch them out; and I, too, next time I come to your house, I will only eat a little; I am truly sorry for my behaviour.' Ndalakubi answered, 'Never act again as you did when I told you, very much to my regret, that there was no more food in the house, and you did nothing but quarrel with me. Well, let me just draw up my knees (till the morning), and when you come to my house again, remember to eat like a decent human being.'

A free version of this tale is to be found in Roscoe, The Baganda, p. 482. The point of it lies in the mutual obligations of blood-brothers, on which Ndyakubi presumes beyond all permission. 


\section{APPENDIX II: BIBLIOGRAPHY}

This Bibliography makes no attempt at completeness, being intended merely as a guide to the books available for the study of the more important Bantu Languages. Continental works not easily accessible have only, as a rule, been indicated where no English ones appeared to exist.

Languages marked * are those into which the whole Bible has been translated; those marked $t$ possess complete versions of the New Testament. These versions are of unequal linguistic value, but as 2 rule are welcome aids to the student. (Most of them, though not all, are published by the British and Foreign Bible Society.) Many others, besides those marked, have translations of separate parts of the Scriptures, and school reading-books, etc., which will of ten be found useful.

Books marked * are to be found in the library of the African Society (open to menibers) at 64, Victoria Street, S.W.

\section{General}

*Anthropos. Revue Interiationale d'Ethnologie et de Linguistique, Salzburg (Zaunrith).

From 1906 onwards. Separate items under Congo (Kiyombe, Kanyoka), Fang, Fipa.

W. H. J. Bleek. Comparative Grammar of the South African Languages. Part I. (Phonology), 1862. 
Part II. The Concord. Section I. The Noun. 1869. (No more published.) London (Trübner and Co.)

C. G. Büttner. Zeitschrift für Afrikanische Sprachen.

Berlin (A. Ascher and Co.), 1887-90.

Contains many valuable contributions, some of which are entered as separate items in the Bibliography. The periodical was discontinued on Dr. Büttner's death in 1890. !

*R. N. Cust. A Sketch of the Modern Languages of Africa, 2 vols. London (Trübner and Co.), 1883.

Journal of the African Society. (Quarterly.) London (Macmillan and Co.) From 1902 onwards. Contains some valuable linguistic articles.

J. T. Last. Polyglotta Africana Orientalis. London (S.P.C.K.), 1885.

Contains vocabularies of over fifty East African Languages (including a few non-Bantu). They are not very full, but form useful starting points for languages not already studied.

*C. Meinhof. Die moderne Sprachforschung in Africa.

1910, Berlin : Berlin Evangelical Missionary Society

(Georgenkirchstrasse).

* An Introduction to the Study of African Languages. (Translated by A. Werner.) London and Toronto (Dent), 1915.

Being the English edition of the preceding.

* _ Grundriss einer Lautlehre der Bantusprachen (Second edition). Berlin (Dietrich Reimer) (Ernst Vohsen), 1910.

*—_ Grundzüge einer vergleichenden Grammatik der Bantusprachen. Same publisher. Berlin, 1906.

- Das Dahlsche Gesetz. Zeitschrift der deutschen morgenländischen Gesellschaft $\mathrm{Bd}$. LVII., p. 302. 
An exposition of the important law of Dissimilation referred to on p. 229.

C. Meinhof. Linguistische Studien in Ostafrilia. Berlin, 1904-8. Mitteilungen des Sem. für orient. Sprachen. Bd. VII.XI.

Phonetic Studies of Swahili, Shambala, Nyamwezi, Sukuma, Digo, 'Nika,' Pokomo, Bondei, Zigula, Mbugu, Dzalain s, Makua, Yà.

*Mitteilungen des Seminars für orientalische Sprachen an der königlichen Friedrich-Wilhelms-Universität $\mathrm{zu}$ Barlin, etc. Berlin (W. Spemann, afterwards G. Reimer), 1898, etc.

These 'Transactions' appear annually in three sections, of which the third is devoted to Africa, under the title of Afrikanische Studien. Some of the more important items are entered separately, under the several languages. Referred to as Mitt. B. Sem. Or. The series of handbooks (Lehrbücher des Seminars für orientalische Sprachen) issued by the same institution contains a number of valuable works, entered under the separate. languages.

Another series of which several volumes will be found entered under various languages is the Archiv fïr das Studum deutscher Kolonialsprachen (same publisher), 1895.

*B. Struck. Collections towards a Bibliography of the Bantu Languages of British E. Africa. Journal of the African Society, London, 1907.

J. Torrend, S. J. A Comparative Grammar of the South African Bantu Languages, comprising those of Zanzibar, Mozambique, the Zambezi, etc., etc. London (Kegan Paul, Trench, Trübner and Co., Ltd.), 1891.

*Zeitschrift für afrikanische und oceanische Sprachen. Berlin (Dietrich Reimer), 1895-1903.

Edited by A. Seidel; 5 vols. square royal 8vo., appeared between January, 1895 and January, 1900. Publication was then suspended, but resumed (in a smaller format) in 
1902, and ceased with the first issue for 1903. Some important contributions are entered under special languages, e.g., Sumbwa, Tabwa. 4 vols. in African Society's Library.

Zeitschrift für Kolonialsprachen. (Quarterly.) Berlin (D. Reimer) and Hamburg (Boysen). From 1910 onwards.

\section{I. Special Languages}

Aduma (Duma). Spoken along the Ogowe River in the northern part of French Congo.

R. P. Dahin: Vocabulaire Adouma-Français. Part I., French-Aduma, pp. 72. Part II., Aduma-French, pp. 72. Kempten (Bavaria), (Jos. Kösel), 1895.

Angola. See Mbundu.

Bangala. See under Congo Languages.

Bangi. See under Congo Languages.

*Bemba. Between the Lualaba and Lake Nyasa.

*IV. G. Robertson. An Introductory Handbook to the Language of the Bemba People. London (L.M.S.), 1904.

*Father Schoeffer. Grammar as spoken in North-east Rhodesia. Edited by J. H. West Sheane. Arranged with Preface by (the late) A. C. Madan. Oxford (Clarendon Press), 1907.

Benga. (Corisco Bay, West Africa.)

*J. L. Mackey. Grammar of the Benga Bantu Language, revised by R. H. Nassau. New York (American Tract Society), 1892.

The original edition of Mackey's Grammar was published at New York (Mission House, 23, Centre Street), in 1855. 
C. Meinhof. Das Zeitwort in der Benga-Sprache. Berlin, 1890. Zeitschrift für Afr. Sprachen, Vol. III., pp. 265-284. Benga und Duala, ib. II., pp. 190-208.

Bondei. Spoken inland from Tanga in East Africa.

G. Dale. Bondei Exercises. Holy Cross, Magila, 1892. *H. W. Woodward. Collections for a Handbook of the Bondei Language. London (S.P.C.K.), 1882.

Stories in the Bondei Language with some Enigmas and Proverbs. Written by Native Students and edited by the Rev. H. W. Woodward. (S.P.C.K.)

Bube. (Fernando Po.)

John Clarke. Introduction to the Fernandian Tongue. Berwick-on-Tweed (Daniel Cameron), 1848.

R. P. Joaquin Juanola. Primer Paso a la Lengua Bubé, pp. 190. This seems to be the most complete grammar hitherto published. Madrid (A. Pérez Dubrull).

"Sir H. H. Johnston. George Grenfell and the Congo, Vol. II., Appendix I., p. 882. London (Hutchinson and Co.), 1908.

This work contains specimen vocabularies of a great many other West African Languages, and a discussion of the various Bantu migrations. The greatest amount of space is devoted to a comparison of numerals.

Bunda. See Mbundu.

Chaga. (Čaga, Dšagga, Djaga, etc.) The Wachaga live on Kilimanjaro.

*J. Raum. Versuch einer Grammatik der DschaggaSprache (Moschi-Dialekt). Archiv. für d. Stud. deutscher Kolonialsprachen, Vol. XI. Berlin (Georg Reimer), 1909.

H. A. Folkken. Das Kisiha. Mitteil. des Sem. für orient. Sprachen. Jahrg. VIII., Abt. 3. Berlin, pp. 44.93, 1905.

Siba is a dialect of Chaga. 
Chasu (also called Pare).

*E. Kotz. Grammatik des Chasu in Deutsch; Ostafrika. Berlin (G. Reimer), 1909. Archiv für das Studium deutscher Kolonialsprachen, Vol. X.

Spoken in the mountains south of Kilimanjaro.

Chinamwanga. See Namwanga.

Chinyanja. See Nyanja.

Chiswina and Chizwina. See Karanga. *Chwana (Sechwana, Secwana).

It is practically identical with Sutu (Sotho, Sesuto), and works relating to both are entered under this heading.

James Archbell. A Grammar of the Bechuana Language. Graham's Town (Meurant and Godlonton), 1837.

J. Brown. L.M.S. Secwana Dictionary. Frome (Butler and Tanner), 1895.

E. Casalis. Études sur la Langue Séchuana. Paris (Imprimerie Royale), 1841.

This is really Sutu. The book is interesting as being one of the earliest on the subject, and the Introduction gives a valuable account of the establishment of the French Mission in Basutoland and its relations with Moshesh.

*W. Crisp. Notes towards a Secwana Grammar, 1900, reprinted 1905. (S.P.C.K.)

A useful book, though not very well arranged. The dialect is that of the Barolong.

K. Endemann. Versuch einer Grammatik des Sotho. Berlin (Wilhelm Hertz), 1876.

* Wörterbuch der Sotho-Sprache, Vol. VII. of Abhandlungen des Hamburgischen Kolonialinstituts. Hamburg (L. Friedrichsen and Co.), 1911.

These are really Chwana rather than Sutu, which is noticed as a dialect under the name of 'Süd-Sotho.' 
E. Jacottet. Practical Method to learn Sesuto. Morija (Sesuto Book Depot), 1906.

Elementary Sketch of Sesuto Grammar, 1893. Published with Mabille's Vocabulary, which see.

E. Jacottet. Treasury of Basuto Lore, Vol. I. (Sesuto Book Depot), Morija, Basutoland, 1908. London (Kegan Paul).

A valuable collection of Native Tales." Subsequent volumes were intended to contain historical traditions, songs, accounts of customs, etc., but no more have yet been issued.

D. Jones and S. T. Plaatje. Sechuana Reader. University of London Press (Hodder and Stoughton), 1916.

F. H. Kruger. Steps to Learn the Sesuto Language (Fourth edition). Morija (Sesuto Book Depot), 1905.

A. Mabille. Sesuto-English and English-Sesuto Vocabulary. (Preceded by Jacottet's Grammar, which see.) (P. E. Mission Press), Morija, 1893.

A. Mabille and H. Dieterlen. Sesuto-English Dictionary. Revised and considerably enlarged. (Sesuto Book Depot), Morija.

*S. T. Plaatje. Sechuana Proverbs with Literal Translation. London (Kegan Paul), 1916.

Puisano ea se-Sotho le se-English. Phrase-Book. Sesuto-English. Morija (Sesuto Book Depot), 1908.

A. J. Wookey, L.M.S. Secwana Grammar, with Exercises. Frome (Butler and Tanner), 1905.

Congo (languages of). The languages included under this heading are :

†Bangi, (Bobangi, Kibangi, Kiyanzi). On both banks of the Congo, from the confluence of the Sankuru to that of the Lulongo. 
Kanyoka, between Lulua and Upper Sankuru.

Kele, below Stanley Falls. ${ }^{1}$

*Kongo, (Congo, Fiote.)

tLolo, (Mongo, Lunkundu) - on the Equator, within the great northern bend of the Congo.

Lulua, on one of the Kasai tributaries.

Ngala, (Bangala, Lingala). Middle Congo, between the confluences of the Mubangi and the Mongala.

Ng'ombe, west of the Ba-ngala.

Poto, at and near Bopoto (Upoto), at the top of the Congo bend.

Soko, near the mouth of the Aruhwimi.

Teke, north of Stanley Pool (also called Ifumu).

Yombe, (Kiombe) in the Mayombe country, North of the Lower Congo, and inland from the $\mathrm{Ba}$ vili.

An excellent bibliography of all publications dealing with the Congo languages up to 1906 (the work of Professor Starr), was issued by the University of Chicago in 1908.

J. Barfield. Concords " of the Congo Language, as spoken at Palaballa. (East London Mission Institute), Harley House, Bow, 1884.

W. Holman Bentley. Dictionary and Grammar of the Kongo Language. London (Trübner and Co.), 1887.

Appendix to the Dictionary, etc. (Same publishers), 1895.

De Boeck. Grammaire et Vocabulaire du Lingala ou Langue du Haut Congo, 1904.

1 Not to be confused with Di-kele, the language of a different tribe of Ba-kele, living near the Gabun estuary.

2 Department of Anthropology, Bulletin V. 
Fra Giacinto Brusciotto di Vetralla. Regulae quaedam pro difficillimi Congensium idiomatis faciliori captu ad grammaticæ normam redactæ. Romæ, 1659.

* Brusciotto di Vetralla. Grammar of the Congo Language, as spoken 200 years ago, translated from the Latin, and edited, with a preface, by $\mathrm{H}$. Grattan Guinness. London (Hodder and Stoughton), 1882.

${ }^{*}$ R. P. J. Calloch. Vocabulaire Francais-Ifumu (Batéké), précédé d'éléments de Grammaire, 1911.

R. P. Cambier. Essai sur la langue Congolaise. Brussels (Imprimerie Polleunis and Ceuterick), 1891 (Boko dialect of Ngala).

${ }^{*} \mathrm{H}_{\mathrm{r}}$ Craven and J. Barfield. English-Congo and CongoEnglish Dictionary. London (Harley House), Bow, 1883.

A. Courboin. 'Bangala,' Langue Commerciale du HautCongo, Élements, Manuel de Conversation, Lexique. Paris (A. Challand), 1908.

R. P. A. Declercq de la Congrégation du C. I. de Marie, Missionnaire au Congo belge. Eléments de la langue Kanioka (Kanyolka.) Vanves près. Paris (Imprimerie Franciscaine Missionnaire), 1900.

Vocabulaire Français - Kanioka. (Same publishers), 1901.

Vocabulaire Kanioka - Français, (Same publishers), 1901.

Grammaire du Kiyombe. Anthropos, Vol. II., pp. 449-466, 761-794. 1907.

R. P. A. Declercq. Grammaire de la Langue des Bena Lulua. Brussels (Polleunis and Ceuterick), 1897.

Légendes des Bena Kanioka (Text, with interlined French translation). Anthropos, Vol. IV., pp. 71-86, 449-456, 1909.

${ }^{*}$ L. M. Hailes. Kilolo-English Vocabulary. (East 
London Institute for Home and Foreign Missions), Harley House, Bow, 1891.

H. H. Johnston. The River Congo. (Sampson Low), 1884, Second ed., 1895.

Contains vocabularies of Kongo, Teke, Buma and Bangi (Yanzi).

J. and F. T. McKittrick. Guide to the Lunkundu Language. (A dialect of Lolo.) (East London Institute for Home and Foreign Misşions), 1897.

*A. T. Ruskin. Proverbs and Similes of the Bamongo (Mongo is a dialect of Lolo.) (East London Institute for Home and Foreign Missions), 1897.

Lomongo Language.

Outlines of the Grammar of the

A. Sims. Vocabulary English-Kibangi (Bangi). London(East London Institute) : Boston (American Baptist Mission Union), 1886.

A. Sims. Vocabulary English-Kiteke and KitekeEnglish (Teke), 1886.

*W. H. Stapleton. Comparative Handbook of Congo Languages, being a Comparative Grammar of the eight principal languages, with appendices on six other Dialects (Baptist Mission Press), Yakusu, Stanley Falls, 1903.

The eight languages included in this book are: Kongo, Bangi, Lolo, Ngala, Poto, Ng'ombe, Soko, Kele.

The six noticed in the Appendix are: Teke, Sakani (a dialect of Lolo), Lomongo (Mongo, also a dialect of Lolo), Boko (a dialect of Ngala), Lulua, and Mpombo, which is not Bantu.

*W. H. Stapleton. Suggestions for a Grammar of Bangala (the Lingua Franca of the Upper Congo), with 2,000 words'and many useful phrases. Yakusu (Baptist Missionary Society), 1903.

R. P. Ussel. Petite Grammaire de la Langue Fiote, Dialecte du Loango, pp. 85. Loango (Mission Press), 1888. 
(This is spoken by the Ba-vili, whose country is somewhat to the north of the Congo estuary. The author is a missionary of the Congrégation du St. Esprit.) R. P. Alexandre Visseq. Dictionnaire Fiot (FrenchKongo), 1889.

1890. Dictionnaire Fiot (dialecte Sorongo),
1890. Dictionnaire Fiot (dialecte du Kakongo),
$\begin{aligned} & \text { St. Antonio). Prammaire (Sorongo dialect spoken at } \\ & \text { of the Holy Ghost), } 30 \text { Rue Lhomond, 1889. }\end{aligned}$

J. Whitehead. Grammar and Dictionary of the Bobangi Language. London (Kegan Faul, Trench, Trübner and Co.), 1899.

*Duala.

Th. Christaller. Handbuch der Duala-Sprache. Grammar and exercises; story with literal interlined translation; dialogues; vocabulary. Basle, 1892.

C. Meinhof. Die Spraclue der Duala in Kamerun, Vol. III. of Deutsche Kolonialsprachen, 1912.

IV.Lederbogen. D:rala-Märchen. 'Mitt. B. Sem.Or. IV, V, VI, Abt. 3, 1901-3.

A large collection of tales, with German translation in parallel columns.

A. Saker. Grammatical Elements of the Dualla Language, with vocabulary. Cameroons (Mission Press), 1853.

A. Seidel. Leitfaden zur Erlernung der Dualla-Sprache (with readings and vocabulary). Berlin (Carl Heymann), 1892.

Die Duala-Sprache in Kamerun. System. atisches Wörterverzeichnis und Einführung in die Grammatik. , Julius Groos' Verlag. Heidelberg, Paris, London, Rome, Petersburg, 1904. 
Duma. See Aduma.

Dzalamo (Zaramo, Zalamo). East Coast, South of Zanzibar.

A. Worms. Grundzüge der Grammatik des Ki-Zaramo in Deutsch-Ost-Afrika. Zeitschr. für afr. u. ocean. Sprachen III, p. 289, 1897.

C. Meinhof. Linguistische Studien in Ostafrika, No. XII., Mitt. B.Sem. Or. X., Abt. 3, pp. 90-110, 1907. Ediya, see Bube.

Fan (Fang, Fanwe, Pahouin, Pamwe, etc.). West Equatorial Africa, North of the Ogowe.

* Rev. H. M. Adams. Fañwe Primer and Vocabulary. Compiled by the Rev. R. H. Nassau, M.D., Gaboon and Corisco Mission [from the MSS. of the Rev. H. M. Adams.] New York (printed by E. G. Jenkins), 1881.

V. Largeau. Encyclopédie Pahouine, 1901.

Includes Grammar and French-Fan Dictionary, containing many valuable anthropological notes and also texts with translation.

R. P. L. Lejeune. Dictionnaire français-fang. Paris (Favre and Teillard), 1892. With a Grammatical Sketch.

*A. Osorio Zabala. Vocabulary of the Fan Language (Fan-Spanish.) London (S.P.C.K.), 1887.

A number of stories, with French translation were published by P. Trilles in Anthropos. Vol. IV., pp. 945-971, Vol. V., pp. 163-180.

Fernandian (See Bube).

Fiote (Kongo. See under Congo).

Fipa (East side of S. part of L. Tanganyika).

B. Struck. Die Fipa-Sprache (Deutsch-Ostafrika). Anthropos, Vol. VI., 1911, pp. 951-993. Grammatical Sketch.

* _ Vocabulary of the Fipa Language. Journal of the African Society, October, 1908 (Vol. VIII.). 
* Ganda (Luganda).

${ }^{*}$ G. R. Blackledge. Luganda-English and English. Luganda Vocabulary (S.P.C.K.); 1904.

${ }^{*} \mathrm{H}$. Wright Duta. Engero za Baganda (Proverbs in the Luganda Language.) (S.P.C.K.), 1902.

*Elements of Luganda Grammar (Exercises and Vocabulary.) By a Missionary of the Church Missionary Society in Uganda. (S.P.C.K.), 1902.

${ }^{*}$ C. W. Hattersley and H. W. Duta (eds.). Luganda Phrases and Idioms. (S.P.C.K.), 1904.

* Sir H. H. Johnston. The Uganda Protectorate, 2 vols. London (Hutchinson), 1904.

Vol. II. contains vocabularies of a number of languages besides Ganda.

Apolo Kagwa. Engero zabaGanda (Folk-stories). Mengo (C.M.S. Press), 1901.

*Ekitabo kyo Bakabaka beBuganda (Book of the Kings of Uganda). London (Headley Brothers), printed, n.d. [1900 ?]

*G. L. Pilkington. Handbook of Luganda. London (S.P.C.K.), 1892 (last edition, 1911).

White Fathers. Manuel de Langue Luganda, par L.L. et C. D. des Pères Blancs (Grammar and Tales). Einsiedeln, Switzerland (Benziger and Co.), 1894.

*Giryama.

W. E. Taylor. Grammar of the Giryama Language (out of print).

Giryama Vocabulary and Collections (Grammatical notes, and two tales, with translation). London (S.P.C.K.), 1891.

Gisu (Masaba). Spoken on and near Mount Elgon. * Rev. J. B. Purvis. A Manual of Lumasaba Grammar (S.P.C.K.), 1897.

tGogo. Ugogo (the country of the IVagogo) is about half-way between Zanzibar and Tabora and is traversed by the Dar-es-Salaam railway. 
G. J. Clark (C.M.S.) Vocabulary of the Chigogo Language. London (Gilbert and Rivington), 1877, pp. 58.

Zimbazi ze Zifumbo, Nhandaguzi ne Zisimo ze Cigogo (Gogo Reading Book-Native Proverbs, Riddles and Fables). London (S.P.C.K.), 1901.

Collected and written out by Andereya and Nhonya. C.M.S. native teachers at Mpwapwa. Preface in English, signed J. E. B [everley].

Gwamba. A dialect of Thonga, spoken in N. E. Transvaal.

P. Berthoud. Grammatical Note on the Gwamba Language [1885]. Journal of the Royal Asiatic Society, Vol. XVI., Part I.

P. Berthoud. Leçons de Si-Gwamba. (Imp. J. Chappins), Lausanne. 46 pp., lithographed, 1883.

Hehe. About 300 miles north of Lake Nyasa and to the south of the Gogo country.

C. Velten. Die Sprache der Wahehe. Mitt. B. Sem: Or. Vol. II. Vol. III. contains a Hehe-German and German-Hehe Vocabulary, by P. Cassian "Spiss, O.S.B.

\section{tHerero.}

P. Brincker. Wörterbuch und kurzgefasste Grammatik der Otji-Herero Sprache. Leipzig (T. O. Weigel), 1886.

The Appendix contains some tales, with literal and free translation into German. Some additional tales, collected by Büttner, are published in $Z$ tschr. für afr. Sprachen.

P. H. Brincker. Deutscher Wortführer für die BantuDialekte, Otji-Herero, Oshindonga, und OshiKuanjama in S. IV. Afrika. Elberfeld (R. L. Friderichs \& Co.), 1897.

A very full German-Herero, etc., dictionary, in four columns. 
C. Hugo Hahn. Grundzüge einer Grammatik des Herero, pp. X+197. Berlin (W. Hertz); London (Williams and Norgate), 1857.

F. W. Kolbe (L.M.S.) English-Herero Dictionary, with an Introduction to the Study of Herero and Bantu in general. Cape Town (Juta), pp. LV. + 569, 1883.

*C. Meinhof. Die Sprache der Herero in Deutsch Südwest-Afrika (Deutsche Kolonialsprachen, Bd. I.). Berlin (Dietrich Reimer), 1909.

*A. Seidel. Praktische Grammatik der Haupt-sprachen Deutsch Südwestafrikas (Nama, Otji-Herero, Oshindonga), Vienna, Leipzig (Hartleben), 1892.

G. Viehe. Grammatik des Otjiherero (with Vocabulary). Vol. XVI. of Lehrbücher des Seminars für orientalische Sprachen.

Stuttgart, Berlin (W. Spemann), 1897.

Ifumu (Teke). See under Congo.

tIla (Seshukulumbwe).

*E. W. Smith. Handbook of the Ila Language. Oxford (University Press), 1907.

Isubu. Bimbia Peninsula, Cameroons, north of the Duala.

C. Meinhof. Das Verbum in der Jsubu-Sprache. Zeitschrift für Afr. Sprachen. Vol. III., pp. 206 234, Berlin, 1889-90.

Joseph Merrick. A Dictionary of the Isubu Tongue. (No publisher's name given in the British Museum copy), 1854. Part I. Isubu-English, only completed as far as $I$.

A Grammar of the Isubu Tongue. Unfinished. This is out of print and no doubt rare. The British Museum copy (Press nark 12907 bb. 22) is bound up in a volume of 'Philological Tracts.'

Kafir. See Xosa. 
Kaguru (Kimegi). One of the dialects of Usagara, lying east of Ugogo.

J. T. Last. Grammar of the Kaguru Language. London (S.P.C.K.), 1886.

Kamba. Spoken in Ukambani, E. Africa-the district in which Nairobi is situated.

E. Brutzer. Handbuch der Kamba-Sprache. Berlin, 1906. Mitt. B. Abt. Sem. Or. IX., 3, pp. 1-100.

*H. Hinde. Vocabularies of the Kamba and Kikuyu Languages. (Cambridge University Press), 1904. *J. T. Last. Grammar of the Kamba Language, pp. 40. London (S.P.C.K.), 1885.

*A. D. Shaw. Vocabulary of Four East African Languages. See under Swahili.

C. G. Büttner, Deutsch-Kikamba Wörterbuch.Ztschr. f. afr. Spr. Vol. I., pp. 81-123, 1888.

Kami. Spoken in the Ukami country, of which Mrogoro, on the Dar-es-Salaam railway, is the centre.

A. Seidel, in Ztschr-für afr. u. oc. Spr. II., 1, p. 20. (Grammatical sketch and short vocabulary).

C. Velten. Die Sprache der Wakami in DeutschOstafrika. Mitt. B. Sem. Or. III., Abt. 3,pp. 1-56, 1899. Grammatical Sketch and Vocabulary.

A few words and phrases are to be found in Last's Polyglotta Africana Orientalis, pp. 69-72.

Kanyoka. See under 'Congo.'

†Ǩ̀ranga(Chino,Chiswina, Chizwina, Mashona, Shuna). E. Biehler (S.J.) English-Chiswina Dictionary, with Outline Grammar. Roermond (J. J. Romer and Sons), 1906.

Four Methods of Teaching English to the Maswina. Roermond (same publishers), 1906.

Testamente. (BibleStories). Roermond (same publishers), 1906. 
Rev. H. Buck. A Dictionary with Notes on the Grammar of the Mashona Language, commonly called Chiswina (Compiled at St. Augustine's Mission, Penhalonga.) (S.P.C.K.), 1911.

W. A. Elliott. Dictionary of the Tebele and Shuna Languages, 1897.

The second edition of this book (1911) which omits the 'Shuna' edition is entered under 'Zulu.'

Louw, Mrs. C. S. A Manual of the Chikaranga Language (Grammar, Exercises, Useful Phrases and Vocabulary), p. $397 . \quad$ Bulawayo (Philpot \& Collins), 1915.

Rev. A. M. Hartmann (S. J.). Outline of a Grammar of the Mashona Language. Cape Town, 1893.

Kele (Lokele). See under 'Congo.'

Kele (Dikele). Spoken near the Gabun Estuary.

Missionaries of the A.B.C.F.M. A Grammar of the Ba-kele Language. New York, 1854.

\section{Kikuyu.}

*A. R. Barlow. Tentative Studies in Kikuyu Grammar and Idiom. Edinburgh (Blackwood), 1914.

Rev. Father A. Hemery. English-Kikuyu Handbook. Zanzibar-Nairobi (Roman Catholic Mission), 1903.

*A. W. McGregor(C.M.S.) English-Kikuyu Vocabulary. (S.P.C.K.), 1904.

A Grammar of the Kikuyu Language. London (Clay and Sons, printed), 1905.

H. Hinde. Vocabulary (See Kamba).

\section{Kinga.}

*R. Wolff. Grammatik der Kinga-Sprache (DeutschOstafrilka, Nyassagebiet), nebst Texten u. IVörterverzeichniss. Berlin, 1905. Archiv für das Studium deutscher Kolonialsprachen, Vol. 3.

Kiniassa. See Nyanja.

Kiyanzi (=Bangi, Kibangi). See under ' Congo.' 
Konde. North end of Lake Nyasa.

C. Schumann. Grundriss einer Grammatik der Kondesprache. Berlin, 1899.

Kongo (See under ' Congo.')

Kwanyama. Spoken by a branch of the people called Ovambo, in S. W. Africa.

P. H. Brincker. Lehrbuch des Oshikuanjama in Verbindung mit Oshindonga. (Stuttgart) Berlin, 1891.

Deutscher Wortführer für

Otji-herero, Oshi-ndonga, u. Oshi-kuanjama. (See also under Herero.)

*H. Tönjes. Lehrbuch der Ovambo-Sprache Osikuanjama. Lehrb. d. Sem. f. or. Spr., Vol. 24.

* Wörterbuch der Ovambo-Sprache. Ib., Vol. 25. Berlin (G. Reimer), 1910.

Lala-Lamba. Spoken to the south of Lake Bangweolo. *A. C. Madan. Lala-Lamba Handbook. Oxford (Clarendon Press), 1908.

*___ Lala-Lamba-Wisa-English, and English-Lala-Lamba-Wısa Dictionary. Oxford (Clarendon Press), 1913.

*Lenge. Also called Chopi and Tswa. Spoken in Portuguese S. E. Africa, between Inhambane and the Limpopo.

*Bp. Smyth and J. Matthews. A Vocabulary with a short Grammar of Xilenge. London (S.P.C.K.), 1902, 1912.

Lenje. North-Western Rhodesia; allied to Ila, which adjoins it on the west, and Tonga, spoken to the north.

*A. C. Madan. Lenje Handbook. (Oxford University Press), 1908.

Lolo. See under 'Congo.'

Lomongo (Mongo) = Lolo. See under 'Congo.' 


\section{$L u b a$.}

W. M. Morrison. Grammar of the Buluba-Lulua Language, and Dictionary. Privately printed, 1907.

"The Buluba and the Lulua people . . . together occupy a large area . . extending, roughly speaking, from the junction of the Lulua and Kasai rivers in a general south-easterly direction into Garenganze, where the language is called Ciluba' [Chiluba-elsewhere Bu-luba]. (Preface).

P. A. Declercq. Grammaire de la Langue Luba, with Vocabulary, pp. 504. Louvain (Istas), 1903.

Grammaire pratique de la Langue

Luba. Brussels (Polleunis and Ceuterick), 1911.

Lulua. See under 'Congo.'

Lunda. An important language spoken on the watershed between the Congo and Zambesi, near the sources of the Kasaind to the south of the Luba country.

H. A. Dias de Carvalho. Methodo Pratico para fallar a lingua de Lunda. Lisbon (Imprensa Nacional), 1890.

Luyi (Rotse). Spoken by the people of Barotseland (Lewanika's country on the Upper Zambezi.)

E. Jacottet. Etudes sur les langues du Haut-Zambèze. $1^{\text {re }}$ Partie. Grammaire Soubiya et Louyi, 1896. $3^{\text {tae }}$ Partie. Textes Louyi, Contes, Légendes. Superstitions et Vocabulaires. Paris (Ernest Leroux), 1901.

Machame. A dialect of Chaga spoken by about 16,000 people living on the western side of Kilimanjaro.

*Julius Augustiny. Kurzer Abriss des Madschamedialekts. Berlin, 1914. Archiv. für d. Stud. deutscher Kolonialsprachen. Vol. 16.

Makonde. Spoken in the country north of the Rovuma. (E. Africa), about as far as Lindi.

E Steere. Collections for a Handbook of the Makonde Language. (U.M.C.A.), Zanzibar, 1876. 
Makua. In Mozambique

*Chauncy Maples. Collections for a Handbook of the Makua Language. London (S.P.C.K.), 1879. Archdeacon Woodward is preparing a new and revised edition of this little work.

D. J. Rankin. Arabian Tales, translated from Swahili to Makua. (Tugulu dialect), London, 1887.

Mang'anja. See Nyanja.

Masaba. See Gisu.

Matumbi.

B. Krumm. Grundriss einer Grammatik des Kimatumbi,

1912. Mitt. B. Sem. Or. XV., Abt. 3, pp. 1-63.

Spoken by the inhabitants of the Matumbi hills, inland

from Kilwa. Vocabulary, ib. XVI. Abt. 3, pp. 1-57. Mbundu (Bunda, Kimbundu, Umbundu, Angola.) Spoken in Portuguese IV.Africa, south of the Congo.

B. M. de Cannecattim. Diccionario da Lingua Bunda ou Angolense. Lisbon (Impressão Regia.), 1804.

Three parallel columns: Portuguese, Latin, Mbundu.

Collecção de Observaçoes grammaticaes sobre a Lingua Bunda ou Angolense, 1805.

Appended to this is a brief Dictionary in four columns.

Portuguese, Latin, Mbundu, Kongo. Second edition, 1859.

${ }^{*}$ H. Chatelain. Kimbundu Grammar (Grammatica elementar do Kimbundu ou lengua de Angola.) (Port. and English), Geneva, 1889.

Grundzüge der Kimbundu-Sprache, 1890.

Published in $Z$ tschr. für afr. Sprachen, avowedly as an abstract of the preceding, though the author says be has introduced some new points. *.

Folk-tales of Angola. Boston, New York, 1894.

Published by the American Folk-Lore Society. Mbundu text, with English translation on opposite page. 
W. H. Sanders, WV. E. Fay and others. Vocabulary of the Umbundu Languroge, comprising, UmbunduEnglish and English-Umbundu. Boston (Beacon Press), A.B.C.F.M., 1885.

Contains 3,000 words of the dialect spoken inland in Benguela.

W. M. Stover. Observations upon the Grammatical Structure and use of the Umbundu. Boston, 1885. Mongo (= Lolo). See under 'Congo.'

Mpongre. Sec Pongwe.

Namroanga. Spoken by the Winamwanga, N. W. of Lake Nyasa.

E. H. Dewar. Chinamwanga Stories (with English translation.) (Livingstonia Mission Press), 1900.

tNdonga. The language of one of the tribes known collectively as Ovambo, in the northern part of 'Damaraland.'

*P. H. Brincker. Lehrbuch des Oshikuanjama in Verbindung mit Oshindonga. Lehrbücher des Seminars für orient. Sprachen, Vol. VIII. Berlin, 1891. See also Kwanyama.

P. H. Brincker. Deutscher Wortführer für die Bantudialekte . . Oshindonga, etc. See under Herero and Kivanyama.

*A. Seidel. Grammatik des Oshindonga, etc. Also entered under Herero.

Ngombe. See under 'Congo.'

Nika (more correctly Nyika).

There is no language properly called by this name, which is applied to the Rabai, Giryama, Duruma, Digo and five smaller tribes.

*J. L. Krapf and J. Rebmann. A Nika-English Dictionary. Edited by T. H. Sparshott. London, 1887.

The words in this book are chiefly Rabai. 
A. D. Shaw. See Vocabulary of four E. African Languages $v$. Swahili.

tNyamrvezi. Spoken over a large area to the south of Lake Victoria. Sukuma and Sumbwa are dialects of it.

${ }^{*} \mathrm{E}$. Steere. Collections for a Handbook of the Nyamwezi Language. London (S.P.C.K.), n.d.

R. Stern. Eine Kinyamwesi Grammatik, Berlin, 1906. Mitt. B. Sem. Or. IX. 3, pp. 129-258.

${ }^{*}$ C. Velten. Grammatik des Kinyamŭesi (with Vocabulary). Göttingen. (Vandenhoeck and Ruprecht), 1901.

* Nyanja (Chinyanja, Mang'anja, Nyasa, Chinyasa).

Is also virtually identical with Sena, and very similar to Nyungwe (Tete).

*Rev. H. C. R. Barnes. Nyanja-English Vocabulary. London (S.P.C.K.), 1902.

This is an enlarged edition of Miss Woodward's Vocabulary of 1892,1895 , q.v.

V. J. Courtois, S.J. Eléments de Grammaire Tetense (Lingua Chi-Nyungue). Coimbra (University Press), 1900.

G. Henry. A Grammar of Chinyanja. Aberdeen, (G. and W. Fraser), 1891. Second edition, 1904.

A. Hetherwick. A Practical Manual of the Nyanja Language. . London (S.P.C.K.), second edition, 1912.

R. Laws. English-Nyanja Dictionary. Edinburgh (James Thin), 1894.

*R. S. Rattray. Some Folklore, Stories and Songs, with English translation and notes. London (S.P.C.K.), 1907.

*J. Rebmann. Dictionary of the Kiniassa Language. Edited by L. Krapf. St. Chrischona, near Basle, 1877.

(Ki-nyasa = Chi-nyanja. The Anyanja are called Anyasa by the Yaos and Swahili, Rebmann obtained his materials from released slaves in East Africa.) 
*Rev. D. C. Scott. Cyclopædic Dictionary of the Mang'anja Language. Edinburgh (Foreign Missions of Church of Scotland), 1892.

*M. E. Woodward. English-Chinyanja and ChinyanjaEnglish Vocabulary, 1892, reprinted 1895 (S.P.C.K.)

Another edition, revised and enlarged by the Rev. H. Barnes, appeared in 1913.

*__ Exercise-book (S.P.C.K.), 1898, 1909.

Nyika. See Nika.

*Nyoro (Uganda Protectorate).

*H. E. Maddox. Elementary Lunyoro Grammar, with Lunyoro-English Vocabulary. London (S.P.C.K.), 1902.

Nyungwe (Tete). Spoken in the country about Tete on the Zambezi. Very similar to, if not identical with Nyanja.

V. J. Courtois. Diccionario Cafre-Tetense-Portuguez, 1900.

Diccionario Portuguez-Cafre-Tetense, 1900.

Elementes de Grammatica, 1909.

A. v. d. Mohl, S. J. Grammatik der Bantusprache von Tete. Mitt. B. Sem. Or. VII. Abt. 3, pp. 32-85, 1904. Vol. VIII. 3 (1905), contains a collection of tales with German translation.

Pahouin. See Fan.

Pogoro. Spoken in E. Africa, somewhat east of the north end of Lake Nyasa, and north of the Rovuma. *J. Hendle (O.S.B.). Die Sprache der Wapogoro. Berlin (G. Reimer), 1907. Archiv für deutsche Kolonialsprachen, Vol. VI.

†Pokomo. Tana River, British East Africa.

*C. Meinhof. Linguistische Studien in Ostafrika. No. VII. Mitt. B. Sem. Or. Jahrg. XIV., Abt. 3. Berlin, 1911. 
Pokomo-Grammatik mit Uebungsstücken. (The work of one or more of the Neukirchen missionaries, but no author's name appears.) Neukirchen, Missionsbuchhandlung (Stursberg und Cie), 1908.

${ }^{*}$ F. Würtz. Wörterbuch des Ki-tikuu und des Kipokomo. Published in Zeitschrift für afrikanische und oceanische Sprachen, Vol. I., p. 193.

This is a German-Tikuu and Pokomo Dictionary. (Tikuu is a Swahili dialect. See under Swahili).

$62,168$.

Grammatik des Pokomo, ib. Vol. II., pp.

Vol. 1. of the same periodical contains some Pokomo songs, and Vol. II. some traditions (all with German translation).

Some grammatical notes (1889), and a PolkomoGerman vocabulary had previously been published by F. Würtz in Büttner's Zeitschrift für Afrikanische Sprachen.

Pongwe (Mpongwe). Spoken in the country adjoining the Gabun estuary, French Congo.

J. R. Wilson (a late Missionary). Heads of the Mpongwe Grammar, containing most of the principles needed by a learner. New York (Mission House, 23, Centre Street), 1879.

R. P. Le Berre. Grammaire de la Langue Pongouée. Paris (Maisonneuve et Cie), 1873.

Missionaires de la Congrégation de Saint Esprit. Dictionnaire Français.Pongué, 1877-81. Dictionnaire Pongué-Français, 1881. Paris (Maisonneuve et $\mathrm{Cie}$ ).

Missionaries of the A.B.C.F.M. Gaboon Mission. A Grammar of the Mpongwe Language, with Vocabularies. New York (Snowden and Prall), 1847.

Poto. See under 'Congo.'

tRonga (Shironga). A branch of the Thonga language, spoken in the neighbourhood of Delagoa Bay. 
H. A. Junod. Grammaire (with Ronga-French-EnglishPortuguese Vocabulary and Dialogues). Lausanne (Bridel), 1896.

Nouveaux Contes Ronga. Neuchatel Imprimerie (Paul Attinger), 1898. See also Thonga.

Rotse. See Luyi.

Ruanda. N. end of L. Tanganyika.

*P. Eugène Hurel. Manuel de Langue Kinyaruanda. Mitt. B. Sem. Or. XIV., Abt. 3, pp. 1-159, 1911.

Rundi. Between Tanganyika and Lake Kivu, on the north. Very similar to Ruanda.

R. P. J. M. van der Burgt, des Pères Blancs. Dictionnaire Français-Kirundi. Bois le Duc, 1900-1903.

* - Eléments d'une Grammaire Kirundi. Mitt. B. Sem. Or. V., Abt. 3.

R. P. F. Menard, des Pères Blancs. Dictionnaire Français-Kirundi et Kirundi-Français. Paris (Guilmoto), 1909.

1908.

Grammaire Kirundi. Same publisher,

Sena (Lower Zambezi, virtually identical with Nyanja). *W. G. Anderson. Introductory Grammar of the Sena Language (S.P.C.K.), 1897.

J. Torrend, S.J. Grammatica do Chisena. Grammar of the Language of the Lower Zambezi. Chipanga, Zamberia. (Mission Press), 1900.

In parallel columns, Portuguese and English.

Senga (Middle Zambezi).

*A. C. Madan. Senga Handbook. Oxford (Clarendon Press), 1905.

tShambala. Usambara, East Africa, inland from Tanga. P. E. Hörner. Kleiner Leitfaden zur Erlernung des Kischambala. Mariannhill (Natal), 1900.

${ }^{*}$ K. Roehl. Versuch einer systematischen Grammatik der Schambalasprache. Hamburg, 1911. 
Frau Rösler and F. Gleiss. Schambala-Grammatik und Wörterbuch. Berlin, 1912. Vol. XIII. of Archiv für das Studium deutscher Kolonialsprachen.

E. Steere. Collections for Handbook of the Shambala Language, 1867. Revised by Archdeacon Woodward. (U.M.C.A.) Msalabani, 1905.

Shangaan. See Thonga.

Shuna. See Mashona.

Siha (Kisihá). See Chaga.

Soko. See under "Congo."

Subiya (Upper Zambezi).

E. Jacottet. Grammaires Soubiya et Louyi, 1896. Textes Soubiya, 1899. See also Luyi.

Sukuma. (On the south-eastern side of the Victoria Nyanza. A dialect of Nyamwezi.)

*Capt. Herrmann. Kissukuma, die Sprache der Wassukuma. Mitt. B. Sem. Or. I., Abt. 3, pp. 146198,1898. Gram. Sketch, with Vocabulary and Texts.

A. Seidel. Das Kisukuma. Granmmatische Skizze (with Vocabulary), 1894.

Sumbwa. Spoken in a district of the N.W. part of Unyamwezi, between Usukuma and Uha, south of Lake Victoria, but separated from it by Uzinja.

*A. Capus (of the White Fathers). Grammaire de Shisumbwa (Ztschr. für afr. u. oc. Spr. Vol., IV., pp. 1-123), 1898.

The preceding volume of the same periodical contains (pp. 358-381) ten stories and some songs and proverbs, with literal French translation.

Saint-Cloud (Impr. Belin Frères), 1901. *Swahili.

H. W. M. Beech. Studies in Ki-Swahili London (Kegan Paul, Trench, Trübner \& Co.), 1918. 
E. Brutel. Vocabulaire Français-Kiswahili et KiswahiliFrançais, 2 ed. Brussels, 1913.

Mrs. F. Burt. Grammar and Vocabulary (Mombasa dialect). (S.P.C.K.), I910.

C. G. Büttner. Wörterbuch der Suaheli-Sprache. 2 pts. Stuttgart (Berlin), 1890.

Suaheli-Schriftstücke in arabischer Schrift. Vol. X. of Lehrbücher des Seminars für orientalische Sprachen. (IV. Spemann), Stuttgart and Berlin, 1892.

Anthologie aus der Suaheli-Litteratur. (E. Felber), Berlin, 1894. 'Texts (prose and poetry) with translation into German.

Habari za Wakilindi. Pt. I., n.d. Pt. II. 1904. Pt. III., 1907. (U.M.C.A.), Msalabani. Traditions of the Washambala written in Swahili by Abdallah bin Hemed bin Ali Liajjem.

R. P. A. Hemery de la Congrégation du St. Esprit et du Saint-Cœur de Marie. Vocabulaire FrançaisSwahili-Teita. Zanzibár (Mission Catholique). Paris (30 Rue Lhomond), 1901.

WV. K [isbey]. Notes and Corrections of Swahili. I.-IV. Zanzibar (U.M.C.A.), ] 898-1899.

Kibaraka. Zanzibar. (Univ. Mission Press), 1896. Stories written or dictated by natives.

J. L: Krapf. Outlines of the Elements of the Kisuaheli Language, with special reference to the Kinika Dialect. Tübingen (Friedr. Fues), 1850.

A Dictionary of the Suahili Language, with Introduction, containing an outline of a Suahili Grammar. London (Trübner \& Co.), 1882.

*A. C. Madan. English-Swahili Dictionary. Oxford (University Press), 1894. Second edition, 1902.

* - Swahili.English Dictionary. Oxford (University Press), 1903. 
*A. C. Madan. Swahili Grammar. Oxford(University Press), 1905.

C. Meinhof. Die Sprache der Suaheli. Berlin (Dietrich Reimer(Ernst Vohsen)), 1910. Deutsche Kolonialsprachen Bd. 2.

W. Planert. Die syntaktischen Verhältnisse des Suaheli. Berlin (W. Süsserott), 1907.

Ch. Sacleux., Dictionnaire Français-Swahili. Zanzibar (Mission des P. P. du St. Esprit.) Paris (30 Rue Lhomond), 1891.

- Grammaire des Dialectes Swahilis. Paris

(Procure des Pères du S. Esprit), 1909.

This book obtained the Prix Volney from the Institut de France.

*A. Downes Shaw. Pocket Vocabulary of Four E. African Languages. (Ki-Swahili, Ki-Nyika, KiTaita and Ki-Kamba; with vocabulary of Kibwyo dialect). London (S.P.C.K.), [1885].

*E. Steere. A Handbook of the Swahili Language, as spoken at Zanzibar. London (S.P.C.K.) First edition, 1871; second edition, 1875 ; third edition revised and enlarged by A. C. Madan, 1884 ; fourth edition, 1913.

1908. Swahili Exercises. (S.P.C.K.), 1894-

- Swahili Tales, 1889. Reprinted, 1906 and 1917. (S.P.C.K.), London.

Practical Guide to Use of the Arabic Alphabet in writing Swahili, 1892. (Out of print.)

Capt. C. H. Stigand. Grammar of Dialects in the Kiswahili Language (with Introduction by the Rev. W. E. Taylor). Cambridge (University Press), 1915.

W. E. Taylor. Groundwork of the Swahili Language Tabulated. London (S.P.C.K.), 1898. 
W. E. Taylor. African Aphorisms, or Saws from Swahililand. London (S.P.C.K.), 1891.

Swahili Proverbs, translated and annotated. Some Rabai and Giryama proverbs are appended.

C. Velten. Suaheli-Wörterbuch (Part I. SwahiliGerman). Berlin. Published by the Author, 1910. - Praktische Grammatik der SuaheliSprache. Berlin (W. Baensch), 1905.

Praktische Anleitung zur Erlernung der Schrift der Suaheli. Göttingen (Vandenhoeck und Ruprecht), 1901-1910.

A useful guicle to the reading and writing of Swahili in the Arabic character.

Safari za Wasuaheli. Göttingen, 1901.

Narratives of journeys into the Interior (and in two cases to Europe), written or dictated by natives.

* — Desturi za Wasuaheli. Göttingen, 1903.

A very full account of native customs, written by natives, in Swahili.

Märchen und Erzählungen. Stuttgart (Spemann), Berlin, 1898. Vol. 18 of Lehrb. d. Sem. für orient. Sprachen.

Prosa und Poesie der Suaheli. Berlin (Published by the Author), 1907.

Contains tales, proverbs, dialogues, poems (mashairi) and popular songs.

Tabwa. Spoken in the Marungu country, between Tanganyika and the Lualaba.

*G. De Beerst. Essai de Grammaire Tabwa. Berlin, 1896. Published in Ztschr. f. afr. u. oc. Spr. Vol. II., Nos. 3 and 4.

Taita (less correctly, Teita). Spoken in the Taita Hills, 120 miles N.W. of Mombasa.

*J. A. Wray. Elementary Introduction to the Taita Language. London (S.P.C.K.), 1894.

A Taita Vocabulary is included in A. D. Shaw, Pocket 
Vocabulary. See under Swahili. Also in Hémery, Voc. Français-Swahili-Teita. See under Swahili.

Tebele. See under Zulu.

Teke. See under Congo.

*Thonga. Spoken over a large area between St. Iucia Bay and the Sabi River and including among its branches Ronga, Hlanganu, Gwamba (now isolated in the Transvaal), Jonga, etc. Not to be confused with Tonga, q.v.

*C. WV. Chatelain and H. A. Junod. Pocket Dictionary Thonga-(Shangaan)-English and English-Thonga. Preceded by an Elementary Grammar. Lausanne (Georges Bidel et Cie), 1904.

Shangaan (properly Hlanganu) is the name by which the Delagoa Bay natives in general are known at the Johannesburg mines. This book, while not 'limiting itself to any particular dialect' of the Thonga language, applies more especially to that spoken in the Spelonken and Leydsdorp district of $\mathrm{E}$. Transvaal.

Tonga (Zambezi). The Tonga (Gitonga) of Inhambane, identical with Lenge (q.v.) or Chopi, is distinct from this. So is the Tonga found on the W. side of L. Nyasa.

J. R. Fell (of the Baila-Batonga Mission). A Tonga Grammar. London (S.P.C.K.), 1918.

A. IV. Griffin. Chitonga Vocabulary of the Zambezi Valley. Oxford (University Press).

This Tonga language has been very fully studied by Father Torrend, who gives some annotated texts in the Appendix of his Comparative Grammar. The people are also called (by the Bechwana) Batoka.

Tugulu. See Makua.

Tumbuka. Spoken W. of Lake Nyasa.

W. A. Elmslie. Notes on the Tumbuka Language. Aberdeen (G. and W. Fraser), 'Belmont' Works, 1891. 
W. A. Elmslie. Table of Concords and Paradigms of Verb. Aberdeen (Fraser), 'Belmont' Works, 1891.

Venda. Spoken in N. Transvaal, within the bend of the Limpopo. Sometimes spelt Wenda; the people are variously called Vavenda, Bavenda, Wawenda, etc.

C. Meinhof. Das Tšivenda. Leipzig, 1901. Reprinted from Z.D.M.G.

Th. and P.Schwellnus. Die Verba des Tšivenda. Mitt. B. Sem. Or. VII. Abt. 3, pp. 12-31. Berlin, 1904.

Vili. Spoken on the Luango (Loango) coast, north of the Congo. Sce also "Congo."

P. C. Marichelle. Dictionnaire Vili-Français, 1902.

Dialecte Vili, 1907.

Méthode Pratique pour l'Etude du

Xilenge (Shilenge, or Chopi). See Lenge.

${ }^{*}$ Xos $a$ ('Kafir'). Spoken in the eastern part of the

Cape Province, and closely allied to (though not quite identical with.) Zulu. .

W. Appleyard. The Kafir Language, comprising a Sketch of its History . . . Remarks upon its Nature and a Grammar, pp. 390. King William's Town, London. (J. Mason), 1850. - (Printed for the Wesleyan Missionary Society.)

J. Ayliff. A Vocabulary of the Kafir Language. London (Wesleyan Mission House), 1846.

W. B. Boyce. A Grammar of the Kaffir Language. London (Wesleyan Missionary Society and J. Mason). First edition, 1834; second edition (augmented and improved), 1844; third edition, (augmented and improved with Exercises), 1863. The Exercises were added to the third edition by W. J. Davis.

C. J. Crawshaw. A first Kafir Course, pp. 133. Lovedale, Cape Town (Juta). Third edition, 1897; 
fourth edition, 1901 ; fifth edition, 1903. Grammar, Exercises and Vocabularies. (These are appended to each exercise, but can be easily consulted by means of an index at the end.)

Wm. J. Davis. A Dictionary of the Kaffir Language; including the Xosa and Zulu Dialects. Part I., Kaffir-English. London (WVesleyan Mission House), 1872.

- An English and Kaffir Dictionary, principally of the Xosa-Kaffir, but including also many words of the Zulu-Kaffir Dialect. London (IVesleyan Missionary Society), 1877.

I. Bud-Mbelle, Interpreter to the High Court of Griqualand. Kaffir Scholar's Companion. (Lovedale Missionary Press), 1903

Contains lists of words, idioms, proverbial expressions, and a variety of miscellaneous information not always easy to find elsewhere.

A. Kropf. A Kaffir-English Dictionary, pp. iv., 486. (Lovedale Mission Press), 1899.

J. McLaren. A Concise Kaffir-English Dictionary. London (Longmans, Green \& Co.), 1915.

A Grammar of the Kaffir Language.

London (Longmans, Green \& Co.), 1906.

C. Meinhof. Hottentottische Laute und Lehnworte im Kafir. (Z.D.M.G.), 1905.

Discusses the question of how far Xosa borrows sounds and words from the Hottentot language, and in particular, the origin of the clicks.

W. B. Rubusana. Zenk'inkomo Magwalandini. Second edition. Frome and London (Butler and Tanner), 1911.

Traditions and songs of the Xosa, Gcaleka, Tembu and other tribes, collected by a native minister of the Congregational Church.

J. Stewart. Outlines of Xosa Grammar, with practical exercises. (Lovedale Mission Press), South Africa, 1901. 
J. Stewart. Kaffir Phrase Book and Vocabulary. Third edition. (Lovedale Mission Press), 1901.

The late Dr. Stewart is well-known as the founder and Tirst Principal of the Lovedale Institution.

J. Torrend. Outline of a Xosa Kafir Grammar, with a few dialogues and a Kaffir Tale. Grahamstown (T. and G. Sheffield), 1887.

tYao (Chiyao, Kihiau). Spoken in the mountains S. E. of Lake Nyasa, and in the Shire Highlands.

*A. Hetherwick. Introductory Handbook and Vocabulary. (S.P.C.K.) Second edition, 1902.

Contains both Yao-English and English-Yao Vocabulary.

A. F. Pott. Über die Kihiausprache. (Z.D.M.G.), V1., pp. 331-348.

*E. Steere. Collections for a Handbook of the Yao Language. London, 1871.

Yaunde (a branch of Fan).

P. Hermann Nekes. Praktische Grammatik der JaundeSprache. Vol. XXVI. of Lehrbücher des Seminars für or. Sprachen. Berlin, 1911.

Yombe. See under 'Congo.'

Zaramo (Zalamo). See Dzalamo.

Zigula. East Africa, near Luvu River, on the mainland opposite Zanzibar.

*W. H. Kisbey. Zigula-English and English-Zigula Dictionary. London (S.P.C.K.), 1906.

$*$ Zigula Exercises. London(S.P.C.K.),

1906.

Rev. W. G. Webster (ed.) Zigula Tales. London (S.P.C.K.), 1912.

Twenty-three stories, written down by natives.

H. W. Woodward. Collections for a Handbook of the Zigula Language. (U.M.C.A.), Msalabani, 1902. 
Ziba (Lusiba). Spoken in Kiziba and some other districts adjoining Lake Victoria on the S.W. It is not very happily named, as the people speaking it appear to be called Batundu. It is closely related to Nyoro.

*Capt. Herrmann (formerly of Bukoba). Lusiba, die Sprache der Länder Kisiba, Bugabu, etc., 1904. Mitt. B. Sem. Or. VII., Abt. 3, pp. 150-200.

*Zulu.

A. T. Bryant. A Zulu-English Dictionary, with Notes on Pronunciation, a revised Orthography, etc. (Mariannhill Mission Press), Pinetown, Natal, 1905.

An important work, somewhat spoilt by its speculative etymologies which are not based on any sound principle. The introduction, too, though containing a great deal of useful information, is of very unequal value, especially the historical part, which is not free from parti pris.

H. Callaway. Nursery Tales, Traditions and Histories of the Zulus. (Zulu Text, Translation and Notes). Springvale, Natal. London (Trübner \& Co.), 1868. Religious System of the Amazulu. (Zulu Text, with Translations and Notes. (Printed, Springvale), Natal. London, 1870.

J. W. Colenso (Bishop of Natal). First Steps in ZuluKaffir. Pietermaritzburg (Vause \& Slatter), fourth edition, 1903.

* - Zulu-English Dictionary, fourth edition. Pietermaritzburg (Vause \& Slatter), 1905.

Three Native accounts of a Visit to, Umpande, King of the Zulus. With Translation, Vocabulary and Notes. Third edition. Pietermaritzburg and Durban (Vause, Slatter \& Co.), 1901.

Izindab'ezinhle, etc. New Testament
(reprinted, 1897 for Miss Colênso), London. (Dent). 
J. W. Colenso. Pilgrim's Progress. Inncwadi ka' Bunyane okutiwa Ukuhamba Kwesihambi. Pietermaritzburg and Durban (Vause, Slatter \&, Co.), 1901.

J. L. Döhne (Missionary to the American Board,C.F.M.). A Zulu-Kafir Diftionary. Cape Town, 1857.

*W. A. Elliott. Notes for a Sindebele Dictionary and Grammar, with illustrative sentences. (Sindebele Publishing Co.), Bristol, 1911.

Sindebele (Tebele) is the dialect of Zulu spoken by the Matabele in Rhodesia.

Lewis Grout. The Isizulu; a grammar of the Zulu Language, with historical introduction. Pietermaritzburg, Durban, London (Trübner \& Co.), 1859.

James Perrin. English-Zulu Dictionary. Pietermaritzburg (P. Dávis \& Sons), new edition, 1901.

Rev. C. Roberts. The Zulu-Kafir Language simplified for Beginners. London (Kegan Paul). Third edition, 1909.

An English-Zulu Dictionary with the Principles of Pronunciation and Classification fully explained. London (Kegan Paul, Trench, Trübner \& Co.), 1911.

London (Kegan Paul), 1900.

A Zulu Manual or Vade Mecum.

A companion volume to the two preceding works, containing grammatical notes and illustrations of special idioms,-medical, zoological and botanical vocabularies, etc.

P. A. Stuart. Zulu Grammar, with 400 Useful Phrases, 1907. 



\section{INDEX}

Abstract nouns, 62.

Adjective roots, 120.

Adjectives, 118, 122.

- few real in Bantu, 118.

- concord of, $124,128$.

- derived from verbs, I 20.

- nouns made to do the work of, $\mathrm{r}$ rg.

- Nyanja, I25.

- verbs derived from, I 30,154 .

- verbs used for, irg.

- which take shortened prefixes, 126.

Adverbial demonstratives, 99, II 4 . Adverbs, 184 .

- invariable, 186.

- locative, 185 .

Agglutinative languages, I2.

Alliterative concord, $\mathrm{r}_{4}, 20$.

Angola and Loango languages, 5 .

Animals, names of, 47,58 .

Applied verbs, $1_{4} 8$.

Arbousset, 7 .

Article, 49, 72 .

Assimilation, 226.

Incomplete, 227.

Augmentative class, 56, 66-68.

Auxiliaries, 174 .

Bantu, 9.

- family, characteristic features of, I4.

- languages, number of known, 2.

- languages, principal features of, 2.

- languages, sounds of, 17 .

- name, 3.

Barlow, 229.

Bentley, 116 .
Bleek, 3, 8, 9, 13, 49, 86, 2 I9.

Boyce's Xosa Grammar, 7.

Brusciotto, Giacinto, 6, 13, 31, 32, Burton, 31.

$[35,72$.

Casalis, 7 .

Causative verbs, $x_{4} 8$.

Cerebral $\mathrm{t}$ and $\mathrm{d}, 222$.

"Chiswina," 42.

Chwana, 4, 16, 47, 48, 52, 95 .

- participle, 118 .

- relative particle, 105.

- verbal nouns, 208

Class, augmentative, 56,68 .

- diminutive, Duala, 62.

- lu, 59 .

- meaning attached to each,

- three, concords of, 50. [43.

Classes, hints of several other, 68.

Clicks in Zulu and Xosa, 219.

Colenso, Bishop, 170, 192, 202.

Compound tenses, 173 .

Compounds, Herero, 213.

$$
\begin{aligned}
& \text { Ila, 217. } \\
& \text { - Nyanja, 2r6. } \\
& \text { Zulu. }
\end{aligned}
$$

Concord of adjectives, I24, I28.

Concords of Class $3,50$.

Congo, Kingdom of, 31, 43.

Conjunetions, 183 .

Continuative mood, 167-8.

Copula, 49.

- combined with personal pronouns, Ir 2.

- old demonstrative root, III.

Cust, 6 sometimes prefixed to

Dahl's Law, 228-9.

De Grezorio, 8.

Degrees of Comparison, 131 .

Demonstrative, adverbial, 99 . pronouns, 97, 98 
Demonstrative, $\gamma a, 4^{8}$.

Demonstratives, adverbial, 99, II4.

Denominative verbs, 2 I 2 .

Dental $t$ and $d, 222$.

Derived Forms, r44, I46, r 56, 192.

Diminutive class, Duala, 62 .

in -ara, 2 I2.

- in ka-, 6o.

Diminutives, 56 . plural prefix, Nyanja,

Dinuzulu, I 9 .

Dissimilation, 226, 228.

Do Couto, P. Antonio, 6.

Double Agreement, 97.

Duala diminutive class, 62 .

- language, 89 .

Ewald, 8.

False Analogy, 226.

Fruits, names of, 52 .

Fulfulde language, 44.

Future Tense, 172 .

Ganda, 16, 25, 26, 66, 68, 295.

- relative particle, 105.

- verb 'to be,' II6.

Gisu, 42, 48, 49, 53, 66 .

Grammatical gender, IO, I I.

Grimm's Law, 218.

Hamitic languages, I4.

Herero, 42, 45, 225, 248.

- compounds, 213.

- relative particle, 106.

- verb 'to be,' I 6.

Hetherwick, Dr., I87, 202.

Hottentot language, 9.

Hottentots, 4 , 10 .

Human beings, names denoting,

Ila, 264,

$[46$.

- compounds, 2 I 7.

Imperative mood, 159.

Incomplete assimilation, 227 .

Indicative present tense, 171 .

Infinitive mood, 159.

Inflected families of language, Io, Initial vowel, $4^{8}$.

absent in the vocative, 49.
'Inseparable Pronoun,' 88.

Intensive verbs, 149.

'Interjectional roots,' 186.

International Phonetic Associa-

Intonation, 15, 16.

[tion, 18.

Invariable adverbs, 186.

- particle, rro.

Irregular verbs, 177 .

Isolating languages, I2.

Johnston, Sir Harry, 9.

Jones, D., I9.

Junod, $186,197$.

'Kafir' (Xosa), 4.

Ki-class, action of a verb, 55 .

- collective sense, 55 .

- instrumental force, 55 .

- 'likeness, fashion, manner,'

Kikuyu, 225, 229.

$[55$.

Kimvita (Mombasa Dialect), 285.

Kinga, 68.

Kongo, 34, 42, 81, 89 .

- relative pronoun, 107 .

Krapf, 7, 3I.

Lamu Dialect (Kiamu), 276.

Laterals, 220.

Law of Vowel-Harmony, 228.

Lepsius, 8, J4, 19.

Lévy-Brubl, $187,188$.

Lichtenstein, 4, 6, 9 .

Liquid's, words denoting, 52 .

Locative aciverbs, 185 .

- class, $76-85,211$.

- prefixes, 66 .

Locatives, in $m u-, 51$.

- suffixed, 82 .

Luganda, see Ganda.

Marsden, William, 5 .

'Mashona,' 42.

Materials, names of, 62 .

Mbundu language, 6 .

Meinhof, 8, I6, I9. 35, 37, 45, 48, 195, 203, 214, 219 , $226,230,231$.

Moffat's translation of the Bible in to Sechwana, 7.

Monosyllabic verbs, $\mathrm{r}_{43}, \mathrm{r} 77$. 
Mood, Continuative, 167 ,

- Imperative, 159.

- Infinitive, 159.

- Negative, 160.

- Relative, 168.

- Subjunctive, 160.

Moods, $156-169$.

Mozambique language, 5 .

Müller, 8.

Negative mood, 160 .

Neuter-Passive verbs, 147.

Noël-Armfield, 223.

Noun agent, 200.

- Indicating result of an Nouns, abstract, 62. [action, 205.

- made to do work of adjectives, IIg.

verbal, 200-211.

Numbers, Ordinal, 140.

Numerals, 133.

- distinct words for 'hundred' and 'thousand,' 137.

table of, 135,138 . [140.

Nyanja, I6, I7, 42, 44, 46, 48, 62,

- adjectives, 125 . $63,98,225,272$.

- compounds, 216.

- no true relative

- verb ' to be,' II6.

Object-Pronoun, 89.

' Onomatopœtic vocables,' r86.

Ordinal numbers, t $_{4} \mathrm{O}$.

Pacconio, P. Francisco, 6.

Particle, invariable, 110.

$$
\text { relative, IOI. }
$$

Participles, 103-6, 118, 169.

Passive verbs, 147 .

Past tense, 172.

Perfect in -ile 154, 158, 166.

Perfect tense, 173 .

Phonetics, General, 230.

Pitch, 16.

Place, word for 79.

Pokomo language, 80.

Possessive, 70-75.

- particle, 74 .

- pronouns, 74, 92, 93.
Pott, 8.

Prefix, eleventh, hu-, 59.

- Gifteenth, ku-, 63.

- fifth, li-, $5 \mathrm{I}$.

- ninth, in- or $n \cdot, 56$.

- ti-in Nyanja, 62.

- ogut, 66.

- sixth, in Gisu, kama-, 53.

- tenth. 37

- tu-, attached to thirteenth

- twelfth, 60. [class, 61.

Prefixes, locative, 66, 77 .

- not identical with Pronoun, 86.

Prepositional verbs, see Applied Prepositions, 72, 84, 182 . [Verbs. Pronominal forms suffixed to, 91 .

Principiation of nouns, $13,32,33$. Pronouns, 86, 182.
- Demonstrative, 97,98 .
- Inseparable, 88.
- Longer forms of, 91 .
- Object, 89 .
- Possessive, 92, 93.
- Prepositional form of, $91,92,93$.
- Reflexive, 91.
- Relative, 99.
- Separable or Substan- tive, 92,94 .

Rebmann, 3r.

Reciprocal verbs, i5r.

Reflexive Pronoun, 89-91.

Relative construction, Zulu, IIg.

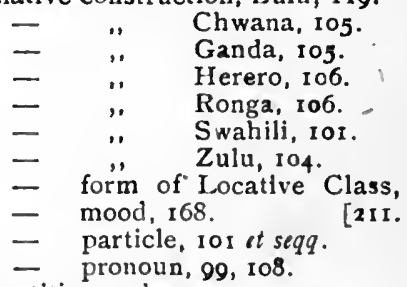

Repetitive verbs, I 33 .

Reversive verbs, 150.

Rhodesia, Southern, main speech

Ronga language, 54. [of, 42. 
Scott, Revs. D. C. and W. A., Semi-Bantu, 2.

Separable, or independent, pro-

Smith, E. W., 194, 195. nouns, 92,94 .

'Sound-pictures,' 186.

Stapleton, I86, 189.

Stative verbs, 152 .

Steere, Bishop, 18.

Stress (accent), I 5 .

Subjunctive mood, 160 .

Substantive pronouns, 94.

Sudan languages, I, I, I4, 75 .

Suffixes, 199, 204.

Swahili language, $7,15,16,18,28$, $42,44,47,67$, IоI,

- verb 'to be,' II6. I I $9,225,276$.

Tense, 157 .

- Compound, I73.

- Future, 172, I73.

- Indicative Present, I7I.

- Past, I72.

- Perfect, 173.

Thonga, 17.

Torrend, 186.

Transposition, 226, 230.

Trees, names of, $5 \mathrm{I}$.

Tribes, names of, 50 .

Tuckey's expedition to the Congo,

'Uncle Remus,' ro, 47.

Van der Kemp, Dr., 7 .

Velten, 192.

Venda language, $17,54,68$.

Verb, Bant ${ }_{4}$ I 43 .

- stems beginning with a

- $t i$, use of, I76. [vowel, I45.

- ' to be,' I09, Iro.

$$
\begin{aligned}
& \text { - . Ganda, Ir6. } \\
& \text { - " Herero, II6. } \\
& \text { - " Kongo, II6. } \\
& \text { - " Nyanja, I } 16 . \\
& \text { - 'to have,' rog. }
\end{aligned}
$$

Verbal nouns, 201, 202, 205, 208.

Verbs, Adjectives derived from, I 20

- Applied, 148.

- Auxiliary, 174.

- Causative, I48.

- Compounded forms, 155 .

- Denominative, 2 I2.

- derived forms, 144, 146, 156.

- derived from adjectives, 130 .

- formed from adjective.

- Intensive, 149. [stems, 154 .

- Irregular, I77.

- Monosyllabic, I43, 177 .

- ." primitive, I79.

- Neuter-Passive, 147.

- Passive, 147.

- Perfect in -ile, 154, 158, 166.

- Reciprocal, I5I.

- Repetitive, 153.

- Reversive, 150.

- Stative, I52.

- used for adjectives, Irg.

- which do not end in a

' Vocal Images,' 189.

Vocative, 70.

'Voices,' I46.

Von der Gabelentz, 8.

Westermann, $187, \mathrm{r} 88$.

' Whistling $s$, ' 54 .

Whitehead, I86, I9o.

Whitney, W. D., 219.

Woodward, Archdeacon, 8I.

Xosa, clicks in, 219.

- language, 4, 7, 16.

Yao, 166, I67, 225.

Zulu, 15, I6, 20, 44-48, 232.

- adjectives, 126 .

- clicks in, 17, 19, 219.

- compounds, 2 I6.

- prepositions, 84 .

- relative construction, IIg.

- . particle, I04. 
LONDON :

Women's Printing Society, Ltd., Brick Street, Piccadilly, IV. I. 


\section{KEGAN PAUL, TRENCH, TRUBNER \& CO.}

BEECH (M. W. H.). Aids to the Study of Ki-Swahili. 6s. net.

Ki-Swahili Writing (with 22 full-page facsimiles, with Transliterations en regard); Ki-Swahili Stories (with Translations and Notes); Enigmas and Aphorisms (with explanations); Magic in Pemba.

FOULKES (Capt. H. D.). Manual of the Angass Grammar. With Vocabulary, $8 s$. $6 d$. net.

HAYWOOD (Capt. H. W.). English-Hausa Yocabulary. Second Edition, containing nearly 1,400 words in everyday use. 2s. $6 d$. net.

LARAJASSE (F. E. de). Somali-English and EnglishSomali Dictionary. I 5 s, net.

and CYPRIEN de SAMPONT, Practical Grammar of the Somali Language. With Sentences. I5s. net.

MERRICK (Capt. G.). Hausa Proverbs. 3s. $6 d$. net.

MIGEOD (F. W. H.). The Languages of West Africa : a Linguistic Survey of about 200 Languages or Dialects. 2 vols., each I 2 s. $6 d$. net.

\section{Grammar of the Hausa Language. 6s, net.}

The Mende Language: including Grammar, Vocabularies, and Useful Phrases. 7s. $6 d$. net.

- Mende Natural History Yocabulary : a description of the Fauna and Flora. 4s. $6 d$. net.

ROBINSON (C.). Grammar of the Hausa Language. 6s. net. STAPLETON (W. H.). Comparatiye Grammar of the Congo Languages, and of Swahili. With Vocabulary. 7 s. 6 d. net.

TORREND (J.). Comparative Grammar of the South African Bantu Languages, comprising those of Zanzibar, Mozambique, the Zambesi, Kafirland, Benguela, Angola, The Congo, The Ogowe, The Cameroons, the Lake Regions, etc. 3os. net.

BROADWAY HOUSE, 68-74, CARTER LANE, LONDON, E.C. 


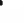

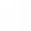

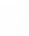





BHDWG CEGT. FEB 101971

PI

8025

.1

W47
Werner, Alice,

$1859-1935$

Introductory sketch of the Bantu languages. K. Prul, Trench, Trubner (1919)
PLEASE DO NOT REMOVE

CARDS OR SLIPS FROM THIS POCKET 
